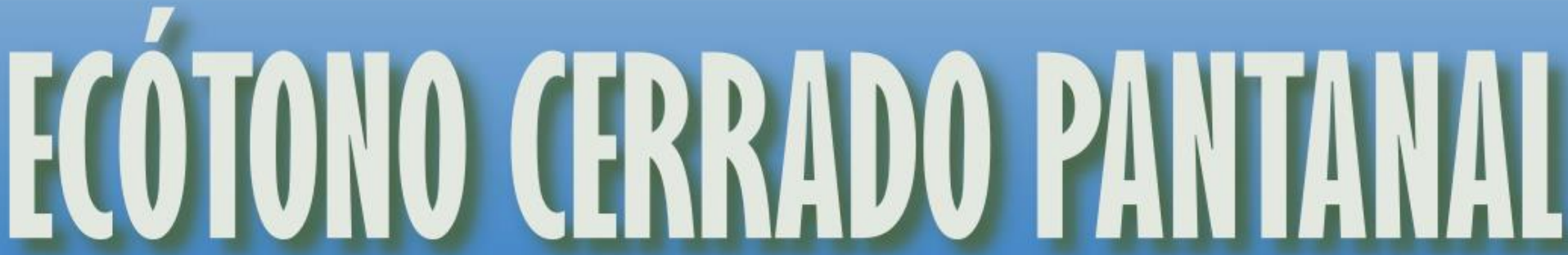

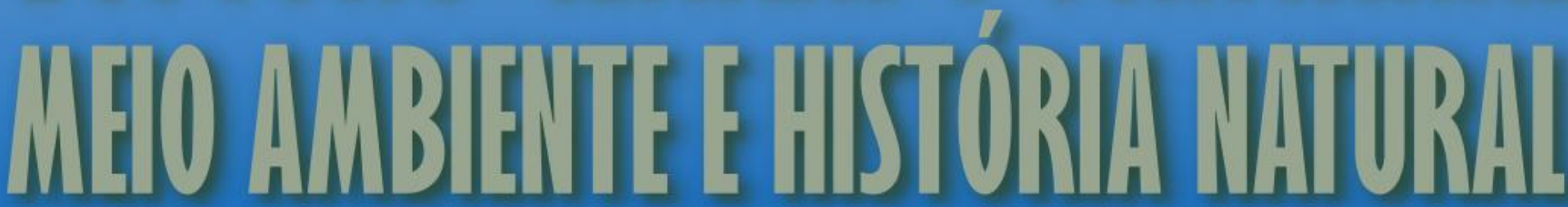

\author{
ORGANIZADORES \\ TATIANE DO NASCIMENTO LIMA \\ ROGÉRIO RODRIGUES FARIA
}

\section{㳷 AMPLLA}




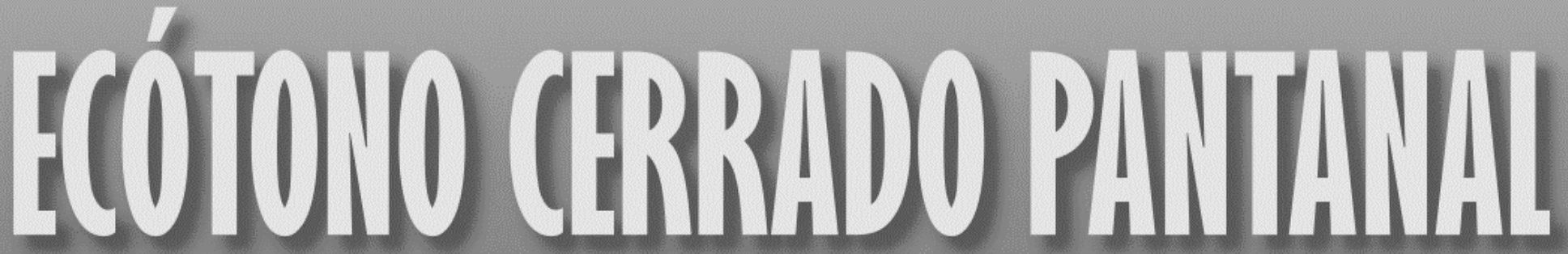

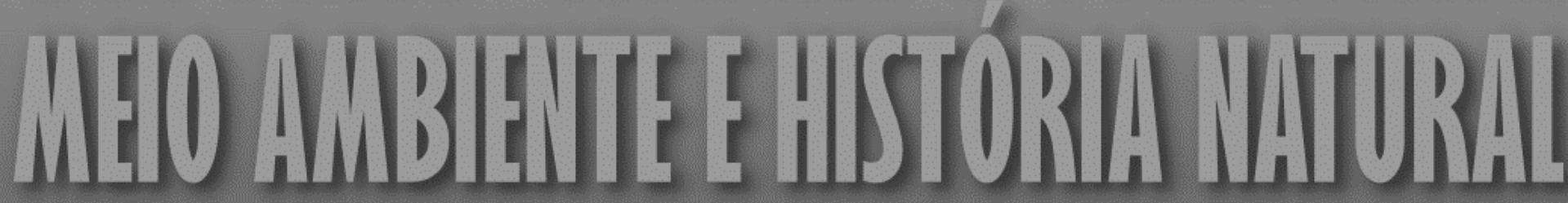

\author{
ORGANIZADORES \\ TATIANE DO NASCIMENTO LIMA \\ ROGÉRIO RODRIGUES FARIA
}

\section{涌 AMPLLA}




\section{1 - Editora Amplla}

Copyright (C) Editora Amplla

Editor Chefe: Leonardo Pereira Tavares

Design da Capa: Editora Amplla

Diagramação: Higor Costa de Brito

Fotografia da Capa: Luiz Felipe Pereira Mendes

Ecótono Cerrado Pantanal: meio ambiente e história natural está licenciado sob CC BY 4.0.

(c) (i) Esta licença exige que as reutilizações deem créditos aos criadores. Ele permite que os reutilizadores distribuam, remixem, adaptem e construam o material em qualquer meio ou formato, mesmo para fins comerciais.

O conteúdo da obra e seus dados em sua forma, correção e confiabilidade são de responsabilidade exclusiva dos autores, não representando a posição oficial da Editora Amplla. É permitido o download da obra e o compartilhamento desde que sejam atribuídos créditos aos autores. Todos os direitos para esta edição foram cedidos à Editora Amplla.

ISBN: 978-65-88332-67-2

DOI: 10.51859/amplla.ecp672.1121-0

Editora Amplla

Campina Grande - PB - Brasil contato@ampllaeditora.com.br www.ampllaeditora.com.br 


\section{CONSELHO EDITORIAL}

Andréa Cátia Leal Badaró - Universidade Tecnológica Federal do Paraná

Andréia Monique Lermen - Universidade Federal do Rio Grande do Sul

Antoniele Silvana de Melo Souza - Universidade Estadual do Ceará

Aryane de Azevedo Pinheiro - Universidade Federal do Ceará

Bergson Rodrigo Siqueira de Melo - Universidade Estadual do Ceará

Bruna Beatriz da Rocha - Instituto Federal do Sudeste de Minas Gerais

Bruno Ferreira - Universidade Federal da Bahia

Caio César Costa Santos - Universidade Federal de Sergipe

Carina Alexandra Rondini - Universidade Estadual Paulista

Carla Caroline Alves Carvalho - Universidade Federal de Campina Grande

Carlos Augusto Trojaner - Prefeitura de Venâncio Aires

Carolina Carbonell Demori - Universidade Federal de Pelotas

Cícero Batista do Nascimento Filho - Universidade Federal do Ceará

Clécio Danilo Dias da Silva - Universidade Federal do Rio Grande do Norte

Daniela de Freitas Lima - Universidade Federal de Campina Grande

Darlei Gutierrez Dantas Bernardo Oliveira - Universidade Estadual da Paraíba

Denise Barguil Nepomuceno - Universidade Federal de Minas Gerais

Dylan Ávila Alves - Instituto Federal Goiano

Edson Lourenço da Silva - Instituto Federal de Educação, Ciência e Tecnologia do Piauí

Elane da Silva Barbosa - Universidade Estadual do Ceará

Érica Rios de Carvalho - Universidade Católica do Salvador

Gabriel Gomes de Oliveira - Universidade Estadual de Campinas

Gilberto de Melo Junior - Instituto Federal do Pará

Givanildo de Oliveira Santos - Instituto Brasileiro de Educação e Cultura

Higor Costa de Brito - Universidade Federal de Campina Grande

Isane Vera Karsburg - Universidade do Estado de Mato Grosso

Israel Gondres Torné - Universidade do Estado do Amazonas

Italan Carneiro Bezerra - Instituto Federal da Paraíba

Ivo Batista Conde - Universidade Estadual do Ceará

Jaqueline Rocha Borges dos Santos - Universidade Federal Rural do Rio de Janeiro

Jessica Wanderley Souza do Nascimento - Instituto de Especialização do Amazonas

João Henriques de Sousa Júnior - Universidade Federal de Santa Catarina

João Manoel Da Silva - Universidade Federal de Alagoas

João Vitor Andrade - Universidade de São Paulo

Joilson Silva de Sousa - Instituto Federal do Rio Grande do Norte

José Cândido Rodrigues Neto - Universidade Estadual da Paraíba

Jose Henrique de Lacerda Furtado - Instituto Federal do Rio de Janeiro

Josenita Luiz da Silva - Faculdade Frassinetti do Recife

Josiney Farias de Araújo - Universidade Federal do Pará

Karina de Araújo Dias - SME/Prefeitura Municipal de Florianópolis

Katia Fernanda Alves Moreira - Universidade Federal de Rondônia

Laíze Lantyer Luz - Universidade Católica do Salvador

Lindon Johnson Pontes Portela - Universidade Federal do Oeste do Pará

Lucas Araújo Ferreira - Universidade Federal do Pará

Lucas Capita Quarto - Universidade Federal do Oeste do Pará

Lúcia Magnólia Albuquerque Soares de Camargo - Unifacisa Centro Universitário

Luciana de Jesus Botelho Sodré dos Santos - Universidade Estadual do Maranhão

Luís Paulo Souza e Souza - Universidade Federal do Amazonas

Luiza Catarina Sobreira de Souza - Faculdade de Ciências Humanas do Sertão Central

Manoel Mariano Neto da Silva - Universidade Federal de Campina Grande

Marcelo Alves Pereira Eufrasio - Centro Universitário Unifacisa

Marcelo Williams Oliveira de Souza - Universidade Federal do Pará

Marcos Pereira dos Santos - Faculdade Rachel de Queiroz

Marcus Vinicius Peralva Santos - Universidade Federal da Bahia

Marina Magalhães de Morais - Universidade Federal de Campina Grande

Michele Antunes - Universidade Feevale 
Milena Roberta Freire da Silva - Universidade Federal de Pernambuco

Nadja Maria Mourão - Universidade do Estado de Minas Gerais

Natan Galves Santana - Universidade Paranaense

Nathalia Bezerra da Silva Ferreira - Universidade do Estado do Rio Grande do Norte

Neide Kazue Sakugawa Shinohara - Universidade Federal Rural de Pernambuco

Neudson Johnson Martinho - Faculdade de Medicina da Universidade Federal de Mato Grosso

Patrícia Appelt - Universidade Tecnológica Federal do Paraná

Paula Milena Melo Casais - Universidade Federal da Bahia

Paulo Henrique Matos de Jesus - Universidade Federal do Maranhão

Rafael Rodrigues Gomides - Faculdade de Quatro Marcos

Reângela Cíntia Rodrigues de Oliveira Lima - Universidade Federal do Ceará

Rebeca Freitas Ivanicska - Universidade Federal de Lavras

Renan Gustavo Pacheco Soares - Autarquia do Ensino Superior de Garanhuns

Renan Monteiro do Nascimento - Universidade de Brasília

Ricardo Leoni Gonçalves Bastos - Universidade Federal do Ceará

Rodrigo da Rosa Pereira - Universidade Federal do Rio Grande

Sabrynna Brito Oliveira - Universidade Federal de Minas Gerais

Samuel Miranda Mattos - Universidade Estadual do Ceará

Shirley Santos Nascimento - Universidade Estadual Do Sudoeste Da Bahia

Silvana Carloto Andres - Universidade Federal de Santa Maria

Silvio de Almeida Junior - Universidade de Franca

Tatiana Paschoalette Rodrigues Bachur - Universidade Estadual do Ceará

Telma Regina Stroparo - Universidade Estadual do Centro-Oeste

Thayla Amorim Santino - Universidade Federal do Rio Grande do Norte

Virgínia Maia de Araújo Oliveira - Instituto Federal da Paraíba

Virginia Tomaz Machado - Faculdade Santa Maria de Cajazeiras

Walmir Fernandes Pereira - Miami University of Science and Technology

Wanessa Dunga de Assis - Universidade Federal de Campina Grande

Wellington Alves Silva - Universidade Estadual de Roraima

Yáscara Maia Araújo de Brito - Universidade Federal de Campina Grande

Yasmin da Silva Santos - Fundação Oswaldo Cruz

Yuciara Barbosa Costa Ferreira - Universidade Federal de Campina Grande 


\section{AMPLLA}

2021 - Editora Amplla

Copyright (C) Editora Amplla

Editor Chefe: Leonardo Pereira Tavares

Design da Capa: Editora Amplla

Diagramação: Higor Costa de Brito

Fotografia da Capa: Luiz Felipe Pereira Mendes

\section{Dados Internacionais de Catalogação na Publicação (CIP)}

Ecótono Cerrado Pantanal [livro eletrônico]: meio

ambiente e história natural / organização Tatiane do Nascimento Lima, Rogério Rodrigues Faria. -- Campina Grande : Editora Amplla, 2021.

$232 \mathrm{p}$.

Formato: PDF

ISBN : $978-65-88332-67-2$

1. Ecossistemas. 2. Biodiversidade. 3. Conservação Recursos naturais. I. Lima, Tatiane do Nascimento. II. Faria, Rogério Rodrigues. III. Título.

$\mathrm{CDD}-577.1$

Sueli Costa - Bibliotecária - CRB-8/5213

(SC Assessoria Editorial, SP, Brasil)

Índices para catálogo sistemático:

1. Ecossistemas 577.1

Editora Amplla

Campina Grande - PB - Brasil contato@ampllaeditora.com.br www.ampllaeditora.com.br

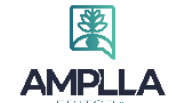




\section{APRESENTAÇÃO}

O termo Bioma refere-se a uma área do espaço geográfico representada por um tipo uniforme de ambiente, dentro do qual é possível identificar características similares de macroclima, fitofisionomia, solo e altitude (WALTER, 1986). Dentro dessas áreas espécies surgiram e se desenvolveram em resposta à essas características do ambiente. Tal processo permite que por exemplo, dentro dessas áreas os vegetais apresentem aspectos, formas e processos fisiológicos característicos (CRAWLEY, 1989). Dessa maneira, a manutenção desses biomas, com suas características ambientais únicas, é de fundamental importância para a manutenção da biodiversidade e dos serviços ecossistêmicos que ali ocorrem (regulação climática, ciclo de matéria, segurança alimentar, entre outros) (PBMC/BPBES, 2018; JOLY et al., 2019).

O Brasil é formado por seis grandes biomas: Amazônia, Caatinga, Cerrado, Mata Atlântica, Pampas e Pantanal (IBGE, 2019). Dentro desses ambientes são encontrados uma grande diversidade de fauna e flora e características únicas de relevo e clima. Essa variedade de biomas está relacionada a grande extensão territorial do Brasil e a sua posição geográfica. Todas essas características fazem do Brasil o maior detentor de biota continental do mundo, sendo estimado um valor entre $15 \%$ e $20 \%$ das aproximadamente 1,5 milhões de espécies descritas no planeta. Só de plantas vasculares os números mais recentes citados são de 56108 espécies, com 12400 (22\%) endêmicas. Esses dados representam aproximadamente $22 \%$ do total mundial (LEWINSOHN; PRADO, 2002; SHEPHERD, 2002; HUBBELL, 2008; GIAM et al., 2010).

Dentro desse contexto, os biomas Cerrado e Pantanal se integram por meio dos rios que nascem nos planaltos do Cerrado. Esses rios contribuem na formação do Pantanal, nas planícies inundáveis da bacia do Paraguai (BRASIL, 2007). No Domínio Cerrado, a dinâmica ambiental é proveniente de uma marcada sazonalidade climática com duas estações bem definidas, o período seco e o período chuvoso (ASSAD, 1994; SILVA, 2011). Essa sazonalidade climática modifica constantemente as propriedades do solo, da flora e da paisagem e a reestruturação de muitas comunidades (AMARAL et al., 2013; MALHEIROS, 2016). No Pantanal as áreas conhecidas como planícies de inundação se caracterizam pela presença de 
hábitats que variam de aquáticos a terrestres, de acordo com o grau de comunicação com o rio principal (PAZ; TUCCI, 2010). Os ciclos de secas e cheias são um importante fenômeno hídrico para a região, criando um sistema complexo e dinâmico (JUNK; DA SILVA, 1999; RESENDE, 2008).

0 Cerrado é uma das 25 áreas do mundo consideradas críticas para a conservação, devido à riqueza biológica e à alta pressão antrópica a que vem sendo submetido (MYERS et al., 2000). O Pantanal, por sua vez, é reconhecido mundialmente pela abundância de sua fauna (MITTERMEIER et al., 1990; HARRIS et al., 2005) e é considerado Reserva da Biosfera e Patrimônio Natural da Humanidade pela Unesco (BRASIL, 2018). O conhecimento dos aspectos que envolvem a fauna, a flora e as características dessas paisagens são de extrema importância para a sua conservação e preservação. As áreas de transição entre esses dois biomas, chamadas áreas de ecótono, se fazem presentes no estado do Mato Grosso do Sul. Nessa região, os biomas Cerrado e Pantanal possuem correlações quanto aos aspectos geomorfológicos e fitogeográficos (RODRIGUES et al., 2017). Na região o encontro entre o Planalto de Maracaju-Campo Grande e a Planície Pantaneira é uma área comum de elementos bióticos e abióticos entre o planalto e a planície (FILHO et al., 2009).

A transição entre dois ecossistemas implica a existência de uma área com valores intermediários para diversos parâmetros ambientais (NEIFF, 2003). Por um lado, a área de transição pode gerar um aumento na biodiversidade, dado o fato dessas áreas apresentarem representantes de fauna e flora dos dois ecossistemas (VELOSO et al., 1991). Contudo, essas áreas de transição podem também representarem barreira ou área de isolamento com ecossistemas vizinhos (MALANSON, 1997). Desta forma, uma análise voltada para as áreas de ecótono entre esses dois biomas faz-se necessária, uma vez que a preservação de um depende da preservação do outro. Sobretudo para o entendimento de que essas paisagens de ecótono podem ser responsáveis pelo isolamento e amortecimento das alterações dentro dos biomas Cerrado e Pantanal.

Este E-book traz estudos desenvolvidos na área de ecótono Cerrado Pantanal no município de Aquidauana (MS) e entorno. 0 município está localizado a $130 \mathrm{Km}$ a oeste da capital Campo Grande. Aquidauana por se tratar de um município com influência dos biomas Cerrado e Pantanal, abriga uma grande biodiversidade, sendo 
citada pelo Ministério do Meio Ambiente (BRASIL, 2002) como área prioritária para conservação da biodiversidade. Na mesma via, o município se destaca por sua vocação turística e agropecuária, o que demanda atenção, devido ao processo de intensa ocupação e exploração antrópica dos recursos naturais. Dessa maneira, o conhecimento de suas características ambientais e dos processos ecológicos desempenhados por sua fauna e flora contribuem para sua preservação e manutenção.

\section{REFERÊNCIAS}

ASSAD, E. D. Chuva nos cerrados. Brasília: EMPRESA BRASILEIRA DE PESQUISA AGROPECUÁRIA - Centro de Pesquisa Agropecuário dos Cerrados, 1994. 423P.

AMARAL, A. G. et al. Vascular flora in dry-shrub and wet grassland Cerrado seven years after a fire, Federal District, Brazil. Check List, v. 9, p. 487-503, 2013.

BRASIL. MINISTÉRIO DO MEIO AMBIENTE. Avaliação e identificação de áreas e ações prioritárias para a conservação, utilização sustentável e repartição dos benefícios da biodiversidade nos biomas brasileiros. Brasília: MMA/SBF, 2002. $404 \mathrm{p}$.

BRASIL. MINISTÉRIO DO MEIO AMBIENTE. Biodiversidade do Cerrado e Pantanal: áreas e ações prioritárias para conservação. Brasília: MMA, 2007.540 p.

BRASIL. MINISTÉRIO DO MEIO AMBIENTE. Resumo Executivo da Proposta de Criação do Mosaico de Unidades de Conservação do Pantanal Norte. Ministério do Meio Ambiente, Instituto Chico Mendes de Conservação da Biodiversidade - ICMBio. Diretoria de Criação e Manejo de Unidades de Conservação, 2018.

CRAWLEY, M. J. The Structure of Plant Communities. Pp. 1-496. In: M.J. Crawley (ed.). Plant Ecology. Oxford, Blackwell Science, 1989.

FILHO, Clódis de Oliveira Andrades; ZANI Hiran; GRADELLA, Frederico dos Santos. Compatibilidade da rede de drenagem obtida através de dados SRTM, ASTER e carta topográfica DSG: estudo de caso no Pantanal de Aquidauana.

Anais 2º Simpósio de Geotecnologias no Pantanal, Corumbá, 7-11 novembro 2009, Embrapa Informática Agropecuária/INPE, p.51-61, 2009.

GIAM, X. et al.. Future Habitat Loss and the Conservation of Plants Biodiversity. Biological Conservation, v. 143, p. 1594-1602, 2010.

HARRIS, M. B. et al. Safeguarding the Pantanal wetlands: Threats and conservation initiatives. Conservation Biology, v. 19, p. 714-720, 2005. HUBBELL, S. P.et al. 
How many tree species are there in the Amazon and how many of them will go extinct?. Proceedings of the National Academy of Sciences, v. 105, n. Supplement 1, p. 11498-11504, 2008.

IBGE. Instituto Brasileiro de Geografia e Estatística. Biomas e sistema costeiromarinho do Brasil: compatível com a escala 1:250 000. Rio de Janeiro, v. 45, p. 168, 2019.

JUNK, W. J.; SILVA, C. J. O conceito do pulso de inundação e suas implicações para o Pantanal de Mato Grosso. (pp. 17-28). In: 2o Simpósio sobre recursos naturais e Sócio-econômicos do Pantanal. Corumbá/Brasil: EMBRAPA, 1999. JOLY, C. A et al.. (Eds.), $1^{\circ}$ Diagnóstico Brasileiro de Biodiversidade e Serviços Ecossistêmicos. Editora Cubo, São Carlos pp.351, 2019.

LEWINSOHN, T.; PRADO, P. I. Biodiversidade brasileira: síntese do estado atual do conhecimento. São Paulo: Editora Contexto, 2002.

MITTERMEIER, R. A. et al. Conservation in the Pantanal of Brazil. Oryx, v. 24, n.2, p. 103-112, 1990.

MITTERMEIER, R.A.; ROBLES-GIL, P,; MITTERMEIER, C. G. (Eds.) Megadiversity: Earth's Biologically Wealthiest Nations. CEMEX, Conservation International, Arlington, 1997.

MALANSON, G. Effects of feedbacks and seed rain on ecotone patterns. Landscape Ecology, v. 12, p. 27-38, 1997.

MYERS, N.; MITTERMEIER, R. A.; MITTERMEIER, C. G.; DA FONSECA, G. A.; KENT, J. Biodiversity hotspots for conservation priorities. Nature, v. 403, n. 6772, p.853-858, 2000.

MALHEIROS, R. A Influência da Sazonalidade na Dinâmica da Vida no Bioma Cerrado. Revista Brasileira de Climatologia, v. 19, p. 2237-8642, 2016.

NEIFF, J. J. Planícies de inundação são ecótonos? In: HENRY, R. (Org.). Ecótonos nas interfaces dos ecossistemas aquáticos. São Carlos: RiMa, p. 2945, 2003.

PAZ, A. R; COLLISCHONN, W; TUCCI, C. E. M. Simulação Hidrológica de Rios com Grandes Planícies de Inundação. Revista Brasileira de Recursos Hídricos, v. 15 , p. 31-43, 2010.

PBMC/BPBES. Potência Ambiental da Biodiversidade: um caminho inovador para o Brasil. Relatório Especial do Painel Brasileiro de Mudanças Climáticas e da Plataforma Brasileira de Biodiversidade e Serviços Ecossistêmicos. 1a edição [Scarano, F.R., Santos, A.S. (Eds.)]. PBMC, COPPE - UFRJ. Rio de Janeiro, Brasil. p. 65, 2018.

RESENDE, E. K. Pulso de Inundação - Processo Ecológico Essencial à Vida no Pantanal. Corumbá, MS: EMBRAPA Pantanal. Boletim de Pesquisa, v. 94, p. 16, 2008. 
RODRIGUES, L. P.; CARVALHO, E. M.; SILVA, J. F. Unidades de Conservação no Ecótono entre Pantanal e Cerrado: o caso do Município de Aquidauana (MS). I Congresso Nacional de Geografia Física. Campinas, p. 1070-1081, 2017.

SHEPHERD, G.J. Conhecimento da diversidade de plantas terrestres no Brasil. In: LEWINSOHN, T.; PRADO, P. I. (Eds.). Biodiversidade brasileira: síntese do estado atual do conhecimento. São Paulo: Editora Contexto, 2002. p. 155159.

SILVA, M. C. A. et al. Caracterização e compartimentação das paisagens no contato Planalto/Planície do Pantanal do Negro e entorno/MS. In: RODRIGUES, Silvio Carlos; MERCANTE, Mercedes Abid (ORG). Paisagens do Pantanal e do Cerrado: fragilidades e potencialidades. Uberlândia: EDUFU, v.1, pg 179 a 214, 2011.

VELOSO, H.P.; RANGEL FILHO, A.L.R.; LIMA, J.C.A. Classificação da vegetação brasileira, adaptada a um sistema universal. IBGE: Rio de Janeiro, 1991.

WALTER, H. Vegetação e Zonas Climáticas. São Paulo, E.P.U. Ltda. 1986. 


\section{SUMÁRIO}

CAPÍTULO I - O RELEVO E 0 USO DA TERRA DA BACIA HIDROGRÁFICA DO RIO MIRANDA, MS. 12

DOI: 10.51859/AMPLLA.ECP672.1121-1

CAPÍTULO II - QUALIDADE DA ÁGUA SUBTERRÂNEA NA ÁREA URBANA DA BACIA DO CÓRREGO JOÃO DIAS, AQUIDAUANA-MS .31 DOI: 10.51859/AMPLLA.ECP672.1121-2

CAPÍTULO III - MACRÓFITAS AQUÁTICAS DO ECÓTONO CERRADO-PANTANAL .55 DOI: 10.51859/AMPLLA.ECP672.1121-3

CAPÍTULO IV - FLORÍSTICA E FITOSSOCIOLOGIA DO PARQUE NATURAL MUNICIPAL DA LAGOA COMPRIDA, AQUIDAUANA, MS ..73 DOI: 10.51859/AMPLLA.ECP672.1121-4

CAPÍTULO V - FLORÍSTICA DO ECÓTONO CERRADO-PANTANAL NO MATO GROSSO DO SUL .86

DOI: $10.51859 /$ AMPLLA. ECP672.1121-5

CAPÍTULO VI - FENOLOGIA DE TRÊS ESPÉCIES DE PLANTAS DANINHAS DE PASTAGEM EM UMA ÁREA DE ECÓTONO CERRADOPANTANAL .110

DOI: 10.51859/AMPLLA. ECP672.1121-6

CAPÍTULO VII - TAMANHO dO FRUTO E DISTÂNCIA DA PLANTA-MÃE AFETAM A tAXA DE PREDAÇÃO DE ATTALEA PHALERATA (ARECACEAE)?

DOI: 10.51859/AMPLLA. ECP672.1121-7

CAPÍTULO VIII - INTERAÇÃO ENTRE FORMIGAS (INSECTA, HYMENOPTERA) E ADENOCALYMMA PEREGRINUM (BIGNONIACEAE) EM PASTAGEM CULTIVADA, AQUIDAUANA-MS .136

DOI: 10.51859/AMPLLA. ECP672.1121-8

CAPÍTULO IX - A FAUNA DE MOLUSCOS E A OCORRÊNCIA DE BIOINVASORES EM DUAS LAGOAS DE MEANDRO ABANDONADO NO MUNICÍPIO DE AQUIDAUANA/MS, UM ESTUDO INICIAL SOBRE A CLASSE BIVALVIA. . .145 DOI: 10.51859/AMPLLA. ECP672.1121-9

CAPÍTULO X - DIVERSIDADE DE ESCORPIÕES (ARACHNIDA: SCORPIONES) EM FRAGMENTOS DE CERRADO NO ECÓTONO CERRADO-PANTANAL SUL MATOGROSSENSE. .166

DOI: 10.51859/AMPLLA.ECP672.1121-10

CAPÍTULO XI - DIVERSIDADE DE BESOUROS SCARABAEINAE (COLEOPTERA: SCARABAEIDAE) DO ECÓTONO CERRADO-PANTANAL

177

DOI: $10.51859 /$ AMPLLA.ECP672.1121-11

CAPITULO XII - FLUTUAÇÃO POPULACIONAL E ASPECTOS MORFOLÓGICOS DAS LARVAS MYRMELEON BRASILIENSIS (NEUROPTERA, MYRMELEONTIDAE) NO ECÓTONO CERRADO-PANTANAL 190

DOI: $10.51859 /$ AMPLLA.ECP672.1121-12

CAPÍTULO XIII - MAMÍFEROS NÃO VOADORES DO ECÓTONO CERRADO-PANTANAL, SUDOESTE DO BRASIL.......................... 206 DOI: 10.51859/AMPLLA. ECP672.1121-13

CAPÍTULO XVI - ALOUATTA CARAYA (HUMBOLDT, 1812): 0 QUE 0 TAMANHO E A DINÂMICA DE UM GRUPO PODEM NOS DIZER? 


\title{
CAPÍ́TULO I
}

\section{O RELEVO E O USO DATERRA DA BACIA HIDROGRÁFICA DO RIO MIRANDA, MS}

\author{
DDI: 10.51859/amplla.ecp672.1121-1
}

Emerson Figueiredo Leite ${ }^{1,2}$
André Geraldo Berezuk ${ }^{3}$
Charlei Aparecido da Silva $^{3}$
ângela Martins de Carvalho ${ }^{1}$

1Universidade Federal de Mato Grosso do Sul, Campus de Aquidauana, Cursos de Graduação e pós-graduação em Geografia, Rua Oscar Trindade de Barros, 740, Bairro da Serraria, Aquidauana, MS, Brasil, CEP: 79200-000.

${ }^{2}$ Universidade Federal da Grande Dourados - UFGD, pós-doutorado no Programa de pós-graduação em Geografia. Dourados-MS;

${ }^{3}$ Universidade Federal da Grande Dourados, Cursos de Graduação e Pós-graduação em Geografia. Dourados-MS.

\section{INTRODUCÃO}

A bacia hidrográfica é a unidade geomorfológica fundamental a ser considerada no planejamento do uso da terra como um sistema de organização espacial (CHRISTOFOLETTI, 1978) e corresponde, conforme Espíndola et al. (2000) a um sistema biofísico e socioeconômico, integrado e interdependente, contemplando diversas atividades antrópicas, todos os habitats e unidades da paisagem. [...] Uma bacia pode ser abordada como uma unidade morfo-fisiográfica [...] uma unidade funcional, com processos e interações ecológicas passíveis de serem estruturalmente caracterizados, quantificados e matematicamente modelados.

Por sua vez, potencial do relevo em desencadear processos morfogenéticos é objeto de diversas pesquisas (SPIRIDONOV, 1981; MENDES, 1993; LEITE; ROSA, 2012; BOIN; ZANATTA; CUNHA, 2014; FERREIRA, 2015, PERBELIN; LEITE, 2021) e foi denominado de energia do relevo por Mendes (1993). Esta análise visa obter dados quantitativos sobre o terreno (declividade, dissecação horizontal e vertical), os quais avaliam hierarquicamente a potencialidade de suas características geométricas para o desenvolvimento de processos morfogenéticos (FERREIRA, 
2015) tais como os processos de erosão laminar e lineares, em sulcos, ravinas e voçorocas (BOIN; ZANATTA; CUNHA, 2014).

Dentre os elementos que caracterizam a energia do relevo temos a declividade, que consiste na inclinação da superfície do terreno em relação ao plano horizontal, sendo que sua mensuração se dá em graus ( 0 a $\left.90^{\circ}\right)$ ou em porcentagem (\%) (CÂMARA et al., 1996). Já a dissecação vertical considera os graus de entalhamento dos canais de drenagem (amplitude altimétrica) (CREPANI et al., 1996; CREPANI et al., 2001) e a dissecação horizontal pode ser entendida como a distância horizontal entre as linhas de cumeada e os talvegues no interior de uma sub-bacia. Constitui-se em um parâmetro morfométrico onde a proximidade entre os cursos fluviais implica em maior potencialidade para a movimentação dos materiais constituintes do relevo (FERREIRA et al. 2014; FERREIRA, 2015).

A análise da energia do relevo pode ser correlacionada com outros estudos da Geografia, facilitando assim uma melhor análise da paisagem (DE BIASI; CUNHA, 1983) e quando correlacionada ao uso e cobertura da terra, proporciona informações sobre suas limitações de usos e indicativos de técnicas e práticas de manejos conservacionistas, visando à redução da ação erosiva e consecutiva perda de solo e de recursos hídricos, quer por quantidade ou qualidade (MEDEIROS et al., 2019).

O uso e cobertura da terra é o elemento que oferece a informação mais acessível numa imagem de satélite e permite a visualização e identificação direta dos elementos ali geometricamente apresentados. Uso, ocupação e cobertura da terra podem ser sintetizados através de mapas, indicando a distribuição espacial da tipologia da ação antrópica que pode ser identificada pelos seus padrões homogêneos característicos na superfície terrestre (LEITE; ROSA, 2012).

O uso e cobertura da terra é uma das formas de intervenção antrópica que podem contribuir para a instabilidade desses locais. A ocupação de terrenos de encostas, por sua vez, tem ocorrido com a remoção da vegetação, alterações no escoamento natural das águas, movimentos de terra (escavações e aterros), disposição incorreta de resíduos sólidos e líquidos, ações essas que contribuem para a desestabilização e o deslizamento dos terrenos com danos ambientais, sociais e econômicos (AQUINO; MOTA, 2019). 
Os impactos provenientes das atividades agropecuárias provocam grave degradação da qualidade da água e do solo por conta do desmatamento, uso de técnicas agrícolas inadequadas, emprego descontrolado de agroquímicos (PHILIPPI Jr.; SOBRAL; CARVALHO, 2019).

Convêm também relembrar que os problemas ambientais causam repercussões em toda a sociedade e tornam-se cada vez mais comuns nas áreas do Cerrado e Pantanal brasileiro. No Estado de Mato Grosso do Sul, p.ex., nas bacias hidrográficas do Paraná e do Paraguai, são comuns problemas ligados a fertilidade do solo, erosão, abastecimento hídrico urbano, enchentes, assoreamento, contaminação e poluição das águas superficiais e subterrâneas (PERBELIN; LEITE, 2021).

Deste modo, este capítulo apresenta uma análise da Geomorfologia, da energia do relevo e do uso e cobertura da terra na Bacia Hidrográfica do Rio Miranda (Figura 1) no Estado de Mato Grosso do Sul. Esta bacia possui uma área de 42.124 $\mathrm{km}^{2}$ conforme medida obtida sobre o shapefile disponível na Base Hidrográfica Ottocodificada da Agência Nacional de Águas, nível 4 (8952).

O Estado de Mato Grosso do Sul possui 79 municípios e destes, 23 possuem parte de seu território nesta bacia, importante afluente do Rio Paraguay, drenando uma grande área em direção ao Pantanal, destacando sua importância social, econômica e ambiental.

Figura 1. Bacia Hidrográfica do Rio Miranda: Localização.

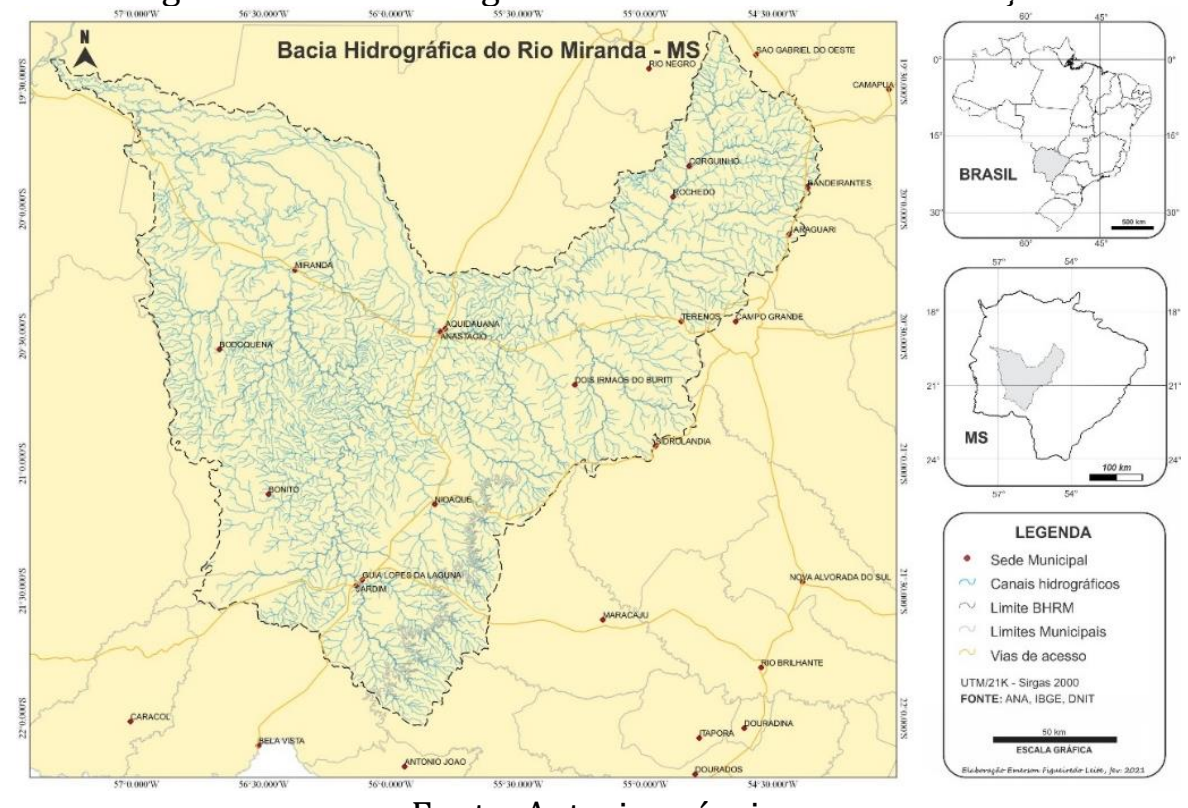

Fonte: Autoria própria. 
O clima predominante na bacia, segundo IBGE (2021) e conforme a classificação Koppen é correspondente ao Tropical Brasil Central, este sendo quente e subquente, podendo apresentar média térmica menor que $18^{\circ} \mathrm{C}$ e até três meses secos. A bacia apresenta volumes pluviométricos acumulados anuais normais variando de 1050 a $1850 \mathrm{~mm}$ (INMET, 2021).

Conforme Pott, Damasceno-Junior e Silva (2014), a vegetação da maior parte desta bacia é de Cerrado, cujos remanescentes cobrem 15\% da BHRM, nas suas diversas fisionomias, mas principalmente cerradão. Na sub-bacia do Aquidauana ocorrem veredas com buriti (Mauritia flexuosa), de grande importância para os recursos hídricos, como reguladores dos cursos d'água. Em áreas de cerradão derrubado ou raleado para pastagem, é frequente a regeneração de espécies lenhosas persistentes. Na Serra da Bodoquena ocorre um prolongamento descontínuo da Mata Atlântica de Interior, que é identificada como a Floresta Estacional Semidecidual. Entre a serra e o Pantanal de Miranda até próximo ao Morro do Azeite, no sopé dessa serra, há uma planície não inundável que já foi coberta por floresta decidual, a ver pelas barrigudas e castelos remanescentes.

Assim sendo, informações sobre o relevo, as formas de uso e ocupação e suas respectivas maneiras de alterar o meio na bacia hidrográfica são do interesse de todos que a ocupam de alguma forma e de especial interesse a quem planeja ou almeja ocupar estes espaços.

\section{MATERIAIS E MÉTODOS}

As unidades geomorfológicas foram compiladas de IBGE (2021) e considerados os limites da área de estudo da bacia. Os procedimentos adotados nesta pesquisa para a determinação da energia do relevo levaram em consideração a proposição de Guimarães et al. (2017) e Oliveira (2021). Foram utilizados dados altimétricos do Topodata (30 m interpolados). Informações sobre os dados Topodata podem ser obtidos em Valeriano (2005).

No software QGIS 3 realizou-se o tratamento e preparação do modelo digital de elevação, com definição do limite de segurança (buffer de $10 \mathrm{~km}$ no limite da bacia), preenchimento das depressões espúrias e recorte da matriz. 
Na sequência realizou-se o mapeamento do grau de entalhamento dos vales, mapeamento da dissecação horizontal média, cálculo da declividade e cruzamento matricial (calculadora raster) para definição da energia do relevo segundo as classes apresentadas na Tabela 1, adaptadas de Boin; Zanatta; Cunha (2014).

Para a determinação do uso e cobertura da terra, utilizou-se dos dados disponibilizados pelo projeto MapBiomas. Foram utilizados os dados da Coleção 5 para o ano de 2019, realizando um mosaico das matrizes disponibilizadas para o Pantanal e Cerrado, posteriormente recortados para os limites da área da Bacia Hidrográfica do Rio Miranda. Realizou-se uma edição matricial para incluir a classe temática Arroz Irrigado utilizando o software Spring/INPE.

Estes dados de uso e cobertura da terra são produzidos a partir da classificação pixel a pixel de imagens dos satélites da série Landsat e apresentados numa matriz na escala de $30 \mathrm{~m}$. 0 processo de classificação das imagens é realiado com a utilização de algoritmos de aprendizagem de máquina (machine learning) através da plataforma Google Earth Engine.

Tabela 1. Critérios morfométricos das classes de energia do relevo.

\begin{tabular}{c|c|c|c|c}
\hline $\begin{array}{c}\text { Declividade } \\
\mathbf{( \% )}\end{array}$ & $\begin{array}{c}\text { Dissecação } \\
\text { Vertical (m) }\end{array}$ & $\begin{array}{c}\text { Dissecação } \\
\text { Horizontal (m) }\end{array}$ & $\begin{array}{c}\text { Energia do } \\
\text { Relevo }\end{array}$ & Cor \\
\hline$<2$ & $<20$ & $>1600$ & Muito fraca & \\
\hline $2-5$ & $20-40$ & $800-1600$ & Fraca & \\
\hline $5-10$ & $40-60$ & $400-800$ & Média & \\
\hline $10-15$ & $60-80$ & $200-400$ & Fediana. forte & \\
\hline $15-20$ & $80-100$ & $100-200$ & Forte & \\
\hline
\end{tabular}

Fonte: Autoria própria.

Conforme disposto no site do projeto, o "Projeto MapBiomas - é uma iniciativa multi-institucional para gerar mapas anuais de uso e cobertura da terra a partir de processos de classificação automática aplicada a imagens de satélite". A descrição completa do projeto encontra-se em http://mapbiomas.org e em Souza Jr. et al. (2020). 


\section{RESULTADOS E DISCUSSÕES}

Os resultados encontrados nesta pesquisa para a área da bacia hidrográfica do Rio Miranda-MS apresentam as principais unidades geomorfológicas (Figura 2), a disposição espacial das classes de energia do relevo (Figura 3), bem como as principais formas de uso ocupação da terra (Figura 4).

Como principais unidades geomorfológicas do baixo curso da bacia, temos o Pantanal do Miranda-Aquidauana, Pantanal do Negro Taboco e as planícies coluviais pré-Pantanal. Nessa região temos as rochas do Grupo Cuiabá e da Formação Pantanal (sedimentos arenosos, siltico-argilosos e argilosos, inconsolidados e semiconsolidados). Os solos são os das classes Neossolos Regoliticos, Argissolos Vermelhos e Planossolos. As s altitudes, por sua vez, variam de 80 a 200 metros.

De acordo com Brasil (1982) os Pantanais compreendem extensas áreas de acumulação inundáveis (Aai) e secundariamente áreas de planície fluviolacustres (Apfl). As áreas de acumulação inundáveis foram hierarquizadas em ordem crescente, segundo o grau de umidade, partindo de menos úmida para a mais úmida, sendo, Aai1 (inundação fraca), Aai2 (inundação média) e Aai3 (inundação forte).

O Pantanal do Miranda-Aquidauana apresenta áreas inundáveis do tipo Aai2 com planossolos eutróficos solódicos, variando apenas a vegetação de Campo Limpo a Campo Sujo (BRASIL, 1982). 
Figura 2. Bacia Hidrográfica do Rio Miranda: Unidades Geomorfológicas.
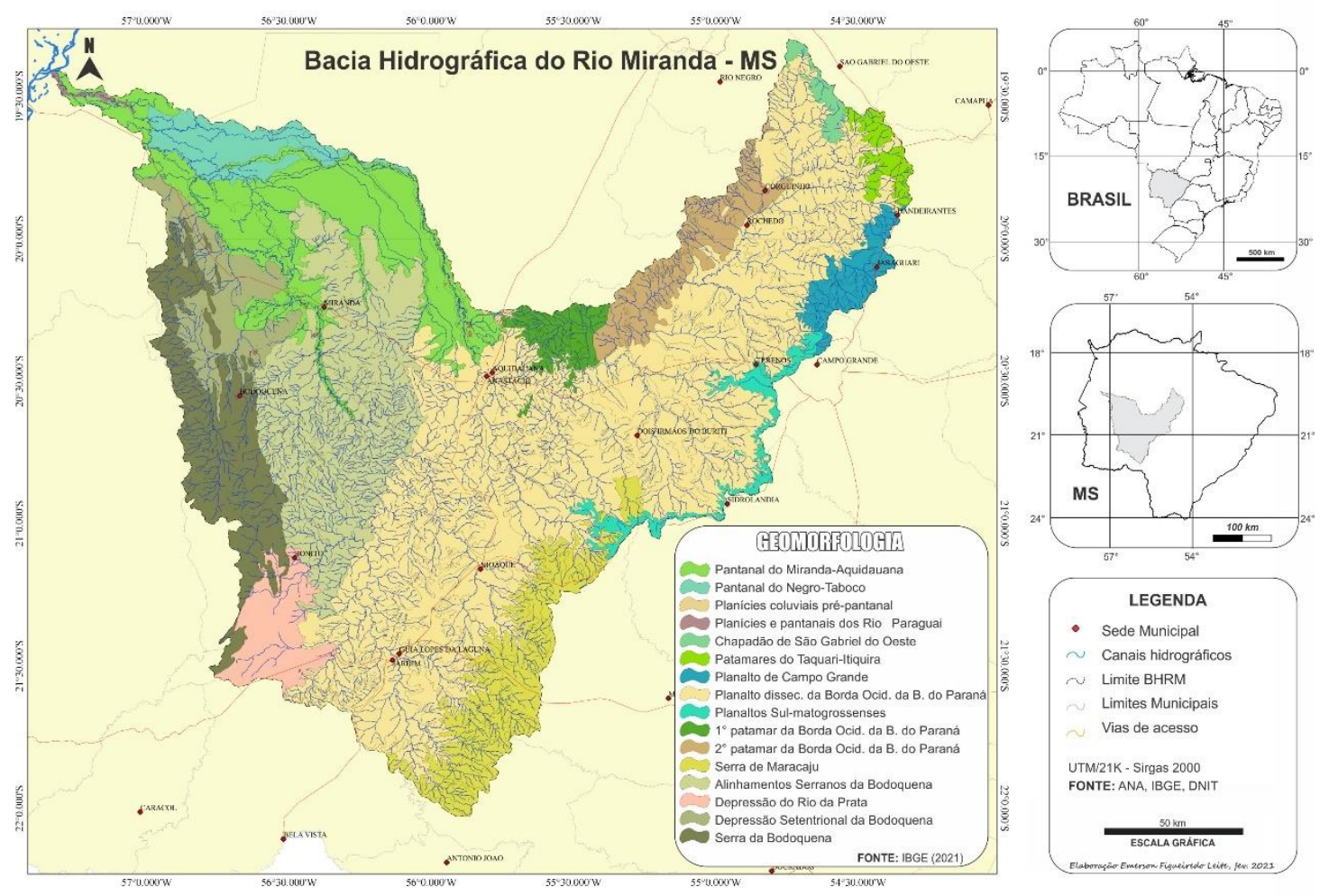

Fonte: Autoria própria.

O Pantanal do Negro-Taboco se caracteriza pela presença de planície fluviolacustre (Apfl) e por área de acumulação inundável do tipo Aai2. No trecho de Aai2 ocorrem solos de Laterita Hidromórfica eutrófica com vegetação de campo sujo. Já nas planícies observam-se planossolos com vegetação de campo limpo. A área compreende também, aluviões holocênicos onde se desenvolveram planossolos eutróficos. Recobre-a uma vegetação de Campo Cerrado (BRASIL, 1982).

O setor oriental tem um alagamento periódico, através da junção das águas dos rios Negro e Taboco, que é aumentado pelas águas do Aquidauana. A ligação entre as "baías", em período de estiagem é feita através da água do subsoslo. Na parte central e ocidental, as aluviões da margem direita do rio Miranda e as aluviões da margem esquerda do Aquidauana se expandem para a zona interposta entre eles, ocasionando a norte uma coalescência de sedimentos aluviais, carreados pelos "corixos", em demanda do rio principal. 0 referido pantanal é caracterizado como área de transição, porque além de apresentar um alagamento mediano (Aai2), tem uma grande variedade botânica, correspondente a ambiente diversos. Na porção oriental registrou-se predominância de Planossolos eutróficos. Na porção ociental, 
predominam os Planossolos eutróficos solódicos e manchas menores de Savana Gramíneo-Lenhosa (Mato Grosso do Sul, 1993).

Estas unidades geomorfológicas apresentam, predominantemente, classes de muito fraca a fraca com relação à energia do relevo. Correspondem, estas duas classes de energia do relevo, a uma área de $11.629,89 \mathrm{~km}^{2}$ ou $27,61 \%$ de toda a bacia (Figura 3 e Tabela 2), tendo sua expressão espacial no baixo curso. Apresentam como principais características a baixa declividade e menores valores de dissecação vertical. Em relação ao uso e cobertura da terra, estas áreas apresentam as classes de remanescentes florestais, formação campestre, campo alagado e área pantanosa. Atividades econômicas ligadas à pecuária (Figura 4 - h) e ao ecoturismo, além do cultivo de arroz irrigado (Miranda-MS) são destaques nesta parte da bacia.

$\mathrm{Na}$ porção oeste da bacia, destacam-se as unidades geomorfológicas denominadas de depressão setentrional da Bodoquena e a Serra da Bodoquena. Apresentam altitudes variando de 100 a 700 metros, destacando-se rochas do Grupo Alto tererê (xistos pelíticos) e rochas das Formações Bocaina (calcários dolomíticos e dolomitos), Cerradinho (sedimentos arenosos, argilosos, calcários, dolomitos, siltitos, argilitos, margas, ardosias, metargilitos, metassiltitos, folhelhos e camadas de sílex), Puga (paraconglomerado epimetamórfico) e Xaraiés (tufa calcária). Os solos são os das classes chernossolos, nitossolos e gleissolos.

A depressão setentrional da Bodoquena em toda sua extensão encontra-se pediplanada e inumada. Evidências da pediplanação a que foi submetida a unidade nessa porção encontram-se na presença de inúmeros inselbergues espalhados pela área, notadamente nas proximidades da Serra da Bodoquena (Mato Grosso do Sul, 1993).

Compreendem extensas superfícies aplanadas (Pri) resultantes do processo de pediplanação. Na parte ocidental da unidade, a retomada da erosão iniciou um processo de dissecação da superfície de aplanamento (Pri). Na parte oriental, a superfície de aplanamento penetrou no interior da Serra da Bodoquena, abrindo uma depressão inter-planáltica. A drenagem, constituída pelo rio Salobra e seus afluentes, se dirige aos Pantanais do Aquidauana-Miranda, aproveitando provavelmente uma linha de fraqueza e abrindo uma garganta (passagem) entre os Alinhamentos Serranos e a Serra da Bodoquena (IBGE, 2021). 
Já a Serra da Bodoquena compreende um conjunto de relevos estruturais dispostos na direção norte-sul. Se destaca pela sua magnitude e importância econômica e ambiental para a região e para o Estado de Mato Grosso do Sul. Estendese por aproximadamente 200 quilômetros no sentido norte-sul e comporta altimetrias que variam de 400 a 750 metros. Predominam declives maiores que 15\%, podendo atingir mais de 100 metros de dissecação vertical, o que caracteriza a maior parte da área da Serra com muito forte energia do relevo.

Figura 3. Bacia Hidrográfica do Rio Miranda: Dissecação vertical e horizontal, declividade e classes de energia do relevo.

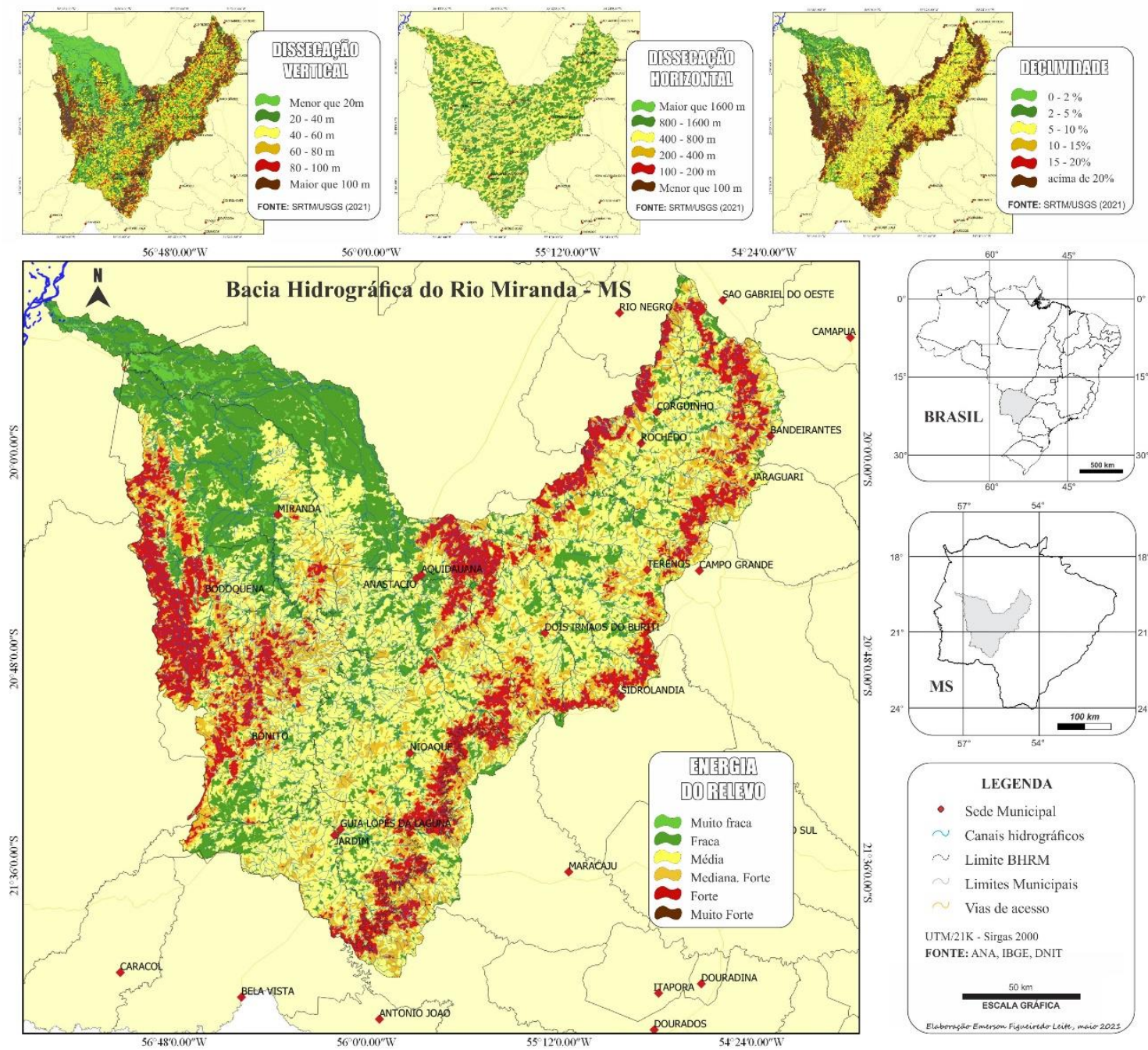

Fonte: Autoria própria.

Medeiros et al. (2019) já constataram maiores classes de dissecação vertical em ambientes cársticos com rochas carbonáticas, sobretudo, devido ao seu relevo acidentado, bem como, nos planaltos cársticos com bacias de maior extensão, da área da serra da Bodoquena. 
No interior do conjunto serrano ocorrem segmentos de escarpas, delimitando vales profundos e constituindo cânions. Alguns desses segmentos correspondem a bordas de relevo afetado por tectônica, como é o caso da escarpa da Falha de Guaicurus (IBGE, 2021).

Apesar de se caracterizar, de um lado, pela existência de formas dissecadas de topo convexo (c12) e, de outro, pelos relevos conservados (Ep), a Serra da Bodoquena apresenta localmente formas cársticas relacionadas às litologias calcárias (BRASIL, 1982).

Tabela 2. Classes de energia do relevo encontradas na bacia hidrográfica do rio Miranda.

\begin{tabular}{l|c|c|c}
\hline \multicolumn{1}{c}{ Energia do Relevo } & Cor & Área $\left(\mathbf{K m}^{\mathbf{2}} \mathbf{)}\right.$ & $\mathbf{\%}$ \\
\hline Muito fraca & & 446,37 & 1,06 \\
\hline Fraca & & $11.183,52$ & 26,55 \\
\hline Média & & $16.565,84$ & 39,33 \\
\hline Mediana. Forte & & $7.435,71$ & 17,65 \\
\hline Forte & & $6.459,96$ & 15,34 \\
\hline Muito forte & & 32,60 & 0,08 \\
\hline Total & & $42.124 \mathrm{~km}^{2}$ & $100 \%$ \\
\hline
\end{tabular}

Fonte: Autoria própria.

Da borda oriental partem os rios da Prata e Formoso, dentre outros. Para sul, correm os rios Perdido e Jacadigo, e para norte segue o rio Salobra, afluente do Miranda. As altimetrias variam dos 100 aos 300m de altitude, com depósitos coluviais associados à base das encostas que emergem em meio da Depressão Setentrional da Bodoquena (IBGE, 2021).

Medeiros et al. (2019) analisaram a energia do relevo da bacia Hidrográfica do Rio Mimoso, uma sub-bacia do rio Formoso, importante bacia que disseca a Serra da Bodoquena. Segundo os autores, seu relevo apresenta altos declives nos morros residuais, seus rios são cachoeirados, que proporcionam rica beleza cênica. 0 relevo acidentado dificulta o processo de ocupação, sendo recobertos por uma ainda exuberante vegetação nativa, com exceção das áreas planas do planalto da serra da Bodoquena, que vem sendo utilizado para a agricultura comercial de exportação, seja da soja (durante boa parte do ano) e do milho (entressafras).

Os solos e a vegetação apresentam-se distribuídos de acordo com o relevo e as litologias. Onde ocorre as formas aplanadas (EP) em litologias da formação 
Cerradinho, domina a Terra Roxa estruturada similar eutrófica latossólica e a vegetação constitui-se como de cerrado. Onde existe a formação Bocaina e o relevo é dissecado do tipo c12, o solo de maior ocorrência é a Rendzina (Chernossolos) refletindo a presença do calcário e a vegetação composta por áreas florestais. Na borda ocidental assinalada por escarpas estruturais esculpidas nas litologias do Complexo Rio Apa, os solos são Litólicos e a vegetação também é de cerrado (BRASIL, 1982).

Nas unidades geomorfológicas depressão setentrional da Bodoquena e da Serra da Bodoquena estão em destaque grandes fragmentos florestais, os maiores da área estudada. Estas áreas encontram-se preservadas pela existência do Parque Nacional da Serra da Bodoquena, unidade de conservação de proteção integral federal implantada no estado de Mato Grosso do Sul. Também, pode-se dizer que esta preservação é imposta pelas próprias limitações do relevo, como altas declividades que dificultam o processo de ocupação antrópica. Também, como no Pantanal, nestas áreas as atividades econômicas caracterizam o uso e cobertura da terra pelo turismo, pela pecuária extensiva e em menor proporção a agricultura comercial (soja, milho).

No médio curso da bacia apresentam-se as unidades geomorfológicas denominadas alinhamentos serranos da Bodoquena, a depressão do rio da Prata e o planalto dissecado da borda ocidental da bacia do Paraná. Estas unidades apresentam como predominantes classes de dissecação vertical de 20 a 60 metros e a 5 a 10\% de declividade. Com intervalos altimétricos de 100 a 300 metros, destacam-se nesta parte da bacia as rochas da Formação Aquidauana (siltitos arenosos e arenitos de variadas granulações) e, na porção central da bacia, cobertura detrito-laterítica. Os solos presentes são os das classes de latossolos vermelhos, argissolos vermelhos e neossolos quartzarênicos.

Os alinhamentos serranos da Bodoquena se apresentam, por sua vez, como um relevo fortemente falhado, com a presença de uma anticlinal erodida unida ao corpo principal da Serra da Bodoquena e estruturas residuais de falha em litologias do Grupo Cuiabá, muito erodidas em decorrência da atuação fluvial no Pantanal do Miranda-Aquidauana. Ocorrem relevos dissecados com alta densidade de drenagem com aprofundamento relativamente baixo (Dc51, Dc52, Dt41, Dt42, Da52) e 
conservados, em posição ligeiramente mais elevada que a superfície geral do entorno (IBGE, 2021).

A depressão do rio da prata apresenta-se como uma área aplanada, mais rebaixada que a Serra da Bodoquena, com caimento no sentido oeste-leste. Predominam relevos de aplanamento (Pri), cortados por uma drenagem incipiente, concentrada nos rios que descem do conjunto serrano da Bodoquena, a exemplo do rio da Prata. 0 limite oriental desta unidade é marcado por escarpas erosivas, onde as cabeceiras de drenagem de primeira ordem desenvolvem um processo de dissecação, promovendo a desconfiguração da superfície de aplanamento (IBGE, 2021).

Figura 4. Bacia Hidrográfica do Rio Miranda: Uso e cobertura da terra.
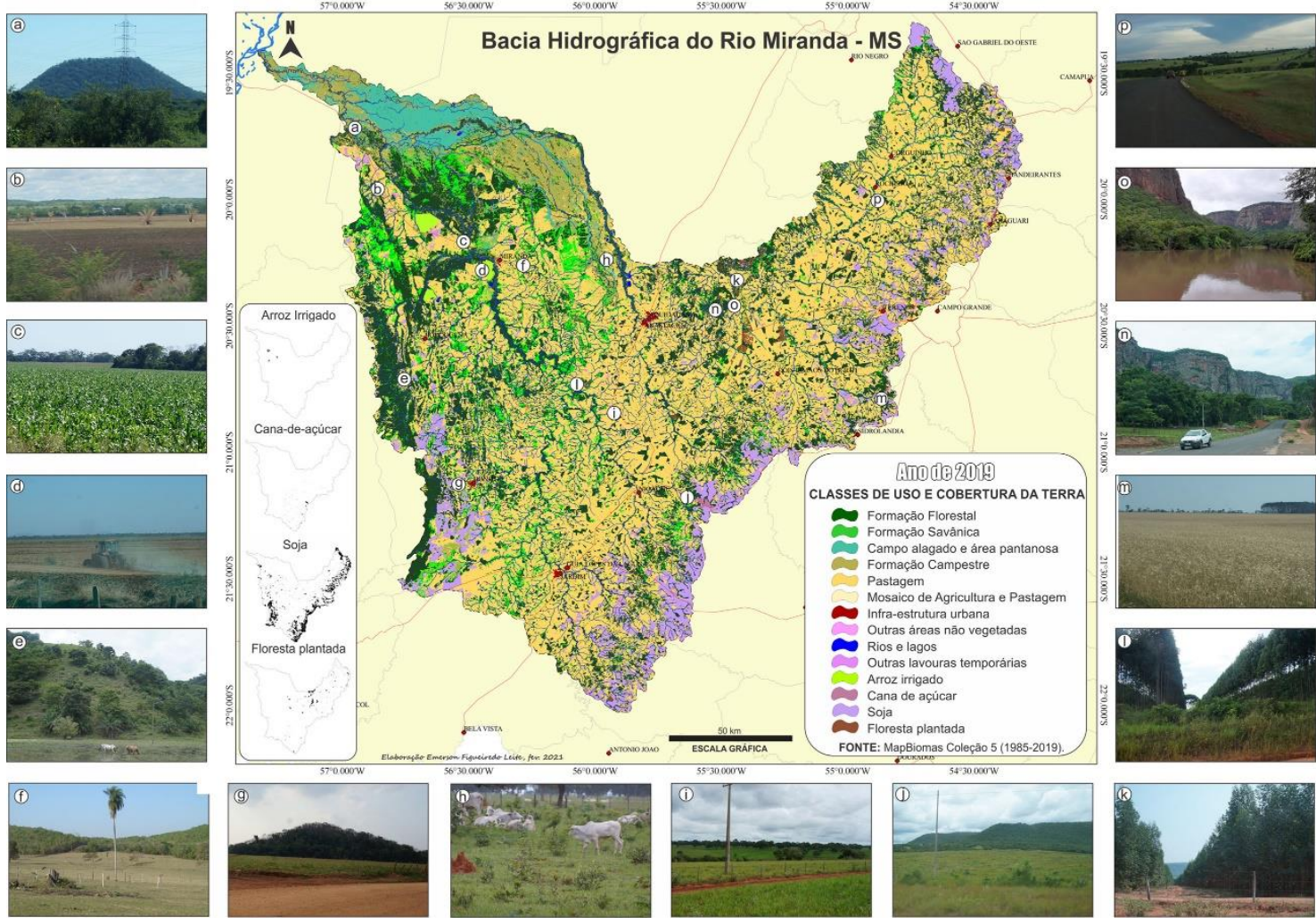

Fonte: Autoria própria.

O planalto dissecado da borda ocidental da bacia do Paraná se estende por todo o médio curso, partindo do sul da bacia no sentido NNE (nor-nordeste). A parte central da unidade constitui um divisor de água entre os afluentes do rio Miranda, que correm para norte em direção ao Pantanal, e o rio Piripucu e seus afluentes, que correm em direção ao Paraguai, ambos seguindo um padrão dendrítico. A parte nordeste da unidade constitui um patamar intermediário entre as unidades da Serra 
do Maracaju, Primeiro Patamar da Borda Ocidental da Bacia do Paraná e o Planalto de Campo Grande, destacando-se a presença de relevos residuais de topos planos.

As formas de relevo dissecados de topos tabulares com baixo aprofundamento (Dt11, Dt41, Dt42) são predominantes, cujos aprofundamentos das encostas variam de 50 a 100 metros (IBGE, 2021).

Em relação ao uso e cobertura da terra, considerando as unidades geomorfológicas dos alinhamentos serranos da Bodoquena e do planalto dissecado da borda ocidental da bacia do Paraná, há destaque para as áreas de pastagem (50,52\%), caracterizando a principal forma de exploração da terra na região, a pecuária extensiva. Em menor proporção existem áreas de floresta plantada (silvicultura) que aparecem em todos os municípios do médio e alto curso, com destaque para Dois Irmãos do Buriti e Anastácio (Figura 4 - k, l). Na depressão do rio da Prata, em áreas do município de Bonito, há grandes extensões de áreas de cultivo de soja e outras lavouras temporárias, aproveitando-se do potencial dos solos e o favorecimento das características do relevo, notadamente o aspecto referente a baixa declividade de muitas áreas.

Tabela 3. Classes uso e cobertura da terra da bacia hidrográfica do rio Miranda.

\begin{tabular}{l|c|c|c}
\hline Uso e cobertura & COR & Área (km $\mathbf{~}$ & \% \\
\hline Formação Florestal & & $11.044,13$ & 26,22 \\
\hline Formação Savânica & $2.944,88$ & 6,99 \\
\hline Campo Alagado e Área Pantanosa & $1.334,22$ & 3,17 \\
\hline Formação Campestre & $2.235,74$ & 5,31 \\
\hline Pastagem & & $21.263,12$ & 0,06 \\
\hline Cana & 25,96 & 0,13 \\
\hline Infraestrutura Urbana & 54,50 & 0,06 \\
\hline Outras Áreas não vegetadas & 26,55 & 0,19 \\
\hline Rio, Lago & & 81,29 & 0,95 \\
\hline Outras Lavouras Temporárias & 400,70 & 0,25 \\
\hline Arroz Irrigado & 103,46 & 0,29 \\
\hline Floresta Plantada & 123,53 & $\mathbf{1 0 0 \%}$ \\
\hline Soja & & $2.467,78$ & \\
\hline Total & & $42.124 \mathrm{~km}{ }^{2}$ & \\
\hline
\end{tabular}

Fonte: Autoria própria.

No alto curso da bacia destacam-se as unidades geomorfológicas da serra de Maracaju, planaltos sul-mato-grossenses, o planalto de Campo Grande, os patamares 
do Taquari Itiquira, chapadões de São Gabriel do Oeste, e o $1^{\circ}$ e $2^{\circ}$ patamares da borda ocidental da Bacia do Paraná. Estas unidades apresentam declividades que variam entre 10 a mais de $20 \%$, e dissecações verticais com mais de 60 a maiores que 100 metros de variação altimétrica (o que caracteriza como forte energia do relevo na maior parte desta área da bacia). Encontram-se no alto curso da bacia, rochas da Formação Caiuá (arenitos), Serra Geral (basalto) e da Formação Botucatu (arenitos)m sendo que a altitude varia de 200 a 700 metros e os solos predominantes são os Latossolos Vermelhos e os Neossolos.

Morfologicamente, o relevo da serra de Maracaju se constitui de uma extensa superfície suavemente dissecada onde predominam formas tabulares amplas, com baixo índice de aprofundamento (Dt31, Dt21), esculpidos em rochas basálticas da Formação Serra Geral. A atividade erosiva da dissecação mascarou grande parte das feições com aspecto cuestiformes, resultando frentes de cuesta descontínuas alternadas com áreas dissecadas (IBGE, 2021).

Presente ao longo do território sul-mato-grossense, a Serra inicia se ao sul do Estado, cruzando-o até o extremo norte. Em sua extensão, a Serra, é formada por conjuntos estruturais geomorfológicos de diferentes configurações, nela encontram-se relevos testemunho intercalados, faixas de contínuas formações rochosas, platôs e grandes paredões areníticos que se destacam na paisagem (LIMA e SILVA, 2019).

Os planaltos sul-matogrossenses apresentam-se com relevo colinoso esculpido principalmente em psamitos da Formação Bauru de idade cretácea, que recobre discordantemente os basaltos da Formação Serra Geral do juro-cretáceo, ocupando a porção basal desta unidade (IBGE, 2021).

O planalto de Campo Grande apresenta suas partes mais elevadas constituídas por relevos residuais (Pgi), nos topos dos alinhamentos serranos, cujas altitudes alcançam de 600 a 700 metros. Há o predomínio de relevos dissecados mais rebaixados, de topos planos e convexos (Dt22, Dc32, Dc42) e áreas deprimidas com vales de fundo chato, com aprofundamento das encostas em torno de 100 metros, conforme podemos observar no mapa de dissecação vertical (IBGE, 2021).

Os patamares do Taquari-Itiquira constituem numa área deprimida em meio aos Planaltos e Patamares da Borda Ocidental da Bacia do Paraná. As altimetrias de maneira geral giram em torno dos 300 e $400 \mathrm{~m}$. As formas de relevo predominantes 
são colinas e interflúvios tabulares com alta densidade de drenagem e baixo índice aprofundamento das incisões Dc41, Dc42, Dt31 e Dt32 (IBGE, 2021).

A unidade denominada chapadão de São Gabriel do Oeste representa relevo alçado com altimetrias em torno de $700 \mathrm{~m}$ correspondendo a uma superfície pediplanada etchplanada (Pge) e degradada inumada (Pgi). A borda ocidental deste relevo, identificada como serra de São Gabriel é marcada por escarpas erosivas com desníveis de aproximadamente $100 \mathrm{~m}$. Modelados de dissecação de topos tabulares e convexos amplos inclinam-se para os vales muito abertos. Sobre as formas aplanadas e tabulares desenvolveram-se Latossolos Vermelho-Escuro, com uso intensivo de agricultura nestes. Nos vales ocorrem Cambissolos. Toda a área é dominada pela vegetação de Cerradão. A borda sul-oriental do chapadão apresenta coalesce gradualmente com o Planalto de Cristalina (IBGE, 2021).

$01^{\circ}$ patamar da borda ocidental da bacia do Paraná se caracteriza com o contato deste patamar a oeste com as Planícies Coluviais Pré-Pantanal. Esta área da bacia hidrográfica do Rio Miranda é marcada por frentes de cuestas festonadas, eventualmente com cornija e pedimentos na base, bem como por vertentes onde a drenagem já instalou estreitas faixas de relevos dissecados do tipo Da51, Da53, Da42 e Dc41. A rede de drenagem corta este planalto no sentido oeste-leste e os rios principais (Negro, Jaguari e Piquiri) abrem vales do tipo cânions nas escarpas das serras. Destacam-se as formas de relevo dissecadas de topos tabulares (Dt11, Dt21, Dt31, Dt22) e alguns residuais de superfícies aplanadas. Eventualmente ocorrem alguns pequenos nichos de maior densidade de dissecação mapeados como Da51 (IBGE, 2021).

Em sua continuidade, o $2^{\circ}$ patamar da borda ocidental da bacia do Paraná apresenta predominantemente, modelados tabulares e é drenado pelas cabeceiras do Rio Aquidauana e seus afluentes. A drenagem de primeira ordem origina localmente modelados convexos (Mato Grosso do Sul, 1993).

Apesar das características de forte energia do relevo na interface dos planaltos (da parte alta da bacia) com o planalto dissecado da borda ocidental da bacia do Paraná, os topos com as formas tabulares, as baixas declividades e os solos da classe latossolos favoreceram a implantação dos usos agrícolas ligados ao cultivo de soja e outras lavouras temporárias. Esse processo espacial ocorre em todas as unidades geomorfológicas da parte alta da bacia. No caso da Serra de Maracaju, 
Lima, Silva e Boin (2017) observaram a pressão exercidas por atividades ligadas à pecuária e agricultura nas áreas de entorno da serra. São atividades que possuem limitações para avançar sobre a área em função das características do relevo. Apesar disso, são áreas com potencial para o desenvolvimento de atividades de contemplação, com ocorrência de corredeiras e cachoeiras, ideais para atividades do turismo de aventura.

\section{CONSIDERAÇÕES FINAIS}

Sobre os elementos do relevo e conforme evidenciado pelos resultados, a área estudada apresenta uma forma aproximada de uma "pera", característica semelhante à de outras grandes bacias. É circundada por planaltos e serras e no interior apresenta depressões, planícies e pantanais.

Os dados levantados de uso e cobertura da terra confirmam supressão da vegetação (formações florestais, savânicas e campestres) que correspondem atualmente a aproximadamente $38 \%$ da área da bacia. A pecuária é a atividade econômica de maior expressividade espacial na bacia, ocupando 50\% da área total com pastagens, que são favorecidas pelas características do relevo de baixa declividade e consequentemente de muito fraca a média energia do relevo (característica de $66 \%$ da bacia).

Há a presença outras formas de uso agrícola nas suas diversas modalidades, silvicultura, soja e cana, p.ex., que ocupam menor extensão de área, sendo $12 \%$ da bacia. Porém, estão localizadas em áreas próximas a relevos escarpados ao logo dos planaltos na parte alta da bacia e nas proximidades da Serra da Bodoquena nos municípios de Jardim e Bonito, pressionando nascentes e remanescentes florestais. As classes de energia do relevo variam nestes locais de medianamente forte a muito forte, com o potencial de desencadeamento a processos morfogenéticos, que suscita o planejamento das diversas formas de uso, cuidados e manejos adequados, considerando as práticas de conservação edáficas, vegetativas e mecânicas.

\section{AGRADECIMENTOS}

O presente trabalho foi realizado com apoio da Universidade Federal de Mato Grosso do Sul - UFMS/MEC - Brasil e com o apoio da Universidade Federal da 
Grande Dourados - UFGD/MEC - Brasil, pós-doutorado no Programa de Pósgraduação em Geografia.

\section{REFERÊNCIAS}

AQUINO, Marisete Dantas; MOTA, Suetônio. Planejamento ambiental e ordenamento territorial em bacias hidrográficas. In. Philippi Jr., Arlindo. Sobral, Maria do Carmo. Gestão de bacias hidrográficas e sustentabilidade. 1.ed. Barueri, SP: Ed. Manole, 2019. Pag. 185-204.

BOIN, Marcos Norberto; ZANATTA, Felipe Augusto Scudeller; CUNHA, Cenira Maria Lupinacci. Avaliação da morfometria do relevo da alta bacia hidrográfica do Ribeirão do Areia Dourada, Marabá Paulista (SP). Caderno Prudentino de Geografia, Presidente Prudente, n.36, v.2, p.5-26, ago./dez. 2014.

BRASIL. Ministério de Minas e Energia. Secretaria Geral. Projeto RADAMBRASIL: Geologia, geomorfologia, pedologia, vegetação e uso potencial da terra. Rio de Janeiro, 1982.

CHRISTOFOLETTI, A. Contribuição ao estudo dos processos morfogenéticos na área dos cerrados. Boletim Paulista De Geografia, (42), 71-77. Recuperado de https://publicacoes.agb.org.br/index.php/boletim-

paulista/article/view/1193, 2017.

CHRISTOFOLETTI, Antônio. Morfologia de bacias de drenagem. Not. Geomorfológica, Campinas, 18 (36): 130 - 132, dez. 1978.

CREPANI, Edison; MEDEIROS, José Simeão de; AZEVEDO, Luiz Guimarães de; HERNANDEZ FILHO, Pedro; FLORENZANO, Teresa Gallotti; DUARTE, Valdete; Curso de sensoriamento remoto aplicado ao zoneamento ecológicoeconômico. INPE, São José dos Campos, 1996, 20 pag.

CREPANI, Edison; MEDEIROS, José Simeão de; HERNANDEZ FILHO, Pedro; FLORENZANO, Teresa Gallotti; DUARTE, Valdete; BARBOSA, Cláudio Clemente Faria. Sensoriamento remoto e geoprocessamento aplicados ao zoneamento ecológico-econômico e ao ordenamento territorial. INPE, São José dos Campos, 2001, 103 pag.

DE BIASI, Mario; CUNHA, Keith Bento da. Cartas de energia do relevo: sua confecção e utilização. Boletim Goiano Geografia. número 3, pag. 195-200, jan./dez. 1983.

ESPÍNDOLA, Evaldo L. G.; SILVA, João S. V.; MARINELLI, Carlos E.; ABDON, Myriam M. A Bacia Hidrográfica do Rio Monjolinho: uma abordagem ecossistêmica e a visão interdisciplinar. São Carlos: Rima Editora, 2000. 188p.

FERREIRA, Mateus Vidotti. Contribuição metodológica ao estudo da dissecação e energia do relevo: proposta e avaliação de técnicas computacionais. [Tese 
orientada por Dra. Paulina Setti Riedel e Coorientada pela Dra. Cenira Maria Lupinacci]. Unesp: Rio Claro, SP, 2015.

FERREIRA, Mateus Vidotti; TINÓS, Thais Minatel; PINTON, Leandro de Godoi; Cunha, Cenira Maria Lupinacci da. A dissecação horizontal como parâmetro morfométrico para avaliação do relevo: proposta de técnica digital automática. Revista Brasileira de Geomorfologia, São Paulo, v.15, n.4, (OutDez) p.585-600, 2014.

GUIMARÃES, Felipe Silva; CORDEIRO, Claudia Mendes; BUENO, Guilherme Taitson; CARVALHO, Vilma Lúcia Macagnan; NERO, Marcelo Antônio. Uma proposta para automatização do índice de dissecação do relevo. Rev. Bras. Geomorfol. (Online), São Paulo, v.18, n.1, (Jan-Mar) p.155-167, 2017.

IBGE. Instituto Brasileiro De Geografia e Estatística (Brasil). Banco de Dados e Informações Ambientais. Disponível em: https://bdiaweb.ibge.gov.br. Acesso em: mai. 2021.

INMET. Instituto Nacional de Meteorologia. Normais Climatológicas do Brasil 19812010. Brasília, DF: INMET, Disponível em https://portal.inmet.gov.br/normais. Acessado em 2021.

LEITE, E.F., $e$ ROSA, R. Mapeamento Geomorfológico: A Carta de Energia do Relevo da Bacia Hidrográfica do Rio Formiga-TO. Revista Brasileira de Geografia Física, 5(2), pag. 269-284, 2012.

LEITE, Emerson Figueiredo. ROSA, Roberto. Análise do uso, ocupação e cobertura da terra na bacia hidrográfica do Rio Formiga, Tocantins. OBSERVATORIUM: Revista Eletrônica de Geografia, v.4, n.12, p. 90-106, dez. 2012.

LIMA, Bruno de Souza; SILVA, Charlei Aparecido da. A qualidade visual da paisagem da Serra de Maracaju-MS/Brasil, um patrimônio a ser desvendado. XIII Enanpege. A Geografia brasileira na ciência-mundo: produção, circulação e apropriação do conhecimento. São Paulo: 2 a 7 de setembro de 2019.

LIMA, Bruno de Souza; SILVA, Charlei Aparecido da; BOIN, Marcos Norberto. Unidades de paisagens da Serra de Maracaju para o turismo de natureza, Folha Nioaque-MS. ENANPEGE, Geografia, Ciência e Política: do pensamento à ação, da ação ao pensamento. 12 a 15 de outubro, Porto Alegre, 2017.

MATO GROSSO DO SUL - Secretaria de Planejamento e Coordenação Geral SEPLAN/MS. Atlas Multirreferencial do Estado de Mato Grosso do Sul. Conv. Fundação IBGE (Solos, Vegetação, Geologia, Geomorfologia e Clima). Campo Grande-MS, 1990.

MEDEIROS, Rafael Brugnolli; BEREZUK, André Geraldo; PINTO, André Luiz. A morfometria da bacia hidrográfica do rio Mimoso, um sistema cárstico do Mato Grosso do Sul/ Brasil. CONFINS - Revista Franco-Brasileira de Geografia: Paris, n.40, 2019. 
MENDES, I. A. A dinâmica erosiva do escoamento pluvial na bacia do Córrego Lafon - Araçatuba - SP. 1993. [Tese de Doutorado em Geografia Física]. Faculdade de Filosofia Letras e Ciências Humanas, Universidade e São Paulo, São Paulo, 1993.

OLIVEIRA, Ulisses Costa de. Índice de Dissecação do Relevo (IDR), Entalhamento dos Vales e Dimensão Interfluvial Média no QGis 3. Disponível em https://www.youtube.com/watch?v=FbD8Ig6JJqo. Acesso em 2021.

PHILIPPI Jr., Arlindo. SOBRAL, Maria do Carmo. CARVALHO, Renata Maria Caminha Mendes de Oliveira. Bacia hidrográfica no contexto da sustentabilidade. In. Philippi Jr., Arlindo. Sobral, Maria do Carmo. Gestão de bacias hidrográficas e sustentabilidade. 1.ed. Barueri, SP: Ed. Manole, p. 3-18, 2019.

POTT, Arnildo; DAMASCENO-JUNIOR, Geraldo Alves; SILVA, Marta Pereira da. Características da Bacia Hidrográfica do Rio Miranda. Revista GeoPantanal, UFMS/AGB. Corumbá/MS, n. 16, p. 125-140, 2014.

RODRIGUES, Lidiane Perbelin; LEITE, Emerson Figueiredo. Análise da Energia do Relevo e do Uso e Cobertura da Terra na Bacia Hidrográfica do córrego Acôgo, MS. Terr@Plural, Ponta Grossa, v.15, p. 1-25, 2021.

SOUZA, C.M., JR.; Z. SHIMBO, J.; ROSA, M.R.; PARENTE, L.L.; A. ALENCAR, A.; RUDORFF, B.F.T.; HASENACK, H.; MATSUMOTO, M.; G. FERREIRA, L.; SOUZAFILHO, P.W.M.; DE OLIVEIRA, S.W.; ROCHA, W.F.; FONSECA, A.V.; MARQUES, C.B.; DINIZ, C.G.; COSTA, D.; MONTEIRO, D.; ROSA, E.R.; VÉLEZ-MARTIN, E.; WEBER, E.J.; LENTI, F.E.B.; PATERNOST, F.F.; PAREYN, F.G.C.; SIQUEIRA, J.V.; VIERA, J.L.; NETO, L.C.F.; SARAIVA, M.M.; SALES, M.H.; SALGADO, M.P.G.; VASCONCELOS, R.; GALANO, S.; MESQUITA, V.V.; AZEVEDO, T. Reconstructing Three Decades of Land Use and Land Cover Changes in Brazilian Biomes with Landsat Archive and Earth Engine. Remote Sens. v. 12, n. 2735, 2020.

SPIRIDONOV, A. I. Principios de La Metodologia de lãs Investigaciones de Campo y El Mapeo Geomorfológico. Universidad de La Havana, Faculdad de Geografia. v.3, 1981.

VALERIANO, M. M. Modelo digital de variáveis morfométricas com dados SRTM para o território nacional: o projeto TOPODATA. In: XII Simpósio Brasileiro de Sensoriamento Remoto, 2005, Goiânia, GO. Anais do XII Simpósio Brasileiro de Sensoriamento Remoto, p. 1-8, 2005. 


\section{CAPÍtULO II}

\section{QUALIDADE DAÁGUA SUBTERRÂNEA NAÁREA URBANA DABACIA DO CÓRREGO JOÃO DIAS, AQUIDAUANA-MS}

DDI: 10.51859/amplla.ecp672.1121-2

\author{
Adriana de Barros $^{1}$ \\ Lucy Ribeiro Ayach ${ }^{2}$ \\ Rui Reinaldo Martinez Benites ${ }^{3}$ \\ Ricardo Henrique Gentil Pereira ${ }^{4}$
}

${ }^{1}$ Universidade Federal de Mato Grosso do Sul - UFMS/CPAQ.
${ }^{2}$ Universidade Federal de Mato Grosso do Sul - UFMS/CPAQ.
${ }^{3}$ Universidade Federal de Mato Grosso do Sul - UFMS/CPAQ.
${ }^{4}$ Universidade Federal de Mato Grosso do Sul - UFMS/CPAQ.

\section{INTRODUÇÃO}

O aumento populacional, além de elevar as necessidades hídricas, também responde pelo aumento da poluição ambiental. Assim, a ação do homem no ambiente está intimamente ligada à qualidade dos recursos hídricos, pois toda mudança reflete em uma série de alterações que afetam o equilíbrio do sistema natural. Desse modo, a ocupação antrópica e irregular das bacias produz alterações nas características físicas, químicas e biológicas dos sistemas aquáticos (CAPPI et al., 2010, p. 153).

Com a degradação dos mananciais superficiais, o uso das águas subterrâneas vem se tornando uma opção, principalmente, para grande parte da população brasileira em áreas urbanas que não tem acesso à rede pública de abastecimento ou cujo abastecimento é irregular, obrigando a população a recorrer às formas alternativas de armazenamento (CAPPI; AYACH, 2012, p.62). Porém, a perfuração de poços sem critérios técnicos e em locais inadequados coloca em risco a qualidade das águas subterrâneas, à medida que cria uma conexão entre as águas mais rasas (mais suscetíveis à contaminação) com águas mais profundas. Além disso, reservatórios abertos e que não passam por limpeza periódica, facilitam a proliferação de vetores, gerando riscos para a saúde (AYACH et al., 2012, p.1258). Desse modo, ainda segundo os autores, o uso de água subterrânea captada de poços 
rasos sem tratamento, desconhecendo a sua qualidade bacteriológica e físicoquímica, pode se tornar um fator de risco aos seres humanos que a utilizam, pelo seu potencial de transmitir doenças causadas pela elevada concentração de nitrato e pela presença de bactérias do grupo Coliformes.

Além disso, as péssimas condições de sobrevivência nos aglomerados urbanos e as formas inadequadas de uso e ocupação do solo implicam a ocorrência de doenças vinculadas à falta de saneamento básico, inclusive no reaparecimento de doenças já anteriormente controladas, o que exige, além de medidas preventivas mais severas, a mudança de comportamento da sociedade diante dessa realidade (AYACH, 2011, p. 128).

Até alguns anos atrás, acreditava-se que as águas subterrâneas estavam naturalmente protegidas da contaminação pelas camadas dos solos e das rochas (SILVA et al., 2014). Santos (2000, p.97) explica que, até então, os padrões de potabilidade da água eram estabelecidos apenas em função da avaliação dos sentidos, porém, com a evolução das técnicas de análises, o padrão de potabilidade para consumo humano foi aprimorado. Atualmente, as características que delimitam o modelo de água destinada ao abastecimento doméstico compreendem critérios essenciais (controle de contaminação por substâncias tóxicas e por microorganismos patogênicos) e complementares (aspectos não essenciais à proteção da saúde pública, como cor, sabor etc.). Assim, segundo o autor, as águas são consideradas potáveis quando podem ser consumidas sem ocasionar prejuízos à saúde, e os limites máximos admitidos para os parâmetros físico-químicos e microbiológicos são aperfeiçoados de acordo com a necessidade de técnicas mais precisas de controle ambiental.

Segundo Silva (2007), o uso de indicadores de qualidade de água consiste no emprego de variáveis que se correlacionam com as alterações ocorridas na bacia, sejam estas de origens antrópicas ou naturais, já que o papel da água na transmissão de determinadas doenças infecciosas e parasitárias é fato bastante conhecido. Dessa forma, uma avaliação de potabilidade da água deve passar, necessariamente, pelo parâmetro bacteriológico.

De acordo com Cappi et al. (2010), as bactérias do grupo coliformes são enterobactérias comumente encontradas no trato intestinal do ser humano e animais de sangue quente e sua presença por si só, não representa perigo à saúde, 
mas indica a possível presença de outros organismos que podem ser patogênicos. 0 subgrupo coliforme termotolerante (ou fecal) está constituído principalmente por Escherichia coli e sua detecção indica poluição fecal proveniente de fezes humanas. Assim, mesmo não havendo uma relação quantitativa entre indicadores biológicos e micro-organismos patogênicos, a probabilidade de se encontrar bactérias patogênicas na água é quanto maior forem os números de coliformes fecais presentes na amostra (DMAE, 2001). A presença de micro-organismos do grupo coliforme na água de consumo humano indica que esta água não está sendo tratada ou que seu tratamento está sendo conduzido de forma inadequada. Porém, a contaminação das águas com coliformes não significa que estas águas estão permanentemente proibidas de serem consumidas, bastando utilizar algum método de desinfecção como: cloro, ozônio, UV, etc. (SILVA, 2007).

Assim, a carência de saneamento obriga a população a captar água de poços escavados e construídos sem parâmetros técnicos, às vezes localizados próximos a fossas. A falta de proteção (tampa, calçada ao redor, revestimento interno e cobertura externa) em grande parte deles não impede a entrada da água da chuva, aumentando, assim, a possibilidade de contaminação química e microbiológica dessas águas.

A área de estudo, bacia do córrego João Dias, compreende o meio rural e urbano do município de Aquidauana-MS. Percorre áreas indígenas, agropecuárias e urbana, além de sofrer a influência de vários impactos oriundos das atividades econômicas e da ocupação irregular. Grande parte dessa bacia apresenta uso e ocupação inadequados, ligados à atividade produtiva rural. Já na área urbana, a situação é agravada por moradias irregulares, localizadas em área de preservação permanente, além de resíduos sólidos e líquidos lançados à céu aberto e no leito do córrego, levando a um processo crescente de degradação que interfere de forma direta e indireta na saúde e na qualidade de vida dos moradores.

Deste modo, em consequência do processo de ocupação diversificado da bacia do córrego João Dias, da falta de saneamento nas áreas periféricas e da demanda crescente do uso das águas subterrâneas, o presente trabalho tem como objetivo avaliar a qualidade das águas subterrâneas no espaço urbano, por meio de variáveis indicadoras de contaminação e comparar a evolução das concentrações 
desses parâmetros e a influência da sazonalidade entre os períodos de julho de 2013 a fevereiro de 2015.

\section{METODOLOGIA}

A cidade de Aquidauana está localizada na região Centro-Oeste do Estado de Mato Grosso do Sul, a $147 \mathrm{~m}$ de altitude. Está a $130 \mathrm{~km}$ de distância de Campo Grande, a capital do Estado, e a sua principal via de acesso é a rodovia BR 262, que corta o Estado no sentido leste-oeste. 0 município encontra-se compreendido entre

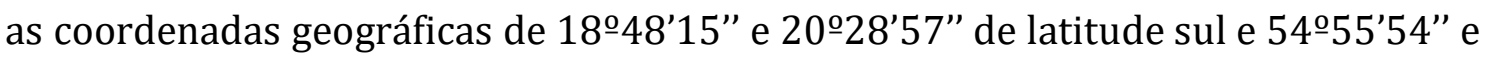
5659'15" de longitude oeste (GRADELLA et al., 2006, p.98). A cidade é separada do município de Anastácio pelo Rio Aquidauana e é cortada por três microbacias que a cruzam no sentido oeste/leste: na porção central encontra-se a Bacia da Lagoa Comprida, ao sul a Bacia do Córrego Guanandy e ao norte está a Bacia do Córrego João Dias.

A bacia hidrográfica do córrego João Dias está localizada na porção sul do município de Aquidauana (Figura 1). Possui 11.412,10 hectares e encontra-se compreendida entre as latitudes sul de $20^{\circ} 18^{\prime} 19^{\prime \prime}$ e $20^{\circ} 28^{\prime} 21^{\prime \prime}$ e as longitudes oeste de 5538'55" e 5548'54" do meridiano de Greenwich (GALVAN et al., 2006). De acordo com Barbosa e Bacani (2012, p. 25), o arcabouço geológico da bacia encontra-se dominantemente estruturado sobre a Formação Aquidauana, a qual se destaca pela presença de arenito com granulometria variável de fina a grosseira, com cores vermelho-tijolo, esbranquiçada e cinza arroxeada, também apresentando base geológica formada por rochas Pré-Cambrianas representadas pelo Grupo Cuiabá e sequências rudimentares paleozóicas dos Grupos Paraná (Formação Furnas e Formação Aquidauana), compostos de arenitos porosos e friáveis (BRASIL, 1982).

O clima, segundo Köppen, pertence ao tipo Aw (tropical úmido), com precipitação pluvial média anual de 1.200 mm e temperaturas máximas e mínimas de 33 e $19^{\circ} \mathrm{C}$, respectivamente. São predominantes duas estações: uma chuvosa e outra seca. 0 período de maior precipitação inicia-se, no mês de outubro e vai prolongando até março, com maior pico nos meses de dezembro a janeiro (SCHIAVO et al., 2010, p.883). 
Na bacia hidrográfica do córrego João Dias há uma diversificada variedade de solos decorrente da estrutura geológica da região. De acordo com Carvalho (2012, p. 27), no alto curso predominam os Neossolos e na foz, os Gleissolos. O Argissolo predomina no restante da bacia, ocupando cerca de $75 \%$ da área, principalmente na área urbana. Estes solos são caracterizados como solos não hidromórficos, bem desenvolvidos, profundos, bem drenados, e em alguns casos com drenagem moderada (MATO GROSSO DO SUL, 1990). Esses solos foram originados da decomposição arenítica e caracterizam-se pela baixa capacidade de retenção de água e elevadas taxas de infiltração, funcionando dessa forma como uma "esponja", o que propicia elevada infiltração e grande disponibilidade hídrica, porém, extremamente suscetível à contaminação (SILVA, 2011).

As coletas das amostras das águas foram realizadas em quatro períodos: Inverno/2013; Verão/2014; Inverno/2014 e Verão/2015. Foram selecionados 10 poços, todos localizados na área urbana. Os pontos de coleta estão representados e descritos, respectivamente, na Tabela 1 e Figura 2. 0 método de coleta, preservação e análises das amostras de água seguiram as orientações descritas de acordo com APHA (1999). As amostras não processadas no dia, foram devidamente acondicionadas e guardadas em condições adequadas até sua posterior utilização. Os dados de temperatura da água e do ar, $\mathrm{pH}$, condutividade elétrica (CE) e sólidos totais (SDT) foram coletados in loco através da sonda multiparâmetro Hanna HI 9525 e a turbidez foi determinada através do turbidímetro de bancada Alfakit. As análises das amostras de água foram executadas no Laboratório Hidrologia Ambiental e Limnologia da Universidade Federal de Mato Grosso do Sul UFMS/Campus de Aquidauana/Unidade II. 
Figura 1. Aquidauana (MS): Localização da bacia hidrográfica do Córrego João Dias, 2012.

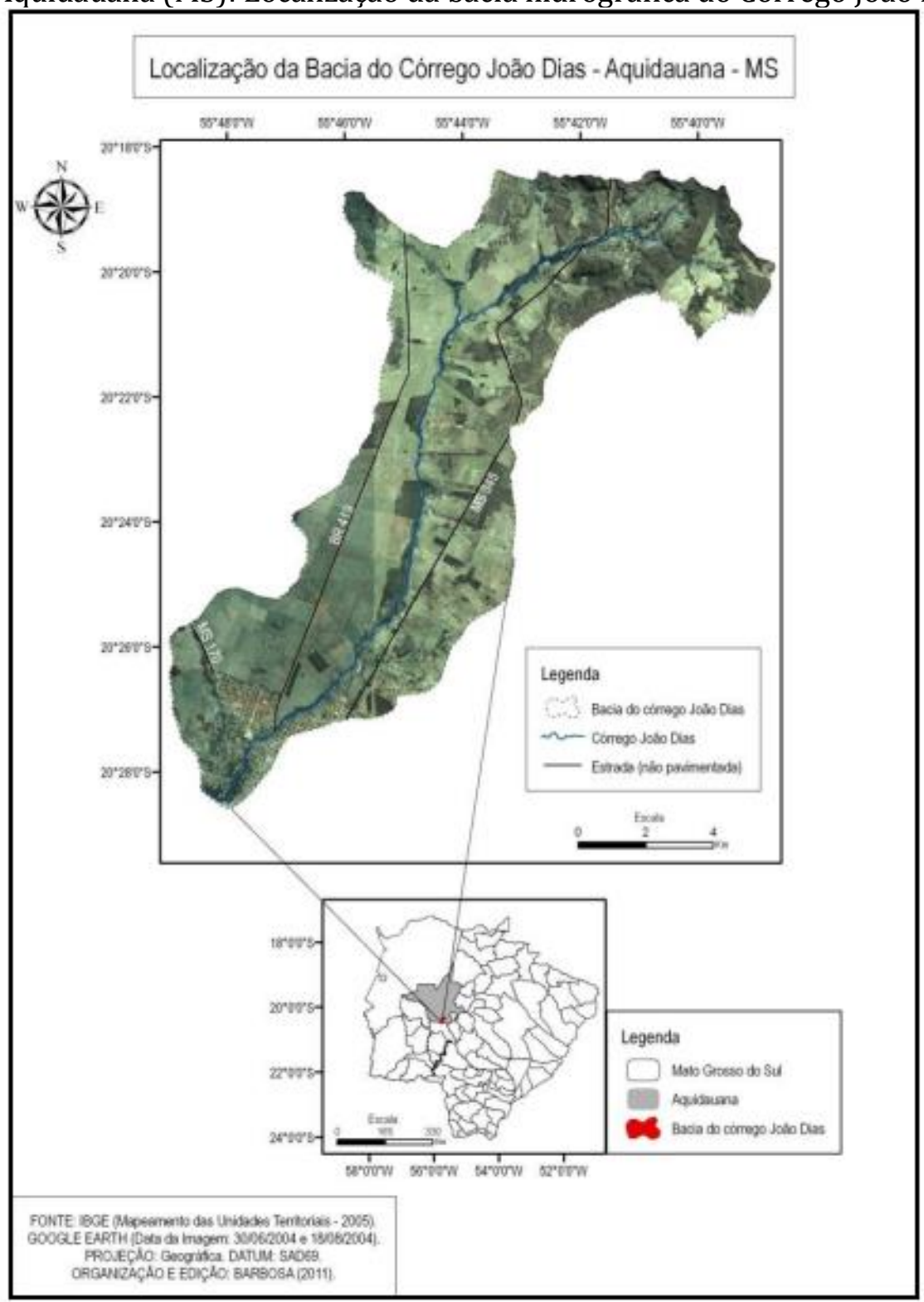

Fonte: Barbosa e Bacani (2012).

Tabela 1. Aquidauana (MS): Descrição dos pontos de amostragem de água subterrânea na bacia urbana do córrego João Dias, 2019.

\begin{tabular}{|c|c|c|c|}
\hline Pontos & \multicolumn{3}{|l|}{ Descrição e localização } \\
\hline P1 & Bairro Centro & $20^{\circ} 28^{\prime} 16.90 " \mathrm{~S}$ & $55^{\circ} 47^{\prime} 41.80^{\prime \prime} \mathrm{W}$ \\
\hline $\mathrm{P} 2$ & Bairro Alto & $20^{\circ} 28^{\prime} 03.1^{\prime \prime S}$ & $55^{\circ} 47^{\prime} 31.5^{\prime \prime W}$ \\
\hline P3 & Vila Trindade & $20^{\circ} 27^{\prime} 57.1^{\prime \prime S}$ & $55^{\circ} 48^{\prime} 03.1^{\prime \prime} \mathrm{W}$ \\
\hline P4 & Vila Trindade & $20^{\circ} 27^{\prime} 40.2^{\prime \prime S}$ & $55^{\circ} 47^{\prime} 53.2^{\prime \prime} \mathrm{W}$ \\
\hline P5 & Bairro Nova Aquidauana & $20^{\circ} 26^{\prime} 29.6^{\prime \prime S}$ & $55^{\circ} 48^{\prime} 08.9^{\prime \prime} \mathrm{W}$ \\
\hline P6 & Bairro Nova Aquidauana & $20^{\circ} 27^{\prime} 08.8^{\prime \prime S}$ & $55^{\circ} 47^{\prime} 13.1^{\prime \prime} \mathrm{W}$ \\
\hline P7 & Bairro Cidade Nova & $20^{\circ} 27^{\prime} 22.9^{\prime \prime S}$ & $55^{\circ} 47^{\prime} 04.1^{\prime \prime} \mathrm{W}$ \\
\hline P8 & Bairro Cidade Nova & $20^{\circ} 27^{\prime} 23.2^{\prime \prime S}$ & $55^{\circ} 47^{\prime} 02.8^{\prime \prime W}$ \\
\hline P9 & Bairro Exposição & $20^{\circ} 26^{\prime} 46.40^{\prime \prime S}$ & $55^{\circ} 45^{\prime} 51.47^{\prime \prime W}$ \\
\hline P10 & Bairro Exposição & $20^{\circ} 26^{\prime} 59.0^{\prime \prime S}$ & $55^{\circ} 45^{\prime} 46.6^{\prime \prime} \mathrm{W}$ \\
\hline
\end{tabular}

Fonte: Autoria própria. 
As análises de alcalinidade, dureza total, cálcio, magnésio e cloreto foram realizadas pelo método titulométrico, seguindo metodologias propostas pela FUNASA (BRASIL, 2006).

As análises dos nutrientes foram realizadas no espectrofotômetro Femto Cirrus 80. As frações de nitrogênio total foram quantificadas após a digestão em autoclave, na presença de um catalisador (VALDERRAMA, 1981). A determinação de nitrato foi realizada através do método espectrofotométrico na região do UV (APHA, 1999), de amônia pela reação com citrato trissódico, fenol e hipoclorito de sódio, os valores de nitrito através da reação com sulfanilamida e N-naftil (MACKERETH et al., 1978) e o ferro total também foi determinado espectrofotometricamente pelo método da fenantrolina.

Figura 2. Aquidauana (MS): Localização dos pontos de coleta, 2019.

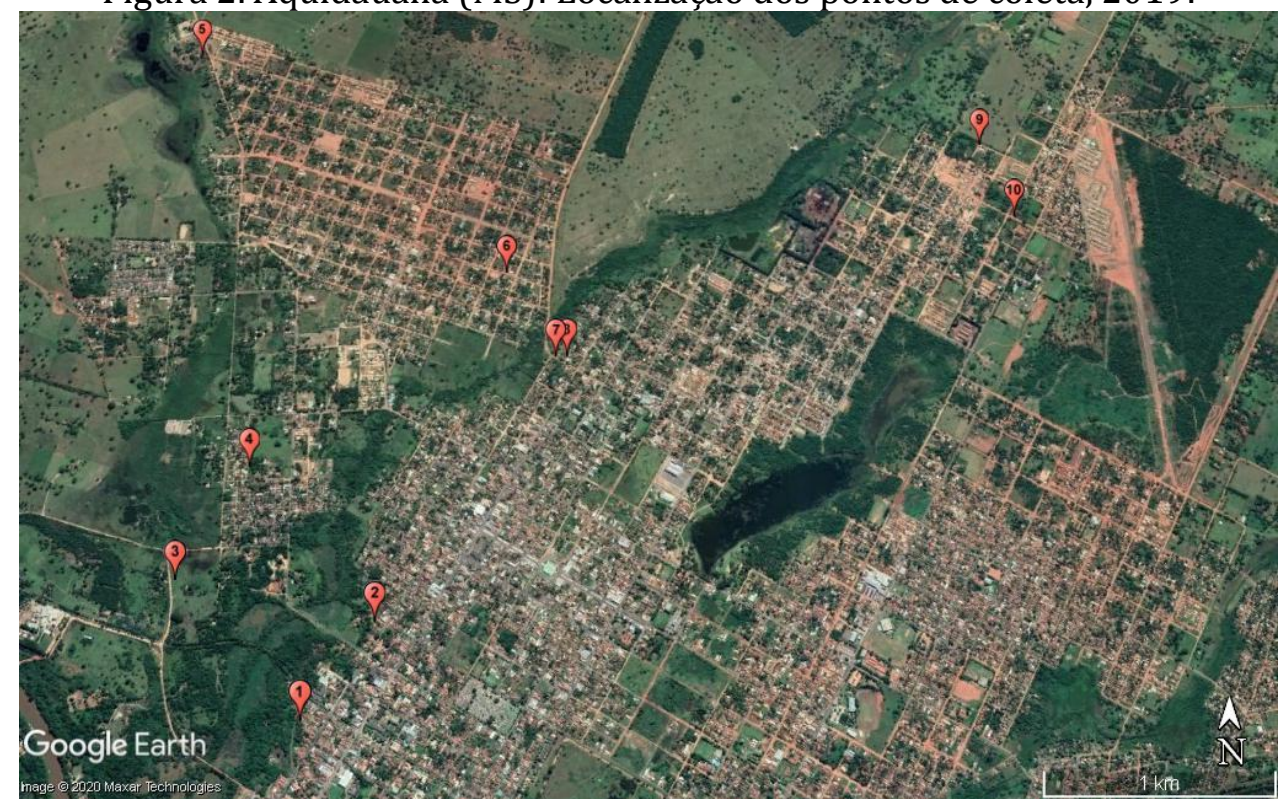

Fonte: Autoria própria.

As análises bacteriológicas foram realizadas através da técnica de Tubos Múltiplos e os resultados expressos em Número Mais Provável (NMP $100 \mathrm{~mL}^{-1}$ ) de coliformes totais (CT) e termotolerantes (CTT) através de uma tabela de contagem específica para o método (SOARES; MAIA, 1999). Foi utilizada como parâmetro para interpretação dos dados a resolução CONAMA 396/08, que estabelece valores para enquadramento das águas subterrâneas do Brasil e as Portarias 518/04 e 2.914/11 do Ministério da Saúde, que apresenta parâmetros de avaliação de potabilidade da água utilizada para consumo, já que as águas destes poços são, dentre diversos usos, também utilizadas para consumo humano. 


\section{RESULTADOS E DISCUSSÃO}

\subsection{CONDIÇÕES SANITÁRIAS E SOCIOECONÔMICAS DOS SETORES URBANOS NA BACIA HIDROGRÁFICA}

De acordo com o levantamento realizado por Simão e Ayach (2014) e Pinto e Ayach (2014), todos os setores da cidade situados na bacia hidrográfica do Córrego João Dias, contam com taxas de abastecimento de água pela rede geral (na faixa dos 90\%), no entanto, na amostragem foram detectados quatro bairros que apresentavam moradias sem canalização interna, o que pode comprometer a qualidade da água usada pelos moradores. Em alguns setores, foi observada ainda a destinação do esgoto de forma inadequada (a céu aberto), fossas rudimentares e ligações clandestinas na rede de escoamento pluvial. Com relação a destinação dos resíduos sólidos, mesmo em setores com 100\% de coleta, os moradores afirmaram que enterravam e ou queimavam parte do lixo produzido. Resultados semelhantes foram encontrados no estudo de Derbocio et al. (2012), onde 75\% dos moradores do bairro Nova Aquidauana, inserido na bacia do córrego, afirmaram que os principais problemas ambientais do bairro eram o lixo urbano e as queimadas, porém 70\% dos entrevistados afirmaram utilizar a mesma técnica, apesar de haver coleta de lixo no bairro três vezes por semana.

Analisando de forma geral as condições socioeconômicas dos moradores dos bairros localizados na bacia hidrográfica do córrego João Dias, verificou-se o ensino fundamental incompleto como grau de escolaridade predominante. Dados similares foram encontrados no estudo de Derbocio et al (2012) onde, apesar do baixo grau de escolaridade, a maioria dos entrevistados associam a preservação do meio ambiente à mudança de comportamento.

Com relação ao rendimento domiciliar, prevaleceu a renda entre 2 a 3 salários mínimos na maioria dos setores, porém, quando computado o rendimento considerando o número de pessoas na família que dependem da renda, verificou-se que a renda per capita em todos os setores variou de 0 a 1,0 salário mínimo por mês. Assim, o baixo rendimento apresentado, portanto, pode ter relação direta com o grau de escolaridade, bem como com as funções ocupadas pelos moradores, destacando-se, segundo o estudo, a prevalência das funções ocupacionais de aposentados/pensionistas e dependentes de bolsa do governo. 


\subsection{QUALIDADE DAS ÁGUAS DOS POÇOS}

A qualidade da água para consumo humano é estabelecida em função dos Valores Máximos Permitidos (VMP) para variáveis físico-químicas e microbiológicas, se enquadrando de acordo com padrões estabelecidos pela legislação (BRASIL, 2004; BRASIL, 2008; BRASIL, 2011). Deve-se levar em consideração que "os Valores Máximos Permitidos para o respectivo uso das águas subterrâneas deverão ser observados quando da sua utilização, com ou sem tratamento, independentemente da classe de enquadramento" (BRASIL, 2008).

Em relação à temperatura, as amostras analisadas apresentaram uma média de $27^{\circ} \mathrm{C}$, variando de 24,8 a $29,2^{\circ} \mathrm{C}$. Segundo Feitosa e Manoel Filho (2000), essa variação pode ser justificada pelas diferentes profundidades dos poços, pois, em aquíferos freáticos, poços mais profundos tendem a apresentar temperatura menor em relação a poços menos profundos.

Com relação aos valores de pH, a legislação estabelece valores entre 6 e 9,5. A maior parte das amostras apresentem o pH fora da faixa recomendada, em pelo menos uma das estações estudadas. 0 único poço que atendeu ao parâmetro em todas as coletas foi o P3, com valores variando entre 6,29 a 7,30. Já os poços P2, P7, P8 e P10 apresentaram valores fora da faixa estipulada em todas as estações estudadas (Figura 3). 
Figura 3. Valores de $\mathrm{pH}$ dos poços da bacia do córrego João Dias e valores máximos e mínimos permitidos pela legislação CONAMA 396/08.

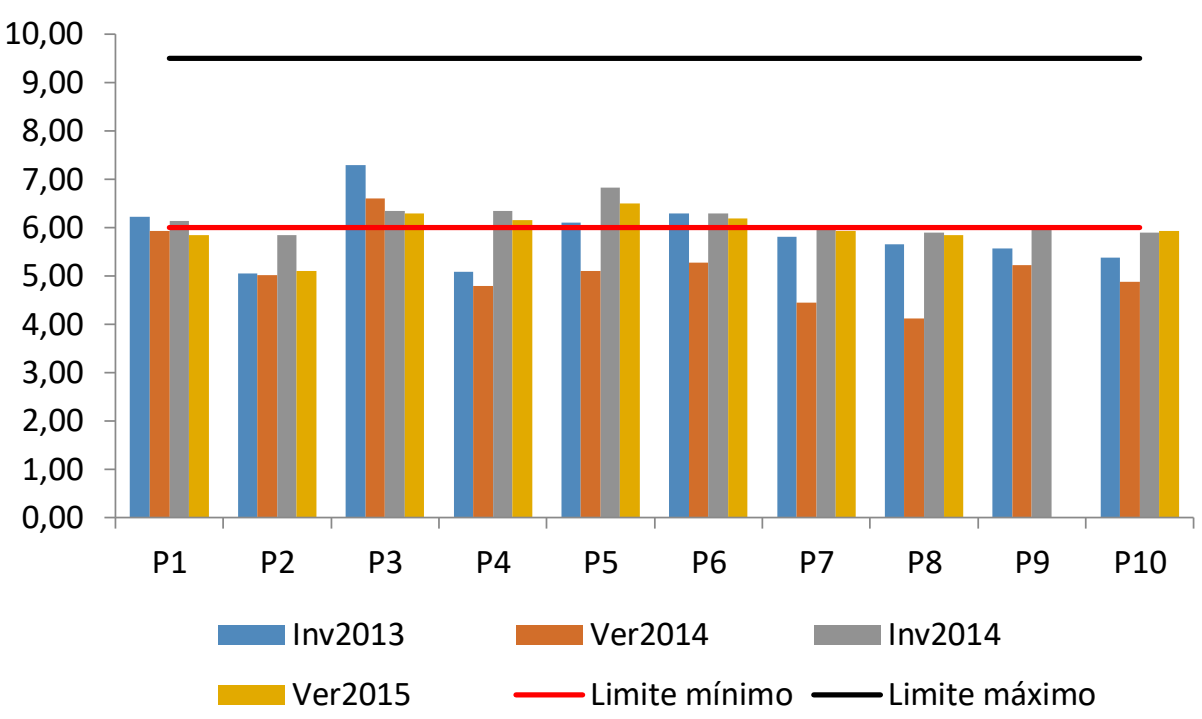

Fonte: Autoria própria.

De acordo com Santos (2000, p.90), a maioria das águas subterrâneas apresenta valores entre 5,5 a 8,5. Segundo Menezes et al. (2013), os baixos valores de $\mathrm{pH}$ podem ser atribuídos à presença de vários fatores, tais como oxidação da matéria orgânica, temperatura da água, além das concentrações de $\mathrm{CO}_{2}$. A dissolução do $\mathrm{CO}_{2}$ na água forma o ácido carbônico $\left(\mathrm{H}_{2} \mathrm{CO}_{3}\right)$, que se dissocia em $\mathrm{H}+$ e $\mathrm{HCO}_{3}$, ocorrendo assim a diminuição do pH da água. Nas águas subterrâneas a origem do bicarbonato está relacionada principalmente aos processos que produzem o gás carbônico no solo por meio da decomposição e oxidação da matéria orgânica e à respiração das raízes das plantas (OBIEFUNA; SHERIFF, 2011). Segundo Cappi et al. (2010), a acidez das águas subterrâneas nos períodos mais chuvosos pode estar relacionada ao processo de lixiviação dos íons, que no início das chuvas percolam mais rápido, atingindo o lençol freático.

Durante a última campanha (Verão/2015) o poço P9 se encontrava seco, assim, não foi possível a coleta da água nesse período.

A turbidez é padrão de potabilidade, assim, é recomendado que seja o mais reduzida possível. Segundo Oliveira et al., (2016), a turbidez elevada pode dificultar a ação do cloro sobre os patógenos existentes na água. A legislação fixa o VMP em 5,0 NTU (BRASIL, 2008), assim os poços P1, P3, P5 e P9 apresentaram valores acima do permitido, não atendendo ao padrão estabelecido na época das coletas (Figura $4)$. 
Os sólidos totais dissolvidos (STD) representam a concentração de todo o material dissolvido na água, seja ele de natureza iônica ou coloidal e os valores obtidos variaram de 3,0 a 389,0 $\mathrm{mgL}^{-1}$, portanto, nenhuma das amostras analisadas ultrapassou o valor máximo de $1.000 \mathrm{mgL}^{-1}$ estabelecido pela legislação (BRASIL, 2008). De acordo com Santos (2000), as águas subterrâneas, na sua maioria, praticamente não tem sólidos em suspensão, excetuando-se as águas que circulam em aquíferos cárstico-fissurais ou em poços rudimentares, com produção de argila, silte e areias.

Figura 4. Valores de turbidez dos poços da bacia do córrego João Dias e o valor máximo permitido (VMP) para consumo humano (BRASIL, 2008).

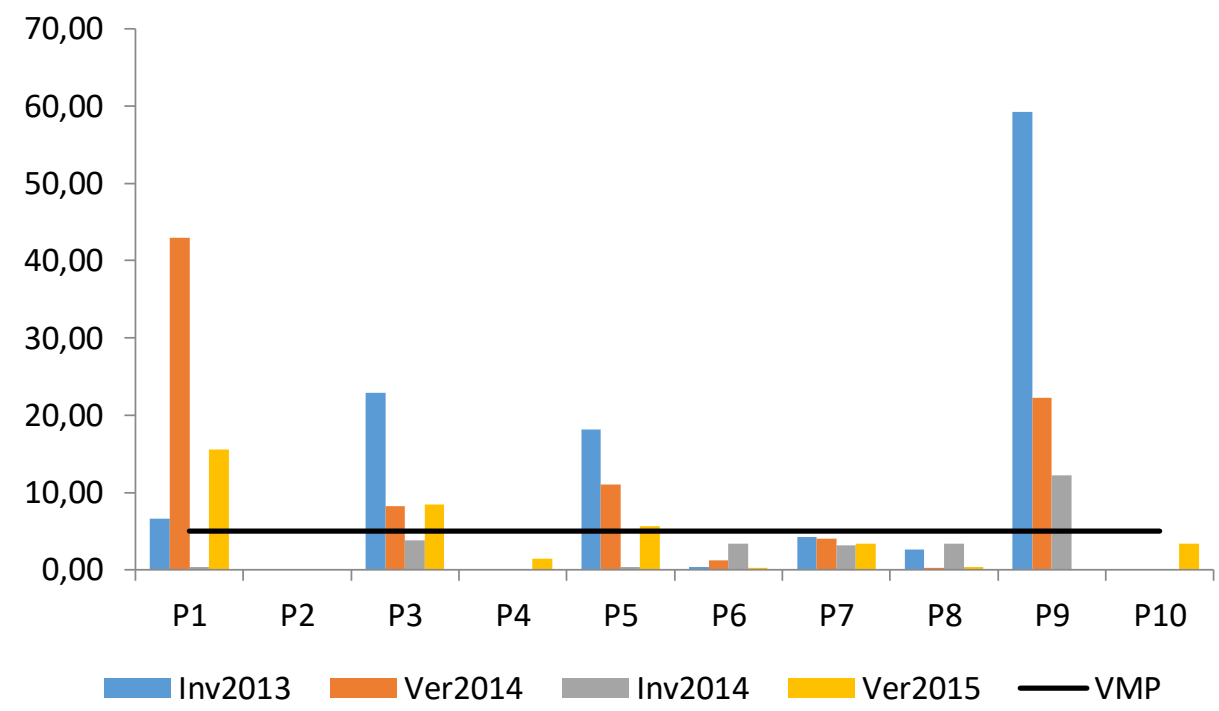

Fonte: Autoria própria.

Já o teor de sais dissolvidos sob a forma de íons foi avaliada através da Condutividade Elétrica (CE). Os poços P1, P2, P3 e P4 apresentaram elevada condutividade elétrica em relação aos outros pontos em todas as estações estudadas. Os valores encontrados variaram de $6,0 \mu \mathrm{Scm}^{-1}$ (P10) a 778,0 $\mu \mathrm{Scm}^{-1}$ no P3 (Figura 5). Apesar de não serem feitas referências diretas a esse parâmetro na legislação no que diz respeito ao consumo humano, considera-se que quanto mais elevada, maior é a quantidade de íons dissolvidos, sugerindo assim uma maior carga de contaminantes.

As águas subterrâneas tendem a possuir concentrações de sais superiores às águas superficiais, já que ao lixiviar os solos e as rochas são enriquecidas pelos sais dissolvidos. Essas reações são favorecidas pelas baixas velocidades de circulação 
das águas subterrâneas, pressão mais elevada e temperatura adequada (SANTOS, 2000, p. 86).

A alcalinidade da água está diretamente ligada ao $\mathrm{pH}$, assim, valores elevados estão relacionados à presença de substâncias como silicatos, fosfatos de sais orgânicos e ácidos húmicos, porém os principais são carbonatos, bicarbonatos e hidróxidos. Águas que apresentam pH na faixa de 4,6 a 8,3, a alcalinidade total é devida somente à presença de bicarbonatos (RICHTER; AZEVEDO NETO, 1991).

Figura 5. Valores de Condutividade Elétrica dos poços da bacia do córrego João Dias no período estudado.

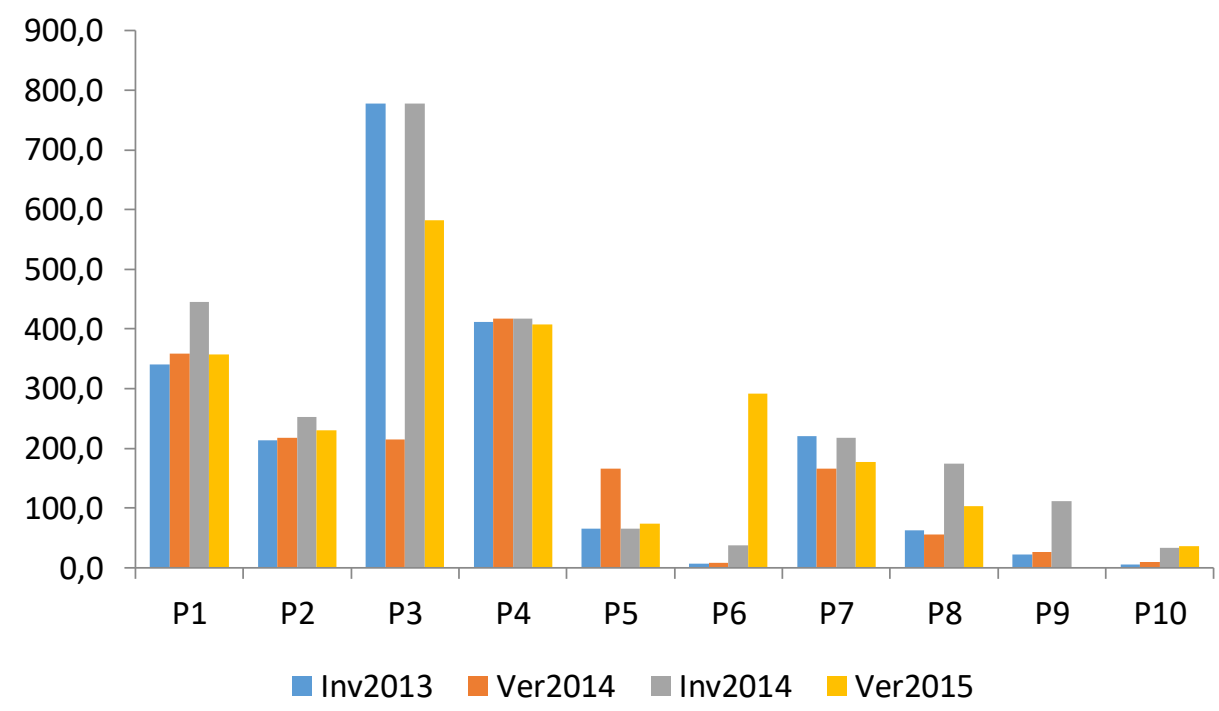

Fonte: Autoria própria.

De acordo com Piveli e Kato (2005, p. 177), a alcalinidade das águas não representa risco potencial à saúde pública, pois não se constitui em padrão de potabilidade, ficando este efeito limitado pelo valor do $\mathrm{pH}$. Pode provocar alteração no paladar, porém a rejeição dessa água tende a ocorrer em concentrações inferiores àquelas que eventualmente possam trazer prejuízos mais sérios. O VMP para alcalinidade em bicarbonatos para águas subterrâneas é $250 \mathrm{mgL}^{-1}$ (GIAMPÁ; GONÇALES, 2005). Valores elevados de alcalinidade ocorreram apenas no poço P3, na primeira coleta (Inv2013), inclusive ultrapassando o limite de $250 \mathrm{mgL}^{-1}$. Todos os outros pontos apresentaram valores reduzidos em todas as coletas (Figura 6). A elevação desse parâmetro provavelmente se deve ao maior tempo de contato das águas com partículas rochosas calco-magnesianas e outros minerais (PADUA, 2002). 
Figura 6. Valores de alcalinidade dos poços da bacia do córrego João Dias e o valor máximo permitido (VMP) para consumo humano.

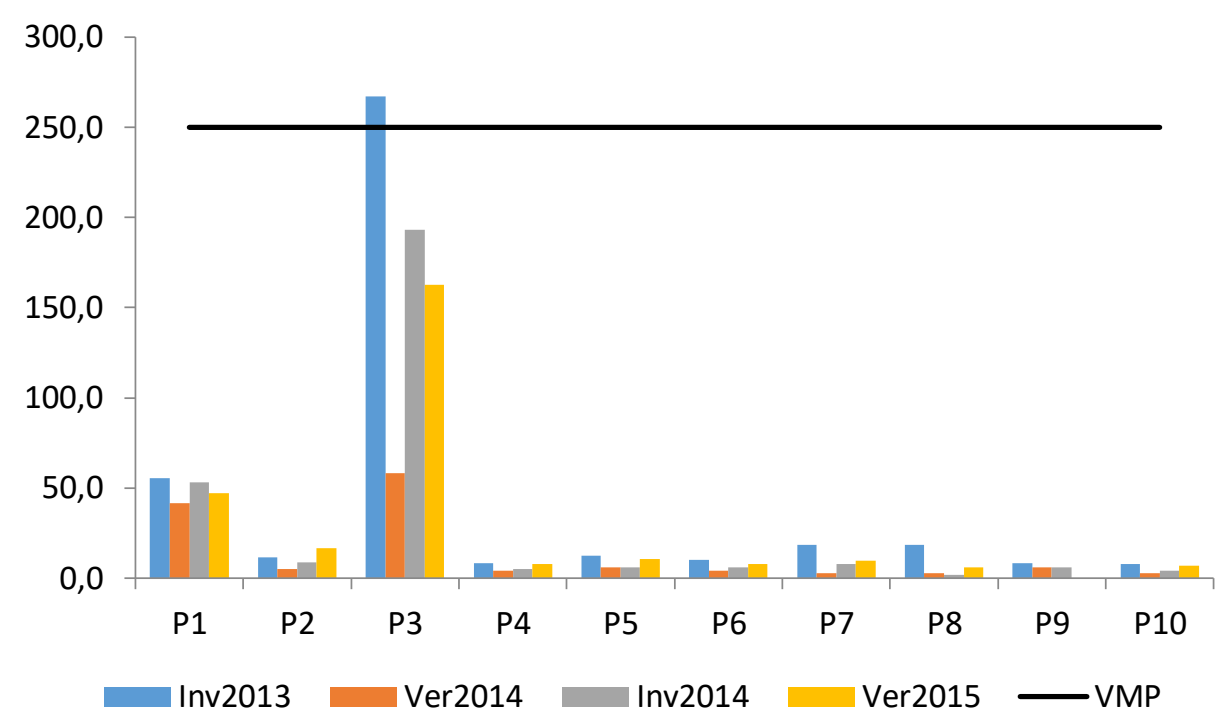

Fonte: Autoria própria.

A principal fonte de dureza nas águas é a sua passagem pelo solo (dissolução de rochas calcárias pelo gás carbônico da água), desta forma, é muito mais frequente que sejam encontradas águas subterrâneas com dureza elevada do que as águas superficiais (PIVELI; KATO, 2005). A dureza da água pode ser expressa em dureza temporária (causada pelos íons de cálcio e magnésio que se combinam com o bicarbonato e o carbonato, podendo ser eliminada por ebulição), dureza permanente (relacionada a cloretos e sulfatos, e que persiste após a fervura) e a dureza total que é a soma das duas (SANTOS, 2000, p.89). No Brasil, os valores de dureza são expressos em mgL-1 de $\mathrm{CaCO}_{3}$ e são classificadas de acordo com o grau (CUSTÓDIO; LLAMAS, 1983, p. 212): branda (abaixo de $50 \mathrm{mgL}^{-1}$ ); pouco dura ou moderada (de 50 a $100 \mathrm{mgL}^{-1}$ ); dura (de 100 a $200 \mathrm{mgL}^{-1}$ ); muito dura (acima de $200 \mathrm{mgL}^{-1}$ ).

Para o abastecimento público de água, o problema se refere inicialmente ao consumo excessivo de sabão nas lavagens domésticas, porém há também indícios da possibilidade de um aumento na incidência de problemas renais em cidades abastecidas com águas duras, o que traduz um efetivo problema de saúde pública (PIVELI; KATO, 2005, p.184). A legislação estabelece o VMP para dureza em 500 $\mathrm{mgL}^{-1}$, e sendo assim, nenhuma das amostras ultrapassou o limite permitido. De acordo com a Figura 7, apenas os poços P5, P6, P7, P8, P9 e P10 apresentaram valores abaixo de $50 \mathrm{mgL}^{-1}$ em todas as coletas. Já os poços P1 e P4 apresentaram 
dureza acima de $100 \mathrm{mgL}^{-1}$ em três das quatro coletas realizadas. 0 P2 apresentou dureza moderada em todas as coletas e o poço P3 teve água moderadamente dura apenas uma coleta (Ver2014) e nas outras, muito dura (acima de $200 \mathrm{mgL}^{-1}$ ).

Figura 7. Valores de dureza total dos poços da bacia do córrego João Dias e a classificação das águas, segundo Custódio e Llamas (1983).

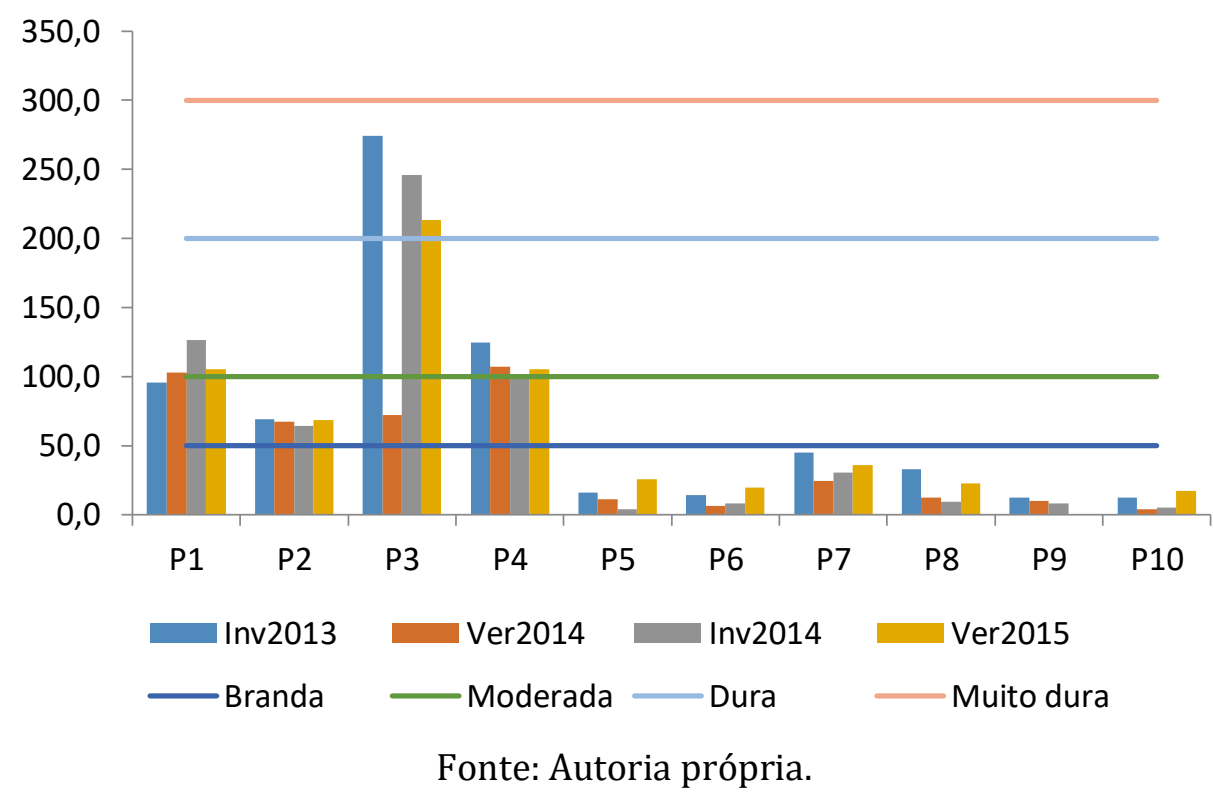

O poço P3 também apresentou valores elevados de cloreto em três das quatro coletas realizadas. $\mathrm{Na}$ primeira coleta (Inv2013), o valor encontrado foi de $309,64 \mathrm{mgL}^{-1}$, ultrapassando o VMP estipulado pela legislação, que é de $250 \mathrm{mgL}^{-1}$ (BRASIL, 2008). Em águas subterrâneas, o ânion cloreto normalmente se apresenta através de solos e rochas. Em grandes quantidades, pode estar ligado a descargas de esgotos sanitários, já que cada pessoa expele através da urina cerca de $6 \mathrm{~g}$ de cloreto por dia, o que faz com que os esgotos apresentem concentrações de cloreto que ultrapassam a $15 \mathrm{mgL}^{-1}$ (PIVELLI; KATO, 2005). Valores elevados de cloretos em águas de consumo humano podem trazer restrições ao sabor, provocar reações fisiológicas e aumentar o efeito corrosivo de tubos e estruturas metálicas, além de ser um bom indicador de poluição para aterros sanitários e lixões (SANTOS, 2000; BRIGANTE et al., 2003).

De acordo com Cappi et al. (2010, p. 165), no período seco o lençol freático é abastecido com água proveniente das áreas de recarga, portanto, a elevação das concentrações de algumas variáveis tem origem nas características do substrato rochoso, ao passo que no período chuvoso ocorre uma diluição dessas 
concentrações em função do aumento da disponibilidade de água originária do escoamento superficial.

De acordo com Silva et al. (2014), antes do desenvolvimento das análises bacteriológicas, as evidências da contaminação das águas eram determinadas pelas concentrações de nitrogênio nas suas diferentes formas: nitrato, nitrito e nitrogênio amoniacal. Em condições normais, a amônia encontra-se em concentrações muito baixas em águas subterrâneas, em virtude de ser adsorvida pelas partículas do solo, principalmente pelas argilas. Segundo a Portaria 2.914/2011 (BRASIL, 2011), o valor máximo permissível para o consumo humano é de $1,5 \mathrm{mg} . \mathrm{L}^{-1}$ e nenhum dos pontos apresentou concentração de amônia acima do VMP. Concentrações de amônia acima do VMP certamente estão ligados à contaminação recente por esgotos domésticos, fossas sépticas, fezes de animais ou mesmo aos fertilizantes nitrogenados.

Já o nitrato pode se apresentar nas águas naturais sem ter sido introduzido diretamente, em decorrência do processo de decomposição biológica da matéria orgânica nitrogenada. Em elevadas concentrações é tóxico, por isso é padrão de potabilidade e a legislação fixa o VMP em $10 \mathrm{mg} \mathrm{N}-\mathrm{NO}_{3} / \mathrm{L}$. De acordo com Santos (2000, p. 93), teores de nitrato acima de $5 \mathrm{mgL}^{-1}$ podem ser indicativos de contaminação da água subterrânea por atividades antrópicas (esgotos, fossas sépticas, depósitos de lixo, cemitérios, adubos nitrogenados etc.).

De acordo com Piveli e Kato (2005), o consumo de água com altas concentrações desse nutriente tem correlação positiva com câncer gástrico e cianose em crianças, pois o nitrato é reduzido a nitrito na corrente sanguínea, competindo com o oxigênio livre.

De acordo com as análises realizadas, todos os poços apresentaram resultados abaixo do VMP, com exceção do poço P4 na primeira coleta (Figura 8).

Resultados semelhantes foram encontrados no estudo realizado por Ayach (2002) em Anastácio-MS e por Silva et al. (2014) em Cuiabá-MT. Foi observado que, embora as concentrações de nitrato estejam na sua grande maioria abaixo dos valores permitidos pela legislação, esses valores estão relativamente elevados, que poderia ser causado pela facilidade de contaminação do aquífero freático por fossas e, possivelmente, também em razão da proximidade do nível da água à superfície do terreno. 
Figura 8 . Valores de nitrato dos poços da bacia do córrego João Dias e o valor máximo permitido (VMP) para consumo humano (BRASIL, 2008).

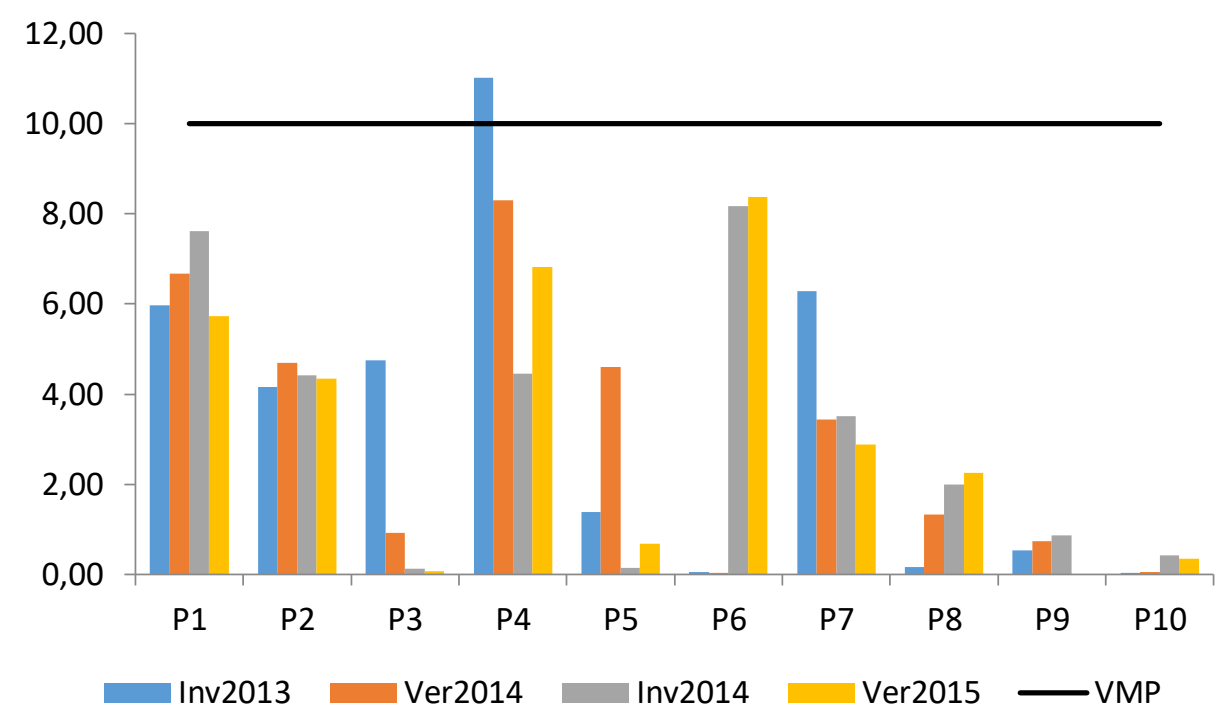

Fonte: Autoria própria.

Já a presença de nitritos em água indica processos biológicos ativos influenciados por poluição orgânica. Normalmente, é encontrado em quantidades reduzidas nas águas superficiais, pois é instável na presença de oxigênio, ocorrendo como uma forma intermediária das formas nitrogenadas. 0 nitrito geralmente também ocorre em baixas concentrações na água subterrânea, já que representa o estágio final da oxidação da matéria orgânica, assim sua elevação nessas águas indica influência de fontes de contaminação antrópicas, possivelmente por fertilizantes ou por fossa séptica (MENEZES et al., 2013, p. 3323). O VMP para nitrito é de $1 \mathrm{mgL}^{-1}$, e de acordo com os resultados obtidos, o poço P1 apresentou valores acima do permitido em duas das quatro coletas (Figura 9). Todos os outros poços apresentaram valores abaixo do estipulado pela legislação.

Dessa forma, os processos bioquímicos de oxidação do amônio ao nitrito e deste para nitrato implicam o consumo de oxigênio dissolvido, ou seja, altas concentrações de nitrito podem significar uma grande atividade bacteriana e carência de oxigênio no corpo hídrico, seja ele superficial ou subterrâneo (PEREIRA, 2004). 
Figura 9. Valores de nitrito dos poços da bacia do córrego João Dias e o valor máximo permitido (VMP) para consumo humano (BRASIL, 2008).

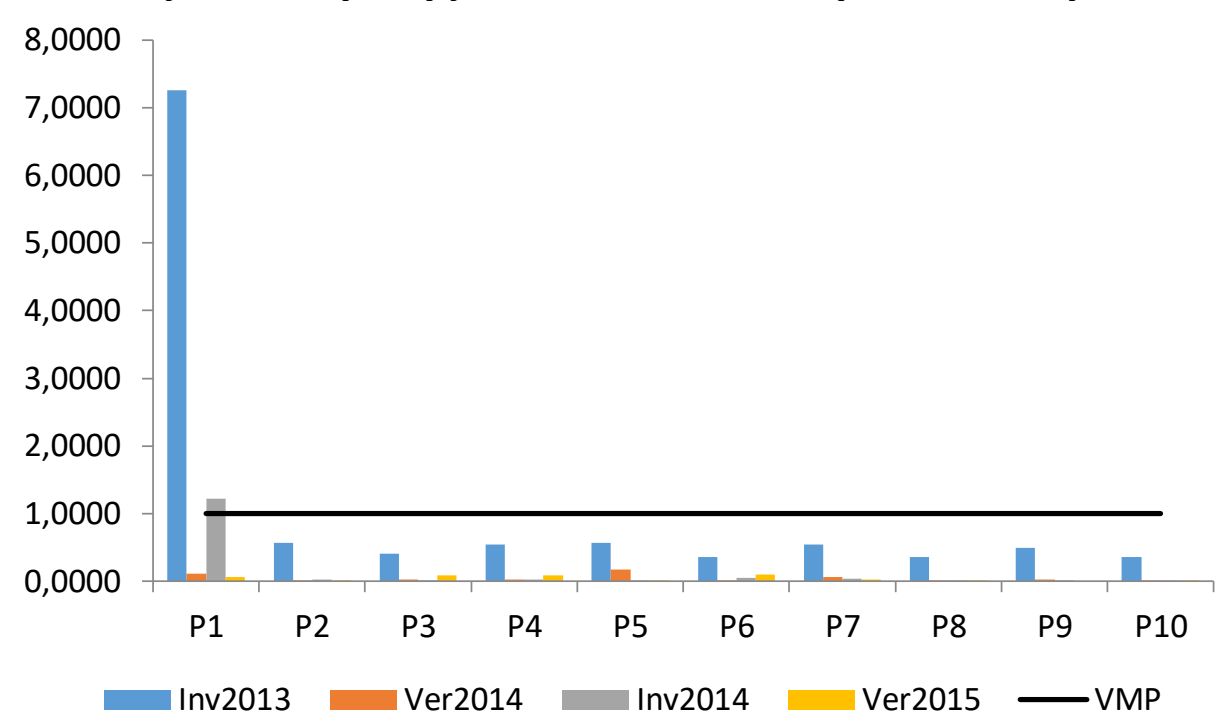

Fonte: Autoria própria.

O ferro aparece principalmente em águas subterrâneas devido à dissolução do minério pelo gás carbônico da água, e em altas concentrações confere cor e sabor à água, além de provocar manchas em roupas e utensílios sanitários (PIVELI; KATO, 2005). Assim, apesar de não se constituir em um elemento tóxico, traz diversos problemas para o abastecimento público de água, portanto, constitui-se em padrão de potabilidade, tendo sido estabelecida a concentração limite de $0,3 \mathrm{mgL}^{-1}$ pela Portaria 518/2004 do Ministério da Saúde (Figura 10).

De acordo com os resultados obtidos, apenas os poços P2, P6 e P10 apresentaram valores abaixo do permitido em todo o monitoramento. Os poços P1, P3 e P7 apresentaram valores acima do permitido em três das quatro coletas realizadas. Os poços P5 e P9 em pelo menos duas delas e os poços P4 e P8 em uma coleta

O grupo de coliformes totais (CT) constitui-se em um grande grupo de bactérias que têm sido isoladas de amostras de águas e solos poluídos e não poluídos, bem como em fezes de seres humanos e outros animais de sangue quente. O subgrupo coliforme termotolerante (CTT) ou fecal é constituído principalmente por Escherichia coli, e sua detecção indica, com certeza, que houve poluição fecal provenientes de fezes humanas, de animais de sangue quente ou de esgotos (SILVA, 2007). 
De acordo com os resultados obtidos, apenas os poços P2, P7 e P8 apresentaram valores reduzidos de coliformes totais em relação aos outros pontos. Apenas o poço P2 não apresentou coliformes termotolerantes em nenhuma das coletas realizadas, sendo o único a apresentar águas com potabilidade aceitável para esse parâmetro (Figuras 11A e 11B). 0 restante das amostras coletadas estava em desacordo com o preconizado pela legislação vigente em relação ao padrão microbiológico, já que o Ministério da Saúde tolera a presença de coliformes totais somente na ausência de Escherichia coli e/ou coliformes termotolerantes. A presença de coliformes nas águas analisadas pode ser explicada pelas más condições de construção de alguns dos poços, localização inadequada e falta de manutenção (MENEZES et al., 2013, p. 3323).

Figura 10. Valores de ferro total dos poços da bacia do córrego João Dias e o valor máximo permitido (VMP) para consumo humano (BRASIL, 2008).

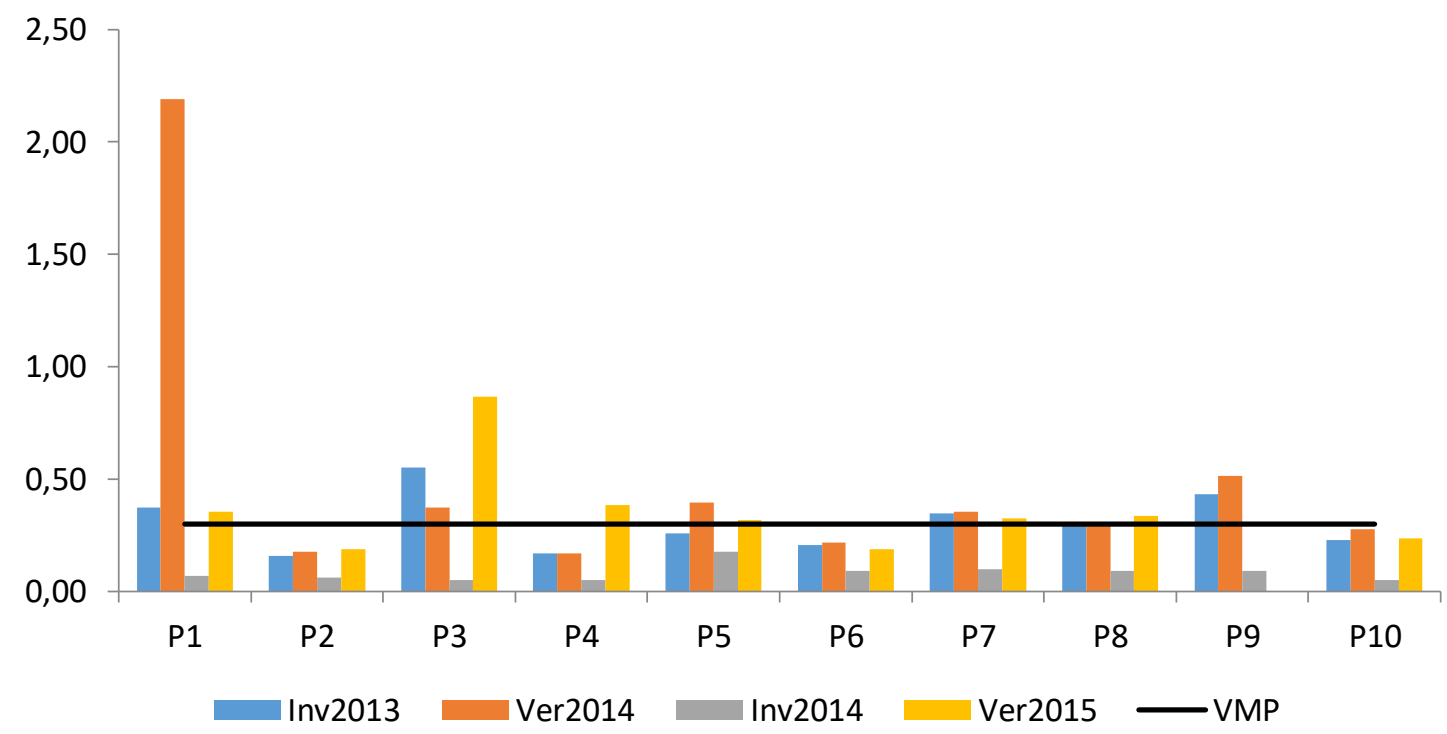

Fonte: Autoria própria.

Figura 11. A) Valores de coliformes totais e B) Valores de coliformes termotolerantes nos poços da bacia do córrego João Dias.
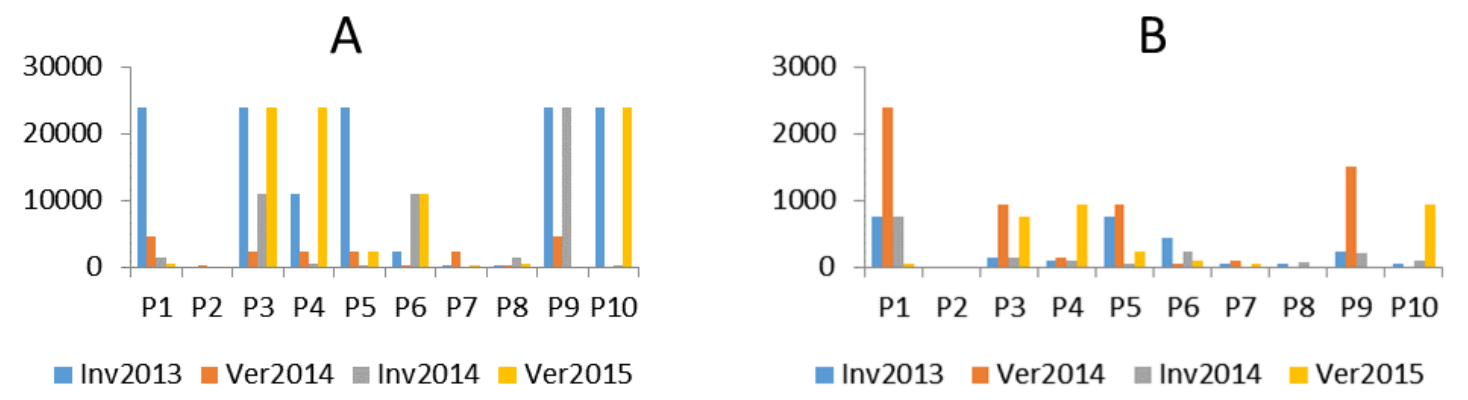

Fonte: Autoria própria. 
Notou-se que ocorreram flutuações sazonais nas concentrações desses parâmetros, apresentando concentrações mais elevadas na época da chuva e reduzidas na época de estiagem, provavelmente em razão dos processos de lixiviação serem mais intensos que os processos de diluição.

Estudos anteriores realizados na bacia, já alertavam sobre a contaminação subterrânea, já que em média, todos os poços já apresentaram valores elevados para CT e CTT. Além da pouca profundidade da maioria dos poços, a localização também pode influenciar na qualidade dessas águas, já que em grande parte se localizam próximos às fossas. Além disso, poços rasos são mais susceptíveis à contaminação, principalmente no período chuvoso, em decorrência da percolação rápida dos micro-organismos em direção à água (SILVA, 2007). A grande maioria dos poços também é do tipo escavado e a captação da água é realizada manualmente com balde, assim, a exposição dos poços ao escoamento superficial também pode aumentar a contaminação das suas águas (CAPPI et al., 2011; CAPPI; AYACH, 2012).

\section{CONSIDERAÇÕES FINAIS}

Pelo fato da bacia do Córrego João Dias sofrer tanta interferência antrópica desde sua nascente até sua foz, conhecer e estudar as características físicas, químicas e biológicas de suas águas torna-se indispensável.

A carência de saneamento obriga a população a captar água de poços escavados e construídos sem parâmetros técnicos, às vezes localizados próximos a fossas. A falta de proteção (tampa, calçada ao redor, revestimento interno e cobertura externa) em grande parte deles não impede a entrada da água da chuva, aumentando, assim, a possibilidade de contaminação química e microbiológica dessas águas.

Quase todos os poços analisados apresentaram contaminação por coliformes, quando segundo a legislação vigente o ideal seria a ausência dessas bactérias em amostras de $100 \mathrm{ml}$. A presença dessas bactérias aliada ao $\mathrm{pH}$ na faixa ácida podem estar relacionados ao saneamento inadequado, que apesar da grande maioria da população contar com o uso de fossas sépticas e coleta de resíduos sólidos, observase a presença de lixo a céu aberto e fossas com características rudimentares nas vizinhanças. Dessa forma, fica evidente a necessidade de ações concretas para a 
preservação do meio ambiente, mas também é necessária uma participação mais ativa da população, principalmente no tocante a mudança de comportamento em relação ao meio em que vivem.

De forma geral, o consumo de água contaminada por agentes biológicos ou físico-químicos tem sido associado a diversos problemas de saúde. Os resultados obtidos apontam contaminação importante da água do manancial subterrâneo e a água da maioria dos poços estudados, que não atendem aos padrões de potabilidade recomendado pela legislação, portanto, o consumo humano dessas águas pode representar risco e agravos à saúde. Soma-se a isso o fato da população pensar que, se a água do poço estiver aparentemente limpa e sem sabor, já é suficiente para ser considerada de boa qualidade, o que acaba impedindo que os consumidores tratem minimamente essa água pelo menos por um processo de desinfecção, o que certamente minimizaria o risco de veiculação de enfermidades.

Alguns dos poços estudados são a única fonte de fornecimento de água para os usuários, assim, na impossibilidade de evitar sua utilização, recomenda-se que seja realizada a desinfecção e filtração da água antes do consumo, além de melhorias estruturais para evitar a entrada do escoamento superficial e para proteção do manancial subterrâneo, no intuito de eliminar ou reduzir as causas de possíveis contaminações.

\section{AGRADECIMENTOS}

O presente trabalho foi realizado com apoio da Universidade Federal de Mato Grosso do Sul - UFMS/MEC - Brasil.

\section{REFERÊNCIAS}

APHA - American Public Health Association. Standart methods for examination of water and wastewater. $20^{\text {th }}$ ed. Washington, 1999. 1569p.

AYACH, L. R.; GUIMARÃES, S. T. L.; CAPPI, N.; PINTO, A. L. Qualidade da água e percepção ambiental: reflexões sobre a realidade urbana de Anastácio (MS). Revista Geonorte, Edição Especial, V.3, N.4. Universidade Federal do Amazonas (UFAM), 2012. p. 1255-1267. 
AYACH, L. R. Implicações sócio-econômicas e sanitárias na qualidade das águas freáticas da cidade de Anastácio-MS. 2002. 110 p. Dissertação (Mestrado em Geografia) - Universidade Federal de Mato Grosso do Sul, Dourados, 2002.

BARBOSA, E. H. B.; BACANI, V. M. Análise da fragilidade ambiental da bacia do Córrego João Dias, Aquidauana - MS. Geografia, v. 21, n.2. p.23-43, LondrinaPR, 2012.

BRASIL. Ministério da Saúde. Fundação Nacional de Saúde (FUNASA). Manual prático de análise de água. Brasília: Funasa, 2006. 146 p.

BRASIL. Portaria MS n 518, de 25 de março de 2004. Estabelece os procedimentos e responsabilidades relativos ao controle e vigilância da qualidade da água para consumo humano e seu padrão de potabilidade, e dá outras providências. Ministério da Saúde, Brasília, 2004.

BRASIL. Portaria MS N 2914 de 12 de dezembro de 2011. Dispõe sobre os procedimentos de controle e de vigilância da qualidade da água para consumo humano e seu padrão de potabilidade. Publicada no D.0 em 14/12/2011. Ministério da Saúde, Brasília, 2011.

BRASIL. Resolução CONAMA n 396, de 03 de abril de 2008. Dispõe sobre a classificação e diretrizes ambientais para o enquadramento das águas subterrâneas e dá outras providências. Publicado no D.O.U. no $\underline{0}$ 66, de 07/04/2008, Seção 1, p. 64-68. Ministério do Meio Ambiente, Brasília, 2008.

BRASIL. Ministério das Minas e Energia. Secretaria Geral. Projeto RADAMBRASIL. Folha SF. 21 - Campo Grande; geologia, geomorfologia, pedologia, vegetação e uso potencial da terra. Rio de Janeiro, 1982.

BRIGANTE, J.; ESPÍNDOLA, E. L. G. POVINELLI, J.; NOGUEIRA, A. M. Caracterização física, química e biológica da água do rio Mogi-Guaçu. In: Limnologia fluvial: um estudo no rio Mogi-Guaçu. São Carlos: RiMa, 2003. p. 55-76.

CAPPI, N.; SANTOS, T. M. B.; OLIVEIRA, A. A.; PINTO, A. L.; AYACH, L. R. Avaliação sazonal da qualidade das águas subterrâneas da bacia do Córrego Fundo, Aquidauana-MS. Geosul, v. 25, n.50. Florianópolis-SC, jul/dez 2010. p.151174.

CAPPI, N; PEREIRA, R. H. G.; SANTOS, T.M.B.; XAVIER, C. A. N. Qualidade química e sanitária da bacia do córrego João Dias, Aquidauana/MS. In: XL Congresso Brasileiro de Engenharia Agrícola. Anais... Cuiabá - MT, 2011, p.1-9.

CAPPI, N.; AYACH, L. R. Evolução da contaminação físico-química e bacteriológica das águas subterrâneas da bacia do córrego João Dias, Aquidauana-MS. In: AYACH, L. R.; CAPPI, N.; PEREIRA, R. H. G. (Org). A bacia hidrográfica do Córrego João Dias: uma análise ambiental integrada. Campo Grande-MS: UFMS Editora, 2012. p.61-75.

CARVALHO, E. M. Análise diagnóstica de indicadores de erosão do solo da bacia hidrográfica do córrego João Dias, Aquidauana-MS. Tese de Doutorado, 
Universidade Estadual Paulista Júlio de Mesquita Filho, Instituto de Geociências e Ciências Exatas. Rio Claro-SP, 2012.

CUSTODIO, E. LLAMAS, M. R. Hidrología subterránea. Barcelona: Ed. Omega, 1976. $1157 p$.

DERBOCIO, A. M.; OLIVEIRA, J. S.; SILVA, D. F.; SANTOS, G. R. A percepção ambiental da comunidade do bairro Nova Aquidauana, Aquidauana - MS, como ferramenta para despertar a Educação Ambiental. In: AYACH, L. R.; CAPPI, N.; PEREIRA, R. H. G. (Org). A bacia hidrográfica do Córrego João Dias: uma análise ambiental integrada. Campo Grande-MS: UFMS Editora, 2012. p.139150.

DMAE - Departamento Municipal de Água e Esgoto. Influência do lançamento de efluentes de lagoas de estabilização das águas do Arroio do Salso. ECOS Pesquisas, n.5, ano 2. Porto Alegre-RS, out 2001. 63p.

FEITOSA, F. A. C.; MANOEL FILHO, J. Hidrogeologia: Conceitos e Aplicações. 2a . ed. Fortaleza: CPRM, LABHID - UFPE, 2000.391 p.

GIAMPÁ, C. E. Q.; GONÇALES, V. G. Orientações para a utilização de águas subterrâneas no Estado de São Paulo. FIESP (Federação das Indústrias do Estado de São Paulo)/DMA (Departamento de Meio Ambiente)/ABAS (Associação Brasileira de Águas Subterrâneas). São Paulo, set 2005.

GALVAN, G. L.; PEREIRA, R. H. G.; CAPPI, N.; SILVA, M. C. Estudo limnológico no córrego João Dias: uma abordagem longitudinal e sazonal. 1ํㅗำósio de Geotecnologias no Pantanal. Anais... Campo Grande: Embrapa Informática Agropecuária/INPE, 2006.

GRADELLA, F. S.; SILVA NETO, J. C. A.; ECHEVERRIA, J. L.; LEITE, E. F.; SILVA, G.; PEREIRA, R. H. G. Análise preliminar dos elementos químicos e físicos da água da bacia hidrográfica do córrego João Dias, Aquidauana-MS. In: $1^{\circ}$ Simpósio de Geotecnologias no Pantanal. Embrapa Informática Agropecuária/INPE. Anais... Campo Grande-MS, 2006. p. 96-105.

MACKERETH, F. J. H.; HERON, J.; TALLING, J. F. Water analysis: some revised methods for limnologists. 1978.

MATO GROSSO DO SUL. Secretaria de Planejamento e Coordenação Geral SEPLAN/MS. Atlas Multirreferencial. Conv. Fundação IBGE (Solos, Vegetação, Geologia, Geomorfologia e Clima). Campo Grande-MS, 1990.

MENEZES, J. P. C.; BERTOSSI, A. P. A.; SANTOS, A. R.; NEVES, M. A. Qualidade da água subterrânea para consumo humano e uso agrícola no sul do estado do Espírito Santo. REGET - Revista Eletrônica em Gestão, Educação e Tecnologia Ambiental, v.17, n.17. Universidade Federal de Santa Maria, Dez 2013. p. 3318-3326.

OBIEFUNA, G. I.; SHERIFF, A. Assessment of Shallow Ground Water Quality of Pindiga Gombe Area, Yola Area, NE, Nigeria for Irrigation and Domestic 
Purposes. Research Journal of Environmental and Earth Sciences, v.3, 2011. p.131-141.

OLIVEIRA, J. M. B.; CASTRO, A. C. L.; PEREIRA, E. D.; AZEVEDO, J. W. J. Qualidade da água subterrânea em comunidades rurais de São Luis-MA. Revista Espacios, v. $37, \mathrm{n}^{\circ} 31$, Caracas-Venezuela, 2016. p. 11-23.

PÁDUA, H. B. Águas com dureza e alcalinidade elevadas. Observações iniciais na Região de Bonito/MS. Registro de dados - 2001/2002. 64p.

PEREIRA, R. S. Poluição Hídrica: causas e consequências. Revista eletrônica de Recursos Hídricos, v. 1, n. 1, 2004, p. 20-36.

PINTO, Y. M.; AYACH, L. R. Saneamento e qualidade da água subterrânea na área urbana da bacia do córrego João Dias, Aquidauana (MS). Relatório final de Iniciação Científica - PIBIC/CNPQ. Universidade Federal de Mato Grosso do Sul, 2014.

PIVELI, R. P.; KATO, M. T. Qualidade das Águas e poluição: aspectos físico-químicos. São Paulo-SP: Abes, 2005. 285p.

RICHTER, C. A.; AZEVEDO NETTO, J. M. Tratamento de água: tecnologia atualizada. São Paulo: Edgard Blucher, 1991. 330p.

SANTOS A. C. Noções de Hidroquímica. In: FEITOSA, F. C.; MANOEL FILHO, J. (Coord.) Hidrogeologia: conceitos e aplicações. 2. Ed. Fortaleza-CE: CPRM/REFO, 2000. p.81-108.

SCHIAVO, J. A.; PEREIRA, M. G.; MIRANDA, L. P. M.; DIAS NETO, A. H.; FONTANA, A. Caracterização e classificação de solos desenvolvidos de arenitos da formação Aquidauana-MS. Revista Brasileira de Ciência do Solo 34:881-889, Sociedade Brasileira de Ciência do Solo, Viçosa-MG, 2010.

SILVA, D. D.; MIGLIORINI, R. B.; CASTRO E SILVA, E.; LIMA, Z. M.; MOURA, I. B. Falta de saneamento básico e as águas subterrâneas em aquífero freático: região do bairro Pedra Noventa, Cuiabá (MT). Engenharia Sanitária Ambiental, v.19, n. 01, jan/mar 2014. p. 43-52.

SILVA, M. C. Sazonalidade de organismos coliformes em água de poço na bacia do córrego João Dias, Aquidauana-MS. In: XIV Congresso Mundial da Água (XIVth IWRA World Water Congress). Anais... Porto de Galinhas-PE, 25 a 29 de setembro de 2011. Disponível em: http://www.iwra.org/congress/resource/PAP00-5989.pdf. Acesso em 01 jun 2017.

SIMÃO, P.; AYACH, L. R. Condições socioeconômicas e sanitárias domiciliares nos setores da área urbana da bacia do córrego João Dias, Aquidauana (MS). Relatório final de Iniciação Científica - PIBIC/CNPQ. Universidade Federal de Mato Grosso do Sul, 2014. 
SOARES, J. B.; MAIA, A. C. F. Água: microbiologia e tratamento. Fortaleza: UFC, 1999. 206p.

VALDERRAMA, J. C. The simultaneous analysis of total nitrogen and total phosphorous in natural waters. Marine chemistry, v.10, p.109-222. 1981. 


\section{CAPÍTULO III}

\section{MACRÓFITAS AQUÁTICAS DO ECÓTONO CERRADO- PANTANAL}

DDI: 10.51859/amplla.ecp672.1121-3

Camila Aoki ${ }^{1,2,3}$

Bruna Alves Coutinho ${ }^{1,3}$

Crisley Helena Simão ${ }^{1,4}$

Lenita da Silva Vieira Ximenes ${ }^{1}$

Lidianei dos Santos Savala ${ }^{1,3}$

Suzana Neves Moreira ${ }^{5}$

Vali Joana Pott 6

${ }^{1}$ Universidade Federal de Mato Grosso do Sul, Campus de Aquidauana, Grupo de Estudos Integrados em Biodiversidade do Cerrado e Pantanal, Rua Oscar Trindade de Barros, 740, Bairro da Serraria, Aquidauana, MS, Brasil, CEP: 79200-000.

${ }^{2}$ Universidade Federal de Mato Grosso do Sul, Programa de Pós-Graduação em Recursos Naturais, Faculdade de Engenharias, Arquitetura e Urbanismo e Geografia (FAENG), Av. Costa e Silva, s/n - Cidade Universitária, Campo Grande, MS, Brasil, CEP 79070-900.

${ }^{3}$ Universidade Federal de Mato Grosso do Sul, Programa de Pós-Graduação em Biologia Vegetal, Instituto de Biociências (INBIO), Av. Costa e Silva, s/n - Bairro Universitário, Campo Grande, MS, Brasil, CEP 79070-900.

${ }^{4}$ Universidade Federal de Mato Grosso do Sul, Programa de Pós-Graduação em Ensino de Ciências, Instituto de Física (INFI), Av. Costa e Silva, s/n - Bairro Universitário, Campo Grande, MS, Brasil, CEP 79070-900.

5Universidade Estadual de Mato Grosso do Sul, Rua General Mendes de Morais, 370, Bairro Jardim Aeroporto, Coxim, MS, Brasil, CEP: 79400-000.

6Universidade Federal de Mato Grosso do Sul, Herbário CGMS, Instituto de Biociências (INBIO), Av. Costa e Silva, s/n - Bairro Universitário, Campo Grande, MS, Brasil, CEP 79070-900.

\section{INTRODUÇÃO}

O termo "macrófitas aquáticas" é utilizado para denominar vegetais que habitam desde brejos até ambientes verdadeiramente aquáticos, independentemente de aspectos taxonômicos (ESTEVES, 1998). São organismos visíveis a olho nu e que apresentam partes fotossinteticamente ativas, permanente a temporariamente submersas ou flutuantes (COOK et al., 1974). Irgang e Gastal (1996) ampliam o conceito de Cook (1974) para a definição de macrófitas aquáticas e afirmam que as partes fotossintetizantes estão permanentemente ou por vários meses, total ou parcial, submersas em água doce ou salobra, ou ainda, de forma flutuante. Macrófitas são importantes na cadeia trófica de ecossistemas aquáticos, 
pois, além de cumprirem o papel de produtoras primárias juntamente com as algas (ESTEVES; CAMARGO, 1986), fornecem abrigo a peixes, insetos aquáticos, moluscos e ao perifíton (POTT; POTT, 1997). Estas plantas também têm importância por suas contribuições diretas às sociedades humanas, fornecendo alimentos, biomassa e materiais de construção (POTT; POTT, 2000).

As macrófitas aquáticas apresentam grande capacidade de adaptação e amplitude ecológica, sendo encontradas nas margens e nas áreas rasas de rios, lagos e reservatórios, mas também em cachoeiras e fitotelmos, nas regiões costeiras, em água doce, salgada e salobra (ESTEVES, 1998). Dada a heterogeneidade filogenética e taxonômica das macrófitas aquáticas, diferentes grupos dessas plantas são reconhecidos no Brasil, e elas são preferencialmente classificadas de acordo com seu biótopo (ESTEVES, 1998). Estes grupos ecológicos podem estar distribuídos de maneira organizada e paralela à margem, formando um gradiente de distribuição da margem para o interior do lago, iniciando pelas plantas emersas, passando pelas plantas de folhas flutuantes até as submersas fixas (ESTEVES, 1998; SCREMIN-DIAS, 1999), em zonação concêntrica (POTT; POTT, 2000). Entretanto, vale ressaltar que a mesma espécie pode ter aparências diferentes, com adaptações (plasticidade), que proporcionam ajustar-se às mudanças impostas pelo ciclo de cheia e seca, variando de tamanho e de hábito (formas), até mesmo de ciclo de vida (anual ou perene), conforme condições do ambiente, principalmente nível e tempo de permanência da água (POTT; POTT, 2000).

De acordo com Ferreira et al. (2011), apesar de sua importância, a riqueza de espécies nas áreas úmidas da América do Sul está longe de ser adequadamente conhecida. Não há publicação com estimativa de todas as espécies ocorrentes no território brasileiro (SCREMIN-DIAS et al., 2018), contudo, para o Pantanal foram computadas, até o momento, 324 espécies, a maioria delas mostradas no manual de identificação de Pott e Pott (2000), considerando vários graus de dependência da água.

Dentre os estudos mais recentes sobre macrófitas aquáticas publicados para o Pantanal, há informações disponíveis para sub-regiões como o Rio Paraguai (CATIAN et al., 2012; CUNHA et al., 2012; AOKI et al., 2017; MOREIRA et al., 2017; CATIAN et al., 2019), Aquidauana (ROCHA et al., 2007; COUTINHO et al., 2017; COUTINHO et al., 2019), Nabileque (ROCHA et al., 2015), Abobral e Nhecolândia 
(LEHN et al., 2011; CATIAN et al., 2017; DELATORRE et al., 2019). Poucos estudos trazem informações para a área de transição Cerrado-Pantanal (GOMES; AOKI, 2015; SIMÃO, 2016; XIMENES et al., 2017).

Apesar do aumento substancial dos trabalhos sobre ambientes aquáticos do Brasil, eles ainda são considerados insuficientes, haja vista a amplitude do território brasileiro, a maior rede hidrográfica do mundo, que abriga grande diversidade de ambientes aquáticos (SCREMIN-DIAS et al., 2018). Neste capítulo, apresentamos uma listagem de macrófitas aquáticas com registro para a região de transição entre a Serra da Maracaju e a Planície Pantaneira, no ecótono entre Cerrado e Pantanal.

\section{METODOLOGIA}

A Serra de Maracaju inicia-se na parte sul do estado de Mato Grosso do Sul, no município de Ponta Porã, atravessa a faixa central do território sulmatogrossense, chegando até a porção norte do estado, no município de Sonora (LIMA et al., 2020). Deste modo, atua como um divisor de águas entre as bacias hidrográficas do Alto Rio Paraguai (a oeste) e do Alto Rio Paraná (a leste). Esta região apresenta grande concentração de mananciais e nascentes, com grande heterogeneidade de ambientes aquáticos ao longo de sua extensão e entorno. 0 clima da região é tropical subúmido (Aw), com duas estações bem definidas, uma quente e chuvosa (novembro a abril) e outra fria e seca (maio a outubro). A precipitação anual pode atingir até $1.180 \mathrm{~mm}$, com médias mensais de temperatura variando entre $21^{\circ} \mathrm{C}$ e $33^{\circ} \mathrm{C}$ (SORIANO; ALVES, 2005).

Para compor a listagem de macrófitas aquáticas da região de ecótono Serra de Maracaju-Planície Pantaneira, compilamos informações disponíveis na literatura (GOMES; AOKI, 2015; SIMÃO, 2016; XIMENES et al., 2017) e em herbários virtuais, e incluímos dados primários obtidos pelo Grupo de Estudos em Biodiversidade do Cerrado e Pantanal. A busca em herbários foi realizada através de consulta ao banco de dados da Rede speciesLink (último acesso em 10 de junho de 2020) e incluiu apenas espécies que continham "Serra de Maracaju” como palavras-chave em qualquer um dos campos. As coordenadas dos locais de coleta disponíveis nos artigos, nos herbários (quando eram coordenadas originais) e as dos dados primários, foram plotadas em mapa (Figura 1). A nomenclatura das espécies segue 
o disposto na Flora do Brasil 2020 (em construção). As macrófitas aquáticas foram classificadas quanto à sua forma de vida em anfíbias, emergentes, flutuantes fixas (enraizadas) ou livres, submersas fixas ou livres e epífitas (IRGANG et al., 1984).

Figura 1. Mapa de distribuição dos pontos de amostragem de macrófitas aquáticas na Serra de Maracaju e entorno (Mato Grosso do Sul), sobre modelo digital de elevação de Pirajá et al. (2018).

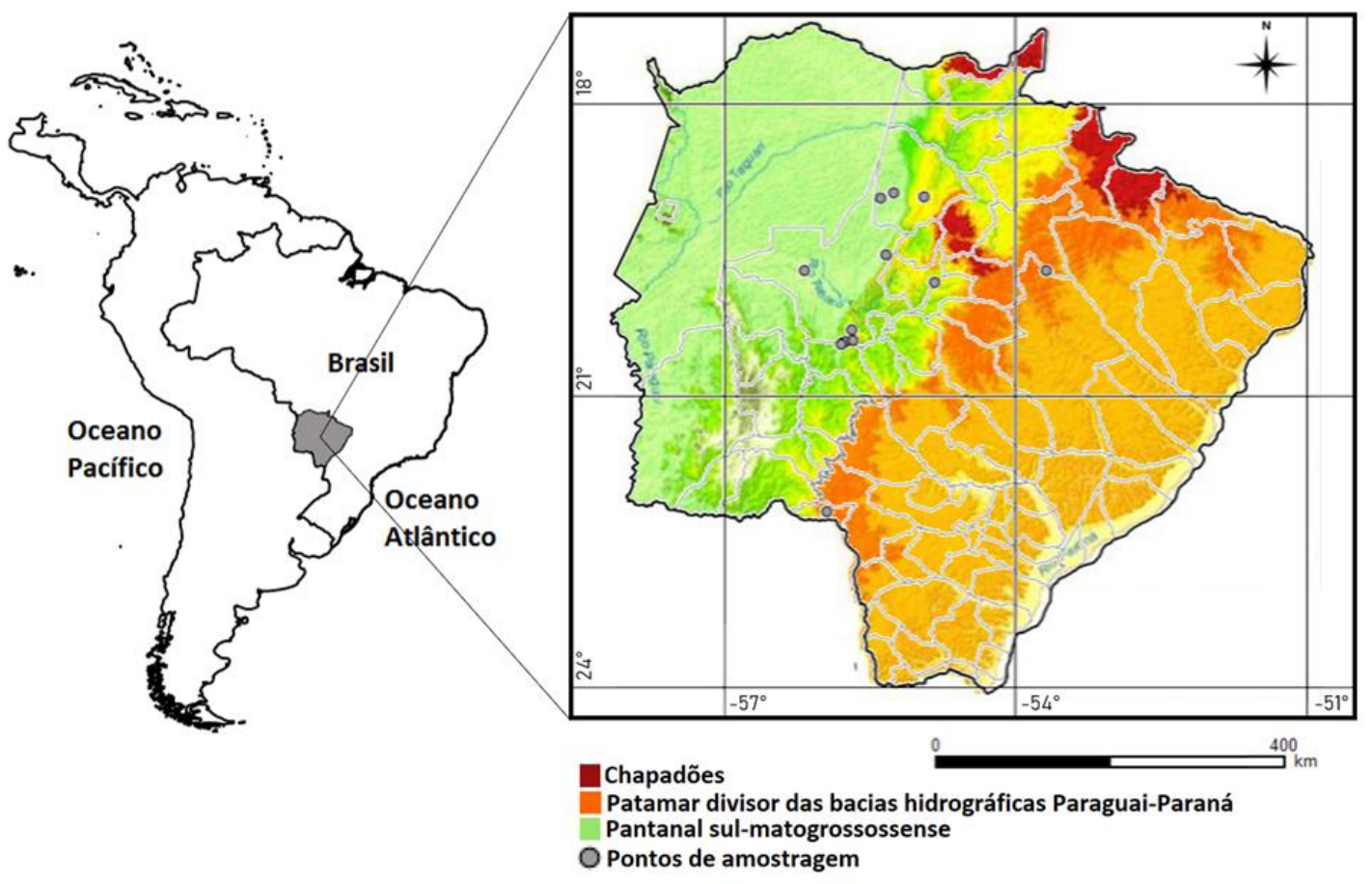

Fonte: Autoria própria.

\section{RESULTADOS E DISCUSSÃO}

Foram registradas 128 espécies, distribuídas em 37 famílias e 75 gêneros (Tabela 1, Figuras 2 e 3). Esta riqueza pode ser considerada alta, uma vez que para todo o Pantanal são estimadas cerca de 324 espécies (POTT; POTT, 2000), mas para as zonas úmidas de Cerrado da Bacia do entorno (como nas veredas) e as cabeceiras da bacia do Paraná há registro de pelo menos 1.056 espécies (MOREIRA, 2015). Considerando que a região ainda apresenta grandes extensões para as quais não encontramos informações, como as microregiões mais ao sul e ao norte do estado, é possível que ainda existam muitas espécies a serem incluídas nesta listagem, especialmente considerando a alta diversidade beta entre os ambientes ocorrentes 
nesta região (nascentes, veredas, lagoas naturais e artificiais, rios, córregos permanentes e sazonais, meandros abandonados, entre outros).

Das espécies registradas, apenas seis são samambaias (Adiantum deflectens, Pityrogramma calomelanos, Salvinia auriculata, S. biloba, Marsilea deflexa, Meniscium angustifolium) e as demais são representantes das angiospermas. Muitas das espécies registradas são elementos de ampla distribuição, comuns tanto no Planalto quanto na planície pantaneira, e também ocorrentes em outras regiões, como a bacia do Paraná. Apesar de ocorrerem em menor riqueza, as samambaias aquáticas desempenham importantes papeis ecológicos na comunidade, como na ciclagem de nutrientes e no fornecimento de recursos para a fauna, como abrigo e refúgio (POTT; POTT, 2000). Além disso, de acordo com Piedade (1993), espécies de Salvinia podem ser utilizadas como indicadores ambientais, uma vez que em ambientes eutrofizados, suas populações podem tornar-se monodominantes.

Cyperaceae foi a família mais rica na zona estudada (26 espécies), seguida de Onagraceae (10), Poaceae (10), Alismataceae (6), Lentibulariaceae (6) e Melastomataceae (6). Estas são, de modo geral, famílias ricas entre a flora de ambientes úmidos ou alagados (POTT, 2008; POTT et al., 2011). Para as veredas do Mato Grosso do Sul, Poaceae e Cyperaceae também são as famílias mais representativas, além de Asteraceae (MOREIRA et al., 2011, 2015, 2019). A família Cyperaceae é cosmopolita e compreende espécies herbáceas que, em sua maioria, habitam regiões alagadas ou sujeitas a inundações, mas também podem ocorrer em locais secos (BOVE et al., 2003; GIL; BOVE, 2004, 2007). Treze famílias (35\%) foram representadas por apenas uma espécie neste levantamento, incluindo Convolvulaceae, Hydroleaceae e Nymphaeaceae.

Os gêneros mais representados foram Cyperus (10 espécies), Ludwigia (10), Eleocharis (6), Bacopa (5) e Utricularia (5). Estes estão entre os gêneros mais ricos na Bacia do Alto Paraguai (POTT et al., 2011). A maioria dos gêneros observados na área de estudo está representada por apenas uma espécie, evidenciando uma elevada diversidade genérica. 
Tabela 1. Macrófitas aquáticas registradas na Serra de Maracaju e entorno, no ecótono CerradoPantanal, com seus respectivos nomes populares e formas de vida.

\begin{tabular}{|c|c|c|c|}
\hline Família & Gênero / Espécie & Nome Popular & Forma de Vida \\
\hline Adiantaceae & Adiantum deflectens Mart. & - & Anfíbia \\
\hline Alismataceae & $\begin{array}{l}\text { Echinodorus paniculatus } \\
\text { Micheli. }\end{array}$ & Chapéu-de-couro & Emergente \\
\hline Alismataceae & $\begin{array}{l}\text { Helanthium tenellum } \\
\text { (Martius) Britton }\end{array}$ & Erva-do-Pântano & Anfíbia \\
\hline Alismataceae & $\begin{array}{l}\text { Limnocharis flava (L.) } \\
\text { Buchenau }\end{array}$ & Camalote & Emergente \\
\hline Alismataceae & $\begin{array}{l}\text { Limnocharis laforestii } \\
\text { Duchass. ex Griseb. }\end{array}$ & - & Emergente \\
\hline Alismataceae & $\begin{array}{l}\text { Sagittaria guayanensis } \\
\text { Kunth }\end{array}$ & Lagartixa & Flutuante fixa \\
\hline Alismataceae & $\begin{array}{l}\text { Sagittaria rhombifolia } \\
\text { Cham. }\end{array}$ & Lagartixa & Emergente \\
\hline Araceae & Lemna aequinoctialis Welw. & Lentilha-d'água & Flutuante livre \\
\hline Araceae & $\begin{array}{l}\text { Urospatha sagittifolia } \\
\text { (Rudge) Schott }\end{array}$ & - & Anfíbia \\
\hline Asteraceae & Eclipta prostrata (L.) L. & Erva-de-botão & Anfíbia \\
\hline Asteraceae & $\begin{array}{l}\text { Elephantopus palustris } \\
\text { Gardner }\end{array}$ & - & Anfíbia \\
\hline Asteraceae & $\begin{array}{l}\text { Erechtites hieraciifolius (L.) } \\
\text { Raf. ex DC. }\end{array}$ & Erva-de-fogo & Anfíbia \\
\hline Asteraceae & Mikania micrantha Kunth & Jasmim-do-brejo & Anfíbia, Emergente \\
\hline Cabombaceae & $\begin{array}{l}\text { Cabomba furcata Schult. \& } \\
\text { Schult.f. }\end{array}$ & - & Submersa fixa \\
\hline Campanulaceae & Lobelia aquatica Cham. & - & Emergente \\
\hline Characeae & Chara rusbyana M. Howe & Chara & Submersa fixa \\
\hline Characeae & $\begin{array}{l}\text { Nitella furcata (Roxburgh ex } \\
\text { Bruzelius) C.Agardh emend. } \\
\text { R.D.Wood. }\end{array}$ & Lodo & Submersa fixa \\
\hline Convolvulaceae & Ipomoea carnea Jacq. & Algodão-bravo & Anfíbia \\
\hline Cyperaceae & $\begin{array}{l}\text { Bulbostylis hirtella (Schrad.) } \\
\text { Urb. }\end{array}$ & - & Anfíbia \\
\hline Cyperaceae & $\begin{array}{l}\text { Calyptrocarya glomerulata } \\
\text { (Brongn.) Urb. }\end{array}$ & - & Emergente \\
\hline Cyperaceae & $\begin{array}{l}\text { Cyperus brasiliensis (Kunth) } \\
\text { Bauters }\end{array}$ & - & Emergente \\
\hline
\end{tabular}




\begin{tabular}{|c|c|c|c|}
\hline Família & Gênero / Espécie & Nome Popular & Forma de Vida \\
\hline Cyperaceae & $\begin{array}{l}\text { Cyperus blepharoleptos } \\
\text { Steud. }\end{array}$ & Baceiro & Epífita \\
\hline Cyperaceae & $\begin{array}{l}\text { Cyperus brevifolius (Rottb.) } \\
\text { Endl. ex Hassk. }\end{array}$ & - & Anfíbia \\
\hline Cyperaceae & $\begin{array}{l}\text { Cyperus friburgensis } \\
\text { Boeckeler }\end{array}$ & - & Emergente \\
\hline Cyperaceae & Cyperus haspan L. & Cebolinha & Anfíbia \\
\hline Cyperaceae & Cyperus lanceolatus Poir. & - & Anfíbia \\
\hline Cyperaceae & Cyperus luzulae (L.) Retz. & Capim-de-botão & Anfíbia \\
\hline Cyperaceae & Cyperus odoratus L. & - & Anfíbia \\
\hline Cyperaceae & $\begin{array}{l}\text { Cyperus schomburgkianus } \\
\text { Nees }\end{array}$ & - & Anfíbia \\
\hline Cyperaceae & $\begin{array}{l}\text { Cyperus sellowianus (Kunth) } \\
\text { T.Koyama }\end{array}$ & - & Emergente \\
\hline Cyperaceae & Cyperus surinamensis Rottb. & Capim-de-rosa & Anfíbia \\
\hline Cyperaceae & $\begin{array}{l}\text { Eleocharis acutangula } \\
\text { (Roxb.) Schult. }\end{array}$ & Cebolinha & Emergente \\
\hline Cyperaceae & Eleocharis filiculmis Kunth & - & Emergente \\
\hline Cyperaceae & $\begin{array}{l}\text { Eleocharis interstincta } \\
\text { (Vahl) Roem. e Schult. }\end{array}$ & Cebolinha & Emergente \\
\hline Cyperaceae & Eleocharis minima Kunth & Lodo & Anfíbia \\
\hline Cyperaceae & $\begin{array}{l}\text { Eleocharis mutata (L.) } \\
\text { Roem. } e \text { Schul }\end{array}$ & Cebolinha & Emergente \\
\hline Cyperaceae & $\begin{array}{l}\text { Eleocharis plicarhachis } \\
\text { (Griseb.) Svenson }\end{array}$ & Cebolinha & Emergente \\
\hline Cyperaceae & $\begin{array}{l}\text { Fimbristylis dichotoma (L.) } \\
\text { Vahl }\end{array}$ & - & Emergente \\
\hline Cyperaceae & Fuirena umbellata Rottb. & Capim-navalha & Emergente \\
\hline Cyperaceae & Kyllinga odorata Vahl & - & Anfíbia \\
\hline Cyperaceae & $\begin{array}{l}\text { Rhynchospora corymbosa } \\
\text { (L.) Britton }\end{array}$ & Capim-navalha & Emergente \\
\hline Cyperaceae & $\begin{array}{l}\text { Rhynchospora emaciata } \\
\text { (Nees) Boeckeler }\end{array}$ & - & Emergente \\
\hline Cyperaceae & $\begin{array}{l}\text { Rhynchospora rugosa (Vahl) } \\
\text { Gale }\end{array}$ & - & Emergente \\
\hline Cyperaceae & $\begin{array}{l}\text { Rhynchospora velutina } \\
\text { (Kunth) Boeckeler }\end{array}$ & Capim-navalha & Anfíbia \\
\hline
\end{tabular}




\begin{tabular}{|c|c|c|c|}
\hline Família & Gênero / Espécie & Nome Popular & Forma de Vida \\
\hline Eriocaulaceae & $\begin{array}{l}\text { Leiothrix fluitans (Mart.) } \\
\text { Ruhland }\end{array}$ & - & $\begin{array}{c}\text { Emergente, Submersa } \\
\text { fixa }\end{array}$ \\
\hline Eriocaulaceae & $\begin{array}{l}\text { Syngonanthus caulescens } \\
\text { (Poir.) Ruhland }\end{array}$ & Jazida-do-brejo & Anfíbia \\
\hline Euphorbiaceae & $\begin{array}{l}\text { Caperonia castaneifolia (L.) } \\
\text { A.St.-Hil }\end{array}$ & $\begin{array}{l}\text { Erva-de-bicho- } \\
\text { branca }\end{array}$ & Emergente \\
\hline Euphorbiaceae & $\begin{array}{l}\text { Caperonia palustris (L.) } \\
\text { A.St.-Hil. }\end{array}$ & Erva-mexicana & Emergente \\
\hline Fabaceae & $\begin{array}{l}\text { Aeschynomene fluminensis } \\
\text { Vell. }\end{array}$ & Cortiça & Anfíbia, Emergente \\
\hline Fabaceae & Aeschynomene histrix Poir. & - & Anfíbia \\
\hline Fabaceae & $\begin{array}{l}\text { Aeschynomene sensitiva Sw. } \\
\text { var. sensitiva }\end{array}$ & Cortiça & Anfíbia, Emergente \\
\hline Fabaceae & Clitoria falcata Lam. & Flor-das-moças & Anfíbia \\
\hline Hydrocharitaceae & Egeria najas Planch. & Lodinho-branco & Flutuante livre \\
\hline Hydrocharitaceae & Najas microcarpa K. Schum. & Lodo & Submersa fixa \\
\hline Hydroleaceae & Hydrolea spinosa L. & Amoroso & Anfíbia, Emergente \\
\hline Lamiaceae & Hyptis balansae Briq. & - & Anfíbia \\
\hline Lamiaceae & Hyptis brevipes Poit. & - & Anfíbia \\
\hline Lamiaceae & Hyptis lorentziana O.Hoffm. & - & Anfíbia \\
\hline Lamiaceae & $\begin{array}{l}\text { Hyptis microphylla Pohl ex } \\
\text { Benth. }\end{array}$ & - & Anfíbia \\
\hline Lamiaceae & Salvia grewiifolia S.Moore & - & Anfíbia \\
\hline Lentibulariaceae & Genlisea sp. & - & - \\
\hline Lentibulariaceae & $\begin{array}{l}\text { Utricularia breviscapa } \\
\text { Wright ex Griseb. }\end{array}$ & Lodo & Submersa livre \\
\hline Lentibulariaceae & Utricularia foliosa L. & Lodo & Submersa livre \\
\hline Lentibulariaceae & Utricularia gibba L. & Lodo & Submersa livre \\
\hline Lentibulariaceae & Utricularia hydrocarpa Vahl & Lodo & Submersa livre \\
\hline Lentibulariaceae & $\begin{array}{l}\text { Utricularia poconensis } \\
\text { Fromm }\end{array}$ & Lodo & Submersa livre \\
\hline Linderniaceae & $\begin{array}{l}\text { Lindernia crustacea (L.) } \\
\text { F.Muell. }\end{array}$ & - & Anfíbia \\
\hline Linderniaceae & Lindernia dubia (L.) Pennell & - & Anfíbia \\
\hline Malvaceae & $\begin{array}{l}\text { Melochia villosa (Mill.) } \\
\text { Fawc. } e \text { Rendle }\end{array}$ & - & Anfíbia \\
\hline Malvaceae & Pavonia angustifolia Benth. & Malva & Anfíbia \\
\hline
\end{tabular}




\begin{tabular}{|c|c|c|c|}
\hline Família & Gênero / Espécie & Nome Popular & Forma de Vida \\
\hline Malvaceae & $\begin{array}{l}\text { Peltaea obsita (Colla) } \\
\text { Krapov. e Cristóbal }\end{array}$ & - & Anfíbia \\
\hline Marsileaceae & Marsilea deflexa A.Braun & $\begin{array}{l}\text { Trevo-de-quatro- } \\
\text { folhas }\end{array}$ & Flutuante fixa \\
\hline Mayacaceae & Mayaca sellowiana Kunth & Lodo & Anfíbia, Submersa fixa \\
\hline Melastomataceae & $\begin{array}{l}\text { Acisanthera variabilis } \\
\text { (Naud.) Triana }\end{array}$ & - & Anfíbia \\
\hline Melastomataceae & Clidemia hirta (L.) D.Don & - & Anfíbia \\
\hline Melastomataceae & $\begin{array}{l}\text { Desmoscelis villosa (Aubl.) } \\
\text { Naudin }\end{array}$ & - & Anfíbia \\
\hline Melastomataceae & $\begin{array}{l}\text { Macairea radula (Bonpl.) } \\
\text { DC. }\end{array}$ & - & Anfíbia \\
\hline Melastomataceae & $\begin{array}{l}\text { Rhynchanthera } \\
\text { novemnervia DC. }\end{array}$ & - & Anfíbia \\
\hline Melastomataceae & $\begin{array}{l}\text { Tibouchina gracilis (Bonpl.) } \\
\text { Cogn. }\end{array}$ & Quaresmeira & Anfíbia \\
\hline Menispermaceae & $\begin{array}{l}\text { Odontocarya tamoides (DC.) } \\
\text { Miers }\end{array}$ & Uva-do-mato-laranja & Anfíbia \\
\hline Menyanthaceae & $\begin{array}{l}\text { Nymphoides grayana } \\
\text { (Griseb.) Kuntze }\end{array}$ & Lagartixa & Flutuante fixa \\
\hline Menyanthaceae & $\begin{array}{l}\text { Nymphoides humboldtiana } \\
\text { (Kunth) Kuntze }\end{array}$ & Ninféia & Flutuante fixa \\
\hline Nymphaceae & $\begin{array}{l}\text { Nymphaea gardneriana } \\
\text { Planch. }\end{array}$ & $\begin{array}{l}\text { Camalote-da-meia- } \\
\text { noite }\end{array}$ & Flutuante fixa \\
\hline Ochnaceae & Sauvagesia erecta L. & São-martinho & Anfíbia \\
\hline Ochnaceae & $\begin{array}{l}\text { Sauvagesia racemosa A.St.- } \\
\text { Hil. }\end{array}$ & - & Anfíbia \\
\hline Onagraceae & Ludwigia decurrens Walter & Florzeiro & Emergente \\
\hline Onagraceae & $\begin{array}{l}\text { Ludwigia elegans } \\
\text { (Cambess.) H.Hara. }\end{array}$ & Cruz-de-malta & Emergente \\
\hline Onagraceae & $\begin{array}{l}\text { Ludwigia inclinata (L. f.) } \\
\text { M.Gómez }\end{array}$ & Lodo-vermelho & Submersa fixa \\
\hline Onagraceae & $\begin{array}{l}\text { Ludwigia lagunae (Morong) } \\
\text { H.Hara }\end{array}$ & Cruz-de-malta & Anfíbia, Emergente \\
\hline Onagraceae & $\begin{array}{l}\text { Ludwigia leptocarpa (Nutt.) } \\
\text { H.Hara }\end{array}$ & Florzeiro & Anfíbia, Emergente \\
\hline Onagraceae & $\begin{array}{l}\text { Ludwigia nervosa (Poir.) H. } \\
\text { Hara }\end{array}$ & Lombrigueira & Anfíbia, Emergente \\
\hline
\end{tabular}




\begin{tabular}{|c|c|c|c|}
\hline Família & Gênero / Espécie & Nome Popular & Forma de Vida \\
\hline Onagraceae & $\begin{array}{l}\text { Ludwigia octovalvis (Jacq.) } \\
\text { P.H.Raven }\end{array}$ & Florzeiro & Anfíbia, Emergente \\
\hline Onagraceae & $\begin{array}{l}\text { Ludwigia sedoides (Bonpl.) } \\
\text { H.Hara }\end{array}$ & Flor-de-mosaico & Flutuante fixa \\
\hline Onagraceae & $\begin{array}{l}\text { Ludwigia tomentosa } \\
\text { (Cambess.) H.Hara }\end{array}$ & Cruz-de-malta & Anfíbia, Emergente \\
\hline Onagraceae & $\begin{array}{l}\text { Ludwigia torulosa (Arn.) } \\
\text { H.Hara }\end{array}$ & & Emergente \\
\hline Orchidaceae & Habenaria repens Nutt. & Orquídea & Epífita \\
\hline Plantaginaceae & $\begin{array}{l}\text { Bacopa arenaria (Schmidt) } \\
\text { Edwall }\end{array}$ & Lodo & Anfíbia \\
\hline Plantaginaceae & $\begin{array}{l}\text { Bacopa monnierioides } \\
\text { (Cham.) Robinson }\end{array}$ & Vick,-cânfora & Anfíbia \\
\hline Plantaginaceae & $\begin{array}{l}\text { Bacopa myriophylloides } \\
\text { (Benth.) Wettst. }\end{array}$ & Lodo & Anfíbia \\
\hline Plantaginaceae & $\begin{array}{l}\text { Bacopa reflexa (Benth.) } \\
\text { Edwall }\end{array}$ & Lodo & Submersa fixa \\
\hline Plantaginaceae & $\begin{array}{l}\text { Bacopa salzmannii (Benth.) } \\
\text { Wettst. ex Edwall }\end{array}$ & - & Anfíbia \\
\hline Poaceae & Andropogon bicornis L. & Rabo-de-burro & Anfíbia \\
\hline Poaceae & $\begin{array}{l}\text { Andropogon leucostachyus } \\
\text { Kunth }\end{array}$ & Capim-colchão & Anfíbia \\
\hline Poaceae & $\begin{array}{l}\text { Anthaenantia lanata } \\
\text { (Kunth) Benth. }\end{array}$ & - & Anfíbia \\
\hline Poaceae & $\begin{array}{l}\text { Hymenachne amplexicaulis } \\
\text { (Rudge) Nees }\end{array}$ & Capim-de-capivara & Emergente \\
\hline Poaceae & Leersia hexandra Sw. & Felpudinho & Anfíbia \\
\hline Poaceae & Luziola fragilis Swallen & Pastinho-d'água & Anfíbia \\
\hline Poaceae & Panicum repens L. & Capim-fofo & Anfíbia \\
\hline Poaceae & $\begin{array}{l}\text { Paspalum carinatum Humb. } \\
\text { \& Bonpl. ex Flüggé }\end{array}$ & - & Emergente \\
\hline Poaceae & $\begin{array}{l}\text { Steinchisma hians (Elliott) } \\
\text { Nash }\end{array}$ & - & Emergente \\
\hline Poaceae & $\begin{array}{l}\text { Urochloa arrecta (Hack. ex } \\
\text { T. Durand e Schinz) } \\
\text { Morrone } e \text { Zuloaga }\end{array}$ & Braquiária-d’água & Emergente \\
\hline Polygonaceae & $\begin{array}{l}\text { Polygonum acuminatum } \\
\text { Kunth }\end{array}$ & Erva-de-bicho & Emergente \\
\hline
\end{tabular}




\begin{tabular}{|c|c|c|c|}
\hline Família & Gênero / Espécie & Nome Popular & Forma de Vida \\
\hline Polygonaceae & $\begin{array}{l}\text { Polygonum hydropiperoides } \\
\text { Michx. }\end{array}$ & Erva-de-bicho & Emergente \\
\hline Polygonaceae & $\begin{array}{l}\text { Polygonum punctatum } \\
\text { Elliott }\end{array}$ & Erva-de-bicho & Emergente \\
\hline Pontederiaceae & $\begin{array}{l}\text { Eichhornia azurea (Sw.) } \\
\text { Kunth }\end{array}$ & Camalote & Flutuante fixa \\
\hline Pontederiaceae & $\begin{array}{l}\text { Eichhornia crassipes (Mart.) } \\
\text { Solms }\end{array}$ & Camalote & Flutuante livre \\
\hline Pontederiaceae & Pontederia reflexa Sousa & Aguapé & Emergente \\
\hline Pontederiaceae & $\begin{array}{l}\text { Pontederia triflora (Seub.) } \\
\text { G.Agostini et al. }\end{array}$ & Camalotinho & Flutuante fixa \\
\hline Pteridaceae & $\begin{array}{l}\text { Pityrogramma calomelanos } \\
\text { (L.) Link }\end{array}$ & Samambaia-do-brejo & Emergente \\
\hline Rubiaceae & Diodia kuntzei K. Schum. & - & Anfíbia \\
\hline Rubiaceae & $\begin{array}{l}\text { Sipanea hispida Benth. ex } \\
\text { Wernahm }\end{array}$ & - & Anfíbia \\
\hline Salvinaceae & Salvinia auriculata Aubl. & Orelha-de-onça & Flutuante livre \\
\hline Salvinaceae & Salvinia biloba Raddi & - & Flutuante livre \\
\hline Thelypteridaceae & $\begin{array}{l}\text { Meniscium angustifolium } \\
\text { Willd. }\end{array}$ & - & Anfíbia \\
\hline Vitaceae & Cissus erosa Rich. & Cipó-de-fogo & Anfíbia \\
\hline Xyridaceae & Xyris jupicai Rich. & Cabeçudinho & Emergente \\
\hline Xyridaceae & Xyris savanensis Miq. & - & Emergente \\
\hline Xyridaceae & Xyris tenella Kunth & $\begin{array}{l}\text { Pimentinha- } \\
\text { alaranjada }\end{array}$ & Emergente \\
\hline
\end{tabular}

Fonte: Autoria própria.

Todas as formas de vida propostas por Irgang et al. (1984) foram registradas (Figura 4), com predomínio de anfíbias (64 spp.), ocorrentes geralmente no litoral, e emergentes (46), principalmente na faixa de água mais rasa. As formas de vida anfíbia e emergente, comumente, correspondem àquelas com maior número de espécies em ambientes aquáticos (POTT; POTT, 2000; FERREIRA et al., 2011; CATIAN et al., 2012). As espécies que compartilham essas formas de vida devem apresentar ajustes morfofisiológicos importantes, por estarem sujeitos a alterações sazonais nos níveis de água e de saturação de solos das margens (MATIAS et al., 2003). Flutuantes fixas e submersas fixas, também foram formas de vida 
representativas na região, com 8 espécies cada. Registramos apenas duas espécies de epífitas, Habenaria repens e Cyperus blepharoleptos, que nas coletas de dados primários foram observadas especialmente sobre Eichhornia azurea, embora $C$. blepharoleptos tenha sido comum também sobre as espécies de Salvinia.

Figura 2. Espécies de macrófitas aquáticas registradas na Serra de Maracaju e entorno (Mato Grosso do Sul): (A) Ludwigia sedoides, (B) Ludwigia nervosa, (C) Ludwigia torulosa, (D) Eichhornia azurea, (E) Helanthium tenellum, (F) Nymphoides humboldtiana. Fotos: Camila Aoki
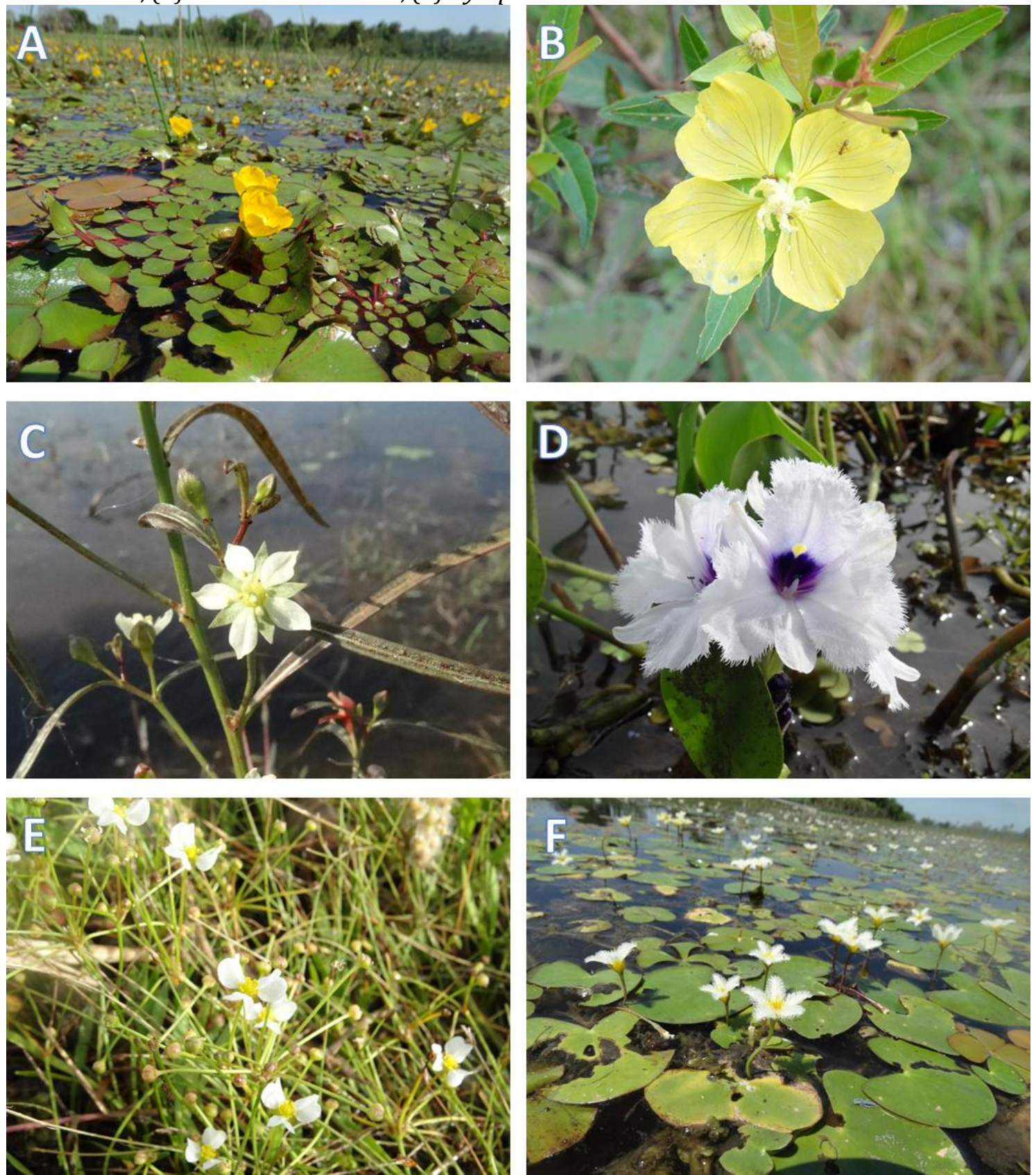

Fonte: Autoria própria.

Figura 3. Espécies de macrófitas aquáticas registradas na Serra de Maracaju e entorno (Mato Grosso do Sul): (A) Hydrolea spinosa, (B) Cabomba furcata, (C) Bacopa arenaria, (D) Sagittaria 


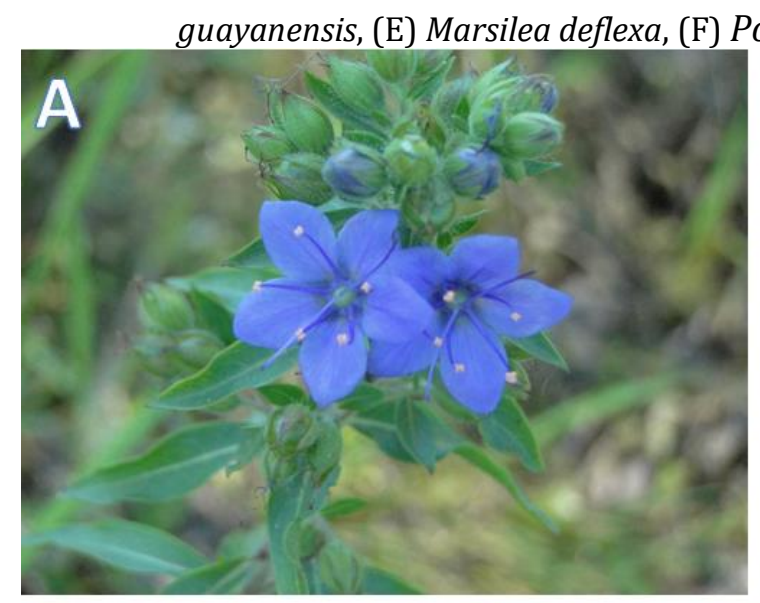

Pontederia reflexa. Fotos: Camila Aoki
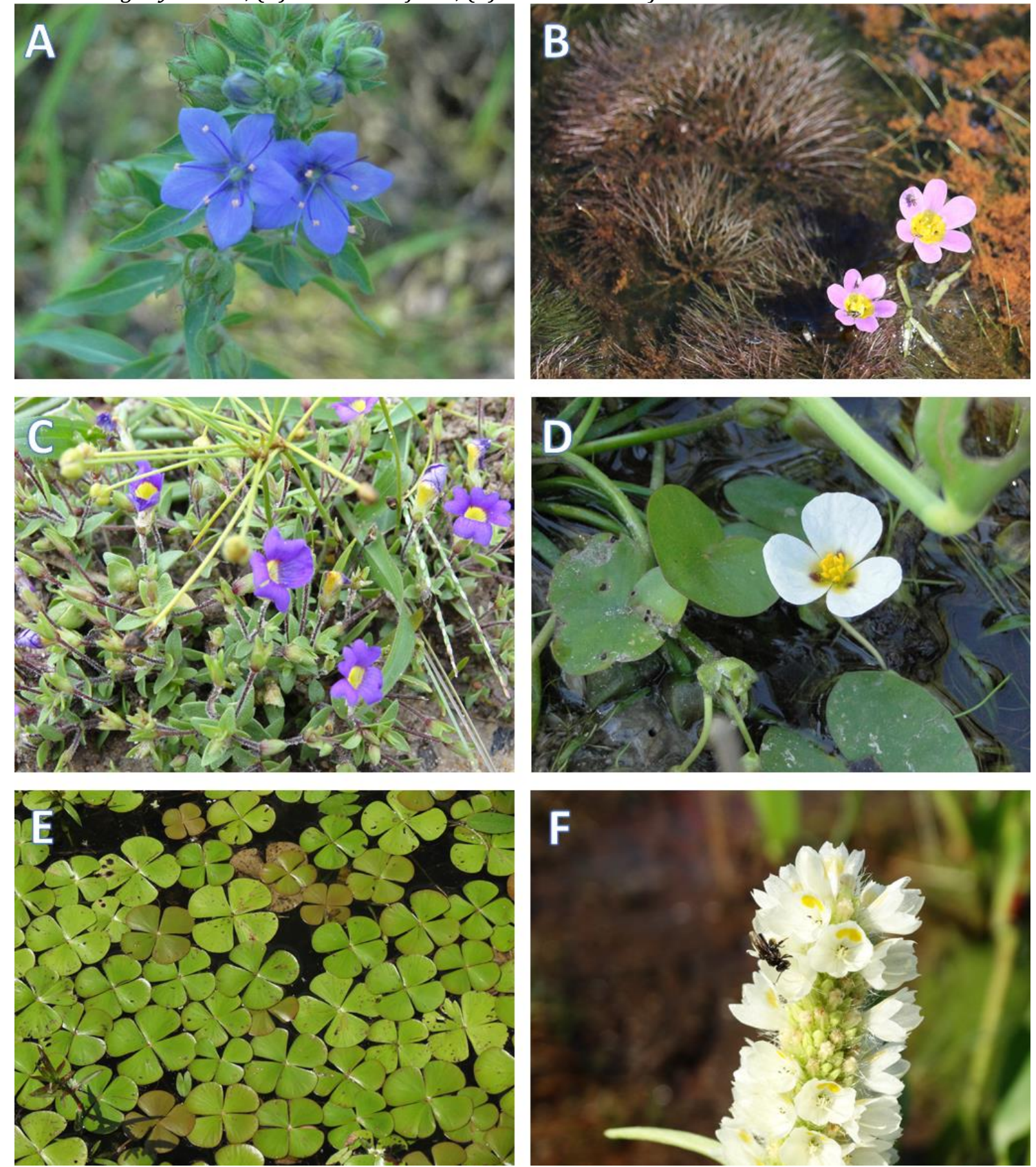

Fonte: Autoria própria.

Figura 4. Riqueza de espécies de macrófitas aquáticas por forma de vida registrada na Serra de Maracaju e entorno, no ecótono Cerrado-Pantanal. 


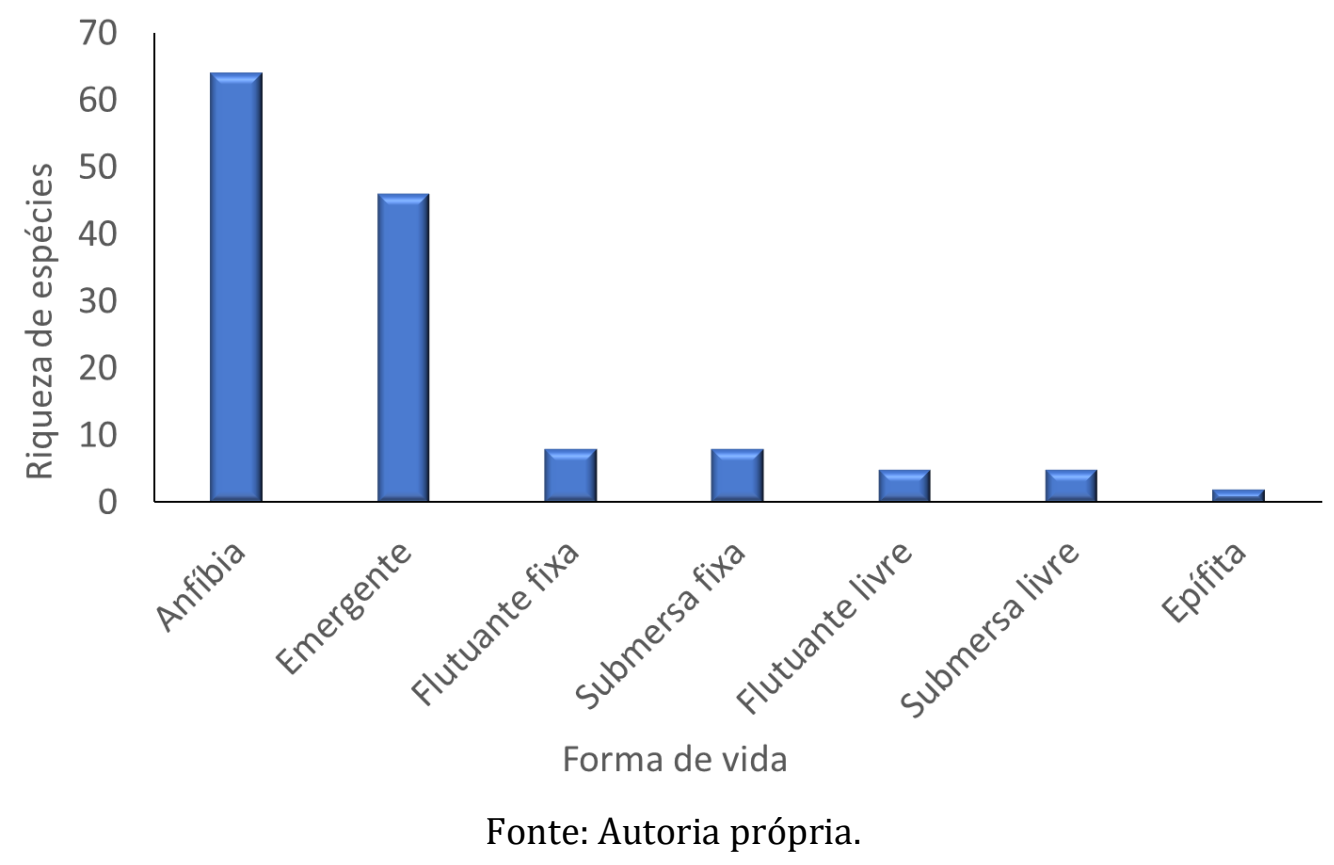

\section{CONSIDERAÇÕES FINAIS}

A partir dos conhecimentos gerados neste capítulo percebemos que ainda existem grandes lacunas de coletas ao longo da Serra de Maracaju, no ecótono Cerrado-Pantanal, tal lacuna de coleta reflete-se também em lacunas de informação sobre este grupo ecológico imprescindível para a manutenção e equilíbrio dos ecossistemas aquáticos. Esforços de coleta devem ser realizados no intuito de incrementar a lista de espécies aqui apresentada, bem como a disponibilização de informações que permitam avanços relacionados, sobretudo, à conservação das espécies e dos ecossistemas associados às áreas úmidas. A zona de transição Cerrado-Pantanal, por sua localização, é a mais impactada do Pantanal, e as macrófitas aquáticas são um dos componentes mais afetados e relevantes para conservação.

\section{AGRADECIMENTOS}

O presente trabalho foi realizado com apoio da Universidade Federal de Mato Grosso do Sul - UFMS/MEC - Brasil e da Coordenação de Aperfeiçoamento de Pessoal de Nível Superior (CAPES). Os autores agradecem à Fundação de Apoio ao Desenvolvimento do Ensino, Ciência e Tecnologia do Estado de Mato Grosso do Sul (FUNDECT) pelo apoio aos projetos desenvolvidos pelo grupo de pesquisa "Estudos 
Integrados em Biodiversidade do Cerrado e Pantanal". Agradecemos ao prof. Dr. Arnildo Pott pela revisão do manuscrito.

\section{REFERÊNCIAS}

AOKI, C. et al. Abiotic factors drive the structure of aquatic plant assemblages in riverine habitats of the Brazilian "Pantanal". Brazilian Journal of Botany, v. 40, n. 2, p. 405-415, 2017.

BOVE, C. P. et al. Hidrófitas fanerogâmicas de ecossistemas aquáticos temporários da planície costeira do Estado do Rio de Janeiro, Brasil. Acta Botanica Brasilica, v. 17, n. 1, p. 119-135, 2003.

CATIAN, G. et al. Macrophyte structure in lotic-lentic habitats from Brazilian Pantanal. Oecologia Australis, v. 16, n. 4, p. 782-796, 2012.

CATIAN, G. et al. Reproductive phenology of Polygonum hispidum Kunth and P. punctatum Elliott (Polygonaceae), in response to the flooding cycle in the Pantanal, Brazil. Boletim do Museu Paraense Emílio Goeldi - Ciências Naturais, v. 12, n. 2, p. 197-207, 2017.

CATIAN, G.; SCREMIN-DIAS, E.; POTT, A. Reproductive phenology of macrophyte community in response to wetland flooding cycle. Oecologia Australis, v. 23, n. 4, p. 856-873, 2019.

COOK, C. D. K. et al. Water plants of the world: A manual for the identification of the genera of freshwater macrophytes. Netherlands: The Hague, Junk Publishers, 1974.

COUTINHO, B. A. et al. Ecological succession of aquatic macrophytes on floating meadows in the Pantanal wetland. Brazilian Journal of Botany, v. 41, n. 1, p. 65-75, 2017.

COUTINHO, B. A. et al. Aquatic vegetation of nearshore and floating meadow of a large oxbow lake in the Brazilian Pantanal. Oecologia Australis, v. 23, n. 4, p. 846-855, 2019.

CRIA (Centro de Referência em Informação Ambiental) - Rede speciesLink. Disponível em: < http://www.splink.org.br/index >. Acesso em 10 junho 2020.

CUNHA, N. L. et al. Structure of aquatic vegetation of a large lake, western border of the Brazilian Pantanal. Brazilian Journal of Biology, v. 72, n. 3, p. 519-531, 2012.

DELATORRE, M. et al. Trait-environment relationship of aquatic vegetation in a tropical pond complex system. Wetlands, p. 1-12, 2019. 
ESTEVES, F. A. Fundamentos de limnologia. 2a ${ }^{a}$ Ed. Rio de Janeiro: Editora Interciência/FINEP, 1998.

ESTEVES, F. A.; CAMARGO, A. F. M. Sobre o papel das macrófitas aquáticas na estocagem e ciclagem de nutrientes. Acta Limnologica Brasiliensia, v. 1, n. 1, p. 273-298, 1986.

FERREIRA, F. A. et al. Macrophytes in the upper Paraná river floodplain: checklist and comparison with other large South American wetlands. Revista de Biologia Tropical, v. 59, 541-556, 2011.

FLORA DO BRASIL 2020 em construção. Jardim Botânico do Rio de Janeiro. Disponível em: < http://floradobrasil.jbrj.gov.br/ >. Acesso em: 11 junho 2020

GIL, A. S. B.; BOVE, C. P. O gênero Eleocharis R. Br. (Cyperaceae) nos ecossistemas aquáticos temporários da planície costeira do Estado do Rio de Janeiro. Arquivos do Museu Nacional, v. 62, n. 2, p. 131-150, 2004.

GIL, A. S. B.; BOVE, C. P. Eleocharis R. Br. (Cyperaceae) no Estado do Rio de Janeiro, Brasil. Biota Neotropica, v. 7, n. 1, p. 36-45, 2007.

GOMES, A.; AOKI, C. Efeito da sazonalidade hídrica sobre a fitossociologia de macrófitas aquáticas em uma lagoa no Pantanal, Brasil. Revista de Biologia Neotropical, v. 12, p. 1-7, 2015.

IRGANG, B. E.; PEDRALLI, G.; WAECHTER, J. I. Macrófitos aquáticos da Estação Ecológica do Taim, Rio Grande do Sul, Brasil. Roessléria, v. 6, p. 395-404, 1984.

IRGANG, B. E.; GASTAL JR, C. V. S. Macrófitas aquáticas da planície costeira do RS. UFRGS, Porto Alegre. CPG-Botânica/UFGS, 1996.

LEHN, C. R. et al. Fitossociologia de macrófitas aquáticas associadas ao rio Miranda, Pantanal, MS, Brasil. Revista de Biologia Neotropical, v. 8, n. 2, p. 23-31, 2011.

LIMA, B. S.; SILVA, C. A; BOIN, M. N.; MEDEIROS, R. B. "As paisagens e as dinâmicas territoriais na Serra de Maracaju, Mato Grosso do Sul, Brasil”. Cuadernos de Geografía: Revista Colombiana de Geografía, v. 29, p. 224-241, 2020.

MATIAS, L. Q.; AMADO, E. R.; NUNES, E. P. Macrófitas aquáticas da lagoa de Jijoca de Jericoacoara, Ceará, Brasil. Acta Botanica Brasilica, v. 17, n. 4, p. 623-631, 2003.

MOREIRA, S. N. et al. Structure of pond vegetation of a vereda in the Brazilian Cerrado. Rodriguésia, v. 62, p. 721-729, 2011.

MOREIRA, S. N. Flora, distribuição e estrutura da vegetação das áreas úmidas de uma região savânica brasileira: implicações para a conservação da biodiversidade. 2015. Tese (Doutorado em Biologia Vegetal) - Universidade Federal de Minas Gerais, Belo Horizonte, 2015. 
MOREIRA, S. N. et al. Aquatic macrophytes in Paraguay River branches in the Brazilian Pantanal, Mato Grosso do Sul, Brazil. Boletim do Museu Paraense Emílio Goeldi - Ciências Naturais, v. 12, n. 2, p. 177-185, 2017.

MOREIRA, S. N., POTT, V. P., POTT, A., SILVA, R. H., DAMASCENO-JUNIOR, G. A. Flora and vegetation structure of vereda in southwestern Cerrado, Oecologia Australis, v. 23, n. 4, p. 776-798, 2019.

PIEDADE, M. T. F. Biologia e ecologia de Echinochloa polystachya (H.B.K.) Hitchcock (Gramineae $=$ Poaceae), capim semi-aquático da várzea amazônica. Acta Limnologica Brasiliensia, v. 6, p. 173-185, 1993.

PIRAJÁ, R. V.; MERCANTE, M. A.; PARANHOS-FILHO, A.; SILVA, M. H. S. Modelo digital de elevação aplicado à taxonomia do relevo: regiões geomorfológicas do Estado de Mato Grosso do Sul e delimitação da bacia hidrográfica do rio Taboco. Anais 7ํㅗ Simpósio de Geotecnologias no Pantanal. Embrapa Informática Agropecuária/INPE, p. 142-151, 2018.

POTT, V. J.; POTT, A. Checklist das macrófitas aquáticas do Pantanal, Brasil. Acta Botanica Brasilica, v. 11, n. 2, p. 215-227, 1997.

POTT, V. J.; POTT, A. Plantas aquáticas do Pantanal. Brasília: Embrapa, 2000.

POTT, V. J. Plantas de ambientes aquáticos e úmidos do Centro-Oeste brasileiro. In Anais do 59o Congresso Nacional de Botânica. Sociedade Brasileira de Botânica, Natal, p. 441-442, 2008.

POTT, V. J.; POTT, A.; LIMA, L. C. P.; MOREIRA, S. N.; OLIVEIRA, A. K. M. Aquatic macrophyte diversity of the Pantanal wetland and upper basin. Brazilian Journal of Biology, v. 71, p. 255-563, 2011.

ROCHA, C. G.; RESENDE, U. M.; LUGNANI, J. S. Diversidade de macrófitas em ambientes aquáticos do IPPAN na Fazenda Santa Emília, Aquidauana, MS. Revista Brasileira de Biociências, v. 5, n. 2, p. 456-458, 2007.

ROCHA, M., SANTOS JÚNIOR, C. C.; DAMASCENO-JÚNIOR, G. A.; POTT, V. J.; POTT, A. Effect of fire on a monodominant floating mat of Cyperus giganteus Vahl in a neotropical wetland. Brazilian Journal of Biology, v. 75, p. 114-124, março 2015.

SCREMIN-DIAS, E. O retorno à origem aquática. In: Nos Jardins Submersos da Bodoquena: guia para identificação de plantas aquáticas de Bonito e região (SCREMIN-DIAS, E.; POTT, V. J.; HORA, R. C.; SOUZA; P. R. (eds.). Campo Grande: Editora Universidade Federal de Mato Grosso do Sul, 1999. p. 25-41.

SCREMIN-DIAS, E. et al. Flora de campos úmidos calcários da Serra da Bodoquena. Iheringia, Série Botânica, Porto Alegre, v. 73, p. 80-92, 2018.

SIMÃO, C. H. Fenologia reprodutiva de macrófitas aquáticas no ecótono CerradoPantanal. 2016. Dissertação (Mestrado em Biologia Vegetal) - Universidade Federal de Mato Grosso do Sul, Campo Grande, 2016. 
SORIANO, B. M. A.; ALVES, M. J. M. Boletim agrometeorológico ano 2002 para a subregião da Nhecolândia, Pantanal, Mato Grosso do Sul, Brasil. EMBRAPA-CPAP, Série Documentos, v. 76, p. 1-29, 2005.

XIMENES, L. S. V.; POTT, V. J.; AOKI, C. Plantas aquáticas do Parque Natural Municipal da Lagoa Comprida, Aquidauana, Mato Grosso do Sul, Brasil. Boletim do Museu Paraense Emílio Goeldi - Ciências Naturais, v. 12, n. 2, p. 187-195, 2017. 


\title{
CAPÍTULO IV
}

\section{FLORÍSTICA E FITOSSOCIOLOGIA DO PARQUE NATURAL MUNICIPAL DA LAGOA COMPRIDA, AQUIDAUANA, MS}

\author{
DDI: 10.51859/amplla.ecp672.1121-4
}

Rosiete Paiz ${ }^{1}$

Camila Aoki ${ }^{1,2,3}$

${ }^{1}$ Universidade Federal de Mato Grosso do Sul, Campus de Aquidauana, Grupo de Estudos Integrados em Biodiversidade do Cerrado e Pantanal, Rua Oscar Trindade de Barros, 740, Bairro da Serraria, Aquidauana, MS, Brasil, CEP: 79200-000.

${ }^{2}$ Universidade Federal de Mato Grosso do Sul, Programa de Pós-Graduação em Recursos Naturais, Faculdade de Engenharias, Arquitetura e Urbanismo e Geografia (FAENG), Av. Costa e Silva, s/n - Cidade Universitária, Campo Grande, MS, Brasil, CEP 79070-900.

${ }^{3}$ Universidade Federal de Mato Grosso do Sul, Programa de Pós-Graduação em Biologia Vegetal, Instituto de Biociências (INBIO), Av. Costa e Silva, s/n - Bairro Universitário, Campo Grande, MS, Brasil, CEP 79070-900.

\section{INTRODUÇÃO}

A realização de estudos básicos, dentre eles o levantamento das espécies de uma dada região, é considerado fundamental, pois é o único meio de se conhecer a real diversidade da flora e fauna brasileiras (MMA, 2008). Apenas a partir da produção de listas de espécies, sua correta identificação e manutenção da biodiversidade amostrada em herbários e coleções zoológicas pode-se contribuir para o estudo dos demais atributos da comunidade e subsidiar programas para sua recuperação ou conservação.

Estudos sobre a composição florística e a estrutura fitossociológica das formações florestais são de fundamental importância, pois oferecem subsídios para a compreensão da estrutura e da dinâmica destas formações, parâmetros imprescindíveis para o manejo e restauração das diferentes comunidades vegetais (CHAVES et al., 2013). Estudos florísticos visam indicar o conjunto de unidades taxonômicas que compõem a floresta, como as suas espécies e famílias (SCHNEIDER; FINGER, 2000), deste modo o objetivo de um levantamento florístico é listar as espécies vegetais ocorrentes em determinada área (CAVASSAN et al., 1984). Os estudos florísticos representam uma importante etapa no conhecimento de um 
ecossistema por fornecer informações básicas para os estudos biológicos subsequentes (GUEDES-BRUNI; PESSOA; KURTZ, 1997).

A fitossociologia, por sua vez, é o ramo da ecologia vegetal mais amplamente utilizado para diagnóstico quali-quantitativo das formações vegetacionais (CHAVES et al., 2013). Os levantamentos da composição florística e da estrutura comunitária geram informações sobre a distribuição geográfica das espécies, sua abundância em diferentes locais e fornecem bases consistentes para a criação e manejo de unidades de conservação (CHAVES et al., 2013). Este trabalho teve por objetivo realizar um inventário florístico e fitossociológico no Parque Natural Municipal da Lagoa Comprida, de modo a fornecer subsídios para o plano de manejo dessa área.

\section{METODOLOGIA}

O estudo foi realizado no Parque Natural Municipal da Lagoa Comprida ( $20^{\circ} 27^{\prime} 44^{\prime \prime}$ S, 5546'26"0), localizado na porção central da área urbana do município de Aquidauana (MS), numa área de ecótono Cerrado-Pantanal. 0 município de Aquidauana localiza-se no estado de Mato Grosso do Sul, que por sua vez está inserido na região Centro Oeste do Brasil. O Parque possui área total de 74,2 hectares e lâmina d'água de aproximadamente 27 hectares de extensão, a qual possui característica semilêntica (SOUZA; MARTINS, 2010).

O clima da região é do tipo Tropical Chuvoso de Savana (subtipo Aw cf. PEEL et al., 2007) com duas estações bem definidas, uma seca e fria (inverno) que vai de maio a setembro, e outra chuvosa e quente (verão), de outubro a abril. A precipitação média anual é de $1.200 \mathrm{~mm}$ e as temperaturas máximas e mínimas de 33 e $19{ }^{\circ} \mathrm{C}$, respectivamente (SCHIAVO et al., 2010).

A coleta de dados foi realizada em janeiro de 2020. Foram montadas 15 parcelas de $100 \mathrm{~m}^{2}$, equidistantes entre si cerca de 300 metros (Figura 1). Todas as espécies arbóreas foram identificadas e, quando apresentaram circunferência à altura do peito (CAP) maior ou igual a $15 \mathrm{~cm}$, foram medidas para as estimativas dos parâmetros da estrutura horizontal, que incluíram a frequência, a densidade, a dominância, valor de importância de cada espécie amostrada, riqueza de espécies. A riqueza de espécies foi comparada por meio do método de rarefação baseado no número de indivíduos (GOTELLI; COLWELL, 2001). As estimativas são calculadas 
por meio das seguintes expressões (LAMPRECHT, 1964; MUELLER-DUMBOIS; ELLENBERG 1974; MARTINS, 1991):

Frequência:

$$
F A_{i}=\left(\frac{u_{i}}{u_{z}}\right) \times 100 ; \quad F R_{i}=\left(\frac{F A_{i}}{\sum_{i=1}^{p} F A_{i}}\right) x 100
$$

em que:

FA i = frequência absoluta da i-ésima espécie na comunidade vegetal;

FR i = frequência relativa da i-ésima espécie na comunidade vegetal;

u i = número de unidades amostrais em que a i-ésima espécie ocorre;

$\mathrm{u} \mathrm{t}=$ número total de unidades amostrais;

$\mathrm{P}=$ número de espécies amostradas.

0 parâmetro frequência informa com que frequência a espécie ocorre nas unidades amostrais. Assim, maiores valores de FA i e FR i indicam que a espécie está bem distribuída horizontalmente ao longo do povoamento amostrado.

Densidade:

$$
D A_{i}=\frac{n_{i}}{A} ; \quad D R_{i}=\frac{D A_{i}}{D T} \times 100 ; \quad D T=\frac{N}{A}
$$

em que:

DA i = densidade absoluta da i-ésima espécie, em número de indivíduos por hectare;

n i = número de indivíduos da i-ésima espécie na amostragem;

$\mathrm{N}$ = número total de indivíduos amostrados;

$\mathrm{A}=$ área total amostrada, em hectare;

DR i = densidade relativa (\%) da i-ésima espécie;

DT = densidade total, em número de indivíduos por hectare (soma das densidades de todas as espécies amostradas).

Este parâmetro informa a densidade, em números de indivíduos por unidade de área, com que a espécie ocorre no povoamento. Assim, maiores valores de DA i e DR i indicam a existência de um maior número de indivíduos por hectare da espécie no povoamento amostrado.

Dominância: 
$D o A_{i}=\frac{A B_{i}}{A} ; \quad D o R=\frac{D o A}{D o T} \times 100 ; \quad D o T=\frac{A B T}{A} ; \quad A B T=\sum_{i=1}^{S} A B_{i}$

em que:

DoA i = dominância absoluta da i-ésima espécie, em $\mathrm{m}^{2} / \mathrm{ha}$;

$\mathrm{AB}$ i = área basal da i-ésima espécie, $\mathrm{em}^{2}$, na área amostrada;

$\mathrm{A}=$ área amostrada, em hectare;

DoR i = dominância relativa (\%) da i-ésima espécie;

DoT = dominância total, em $\mathrm{m}^{2} /$ ha (soma das dominâncias de todas as espécies).

Este parâmetro também informa a densidade da espécie, contudo, em termos de área basal, identificando sua dominância sob esse aspecto. A dominância absoluta nada mais é do que a soma das áreas seccionais dos indivíduos pertencentes a uma mesma espécie, por unidade de área. Assim, maiores valores de DoA i e DoR i indicam que a espécie exerce dominância no povoamento amostrado em termos de área basal por hectare.

Valor de Importância (VI i):

$$
V I_{i}=D R_{i}+D o R_{i}+F R_{i} ; \quad V I_{i}(\%)=\frac{V l_{i}}{3}
$$

Este parâmetro é o somatório dos parâmetros relativos de densidade, dominância e frequência das espécies amostradas, informando a importância ecológica da espécie em termos de distribuição horizontal. As espécies foram identificadas com auxílio de manuais de identificação (POTT; POTT, 1994; LORENZI, 2002; SILVA JUNIOR, 2005; RAMOS et al., 2008; SILVA JUNIOR; PEREIRA, 2009), comparação com material de herbário e consulta a especialistas. A nomenclatura das espécies seguiu o disposto na Flora do Brasil 2020 (em construção). 
Figura 1. Localização do Parque Natural Municipal da Lagoa Comprida, Aquidauana, MS. Pontos vermelhos indicam localização aproximada das parcelas amostradas.
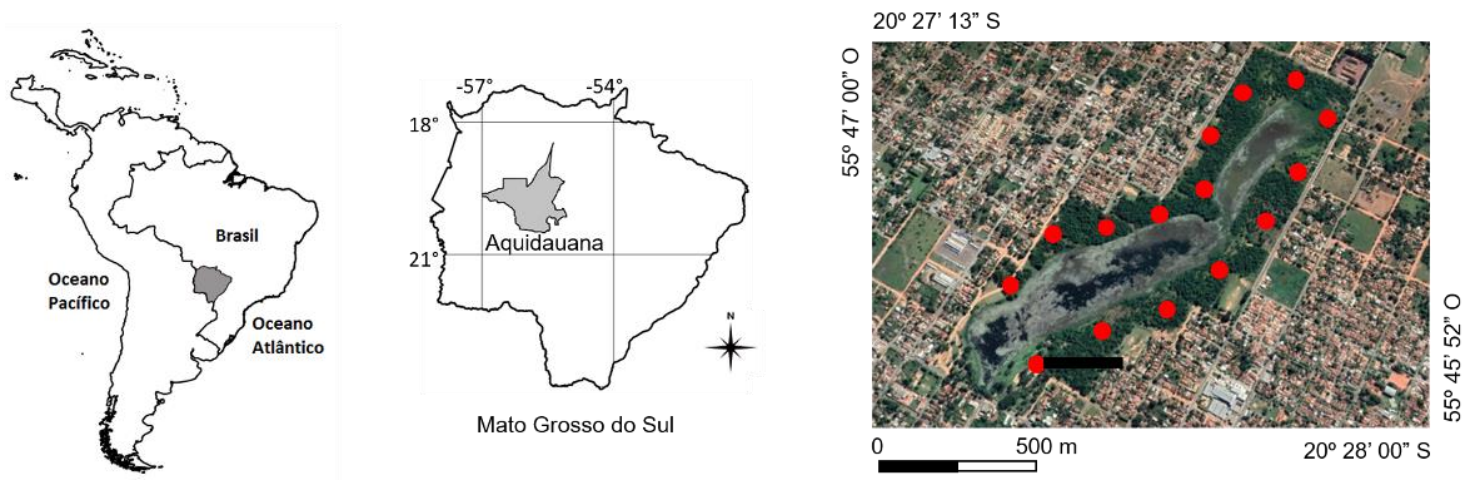

Fonte: Autoria própria.

\section{RESULTADOS E DISCUSSÃO}

\subsection{FLORÍSTICA}

Foram amostrados 218 indivíduos lenhosos, pertencentes a 21 famílias, 30 gêneros e 31 espécies (Tabela 1). A curva para verificar a suficiência amostral mostrou um rápido crescimento inicial e não apresentou estabilização (não atingiu a assíntota), indicando que outras espécies devem ser incluídas caso a amostragem aumente (Figura 2). Contudo, é conveniente mencionar que esta é uma técnica usual, porém controversa, uma vez que em florestas tropicais as curvas espécie-área raramente têm o comportamento esperado, em virtude da elevada diversidade nessas áreas raramente apresentam-se assintóticas (SCHILLING; BATISTA, 2008).

Fabaceae foi, com ênfase, a família mais rica neste levantamento (Figura 3). Esta família frequentemente figura como a mais representativa em distintas regiões brasileiras (SARTORI et al., 2014). Fabaceae (ou Leguminosae) é uma das três maiores famílias de Angiospermas, com 19.327 espécies e 727 gêneros arranjados em 36 tribos (LEWIS et al., 2005), sendo também uma das principais do ponto de vista econômico (SOUZA; LORENZI, 2005). 
Tabela 1. Espécies arbóreas com suas respectivas famílias e nomes populares, ocorrentes no Parque Natural Municipal da Lagoa Comprida, Aquidauana, MS.

\begin{tabular}{|c|c|c|}
\hline Família & Nome Científico & Nome Comum \\
\hline Anacardiaceae & Astronium urundeuva (M. Allemão) Engl. & Aroeira \\
\hline Anacardiaceae & Tapirira guianensis Aubl. & Peito-de-pombo \\
\hline Annonaceae & Xylopia aromatica (Lam.) Mart. & Pimenta-de-macaco \\
\hline Annonaceae & Duguetia furfuracea (A.St.-Hil.) Saff. & Araticum-seco \\
\hline Apocynaceae & Aspidosperma sp. & Peroba \\
\hline Arecaceae & Acrocomia aculeata (Jacq.) Lodd. ex Mart. & Bocaiúva \\
\hline Arecaceae & Attalea speciosa Mart. ex Spreng. & Babaçu \\
\hline Asteraceae & Espécie indeterminada & - \\
\hline Bignoniaceae & Handroanthus ochraceus (Cham.) Mattos & Ipê-amarelo \\
\hline Boraginaceae & Cordia glabrata (Mart.) A.DC. & Louro-preto \\
\hline Calophyllaceae & Kielmeyera coriacea Mart. e Zucc. & Pau-santo \\
\hline Dilleniaceae & Curatella americana $\mathrm{L}$. & Lixera \\
\hline Erythroxylaceae & Erythroxylum anguifugum Mart. & Pimenteirinha \\
\hline Euphorbiaceae & Sapium haematospermum Müll.Arg. & Leiteiro, sarã-de-leite \\
\hline Fabaceae & Andira cujabensis Benth & Morcegueiro \\
\hline Fabaceae & Dimorphandra mollis Benth. & Barbatimão-falso \\
\hline Fabaceae & Dipteryx alata Vogel & Cumbarú \\
\hline Fabaceae & Enterolobium contortisiliquum (Vell.) Morong & $\begin{array}{c}\text { Orelha-de-negro, } \\
\text { ximbuva }\end{array}$ \\
\hline Fabaceae & Leptolobium elegans Vogel & Quina-genciana \\
\hline Fabaceae & Machaerium acutifolium Vogel & Jacarandá-do-campo \\
\hline Fabaceae & Vatairea macrocarpa (Benth.) Ducke & Amargoso, angelim \\
\hline Fabaceae & Stryphnodendron adstringens (Mart.) Coville & Barbatimão \\
\hline Lamiaceae & Aegiphila verticillata Vell. & Milho-de-grilo \\
\hline Lauraceae & Ocotea cf. diospyrifolia (Meisn.) Mez & Canela \\
\hline Rubiaceae & Tocoyena formosa (Cham. e Schltdl.) K.Schum. & Jenipapo-bravo \\
\hline Rutaceae & Zanthoxylum hasslerianum (Chodat) Pirani & Maminha-de-porca \\
\hline Rutaceae & Zanthoxylum riedelianum Engl. & Laranjeira brava \\
\hline Salicaceae & Casearia sylvestris Sw. & Chá-de-frade \\
\hline Simaroubaceae & Simarouba versicolor A.St.-Hil. & Perdiz \\
\hline Solanaceae & Solanum paniculatum L. & Jurubeba \\
\hline Urticaceae & Cecropia pachystachya Trécul & Embaúba \\
\hline
\end{tabular}

Fonte: Autoria própria. 
Figura 2. Curva de acumulação de espécies pelo método de rarefação, no Parque Natural Municipal da Lagoa Comprida, Aquidauana, MS.

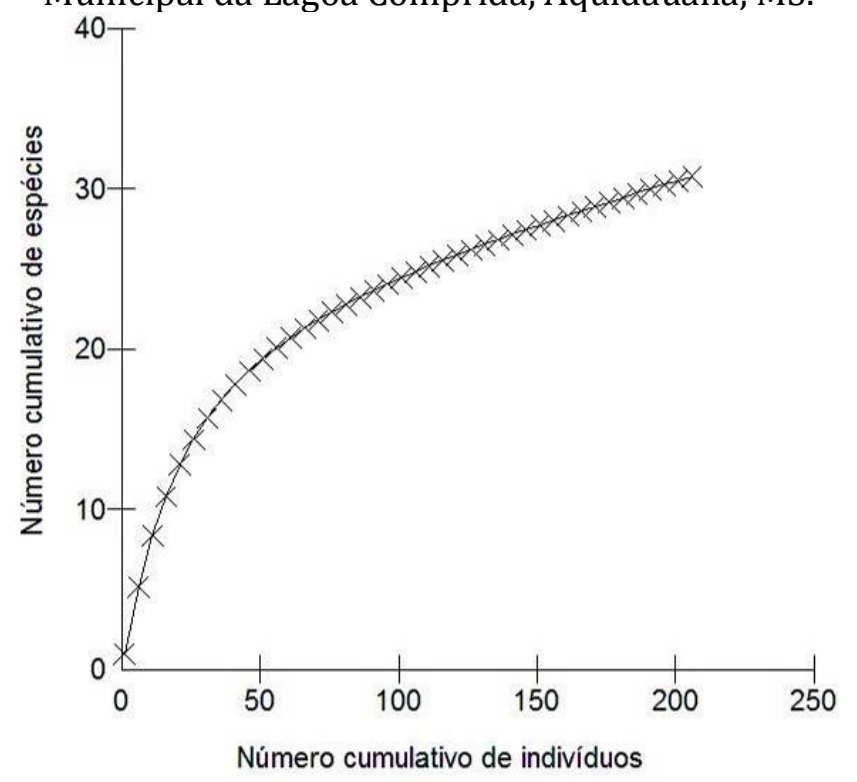

Fonte: Autoria própria.

Figura 3. Famílias com maior riqueza de espécies, Parque Natural Municipal da Lagoa Comprida, Aquidauana, MS.

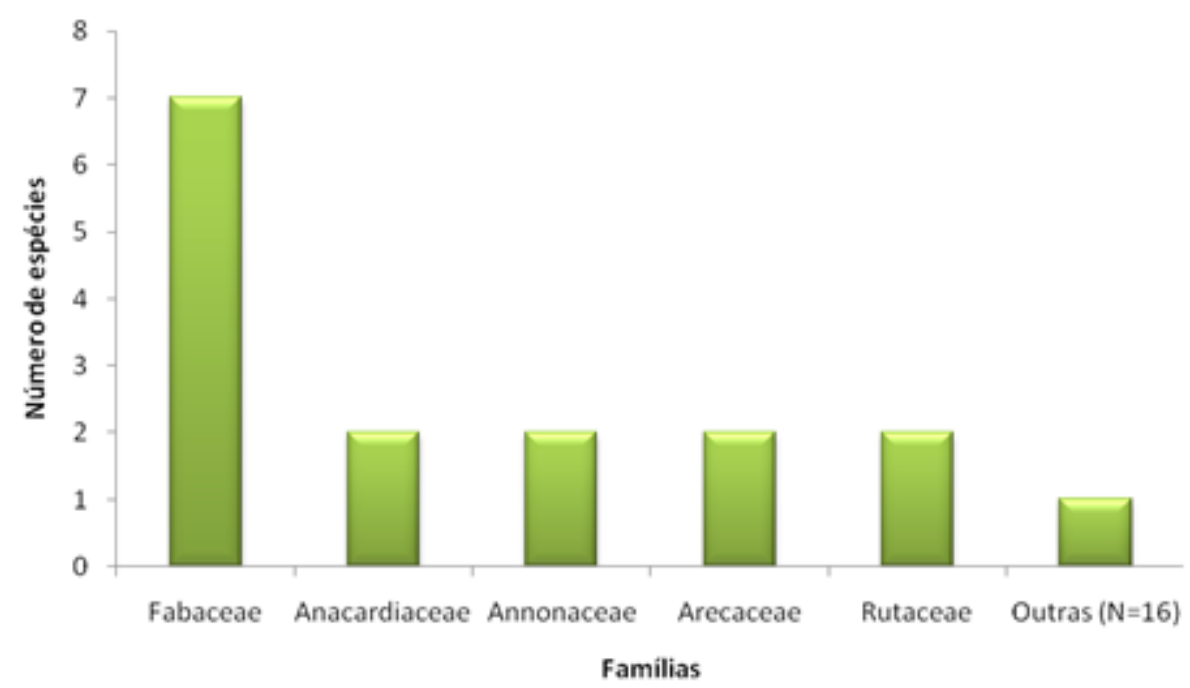

Fonte: Autoria própria.

\subsection{FITOSSOCIOLOGIA}

A densidade específica e a área basal estimada por hectare foi de 1453,3 indivíduos/ha e 18,06 $\mathrm{m}^{2} /$ ha, respectivamente. Estes valores são baixos quando comparados com outros estudos conduzidos em formações ciliares. Por exemplo, Botrel et al. (2002) registraram 2.683 indíviduos/ha e área basal de 29,309 m²/ha para em floresta estacional semidecidual ribeirinha em Ingaí (MG). Sampaio, Walter e Felfili (2000) amostraram 1.333 indíviduos/ha e área basal de 34,4 $\mathrm{m}^{2} / \mathrm{ha}$ em 
matas de galeria na micro-bacia do Riacho Fundo (DF). Contudo, em estudo desenvolvido no Mato Grosso do Sul, Battilani et al. (2005) estimaram 734,44 indivíduos/ha de densidade e $21,32 \mathrm{~m}^{2}$ /ha de área basal em mata ciliar do rio da Prata, Jardim (MS), valores próximos ao registrado no Parque. As condições climáticas e edáficas podem explicar parcialmente os resultados, mas provavelmente os fatores antrópicos sejam os principais responsáveis pelo baixo número de indivíduos e pequena área basal, uma vez que muitas pessoas habitam o entorno, interferem na paisagem e o fogo é um impacto recorrente nesta Unidade de Conservação. Nesse sentido, medidas como o cercamento da Unidade de Conservação e projetos de educação ambiental que incluam os moradores do entorno e frequentantes da área devem ser estudadas como medidas de conservação da área.

As espécies com maior densidade e frequência, consequentemente, com maior valor de importância, foram a lixeira Curatella americana (Figura 4A), a pimenta-de-macaco Xylopia aromatica (Figura 4B) e a canela Ocotea cf. diospyrifolia (Figura 4C). Juntas, essas espécies correspondem a quase 30\% de todos os indivíduos e do valor de importância (Tabela 2, Figura 5). Em dominância, o louropreto Cordia glabrata apresentou o segundo maior valor, atrás apenas de $C$. americana. Esse padrão de poucas espécies com elevada abundância e valor de importância e muitas espécies raras é um padrão comum em estudos fitossociológicos realizados no Cerrado (FELFILI; SILVA-JUNIOR, 1993; FELFILI et al., 1994, 1997, 2002).

Figura 4. Espécies com maior valor de importância no Parque Natural Municipal da Lagoa Comprida, Aquidauana, MS. (A) Curatella americana, (B) Xylopia aromatica, (C) Ocotea cf.
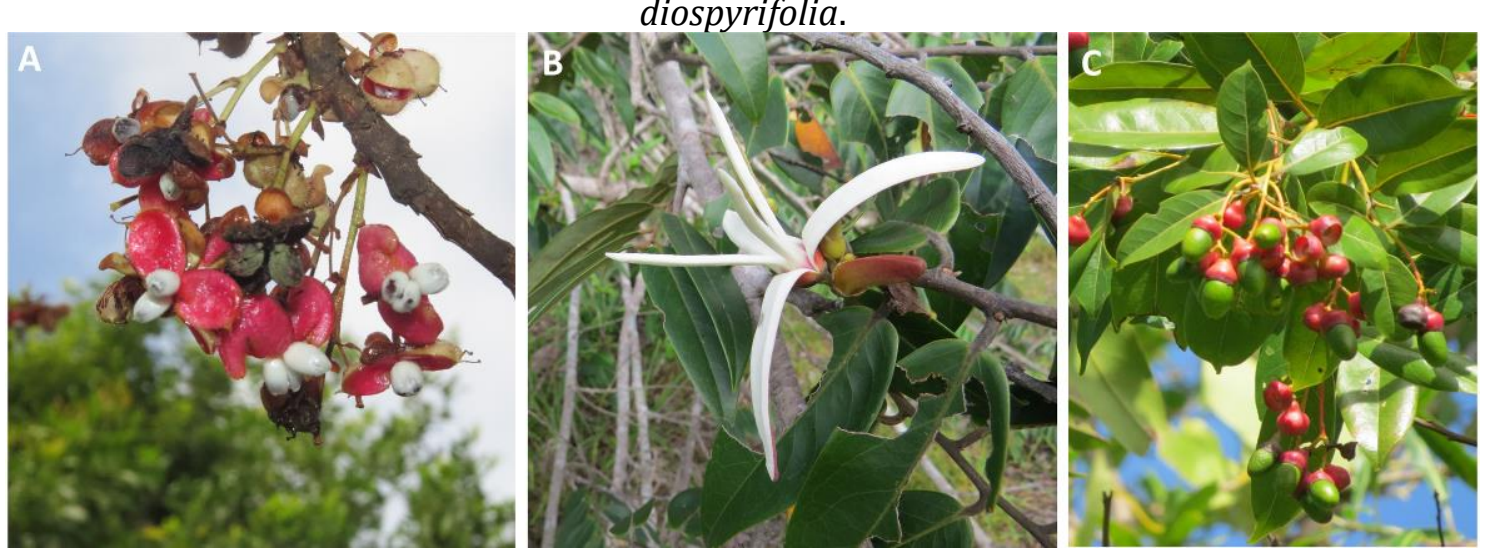

Fonte: Camila Aoki. 
Tabela 2. Parâmetros fitossociológicos das espécies arbóreas inventariadas no Parque Natural Municipal da Lagoa Comprida, Aquidauana, MS. Ordem decrescente do valor de importância. Legenda: $\mathrm{DA}=$ densidade absoluta, $\mathrm{DR}=$ densidade relativa, $\mathrm{FA}=$ frequência absoluta, $\mathrm{FR}=$ frequência relativa, $\mathrm{DoA}=$ dominância absoluta, $\mathrm{DoR}=$ dominância relativa, VI= valor de importância.

\begin{tabular}{|c|c|c|c|c|c|c|c|}
\hline Espécie & DA & DR & FA & FR & DoA & DoR & VI \\
\hline Curatella americana $\mathrm{L}$. & 200 & 11,01 & 50 & 6,32 & 5,03 & 22,36 & 39,68 \\
\hline Xylopia aromatica (Lam.) Mart. & 166,67 & 9,17 & 58,33 & 7,37 & 1,85 & 8,21 & 24,75 \\
\hline Ocotea cf. diospyrifolia (Meisn.) Mez & 150 & 8,26 & 58,33 & 7,37 & 1,46 & 6,49 & 22,12 \\
\hline Cordia glabrata (Mart.) A.DC. & 108,33 & 5,96 & 41,67 & 5,26 & 2,22 & 9,87 & 21,1 \\
\hline Dipteryx alata Vogel & 108,33 & 5,96 & 41,67 & 5,26 & 1,79 & 7,96 & 19,19 \\
\hline Sapium haematospermum Müll.Arg. & 166,67 & 9,17 & 41,67 & 5,26 & 0,91 & 4,06 & 18,5 \\
\hline Machaerium acutifolium Vogel & 83,33 & 4,59 & 50 & 6,32 & 0,86 & 3,8 & 14,7 \\
\hline Acrocomia aculeata (Jacq.) Lodd. ex Mart. & 50 & 2,75 & 25 & 3,16 & 1,85 & 8,2 & 14,11 \\
\hline Morta em pé & 66,67 & 3,67 & 58,33 & 7,37 & 0,37 & 1,65 & 12,69 \\
\hline Vatairea macrocarpa (Benth.) Ducke & 83,33 & 4,59 & 16,67 & 2,11 & 1,29 & 5,72 & 12,41 \\
\hline Tocoyena formosa (Cham. $e$ Schltdl.) K.Schum. & 83,33 & 4,59 & 50 & 6,32 & 0,16 & 0,73 & 11,63 \\
\hline Handroanthus ochraceus (Cham.) Mattos & 100 & 5,5 & 33,33 & 4,21 & 0,32 & 1,41 & 11,13 \\
\hline Astronium urundeuva (M. Allemão) Engl. & 75 & 4,13 & 33,33 & 4,21 & 0,2 & 0,88 & 9,22 \\
\hline Attalea speciosa Mart. ex Spreng. & 8,33 & 0,46 & 8,33 & 1,05 & 1,68 & 7,45 & 8,96 \\
\hline Zanthoxylum hasslerianum (Chodat) Pirani & 58,33 & 3,21 & 16,67 & 2,11 & 0,7 & 3,12 & 8,44 \\
\hline Tapirira guianensis Aubl. & 58,33 & 3,21 & 25 & 3,16 & 0,18 & 0,79 & 7,16 \\
\hline Stryphnodendron adstringens (Mart.) Coville & 41,67 & 2,29 & 25 & 3,16 & 0,1 & 0,46 & 5,91 \\
\hline Zanthoxylum riedelianum Engl. & 33,33 & 1,83 & 16,67 & 2,11 & 0,25 & 1,12 & 5,06 \\
\hline Kielmeyera coriacea Mart. e Zucc. & 25 & 1,38 & 25 & 3,16 & 0,03 & 0,12 & 4,65 \\
\hline Leptolobium elegans Vogel & 25 & 1,38 & 8,33 & 1,05 & 0,2 & 0,88 & 3,3 \\
\hline Enterolobium contortisiliquum (Vell.) Morong & 16,67 & 0,92 & 16,67 & 2,11 & 0,01 & 0,04 & 3,06 \\
\hline Simarouba versicolor A.St.-Hil. & 8,33 & 0,46 & 8,33 & 1,05 & 0,33 & 1,44 & 2,96 \\
\hline Andira cujabensis Benth & 8,33 & 0,46 & 8,33 & 1,05 & 0,26 & 1,17 & 2,68 \\
\hline Solanum paniculatum $\mathrm{L}$. & 25 & 1,38 & 8,33 & 1,05 & 0,03 & 0,11 & 2,54 \\
\hline Cecropia pachystachya Trécul & 8,33 & 0,46 & 8,33 & 1,05 & 0,17 & 0,74 & 2,25 \\
\hline Aegiphila verticillata Vell. & 8,33 & 0,46 & 8,33 & 1,05 & 0,13 & 0,57 & 2,08 \\
\hline Dimorphandra mollis Benth. & 8,33 & 0,46 & 8,33 & 1,05 & 0,06 & 0,27 & 1,78 \\
\hline Aspidosperma sp. & 8,33 & 0,46 & 8,33 & 1,05 & 0,04 & 0,17 & 1,68 \\
\hline Erythroxylum anguifugum Mart. & 8,33 & 0,46 & 8,33 & 1,05 & 0,02 & 0,11 & 1,62 \\
\hline Casearia sylvestris $\mathrm{Sw}$. & 8,33 & 0,46 & 8,33 & 1,05 & 0,01 & 0,05 & 1,56 \\
\hline Duguetia furfuracea (A.St.-Hil.) Saff. & 8,33 & 0,46 & 8,33 & 1,05 & 0,01 & 0,04 & 1,55 \\
\hline Espécie indeterminada & 8,33 & 0,46 & 8,33 & 1,05 & 0,01 & 0,02 & 1,54 \\
\hline Total & 1816,67 & 100 & 791,67 & 100 & 22,52 & 100 & 300 \\
\hline
\end{tabular}


Figura 5. Densidade relativa (DR), frequência relativa (FR), dominância relativa (DoR) e valor de importância das principais espécies registradas no Parque Natural Municipal da Lagoa Comprida, Aquidauana, MS.

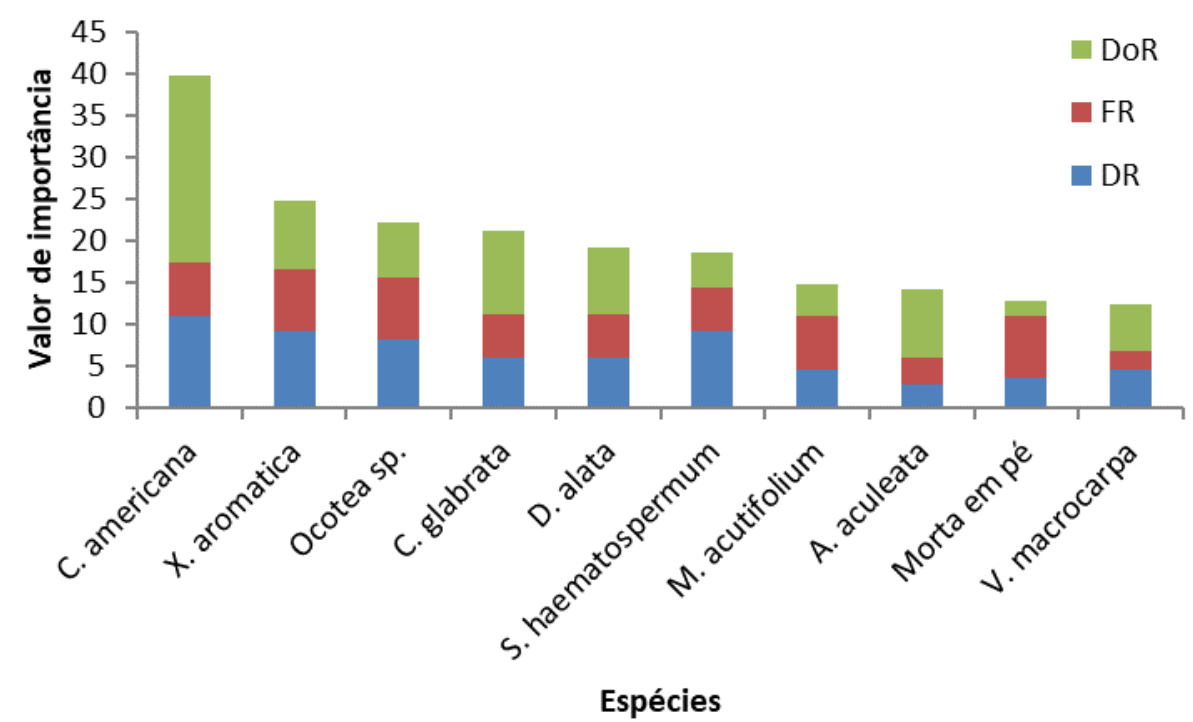

Fonte: Autoria própria.

\subsection{ESPÉCIES AMEAÇADAS DE EXTIINÇÃO}

Segundo Pott $e$ Pott (2003) ainda não há dados suficientes para afirmar se alguma espécie arbórea está realmente ameaçada de extinção no Estado. Entretanto, podem ser consideradas espécies raras em fragmentos florestais do Mato Grosso do Sul: Aspidosperma cylindrocarpa (peroba), A. polyneuron (peroba-rosa) e Balfourodendron riedelianum (pau-mafim) devido à exploração madeireira (POTT; POTT, 2003), A. polyneuron, inclusive, é considerada em perigo de extinção (CARVALHO, 1994 apud POTT; POTT, 2003), entretanto, nenhuma destas espécies foi registrada na área de estudo. Das espécies registradas, nenhuma é considerada endêmica. 0 cumbaru Dipteryx alata encontra-se como vulnerável na lista da IUCN (2020) e a aroeira (Astronium urundeuva) é considerada madeira de lei. As espécies de ipê (Tabebuia spp. e Handroanthus spp.) também são protegidas do corte em vários Estados.

\section{CONSIDERACÕ̃ES FINAIS}

Registramos 218 indivíduos lenhosos, pertencentes a 21 famílias, 30 gêneros e 31 espécies no Parque Natural Municipal da Lagoa Comprida, com indícios de que outras espécies devem ser adicionadas à listagem em caso de continuidade do 
estudo. Estimamos uma densidade de 1453,3 indivíduos/ha e a área basal 18,06 $\mathrm{m}^{2} /$ ha, valores abaixo do esperado, o que provavelmente se deve ao histórico de ocupação e perturbação da área. Nesse sentido, medidas como o cercamento da Unidade de Conservação e projetos de educação ambiental que incluam os moradores do entorno e frequentantes da área devem ser estudadas como medidas de conservação da área.

\section{AGRADECIMENTOS}

O presente trabalho foi realizado com apoio da Universidade Federal de Mato Grosso do Sul - UFMS/MEC - Brasil e da Coordenação de Aperfeiçoamento de Pessoal de Nível Superior (CAPES). Os autores agradecem à Fundação de Apoio ao Desenvolvimento do Ensino, Ciência e Tecnologia do Estado de Mato Grosso do Sul (FUNDECT) pelo apoio aos projetos desenvolvidos pelo grupo de pesquisa "Estudos Integrados em Biodiversidade do Cerrado e Pantanal". Agradecemos à Edivaldo Oliveira de Souza pelo auxílio em campo.

\section{REFERÊNCIAS}

BATTILANI, J.L.; SREMIN-DIAS, E.; SOUZA ALT. Fitossociologia de um trecho da mata ciliar do rio da Prata, Jardim, MS, Brasil. Acta Botanica Brasilica, v. 19, n. 3, p. 597-608, 2005.

BOTREL, R.T.; OLIVEIRA-FILHO, A.T.; RODRIGUES, L.A.; CURI, N. 2002. Influência do solo e topografia sobre as variações da composição florística e estrutura da comunidade arbóreo-arbustiva de uma floresta estacional semidecidual em Ingaí, MG. Revista Brasileira de Botânica, v. 25, n. 2, p. 195-213.

CAVASSAN, O.; CESAR, O.; MARTINS FR. 1984. Fitossociologia da vegetação arbórea da reserva estadual de Bauru, Estado de São Paulo. Revista Brasileira de Botânica, v. 7, n. 2, p. 91-106, 1984.

CHAVES, A. D. C. G.; SANTOS, R. M. S.; SANTOS, J. O.; FERNANDES, A. A.; MARACAJÁ P. B. A importância dos levantamentos florístico e fitossociológico para a conservação e preservação das florestas. Revista ACSA, v. 9, n. 2, p. 42-48, 2013.

FELFILI, J. M.; FILGUEIRAS, T. S.; HARIDASSAN, M.; SILVA-JÚNIOR, M. C.; MENDONÇA, R. C.; REZENDE, A. V. Projeto biogeografia do bioma Cerrado: vegetação e solos. Cadernos de Geociências, v. 12, p.75-166, 1994.

FELFILI, J. M.; SILVA-JUNIOR, M. C.; REZENDE, A. V.; NOGUEIRA, P. E.; WALTER, B. M. T., SILVA, M. A.; ENCINAS, J. I. Comparação florística e 
fitossociológica do cerrado nas chapadas Pratinha e dos Veadeiros. Pp. 6-11. In: L. Leite $e$ C.H. Saito (Eds.). Contribuição ao conhecimento ecológico do cerrado. Ed. Universidade de Brasília. Brasília, DF. 1997.

FELFILI, J. M.; NOGUEIRA, P. E. JÚNIOR, M. C. S.; MARIMON, B. S.; DELITTI, W. B. C. 2002. Composição florística e fitossociologia de um cerrado sentido restrito no município de Água Boa-MT. Acta Botanica Brasilica, v. 16, n.1, p. 103-112.

FELFILI, J. M.; SILVA-JÚNIOR, M. C. A comparative study of cerrado (sensu stricto) vegetation in Central Brazil. Journal of Tropical Ecology, v. 9, p. 277-289, 1993.

GOTELLI, N.J.; COLWELL, R.K. 2001. Quantifying biodiversity: procedures and pitfalls in the measurement and comparison of species richness. Ecol. Lett. v. 4, n. 4, p. 379-391, 2001.

GUEDES-BRUNI R.R.; PESSOA S.V.A.; KURTZ B.C. Florística e estrutura do componente arbustivo-arbóreo de um trecho preservado de floresta montana na Reserva Ecológica de Macaé de Cima. In: LIMA H.C.; GUEDESBRUNI R.R., editores. Serra de Macaé de Cima: Diversidade florística e conservação em Mata Atlântica. Rio de Janeiro: Jardim Botânico do Rio de Janeiro. 1997, v. 1.

IUCN. The IUCN Red List of Threatened Species. Version 2020-1. https://www.iucnredlist.org. Acesso em junho de 2020.

LAMPRECHT, H. Silvicultura en los trópicos. Gottingen: Instituto de Silvicultura de la Universidad de Gottingen. 1986, 335 p.

LEWIS, G.P.; SCHIRE, B.D.; MACKINDER, B.A.; LOCK, J.M. Legumes of the World. Royal Botanic Gardens, Kew. 2005.

LORENZI, H. Árvores brasileiras: Manual de identificação e cultivo de plantas arbóreas nativas do Brasil. Nova odessa: Editora Plantarum. volumes 1 e 2, 2002.

MARTINS, F.R. Estrutura de uma floresta mesófila. Campinas: UNICAMP. 1991, 246 p.

MINISTÉRIO DO MEIO AMBIENTE (MMA). Livro vermelho da fauna brasileira ameaçada de extinção. Machado, A.B.M.; Drummond, G.M.; Paglia, A.P. 1.ed. Brasília, DF, Fundação Biodiversitas. Acesso em: http://www.mma.gov.br, 2008.

MUELLER-DOMBOIS, D.; ELLENBERG, H. Aims and methods of vegetation ecology. New York: Jonh Wiley. 1974, 547p.

PEEL, M. C.; FINLAYSON, B. L.; MCMAHON, T. A. Updated world map of the Köppen Geiger climate classification. Hydrology and Earth System Sciences, v. 11, n. 5, p. 1633-1644, 2007. 
POTT, A.; POTT, V.J. Espécies de Fragmentos Florestais em Mato Grosso do Sul. In: Fragmentação florestal e alternativas de desenvolvimento rural na região Centro-Oeste. (R.B. da Costa, ed.). Universidade Católica Dom Bosco, Campo Grande. 2003, p. 26-52.

POTT. A.; POTT. V.J. 1994. Plantas do Pantanal. Brasília, DF: Embrapa CPAP; Embrapa SPI. 1994, 320 p.

RAMOS, V. S.; DURIGAN, G.; FRANCO, G. A. D. C.; SIQUEIRA, M. F.; RODRIGUES, R. R. Árvores da Floresta Estacional Semidecidual: Guia de identificação de espécies. Ed: Edusp, São Paulo. 2008.

SAMPAIO, A.B.; WALTER, B.M.T.; FELFILI, J.M. 2000. Diversidade e distribuição de espécies arbóreas em duas matas de galeria na micro-bacia do Riacho Fundo, Distrito Federal. Acta Botanica Brasilica, v. 14, n. 2, p. 197-214.

SARTORI, A.L.B.; LIMA, H.C.; QUEIROZ, L.P.; MORIM, M.P.; SOUZA, V.C.; DUTRA, V.F.; BORTOLUZZI, R.L.C.; IGANCI, J.R.V.; FORTUNATO, R.H.; VAZ, A.M.S.F.; SOUZA, E.R. DE; FILARDI, F.L.R.; VALLS, J.F.M.; GARCIA, F.C.P.; FERNANDES, J.M.; MARTINS-DA-SILVA, R.C.V.; PEREZ, A.P.F.; MANSANO, V.F.; MIOTTO, S.T.S.; TOZZI, A.M.G.A.; MEIRELES, J.E.; LIMA, L.C.P. ; OLIVEIRA, M.L.A.A.; FLORES, A.S.; TORKE, B.M.; PINTO, R.B.; LEWIS, G.P.; BARROS, M.J.F.; SCHÜTZ, R.; PENNINGTON, T.; KLITGAARD, B.B.; RANDO, J.G.; SCALON, V.R.; CARDOSO, D.B.O.S.; COSTA, L.C. DA; SILVA, M.J. DA; MOURA, T.M.; BARROS, L.A.V. DE; SILVA, M.C.R.; QUEIROZ, R.T.; CAMARGO, R. A. e LIMA, I.B. Fabaceae. In: Lista de Espécies da Flora do Brasil. Jardim Botânico do Rio de Janeiro. 2014.

SCHIAVO, J.A., M.G. PEREIRA, L.P.M. MIRANDA, A.H. DIAS NETO $e$ A. FONTANA. Caracterização e classificação de solos desenvolvidos de arenitos da formação Aquidauana- MS. Rev. Bras. Ciência do Solo, v. 34, p. 881-889, 2010.

SCHILLING, A.C.; BATISTA, J.L.F. Curva de acumulação de espécies e suficiência amostral em florestas tropicais. Rev. bras. Bot., vol.31, n.1, pp.179-187, 2008.

SCHNEIDER, P.R.; FINGER, C.A.G. Manejo sustentado de floresta inequiâneas heterogêneas. Santa Maria: UFSM. 2000.

SILVA JUNIOR, M.C. $e$ PEREIRA, B.A.S. Mais 100 árvores do Cerrado e Matas de Galeria: guia de campo. Ed. Rede de Sementes do Cerrado, Brasília. 2009.

SILVA JÚNIOR, M.C. 100 Árvores do Cerrado: guia de campo. Ed. Rede de Sementes do. Cerrado. 278p., 2005.

SOUZA, E.P.; S.R.O. MARTINS. Conflitos territoriais no entorno do Parque Natural Municipal da Lagoa Comprida em Aquidauana/ MS. Percurso: Sociedade, Natureza Cultura, v. 11, p. 291-306, 2010.

SOUZA, V. C., LORENZI, H. L. Botânica Sistemática. Nova Odessa: Instituto Plantarum: p. $640,2005$. 


\section{CAPÍtULLO $v$}

\section{FLORISTICA DO ECÓTONO CERRADO-PANTANAL NO MATO GROSSO DO SUL}

DDI: 10.51859/amplla.ecp672.1121-5

Bruna Gardenal Fina ${ }^{1}$

Norton Hayd Rego ${ }^{2}$

Camila Aoki ${ }^{1,3,4}$

${ }^{1}$ Universidade Federal de Mato Grosso do Sul, Campus de Aquidauana, Grupo de Estudos Integrados em Biodiversidade do Cerrado e Pantanal, Rua Oscar Trindade de Barros, 740, Bairro da Serraria, Aquidauana, MS, Brasil, CEP: 79200-000.

${ }^{2}$ Universidade Estadual de Mato Grosso do Sul. Unidade de Aquidauana-MS, Rodovia Graziela Maciel Barroso, km 12, CEP 79200-000, Aquidauana, MS, Brasil, CEP 79200-000.

${ }^{3}$ Universidade Federal de Mato Grosso do Sul, Programa de Pós-Graduação em Recursos Naturais, Faculdade de Engenharias, Arquitetura e Urbanismo e Geografia (FAENG), Av. Costa e Silva, s/n - Cidade Universitária, Campo Grande, MS, Brasil, CEP 79070-900.

${ }^{4}$ Universidade Federal de Mato Grosso do Sul, Programa de Pós-Graduação em Biologia Vegetal, Instituto de Biociências (INBIO), Av. Costa e Silva, s/n - Bairro Universitário, Campo Grande, MS, Brasil, CEP 79070-900.

\section{INTRODUÇÃO}

Mato Grosso do Sul encontra-se numa região estratégica em termos de biodiversidade pois conta com a presença de três biomas, Pantanal a noroeste, Mata Atlântica lato sensu ao sul e o Cerrado, que ocupava mais de 60\% de seu território, restando atualmente menos de 25\% (MINISTÉRIO DO MEIO AMBIENTE, 2009). Sua grande extensão territorial e a presença de diferentes biomas possibilita o contato entre o Cerrado, Chaco, Floresta Chiquitana, Floresta Atlântica e Floresta Amazônica (FARINACCIO et al., 2018). Assim, o Estado agrega em seu território variadas fitofisionomias, como cerrado, cerradão, veredas, matas semidecíduas, matas calcárias, matas de galeria, campos e vegetação aquática (MATO GROSSO DO SUL, 1989).

Apesar de sua localização privilegiada, é um dos Estados brasileiros com menores taxas de coleções botânicas por quilômetro quadrado (PEIXOTO, 2003; SHEPHERD, 2003; ALVES et al., 2017), havendo extensas áreas com baixos ou insignificantes índices de coleta (MARTINELLI; MARTINS, 2010; ALVES et al., 2017). As coletas e confecção de listas de espécies são um primeiro passo para 
acessar a biodiversidade e então fornecer subsídios para o manejo e conservação de espécies e/ou paisagens, além de fornecer informações para análises biogeográficas das espécies.

Dentre as paisagens ainda pouco exploradas no estado, está a Serra de Maracaju que se inicia na parte sul do Estado (Ponta Porã) atravessa a faixa central do território sul-mato-grossense, chegando até a porção norte do estado (Sonora). Nesta região de ecótono entre Cerrado e Pantanal, ainda são encontradas muitas áreas de vegetação nativa, devido principalmente ao seu relevo. Mas segundo o Governo do Estado de Mato Grosso do Sul (2009) é uma das áreas mais ameaçadas no estado considerando a conservação da vegetação. Este trabalho teve o intuito de compilar dados de levantamentos florísticos realizados em diferentes fragmentos de vegetação neste ecótono Cerrado-Pantanal, bem como, complementá-los com dados de coletas pontuais.

\section{METODOLOGIA}

A lista de plantas foi elaborada a partir de levantamentos florísticos realizados pelos autores em diversos fragmentos no ecótono Cerrado-Pantanal, na Serra de Maracaju e entorno (Figura 1) e também com listagens já disponibilizadas em periódicos científicos para essa região (REGO, 2008; FINA et al., 2012; FINA; MONTEIRO, 2013; RAMOS e SARTORI, 2013; ABREU et al., 2015; ZAVALA et al. 2017; OLIVEIRA et al., 2019;). 
Figura 1. Mapa de distribuição de pontos dos estudos incluídos neste levantamento, em verde está o contorno da Serra de Maracaju, Mato Grosso do Sul.
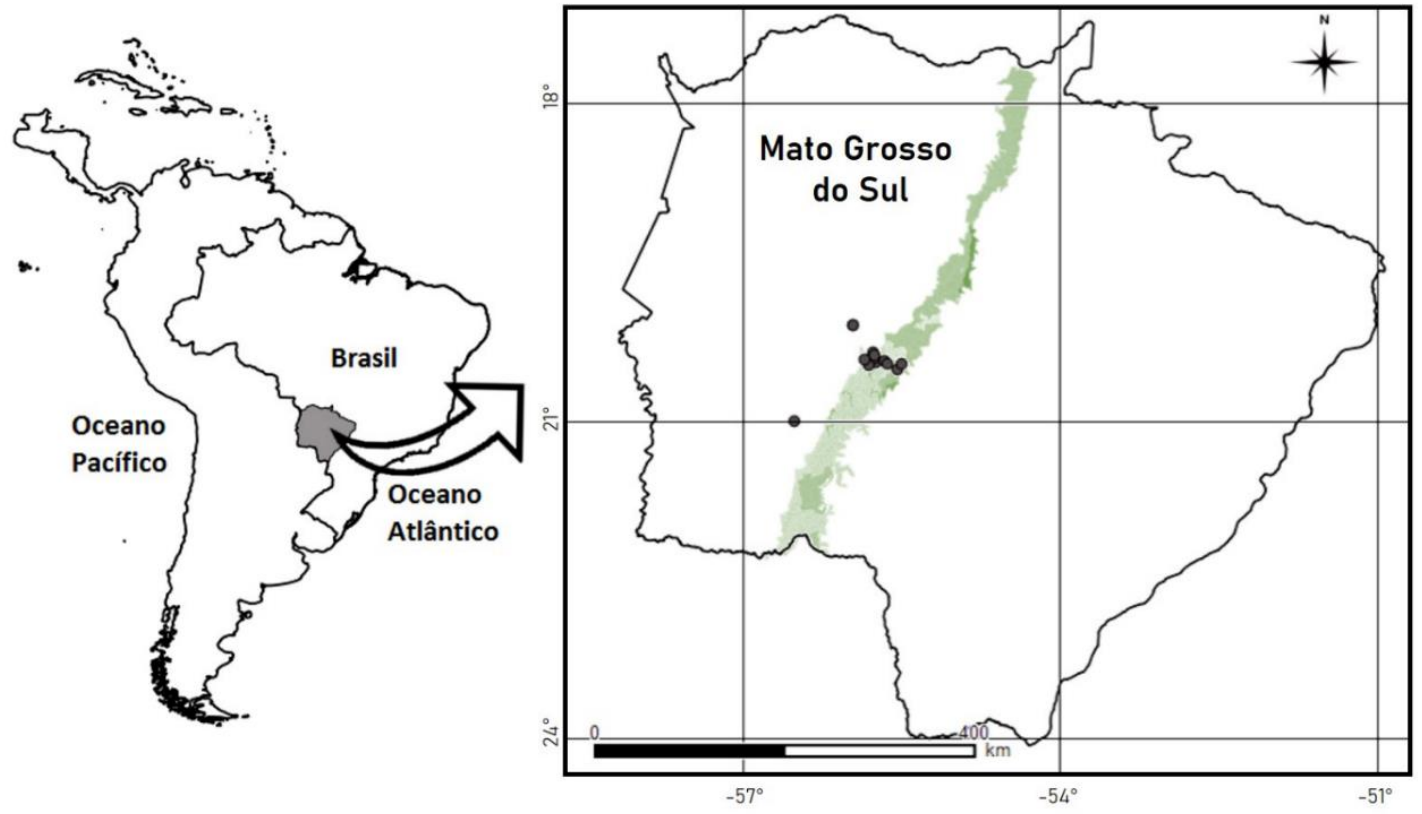

Fonte: Autoria própria.

Foram considerados os componentes arbóreos, arbustivos, sub-arbustivos, herbáceos e lianas. 0 sistema de classificação adotado para famílias foi APG-IV (2016) e os nomes botânicos foram atualizados segundo dados disponíveis no Flora do Brasil 2020 (em construção). Há também na região estudos sobre a Brioflora (YANO; BASTOS, 2004), Pteridoflora (ASSIS; LABIAK, 2009a, 2009b; BARBOSASILVA et al., 2010) e Macrófitas (ROCHA et al., 2007; GOMES; AOKI, 2015), não incluídos na atual revisão.

\section{RESULTADOS E DISCUSSÃO}

Foi registrado um total de 361 espécies, distribuídas em 77 famílias e 242 gêneros (Tabela 1, Figura 2). As famílias mais ricas foram Fabaceae (73 espécies), Malvaceae (16), Rubiaceae (15), Myrtaceae (14) e Melastomataceae (13). Essas famílias apresentam ampla distribuição nas diferentes formações vegetais do Brasil e estão, via de regra, entre as mais ricas em espécies (Figura 3). Fabaceae e Myrtaceae são duas das principais famílias com representantes na flora brasileira (SOUZA et al., 2018), com grande biodiversidade e muitas espécies de importância econômica. Malvaceae, Melastomaceae e Rubiaceae são famílias comuns nas áreas 
de cerrado, apresentando-se com muitas espécies, algumas de uso alimentício, medicinal e/ou ornamental.

Tabela 1. Espécies vegetais com registro para o ecótono Cerrado-Pantanal, Mato Grosso do Sul. Fisionomias de ocorrência: CD - cerradão, CE- cerrado stricto sensu, MC: mata ciliar, MG: mata de galeria, MS: mata estacional semidecidual. Hábitos: Ab - arbustivo, Avarbóreo, $\mathrm{He}$ - herbáceo, $\mathrm{Sb}$ - subarbustivo, Li - liana, Pal - palmeira.

\begin{tabular}{|c|c|c|c|}
\hline \multirow[b]{2}{*}{ Família } & \multirow[b]{2}{*}{ Espécie } & \multicolumn{2}{|l|}{ Fisionomias } \\
\hline & & $\begin{array}{c}\text { de } \\
\text { ocorrência }\end{array}$ & Hábito \\
\hline Alismataceae & Helanthium tenellum (Mart.) Britton & MG & $\mathrm{He}$ \\
\hline Alismataceae & Sagittaria guayanensis Kunth & MG & $\mathrm{He}$ \\
\hline Amaranthaceae & Alternanthera brasiliana (L.) Kuntze & $\mathrm{CE}$ & $\mathrm{Ab}$ \\
\hline Anacardiaceae & Anacardium humile A.St.-Hil. & $\mathrm{CE}$ & $\mathrm{Ab}$ \\
\hline Anacardiaceae & Astronium fraxinifolium Schott & MC, MG, MS & Av \\
\hline Anacardiaceae & Astronium urundeuva (M. Allemão) Engl. & $\begin{array}{c}\mathrm{MC}, \mathrm{CE}, \mathrm{MS}, \\
\mathrm{CD}\end{array}$ & Av \\
\hline Anacardiaceae & Lithraea molleoides (Vell.) Engl. & MC, MG & Av \\
\hline Anacardiaceae & Schinus terebinthifolia Raddi & $\begin{array}{c}\text { CE, MS } \\
\text { CD }\end{array}$ & Av \\
\hline Anacardiaceae & Tapirira guianensis Aubl. & $\begin{array}{c}\text { CE, MS } \\
\text { CD }\end{array}$ & Av \\
\hline Annonaceae & Annona coriacea Mart. & $\begin{array}{c}\mathrm{MC}, \mathrm{CE} \\
\mathrm{CD}\end{array}$ & Av \\
\hline Annonaceae & Annona crassiflora Mart. & CE & $\mathrm{Ab}$ \\
\hline Annonaceae & Annona dioica A.St.-Hil. & $\mathrm{CE}$ & $\mathrm{Ab}$ \\
\hline Annonaceae & Duguetia furfuracea (A.St.-Hil.) Saff. & $\mathrm{CE}$ & $\mathrm{Ab}$ \\
\hline Annonaceae & Unonopsis lindmanii R.E.Fr. & MC, MG & Av \\
\hline Annonaceae & Xylopia aromatica (Lam.) Mart. & $\begin{array}{c}\mathrm{CE}, \mathrm{MG}, \mathrm{MS}, \\
\mathrm{CD}\end{array}$ & Av \\
\hline Apocynaceae & Aspidosperma australe Müll.Arg. & $\mathrm{CE}$ & Av \\
\hline Apocynaceae & Aspidosperma cylindrocarpon Müll.Arg. & $\mathrm{CE}, \mathrm{MG}$ & Av \\
\hline Apocynaceae & Aspidosperma polyneuron Müll.Arg. & MS & Av \\
\hline Apocynaceae & Aspidosperma subincanum Mart. & $\mathrm{CD}, \mathrm{MS}$ & Av \\
\hline Apocynaceae & Aspidosperma tomentosum Mart. e Zucc. & $\begin{array}{c}\text { CE, MS, } \\
\text { CD }\end{array}$ & Av \\
\hline Apocynaceae & Himatanthus obovatus (Müll. Arg.) Woodson & CE, MS & Av \\
\hline Araceae & Philodendron sp & MC & $\mathrm{Li}$ \\
\hline Araceae & Taccarum weddellianum Brongn. ex Schott & MC & $\mathrm{He}$ \\
\hline
\end{tabular}




\begin{tabular}{|c|c|c|c|}
\hline \multirow[b]{2}{*}{ Família } & \multirow[b]{2}{*}{ Espécie } & \multicolumn{2}{|l|}{ Fisionomias } \\
\hline & & $\begin{array}{c}\text { de } \\
\text { ocorrência }\end{array}$ & Hábito \\
\hline Araliaceae & Dendropanax cuneatus (DC.) Decne. e Planch. & CE, MG & $\mathrm{Ab}$ \\
\hline Araliaceae & Schefflera morototoni (Aubl.) Maguire et al. & MS & $\mathrm{Av}$ \\
\hline Arecaceae & Acrocomia aculeata (Jacq.) Lodd. ex Mart. & $\begin{array}{l}\mathrm{MG}, \mathrm{CE} \\
\mathrm{CD}\end{array}$ & Pal \\
\hline Arecaceae & Attalea phalerata Mart. ex Spreng. & $\begin{array}{l}\text { MG, CE, MS, } \\
\quad \mathrm{CD}\end{array}$ & Pal \\
\hline Arecaceae & Syagrus romanzoffiana (Cham.) Glassman & MS, MD & Pal \\
\hline Aristolochiaceae & Aristolochia sp. & $\mathrm{CE}$ & $\mathrm{Li}$ \\
\hline Asteraceae & Baccharis dracunculifolia DC. & CE, MG, MS & $\mathrm{Ab}$ \\
\hline Asteraceae & Centratherum punctatum Cass. & MG & $\mathrm{He}$ \\
\hline Asteraceae & Chromolaena odorata (L.) R.M.King e H.Rob. & MC & $\mathrm{Sb}$ \\
\hline Asteraceae & Chromolaena squalida (DC.) R.M.King e H.Rob. & $\mathrm{CE}$ & $\mathrm{Sb}$ \\
\hline Asteraceae & Elephantopus mollis Kunth & MG & $\mathrm{He}$ \\
\hline Asteraceae & $\begin{array}{l}\text { Gymnanthemum cf. amygdalinum (Delile) } \\
\text { Sch.Bip. ex Walp. }\end{array}$ & CE, MG & $\mathrm{Ab}$ \\
\hline Asteraceae & Lessingianthus scabrifoliatus (Hieron.) H.Rob. & $\mathrm{MC}$ & $\mathrm{Ab}$ \\
\hline Asteraceae & Mikania micrantha Kunth & CE & $\mathrm{Li}$ \\
\hline Asteraceae & Orthopappus angustifolius (Sw.) Gleason & MG & $\mathrm{He}$ \\
\hline Asteraceae & Vernonanthura brasiliana (L.) H. Rob. & MG & $\mathrm{He}$ \\
\hline Asteraceae & Vernonanthura ferruginea (Less.) H.Rob. & CE & $\mathrm{Ab}$ \\
\hline Begoniaceae & Begonia lindmanii Brade & MG & $\mathrm{Ab}$ \\
\hline Bignoniaceae & Cuspidaria sp. & MG & $\mathrm{Li}$ \\
\hline Bignoniaceae & Fridericia caudigera (S.Moore) L.G.Lohmann & MG & $\mathrm{Li}$ \\
\hline Bignoniaceae & Handroanthus heptaphyllus (Vell.) Mattos & CE, MS & $\mathrm{Av}$ \\
\hline Bignoniaceae & $\begin{array}{l}\text { Handroanthus impetiginosus (Mart. Ex DC) } \\
\text { Mattos }\end{array}$ & CE & Av \\
\hline Bignoniaceae & Handroanthus ochraceus (Cham.) Mattos & $\begin{array}{l}\text { CE, MS } \\
\text { CD }\end{array}$ & Av \\
\hline Bignoniaceae & Handroanthus vellosoi (Toledo) Mattos & MS & $\mathrm{Av}$ \\
\hline Bignoniaceae & Jacaranda cuspidifolia Mart. & CE, MG & $\mathrm{Av}$ \\
\hline Bignoniaceae & Jacaranda mutabilis Hassl. & $\mathrm{CE}, \mathrm{CD}$ & $\mathrm{Av}$ \\
\hline Bignoniaceae & $\begin{array}{l}\text { Tabebuia aurea (Silva Manso) Benth. } e \text { Hook.f. } \\
\text { ex S.Moore }\end{array}$ & $\begin{array}{l}\text { CE, MS } \\
\text { CD }\end{array}$ & $\mathrm{Av}$ \\
\hline Bignoniaceae & Tabebuia roseoalba (Ridl.) Sandwith & $\begin{array}{l}\mathrm{CE}, \mathrm{MS} \\
\mathrm{CD}\end{array}$ & $\mathrm{Av}$ \\
\hline
\end{tabular}




\begin{tabular}{|c|c|c|c|}
\hline \multirow[b]{2}{*}{ Família } & \multirow[b]{2}{*}{ Espécie } & \multicolumn{2}{|l|}{ Fisionomias } \\
\hline & & $\begin{array}{c}\text { de } \\
\text { ocorrência }\end{array}$ & Hábito \\
\hline Boraginaceae & Cordia americana (L.) Gottschling e J.S.Mill. & MS & $\mathrm{Av}$ \\
\hline Boraginaceae & Cordia glabrata (Mart.) A.DC. & MC & $\mathrm{Av}$ \\
\hline Boraginaceae & Cordia sellowiana Cham. & MS & $\mathrm{Av}$ \\
\hline Boraginaceae & Cordia trichotoma (Vell.) Arráb. ex Steud. & $\mathrm{CE}$ & $\mathrm{Av}$ \\
\hline Boraginaceae & Varronia polycephala Lam. & MG & $\mathrm{Ab}$ \\
\hline Bromeliaceae & Bromelia balansae Mez & MG & $\mathrm{He}$ \\
\hline Burseraceae & Protium heptaphyllum (Aubl.) Marchand & CE, CD & $\mathrm{Av}$ \\
\hline Calophyllaceae & Kielmeyera rubriflora Cambess & $\mathrm{CE}$ & $\mathrm{Av}$ \\
\hline Cannabaceae & Celtis iguanaea (Jacq.) Sarg. & CE, MG & $\mathrm{Av}$ \\
\hline Cannabaceae & Trema micrantha (L.) Blume & CE, MG & $\mathrm{Av}$ \\
\hline Capparaceae & Crataeva tapia $\mathrm{L}$. & MC & $\mathrm{Av}$ \\
\hline Caryocaraceae & Caryocar brasiliense Cambess. & $\mathrm{CE}$ & $\mathrm{Av}$ \\
\hline Celastraceae & Monteverdia ilicifolia (Mart. ex Reissek) Biral & CE & $\mathrm{Ab}$ \\
\hline Celastraceae & Plenckia populnea Reissek & $\mathrm{CE}$ & $\mathrm{Av}$ \\
\hline Celastraceae & Salacia elliptica (Mart.) G. Don & MG & $\mathrm{Av}$ \\
\hline Chrysobalanaceae & Hirtella glandulosa Spreng. & CE & $\mathrm{Av}$ \\
\hline Chrysobalanaceae & Hirtella gracilipes (Hook.f.) Prance & $\mathrm{CE}$ & $\mathrm{Av}$ \\
\hline Chrysobalanaceae & Licania kunthiana Hook. f. & CE & $\mathrm{Av}$ \\
\hline Combretaceae & Buchenavia tomentosa Eichler & CE, MG, MS & $\mathrm{Av}$ \\
\hline Combretaceae & Combretum discolor Taub. & MC & $\mathrm{Av}$ \\
\hline Combretaceae & Combretum leprosum Mart. & $\begin{array}{c}\mathrm{CE}, \mathrm{MG}, \mathrm{MS}, \\
\mathrm{CD}\end{array}$ & $\mathrm{Ab}$ \\
\hline Combretaceae & Combretum rotundifolium Rich. & CE, MG & $\mathrm{Av}$ \\
\hline Combretaceae & Terminalia argentea Mart. e Zucc. & $\begin{array}{c}\text { CE, MS } \\
\text { CD }\end{array}$ & $\mathrm{Av}$ \\
\hline Combretaceae & Terminalia brasiliensis (Cambess.) Eichler & $\mathrm{CE}, \mathrm{CD}$ & $\mathrm{Av}$ \\
\hline Combretaceae & Terminalia fagifolia Mart. & $\mathrm{CE}$ & $\mathrm{Av}$ \\
\hline Combretaceae & Terminalia glabrescens Mart. & $\mathrm{CE}$ & $\mathrm{Av}$ \\
\hline Commelinaceae & Commelina erecta $\mathrm{L}$. & MG & $\mathrm{He}$ \\
\hline Connaraceae & Connarus suberosus Planch. & $\mathrm{CE}$ & $\mathrm{Av}$ \\
\hline Crhysobalanaceae & Couepia grandiflora (Mart. e Zucc.) Benth. & MS & $\mathrm{Av}$ \\
\hline Cyperaceae & Cyperus brasiliensis (Kunth) Bauters & MG & $\mathrm{He}$ \\
\hline Cyperaceae & Cyperus brevifolius (Rottb.) Endl. ex Hassk. & MG & $\mathrm{He}$ \\
\hline Cyperaceae & Cyperus friburgensis Boeckeler & MG & $\mathrm{He}$ \\
\hline Cyperaceae & Cyperus haspan L. & MG & $\mathrm{He}$ \\
\hline
\end{tabular}




\begin{tabular}{|c|c|c|c|}
\hline & & Fisionomias & \\
\hline Família & Espécie & $\begin{array}{c}\text { de } \\
\text { ocorrência }\end{array}$ & Hábito \\
\hline Cyperaceae & Cyperus lanceolatus Poir. & MG & $\mathrm{He}$ \\
\hline Cyperaceae & Cyperus luzulae (L.) Retz. & MG & $\mathrm{He}$ \\
\hline Cyperaceae & Cyperus odoratus L. & MG & $\mathrm{He}$ \\
\hline Cyperaceae & Cyperus schomburgkianus Nees & MG & $\mathrm{He}$ \\
\hline Cyperaceae & Cyperus sellowianus (Kunth) T.Koyama & MG & $\mathrm{He}$ \\
\hline Cyperaceae & Cyperus surinamensis Rottb. & MG & $\mathrm{He}$ \\
\hline Cyperaceae & Eleocharis filiculmis Kunth & MG & $\mathrm{He}$ \\
\hline Dilleniaceae & Curatella americana $\mathrm{L}$. & CE, CD & $\mathrm{Av}$ \\
\hline Dilleniaceae & Davilla elliptica A.St.-Hil. & $\begin{array}{l}\text { CE, MS } \\
\text { CD }\end{array}$ & $\mathrm{Ab}$ \\
\hline Dilleniaceae & Doliocarpus dentatus (Aubl.) Standl. & CE, MG & $\mathrm{Li}$ \\
\hline Ebenaceae & Diospyros lasiocalyx (Mart.) B.Walln. & CE, MG, MS & Av \\
\hline Ebenaceae & Diospyros obovata Jacq. & MG & Av \\
\hline Elaeocarpaceae & Sloanea guianensis (Aubl.) Benth. & MG & Av \\
\hline Eriocaulaceae & Syngonanthus caulescens (Poir) Ruhland & MG & $\mathrm{He}$ \\
\hline Eriocaulaceae & Syngonanthus gracilis (Bong) Ruhland & MG & $\mathrm{He}$ \\
\hline Erythroxylaceae & Erythroxylum deciduum A.St.-Hil. & $\begin{array}{l}\text { CE, MS } \\
\text { CD }\end{array}$ & $\mathrm{Ab}$ \\
\hline Erythroxylaceae & Erythroxylum suberosum A. St.-Hil. & $\mathrm{CE}, \mathrm{CD}$ & $\mathrm{Ab}$ \\
\hline Euphorbiaceae & Acalypha communis Müll.Arg. & MG & $\mathrm{Ab}$ \\
\hline Euphorbiaceae & $\begin{array}{l}\text { Adelia membranifolia (Müll. Arg.) Chodat } e \\
\text { Hassl. }\end{array}$ & MC & $\mathrm{Ab}$ \\
\hline Euphorbiaceae & Alchornea castaneifolia (Willd.) A. Juss. & $\mathrm{MC}$ & $\mathrm{Ab}$ \\
\hline Euphorbiaceae & Croton macrobothrys Baill. & CE, MG & Av \\
\hline Euphorbiaceae & Croton piptocalyx Müll.Arg. & MS & $\mathrm{Av}$ \\
\hline Euphorbiaceae & Croton urucurana Baill. & CE, MG & Av \\
\hline Euphorbiaceae & Jatropha elliptica (Pohl) Oken & $\mathrm{CE}$ & $\mathrm{Ab}$ \\
\hline Euphorbiaceae & $\begin{array}{l}\text { Pleradenophora membranifolia (Müll. Arg.) } \\
\text { Esser } e \text { A. L. Melo MC Ab }\end{array}$ & MS & Av \\
\hline Euphorbiaceae & Sapium haematospermum Müll.Arg. & CE, MG & Av \\
\hline Euphorbiaceae & Sapium obovatum Klotzsch ex Müll.Arg. & MG & Av \\
\hline Euphorbiaceae & Sebastiania brasiliensis Spreng. & CE, MG & $\mathrm{Ab}$ \\
\hline Fabaceae & Acacia polyphylla D.C. & CE, MG & $\mathrm{Av}$ \\
\hline Fabaceae & Acosmium cardenasii H.S.Irwin $e$ Arroyo & MS & Av \\
\hline Fabaceae & Albizia niopoides (Spruce ex Benth.) Burkart & $\mathrm{CE}, \mathrm{CD}$ & $\mathrm{Av}$ \\
\hline
\end{tabular}




\begin{tabular}{|c|c|c|c|}
\hline \multirow[b]{2}{*}{ Família } & \multirow[b]{2}{*}{ Espécie } & \multicolumn{2}{|l|}{ Fisionomias } \\
\hline & & $\begin{array}{c}\text { de } \\
\text { ocorrência }\end{array}$ & Hábito \\
\hline Fabaceae & Albizia polycephala (Benth.) Killip ex Record & CE, MS & $\mathrm{Av}$ \\
\hline Fabaceae & Anadenanthera colubrina (Vell.) Brenan & CE, MG, MS & $\mathrm{Av}$ \\
\hline Fabaceae & $\begin{array}{l}\text { Anadenanthera colubrina var. cebil (Griseb.) } \\
\text { Altschul }\end{array}$ & $\mathrm{CE}, \mathrm{CD}$ & $\mathrm{Av}$ \\
\hline Fabaceae & $\begin{array}{l}\text { Anadenanthera peregrina var. falcata (Benth.) } \\
\text { Altschul }\end{array}$ & $\begin{array}{l}\text { CE, MG, MS, } \\
\text { CD }\end{array}$ & $\mathrm{Av}$ \\
\hline Fabaceae & Andira cujabensis Benth. & CE, CD & $\mathrm{Av}$ \\
\hline Fabaceae & Andira fraxinifolia Benth. & MG & $\mathrm{Av}$ \\
\hline Fabaceae & Andira inermis (W.Wright) DC. & MG & $\mathrm{Av}$ \\
\hline Fabaceae & Bauhinia cheilantha (Bong.) Steud. & CE, MG & $\mathrm{Ab}$ \\
\hline Fabaceae & Bauhinia forficata Link & CE, MS & $\mathrm{Ab}$ \\
\hline Fabaceae & Bauhinia longifolia (Bong.) Steud. & CE, MG, MS & $\mathrm{Av}$ \\
\hline Fabaceae & Bauhinia mollis (Bong.) D. Dietr & CE & $\mathrm{Ab}$ \\
\hline Fabaceae & Bauhinia pulchella Benth. & MS, CD & $\mathrm{Ab}$ \\
\hline Fabaceae & Bauhinia rufa (Bong.) Steud. & $\begin{array}{l}\text { CE, MS } \\
\text { CD }\end{array}$ & $\mathrm{Ab}$ \\
\hline Fabaceae & Bauhinia ungulata $\mathrm{L}$. & CE, MG & $\mathrm{Ab}$ \\
\hline Fabaceae & Bowdichia virgilioides Kunth & $\begin{array}{l}\text { CE, MS } \\
\text { CD }\end{array}$ & Av \\
\hline Fabaceae & Calopogonium caeruleum (Benth.) C.Wright & MG & $\mathrm{He}$ \\
\hline Fabaceae & Chloroleucon tortum (Mart.) Pittier & MC & $\mathrm{Av}$ \\
\hline Fabaceae & Copaifera langsdorffii Desf. & $\mathrm{CE}, \mathrm{MS}, \mathrm{CD}$ & $\mathrm{Av}$ \\
\hline Fabaceae & Copaifera martii Hayne & CE, MG & $\mathrm{Av}$ \\
\hline Fabaceae & Cratylia sp. & CE, MG & $\mathrm{Ab}$ \\
\hline Fabaceae & $\begin{array}{l}\text { Dahlstedtia cf. muehlbergiana (Hassl.) M.J.Silva } \\
\text { e A.M.G. Azevedo }\end{array}$ & MG & $\mathrm{Ab}$ \\
\hline Fabaceae & Dalbergia miscolobium Benth. & $\mathrm{CE}, \mathrm{CD}$ & $\mathrm{Av}$ \\
\hline Fabaceae & Delonix regia (Bojer ex Hook.) Raf. & MC & $\mathrm{Av}$ \\
\hline Fabaceae & Desmodium affine Schltdl & MG & $\mathrm{Sb}$ \\
\hline Fabaceae & Dimorphandra mollis Benth. & CE, MS & $\mathrm{Av}$ \\
\hline Fabaceae & Dipteryx alata Vogel & $\mathrm{CE}, \mathrm{CD}$ & $\mathrm{Av}$ \\
\hline Fabaceae & Diptychandra aurantiaca Tul. & $\begin{array}{l}\text { CE, MS } \\
\text { CD }\end{array}$ & $\mathrm{Av}$ \\
\hline Fabaceae & Erythrina mulungu Mart & MS & $\mathrm{Av}$ \\
\hline Fabaceae & Geoffroea spinosa Jacq. & MS & $\mathrm{Av}$ \\
\hline
\end{tabular}




\begin{tabular}{|c|c|c|c|}
\hline \multirow[b]{2}{*}{ Família } & \multicolumn{3}{|c|}{ Fisionomias } \\
\hline & Espécie & $\begin{array}{c}\text { de } \\
\text { ocorrência }\end{array}$ & Hábito \\
\hline Fabaceae & Guibourtia hymenaeifolia (Moric.) J. Léonard & MC & $\mathrm{Av}$ \\
\hline Fabaceae & Holocalyx balansae Micheli & MS & $\mathrm{Av}$ \\
\hline Fabaceae & Hymenaea courbaril L. & $\begin{array}{l}\text { CE, MS } \\
\text { CD }\end{array}$ & $\mathrm{Av}$ \\
\hline Fabaceae & Hymenaea stigonocarpa Mart. ex Hayne & CE, CD & $\mathrm{Av}$ \\
\hline Fabaceae & Indigofera hirsuta $\mathrm{L}$. & CE & $\mathrm{He}$ \\
\hline Fabaceae & Indigofera suffruticosa Mill. & CE & $\mathrm{He}$ \\
\hline Fabaceae & Inga laurina (Sw.) Willd & MS & $\mathrm{Av}$ \\
\hline Fabaceae & Inga vera Willd. & MG, MS & $\mathrm{Av}$ \\
\hline Fabaceae & Leptolobium elegans Vogel & MS, CD & $\mathrm{Av}$ \\
\hline Fabaceae & Leucaena leucocephala (Lam.) de Wit & MC & Av \\
\hline Fabaceae & $\begin{array}{l}\text { Lonchocarpus cultratus (Vell.) A.M.G.Azevedo } e \\
\text { H.C. Lima MD }\end{array}$ & $\mathrm{Av}$ & \\
\hline Fabaceae & Lonchocarpus sericeus (Poir.) Kunth ex DC. & MC & Av \\
\hline Fabaceae & Machaerium acutifolium Vog. & CE, MS & $\mathrm{Av}$ \\
\hline Fabaceae & Machaerium amplum Benth. & CE, MG & $\mathrm{Av}$ \\
\hline Fabaceae & Machaerium hirtum (Vell.) Stellfeld & CE & Av \\
\hline Fabaceae & Machaerium stipitatum Vogel & CE, CD & $\mathrm{Av}$ \\
\hline Fabaceae & $\begin{array}{l}\text { Macroptilium atropurpureum (Sessé } e \text { Moc. ex } \\
\text { DC.) Urb. }\end{array}$ & MG & $\mathrm{He}$ \\
\hline Fabaceae & Mimosa caesalpiniifolia Benth. & MG & $\mathrm{Ab}$ \\
\hline Fabaceae & Mimosa polycarpa Kunth & CE, MG & $\mathrm{Ab}$ \\
\hline Fabaceae & Myrocarpus venezuelensis Rudd & MG & $\mathrm{Av}$ \\
\hline Fabaceae & Myroxylon peruiferum L.f. & MS & $\mathrm{Av}$ \\
\hline Fabaceae & Peltogyne confertiflora (Mart. Ex Hayne) Benth. & $\mathrm{CE}$ & $\mathrm{Av}$ \\
\hline Fabaceae & Peltophorum dubium (Spreng.) Taub. & CE, MG & $\mathrm{Av}$ \\
\hline Fabaceae & Plathymenia reticulata Benth. & $\mathrm{CE}, \mathrm{CD}$ & $\mathrm{Av}$ \\
\hline Fabaceae & Platypodium elegans Vogel & $\begin{array}{l}\text { CE, MG } \\
\text { CD }\end{array}$ & $\mathrm{Av}$ \\
\hline Fabaceae & Prosopis rubriflora Hassler. & MG & $\mathrm{Ab}$ \\
\hline Fabaceae & Pterocarpus sp. & MG & $\mathrm{Av}$ \\
\hline Fabaceae & Pterodon emarginatus Vogel & $\mathrm{CE}, \mathrm{CD}$ & $\mathrm{Av}$ \\
\hline Fabaceae & Pterogyne nitens Tul. & CE & $\mathrm{Av}$ \\
\hline Fabaceae & Samanea saman (Jacq.) Merr. & CE, MG & $\mathrm{Av}$ \\
\hline
\end{tabular}




\begin{tabular}{|c|c|c|c|}
\hline \multirow[b]{2}{*}{ Família } & \multirow[b]{2}{*}{ Espécie } & \multicolumn{2}{|l|}{ Fisionomias } \\
\hline & & $\begin{array}{c}\text { de } \\
\text { ocorrência }\end{array}$ & Hábito \\
\hline Fabaceae & $\begin{array}{l}\text { Samanea tubulosa (Benth.) Barneby e J.W. } \\
\text { Grimes }\end{array}$ & $\mathrm{CE}$ & $\mathrm{Av}$ \\
\hline Fabaceae & Senegalia polyphylla (DC.) Britton $e$ Rose & $\mathrm{CE}$ & Av \\
\hline Fabaceae & Senna alata (L.) Roxb. & MG & $\mathrm{Ab}$ \\
\hline Fabaceae & Senna occidentalis (L.) Link. & $\mathrm{CE}$ & Av \\
\hline Fabaceae & Senna velutina (Vog.) Irwin $e$ Barneby & $\mathrm{CE}$ & Av \\
\hline Fabaceae & Stryphnodendron adstringens (Mart.) Coville & MS & Av \\
\hline Fabaceae & Stryphnodendron rotundifolium Mart. & $\mathrm{CE}$ & Av \\
\hline Fabaceae & Sweetia fruticosa Spreng. & MD & Av \\
\hline Fabaceae & Tachigali aurea Tul & MS & Av \\
\hline Fabaceae & Tachigali vulgaris L.G.Silva $e$ H.C.Lima & $\mathrm{CE}, \mathrm{CD}$ & Av \\
\hline Fabaceae & Vatairea macrocarpa (Benth.) Ducke & $\mathrm{CE}$ & Av \\
\hline Hypericaceae & Vismia guianensis (Aubl.) Choisy & MG & $\mathrm{Av}$ \\
\hline Lamiaceae & Hyptis radicans (Pohl) Harley e J.F.B. Pastore & $\mathrm{CE}$ & $\mathrm{He}$ \\
\hline Lamiaceae & Aegiphila vitelliniflora Walp. & MG & Av \\
\hline Lamiaceae & $\begin{array}{l}\text { Cantinoa mutabilis (Rich.) Harley } e \\
\text { J.F.B.Pastore }\end{array}$ & MG & $\mathrm{He}$ \\
\hline Lamiaceae & Vitex суmosa Bertero ex Spreng. & MC & Av \\
\hline Lauraceae & Nectandra membranacea (Sw.) Griseb. & $\mathrm{CE}$ & Av \\
\hline Lauraceae & Ocotea diospyrifolia (Meisn.) Mez & $\mathrm{CE}, \mathrm{MG}$ & Av \\
\hline Lauraceae & Ocotea velloziana (Meissn.) Mez & CE, MG & Av \\
\hline Lecythidaceae & Cariniana legalis (Mart.) Kuntze & MS & Av \\
\hline Loganiaceae & Strychnos pseudoquina A.St.-Hil. & MG, CD & $\mathrm{Ab}$ \\
\hline Lythraceae & Cuphea melvilla Lindl. & MC & $\mathrm{He}$ \\
\hline Lythraceae & Lafoensia pacari A. St.-Hil. & $\begin{array}{c}\mathrm{CE}, \mathrm{MG}, \mathrm{MS}, \\
\mathrm{CD}\end{array}$ & $\mathrm{Av}$ \\
\hline Malpighiaceae & Banisteriopsis laevifolia (A. Juss) B. Gates & $\mathrm{CE}$ & $\mathrm{Ab}$ \\
\hline Malpighiaceae & Bunchosia paraguariensis Nield & $\mathrm{CE}, \mathrm{MG}$ & Av \\
\hline Malpighiaceae & Byrsonima basiloba A. Juss. & $\mathrm{CE}$ & $\mathrm{Ab}$ \\
\hline Malpighiaceae & Byrsonima coccolobifolia Kunth & $\mathrm{CE}, \mathrm{CD}$ & Av \\
\hline Malpighiaceae & Byrsonima crassifolia (L.) Kunth. & CE, MG & $\mathrm{Ab}$ \\
\hline Malpighiaceae & Byrsonima verbascifolia (L.) DC. & CE, CD & $\mathrm{Ab}$ \\
\hline Malpighiaceae & Heteropterys sp. & $\mathrm{CE}$ & $\mathrm{Li}$ \\
\hline Malpighiaceae & $\begin{array}{l}\text { Mascagnia benthamiana } \quad \text { (Griseb.) } \\
\text { W.R.Anderson }\end{array}$ & $\mathrm{CE}$ & $\mathrm{Li}$ \\
\hline
\end{tabular}




\begin{tabular}{|c|c|c|c|}
\hline \multirow[b]{2}{*}{ Família } & \multirow[b]{2}{*}{ Espécie } & \multicolumn{2}{|l|}{ Fisionomias } \\
\hline & & $\begin{array}{c}\text { de } \\
\text { ocorrência }\end{array}$ & Hábito \\
\hline Malpighiaceae & Niedenzuella stannea (Griseb.) W.R.Anderson & $\mathrm{CE}$ & $\mathrm{Li}$ \\
\hline Malpighiaceae & Peixotoa cordistipula A. Juss. & CE & $\mathrm{Li}$ \\
\hline Malvaceae & Apeiba tibourbou Aubl. & $\begin{array}{l}\mathrm{CE}, \mathrm{MG} \\
\mathrm{CD}\end{array}$ & Av \\
\hline Malvaceae & $\begin{array}{l}\text { Bastardiopsis densiflora (Hook. e Arn.) Hassl. } \\
\text { MC }\end{array}$ & MC & $\mathrm{Ab}$ \\
\hline Malvaceae & Eriotheca gracilipes (K.Schum.) A.Robyns & CE & Av \\
\hline Malvaceae & Guazuma ulmifolia Lam. & $\begin{array}{l}\mathrm{CE}, \mathrm{MG}, \mathrm{MS}, \\
\mathrm{CD}\end{array}$ & $\mathrm{Av}$ \\
\hline Malvaceae & Helicteres guazumifolia Kunth & CE, MG & Av \\
\hline Malvaceae & Helicteres Ihotzkyana (Schott $e$ Endl.) K.Schum. & $\mathrm{CE}$ & $\mathrm{Ab}$ \\
\hline Malvaceae & Luehea cf. candicans Mart. e Zucc. & CE & $\mathrm{Ab}$ \\
\hline Malvaceae & Luehea grandiflora Mart. e Zucc. & $\begin{array}{l}\text { CE, MG, MS, } \\
\text { CD }\end{array}$ & Av \\
\hline Malvaceae & Luehea paniculata Mart. e Zucc. & CE, MG, MS & Av \\
\hline Malvaceae & Pseudobombax longiflorum (Mart.) A.Robyns & CE, MS & Av \\
\hline Malvaceae & Pseudobombax tomentosum (Mart.) A.Robyns & CE, MG, MS & $\mathrm{Av}$ \\
\hline Malvaceae & Sterculia apetala (Jacq.) H.Karst. & $\mathrm{CE}, \mathrm{MC}$ & $\mathrm{Av}$ \\
\hline Malvaceae & Sterculia striata A. St.-Hil. $e$ Naudin & CE & Av \\
\hline Malvaceae & Triumphetta sp. & MG & $\mathrm{He}$ \\
\hline Malvaceae & Urena lobata L. & CE & $\mathrm{He}$ \\
\hline Malvaceae & Waltheria indica $\mathrm{L}$. & $\mathrm{CE}$ & $\mathrm{He}$ \\
\hline Marcgraviaceae & Norantea guianensis Aubl & $\mathrm{CE}$ & $\mathrm{Ab}$ \\
\hline Mayacaceae & Mayaca sellowiana Kunt. & MG & $\mathrm{He}$ \\
\hline Melastomataceae & Clidemia biserrata DC & MG & $\mathrm{Ab}$ \\
\hline Melastomataceae & Desmoscelis villosa (Aubl.) Naudin & MG & $\mathrm{He}$ \\
\hline Melastomataceae & Miconia albicans (Sw.) Triana & $\begin{array}{l}\mathrm{CE}, \mathrm{MG} \\
\mathrm{CD}\end{array}$ & $\mathrm{Ab}$ \\
\hline Melastomataceae & Miconia burchellii Triana & CE, MG & $\mathrm{Ab}$ \\
\hline Melastomataceae & Miconia cf. calvescens DC. & CE & $\mathrm{Ab}$ \\
\hline Melastomataceae & Miconia chamissois Naudin & MG & $\mathrm{Ab}$ \\
\hline Melastomataceae & Miconia fallax DC. & CE, MG & $\mathrm{Ab}$ \\
\hline Melastomataceae & Miconia prasina (Sw.) DC. & MG & $\mathrm{He}$ \\
\hline Melastomataceae & Mouriri elliptica Mart. & $\mathrm{CD}$ & $\mathrm{Ab}$ \\
\hline Melastomataceae & Mouriri guianensis Aubl. & CE, CD & $\mathrm{Ab}$ \\
\hline
\end{tabular}




\begin{tabular}{|c|c|c|c|}
\hline \multirow[b]{2}{*}{ Família } & \multirow[b]{2}{*}{ Espécie } & \multicolumn{2}{|l|}{ Fisionomias } \\
\hline & & $\begin{array}{c}\text { de } \\
\text { ocorrência }\end{array}$ & Hábito \\
\hline Melastomataceae & Pterolepis glomerata (Rottb.) Miq. & MG & $\mathrm{He}$ \\
\hline Melastomataceae & Rhynchanthera dichotoma (Desr.) DC. & $\mathrm{CE}$ & $\mathrm{He}$ \\
\hline Melastomataceae & Rhynchanthera novemnervia DC. & MG & $\mathrm{Sb}$ \\
\hline Meliaceae & Cabralea canjerana (Vell.) Mart. & $\mathrm{CE}, \mathrm{CD}$ & $\mathrm{Av}$ \\
\hline Meliaceae & Cedrela fissilis Vell. & $\begin{array}{c}\text { CE, MG } \\
\text { CD }\end{array}$ & $\mathrm{Av}$ \\
\hline Meliaceae & Cedrela odorata L. & MG & $\mathrm{Av}$ \\
\hline Meliaceae & Guarea guidonia (L.) Sleumer & CE, MG & $\mathrm{Av}$ \\
\hline Meliaceae & Guarea kunthiana A.Juss. & MG & $\mathrm{Av}$ \\
\hline Meliaceae & Trichilia catigua A. Juss. & MD, MS & $\mathrm{Av}$ \\
\hline Meliaceae & Trichilia elegans A.Juss & MG & $\mathrm{Ab}$ \\
\hline Meliaceae & Trichilia hirta L. & MG & $\mathrm{Ab}$ \\
\hline Meliaceae & Trichilia pallida Sw. & MG & $\mathrm{Av}$ \\
\hline Meliaceae & Trichilia silvatica C. DC. & MS & $\mathrm{Av}$ \\
\hline Menispermaceae & Abuta grandifolia (Mart.) Sandwith & CE, MG & $\mathrm{Av}$ \\
\hline Menispermaceae & Odontocarya tamoides (DC.) Miers & CE, MG & $\mathrm{Li}$ \\
\hline Mettniusaceae & Emmotum nitens (Benth.) Miers & CE, MG & $\mathrm{Ab}$ \\
\hline Moraceae & Brosimum gaudichaudii Trécul & MG & $\mathrm{Av}$ \\
\hline Moraceae & Ficus dendrocida Kunth & MS & $\mathrm{Av}$ \\
\hline Moraceae & Ficus enormis Mart. ex Miq. & MC, MG & $\mathrm{Av}$ \\
\hline Moraceae & Ficus guaranitica Chodat & MD, MS & $\mathrm{Av}$ \\
\hline Moraceae & Ficus obtusifolia Kunth & MS & $\mathrm{Av}$ \\
\hline Moraceae & Ficus pertusa L.f. & MG & $\mathrm{Av}$ \\
\hline Moraceae & Maclura tinctoria (L.) D. Donex Steud. & MD, MS & $\mathrm{Av}$ \\
\hline Moraceae & Sorocea sprucei (Baill.) J.F. Macbr. & CE, MG & $\mathrm{Ab}$ \\
\hline Myrtaceae & Campomanesia pubescens (Mart. ex DC.) O.Berg & CE & $\mathrm{Ab}$ \\
\hline Myrtaceae & Eugenia aurata O.Berg. & $\begin{array}{c}\text { CE, MS } \\
\text { CD }\end{array}$ & $\mathrm{Ab}$ \\
\hline Myrtaceae & Eugenia biflora (L.) DC. & CE, MG & $\mathrm{Ab}$ \\
\hline Myrtaceae & Eugenia bimarginata DC. & CE & $\mathrm{Ab}$ \\
\hline Myrtaceae & Eugenia egensis DC. & CE, MG & $\mathrm{Ab}$ \\
\hline Myrtaceae & Eugenia francavilleana O.Berg & CE, MG & $\mathrm{Ab}$ \\
\hline Myrtaceae & Eugenia myrcianthes Nied. & MD, MS & $\mathrm{Ab}$ \\
\hline Myrtaceae & Myrcia laruotteana Cambess. & MG & $\mathrm{Ab}$ \\
\hline Myrtaceae & Myrcia splendens (Sw.) DC. & $\mathrm{CE}$ & $\mathrm{Ab}$ \\
\hline
\end{tabular}




\begin{tabular}{|c|c|c|c|}
\hline \multirow[b]{2}{*}{ Família } & \multirow[b]{2}{*}{ Espécie } & \multicolumn{2}{|l|}{ Fisionomias } \\
\hline & & $\begin{array}{c}\text { de } \\
\text { ocorrência }\end{array}$ & Hábito \\
\hline Myrtaceae & Myrciaria floribunda (H.West ex Willd.) O.Berg & $\mathrm{CE}, \mathrm{MG}$ & $\mathrm{Ab}$ \\
\hline Myrtaceae & Psidium guajava $\mathrm{L}$. & MC & $\mathrm{Ab}$ \\
\hline Myrtaceae & Psidium guienense $\mathrm{Sw}$ & $\mathrm{CE}$ & $\mathrm{Ab}$ \\
\hline Myrtaceae & Psidium sartorianum (O.Berg) Nied. & MD & $\mathrm{Ab}$ \\
\hline Myrtaceae & Syzygium cumini (L.) Skeels & CE, MG & Av \\
\hline Nyctaginaceae & Guapira areolata (Heimerl) Lundell. & MG & Av \\
\hline Nyctaginaceae & Guapira hirsuta (Choisy) Lundell & MS, MC & $\mathrm{Av}$ \\
\hline Nyctaginaceae & Guapira noxia (Netto) Lundell & CE, CD & Av \\
\hline Nyctaginaceae & Neea hermaphrodita S. Moore & CE, MG & Av \\
\hline Ochnaceae & Ouratea castaneifolia (DC.) Engl. & CE, MG & Av \\
\hline Ochnaceae & Sauvagesia racemosa A.St.-Hil. & MG & $\mathrm{He}$ \\
\hline Oleaceae & $\begin{array}{l}\text { Priogymnanthus hasslerianus (Chodat) } \\
\text { P.S.Green }\end{array}$ & MD, CD & $\mathrm{Av}$ \\
\hline Onagraceae & Ludwigia lagunae (Morong) H.Hara & MG & $\mathrm{He}$ \\
\hline Onagraceae & Ludwigia nervosa (Poir.) H.Hara & MC & $\mathrm{He}$ \\
\hline Onagraceae & Ludwigia tomentosa (Cambess) H. Hara & MG & $\mathrm{Sb}$ \\
\hline Opiliaceae & $\begin{array}{l}\text { Agonandra brasiliensis Miers ex Benth. } e \\
\text { Hook.f. }\end{array}$ & $\begin{array}{l}\text { CE, MS } \\
\text { CD }\end{array}$ & Av \\
\hline Oxalidaceae & Oxalis sp. & MG & $\mathrm{He}$ \\
\hline Phytolacaceae & Phytolacca dioica L. & MS & $\mathrm{Ab}$ \\
\hline Piperaceae & Piper aduncum L. & CE, MG & $\mathrm{He}$ \\
\hline Piperaceae & Piper arboreum Aubl. & $\mathrm{CE}, \mathrm{MG}$ & Av \\
\hline Piperaceae & Piper cf. glabratum Kunth & MG & $\mathrm{He}$ \\
\hline Piperaceae & Piper gaudichaudianum Kunth & MG & $\mathrm{He}$ \\
\hline Piperaceae & Piper tuberculatum Jacq. & $\mathrm{CE}, \mathrm{MG}$ & $\mathrm{He}$ \\
\hline Plantaginaceae & Bacopa salzmannii (Benth.) Wettst. ex Edwall & MG & $\mathrm{He}$ \\
\hline Poaceae & Guadua paniculata Munro & MC & $\mathrm{He}$ \\
\hline Poaceae & Melinis minutiflora P. Beauv. & MG & $\mathrm{He}$ \\
\hline Poaceae & Melinis repens (Willd) Zizka & MG & $\mathrm{He}$ \\
\hline Poaceae & $\begin{array}{l}\text { Schizachyrium microstachyum (Desv. ex Ham.) } \\
\text { Roseng., B.R. Arrill. e Izag. }\end{array}$ & MG & $\mathrm{He}$ \\
\hline Polygonaceae & Coccoloba mollis Casar. & CE, MG & Av \\
\hline Polygonaceae & Polygala sp. & MG & $\mathrm{He}$ \\
\hline Polygonaceae & Triplaris americana $\mathrm{L}$. & MG, MC & Av \\
\hline Polygonaceae & Triplaris gardneriana Wedd. & MS & Av \\
\hline
\end{tabular}




\begin{tabular}{|c|c|c|c|}
\hline \multirow[b]{2}{*}{ Família } & \multirow[b]{2}{*}{ Espécie } & \multicolumn{2}{|l|}{ Fisionomias } \\
\hline & & $\begin{array}{c}\text { de } \\
\text { ocorrência }\end{array}$ & Hábito \\
\hline Pontederiaceae & Eichhornia azurea $(\mathrm{Sw})$ Kunth. & MG & $\mathrm{He}$ \\
\hline Primulaceae & Myrsine umbellata Mart. & $\begin{array}{l}\text { CE, CD, MD, } \\
\quad \text { MS }\end{array}$ & Av \\
\hline Rhamnaceae & Rhamnidium elaeocarpum Reissek & CE, MG, MS & $\mathrm{Av}$ \\
\hline Rubiaceae & Alibertia edulis (Rich.) A.Rich. & $\begin{array}{l}\text { CE, MG, MS, } \\
\text { CD }\end{array}$ & $\mathrm{Av}$ \\
\hline Rubiaceae & Calycophyllum multiflorum Griseb. & MG & $\mathrm{Ab}$ \\
\hline Rubiaceae & Chomelia polyantha S.F.Blake & MG & $\mathrm{Ab}$ \\
\hline Rubiaceae & Cordiera sessilis (Vell.) Kuntze & $\mathrm{CE}, \mathrm{CD}, \mathrm{MD}$ & Av \\
\hline Rubiaceae & Coussarea hydrangeifolia (Benth.) Müll.Arg. & MG & Av \\
\hline Rubiaceae & Genipa americana L. & $\begin{array}{l}\text { CE, MG } \\
\text { CD }\end{array}$ & Av \\
\hline Rubiaceae & Guettarda viburnoides Cham. e Schltdl. & $\mathrm{CD}, \mathrm{MD}, \mathrm{MS}$ & Av \\
\hline Rubiaceae & $\begin{array}{l}\text { Margaritopsis cf. deinocalyx (Sandwith) } \\
\text { C.M.Taylor }\end{array}$ & MG & $\mathrm{Ab}$ \\
\hline Rubiaceae & Palicourea marcgravii A.St.-Hil. & MG & $\mathrm{Ab}$ \\
\hline Rubiaceae & Pogonopus tubulosus (A.Rich. ex DC.) K.Schum. & MG & $\mathrm{Av}$ \\
\hline Rubiaceae & Psychotria carthagenensis Jacq. & CE, MG & $\mathrm{Ab}$ \\
\hline Rubiaceae & Randia armata (Sw.) DC. & MC & $\mathrm{Ab}$ \\
\hline Rubiaceae & Rudgea viburnoides (Cham.) Benth. & $\mathrm{MC}, \mathrm{CE}$ & $\mathrm{Ab}$ \\
\hline Rubiaceae & Tocoyena formosa (Cham. e Schltdl.) K. Schum. & $\mathrm{CE}$ & $\mathrm{Ab}$ \\
\hline Rubiaceae & Coutarea hexandra (Jacq.) K.Schum. & MC & $\mathrm{Ab}$ \\
\hline Rutaceae & Balfourodendron riedelianum (Engl.) Engl. & MS & $\mathrm{Av}$ \\
\hline Rutaceae & Esenbeckia grandiflora Mart. & MC & $\mathrm{Av}$ \\
\hline Rutaceae & Zanthoxylum hamadryadicum Pirani & $\mathrm{CE}$ & $\mathrm{Av}$ \\
\hline Rutaceae & Zanthoxylum hasslerianum (Chodat) Pirani & MS, CD & $\mathrm{Av}$ \\
\hline Rutaceae & Zanthoxylum riedelianum Engl. & $\mathrm{CE}$ & Av \\
\hline Salicaceae & Casearia decandra Jacq. & CE, MG, MS & Av \\
\hline Salicaceae & Casearia gossypiosperma Briq. & CE, MG & $\mathrm{Ab}$ \\
\hline Salicaceae & Casearia rupestris Eichler. & CE, MG & $\mathrm{Av}$ \\
\hline Salicaceae & Casearia sylvestris Sw. & CE, MG, MS & $\mathrm{Av}$ \\
\hline Sapindaceae & Averrhoidium paraguaiense Radlk. & MS & $\mathrm{Av}$ \\
\hline Sapindaceae & Cupania sp. & $\mathrm{CE}$ & $\mathrm{Av}$ \\
\hline Sapindaceae & Cupania vernalis Cambess. & $\begin{array}{l}\mathrm{CD}, \mathrm{MD}, \mathrm{MS}, \\
\mathrm{CD}\end{array}$ & $\mathrm{Av}$ \\
\hline
\end{tabular}




\begin{tabular}{|c|c|c|c|}
\hline \multirow[b]{2}{*}{ Família } & \multirow[b]{2}{*}{ Espécie } & \multicolumn{2}{|l|}{ Fisionomias } \\
\hline & & $\begin{array}{c}\text { de } \\
\text { ocorrência }\end{array}$ & Hábito \\
\hline Sapindaceae & Dilodendron bipinnatum Radlk. & $\begin{array}{l}\text { CE, MS } \\
\text { CD }\end{array}$ & $\mathrm{Av}$ \\
\hline Sapindaceae & Diplokeleba floribunda N.E.Br. & $\mathrm{CE}$ & $\mathrm{Av}$ \\
\hline Sapindaceae & $\begin{array}{l}\text { llophylus edulis (A.St.-Hil. et al.) Hieron. ex } \\
\text { Niederl. }\end{array}$ & MC & Av \\
\hline Sapindaceae & Magonia pubescens A.St.-Hil. & CE, CD & $\mathrm{Av}$ \\
\hline Sapindaceae & Matayba elaeagnoides Radlk. & MS, CD & $\mathrm{Av}$ \\
\hline Sapindaceae & Matayba guianensis Aubl. & CE, MG & $\mathrm{Av}$ \\
\hline Sapindaceae & Paullinia pinnata $\mathrm{L}$. & CE, MC & $\mathrm{Li}$ \\
\hline Sapindaceae & Talisia esculenta (Cambess.) Radlk. & MD, MS & Av \\
\hline Sapotaceae & $\begin{array}{l}\text { Chrysophyllum gonocarpum (Mart. } e \text { Eichler ex } \\
\text { Miq.) Engl. MD }\end{array}$ & $\mathrm{Av}$ & \\
\hline Sapotaceae & $\begin{array}{l}\text { Chrysophyllum marginatum (Hook. e Arn.) } \\
\text { Radlk. }\end{array}$ & MG & Av \\
\hline Sapotaceae & Pouteria glomerata (Miq.) Radlk. & MC & Av \\
\hline Simaroubaceae & Simarouba versicolor A. St.-Hil. & CE, CD & $\mathrm{Av}$ \\
\hline Siparunaceae & Siparuna guianensis Aubl. & CE, MS & $\mathrm{Av}$ \\
\hline Smilacaceae & Smilax fluminensis Steud. & $\mathrm{CE}$ & $\mathrm{Li}$ \\
\hline Solanaceae & Cestrum strigilatum Ruiz e Pav. & MG & $\mathrm{Ab}$ \\
\hline Solanaceae & Solanum paniculatum L. & MG & $\mathrm{Ab}$ \\
\hline Urticaceae & Boehmeria caudata Sw. & MS & \\
\hline Urticaceae & Cecropia pachystachya Trécul & CE, MG & $\mathrm{Av}$ \\
\hline Urticaceae & Urera aurantiaca Wedd. & MC & $\mathrm{Sb}$ \\
\hline Verbenaceae & Aloysia virgata (Ruiz e Pav.) Juss. & MG & $\mathrm{Av}$ \\
\hline Verbenaceae & Lantana sp. & MG & $\mathrm{Ab}$ \\
\hline Verbenaceae & Stachytarpheta cayennensis (Rich.) Vahl & CE, MG, MS & $\mathrm{Ab}$ \\
\hline Vitaceae & Cissus erosa Rich. & MG & $\mathrm{Li}$ \\
\hline Vochysiaceae & Callisthene fasciculata Mart. & $\begin{array}{l}\text { CE, MG, MS, } \\
\text { CD }\end{array}$ & $\mathrm{Av}$ \\
\hline Vochysiaceae & Callisthene major Mart. & MS & $\mathrm{Av}$ \\
\hline Vochysiaceae & Callisthene minor Mart. & $\begin{array}{l}\text { CE, MS } \\
\text { CD }\end{array}$ & $\mathrm{Av}$ \\
\hline Vochysiaceae & Qualea cordata (Mart.) Spreng. & MS & $\mathrm{Av}$ \\
\hline Vochysiaceae & Qualea grandiflora Mart. & $\begin{array}{l}\mathrm{CE}, \mathrm{MS} \\
\mathrm{CD}\end{array}$ & $\mathrm{Av}$ \\
\hline
\end{tabular}




\begin{tabular}{|l|l|c|c|}
\hline \multicolumn{1}{|c}{} & \multicolumn{2}{c}{ Família } & \multicolumn{1}{c}{ Fisionomias } \\
& & $\begin{array}{c}\text { de } \\
\text { ocorrência }\end{array}$ & Hábito \\
\hline Vochysiaceae & Qualea parviflora Mart & CE, MS & $\mathrm{Av}$ \\
& & $\mathrm{CD}$ & \\
\hline Xyridaceae & Xyris jupicai Rich & $\mathrm{MG}$ & $\mathrm{He}$ \\
\hline Xyridaceae & Xyris savanensis Miq & $\mathrm{MG}$ & $\mathrm{He}$ \\
\hline
\end{tabular}

Fonte: Autoria própria.

Figura 2. Espécies registradas na área de ecótono Cerrado-Pantanal, do Mato Grosso do Sul: (A) Alibertia edulis (Rich.) A.Rich., (B) Mouriri elliptica Mart., (C) Caryocar brasiliense Cambess., (D) Tocoyena formosa (Cham. e Schltdl.) K. Schum., (E) Zanthoxylum riedelianum Engl. e (F) Psidium guienense Sw.
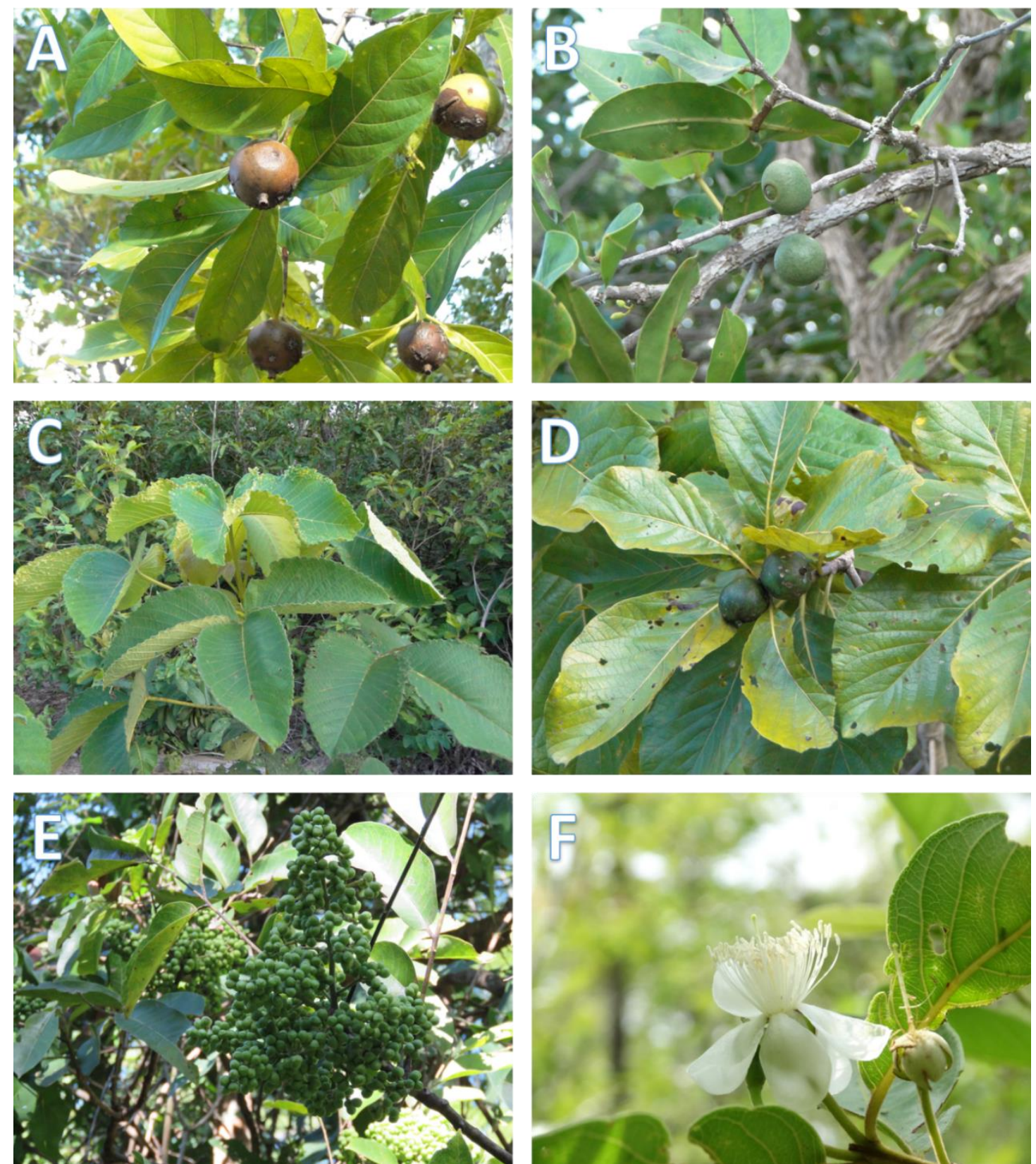

Fonte: Autoria própria. 
Figura 3. Riqueza das famílias amostradas. Área de ecótono Cerrado-Pantanal, MS.

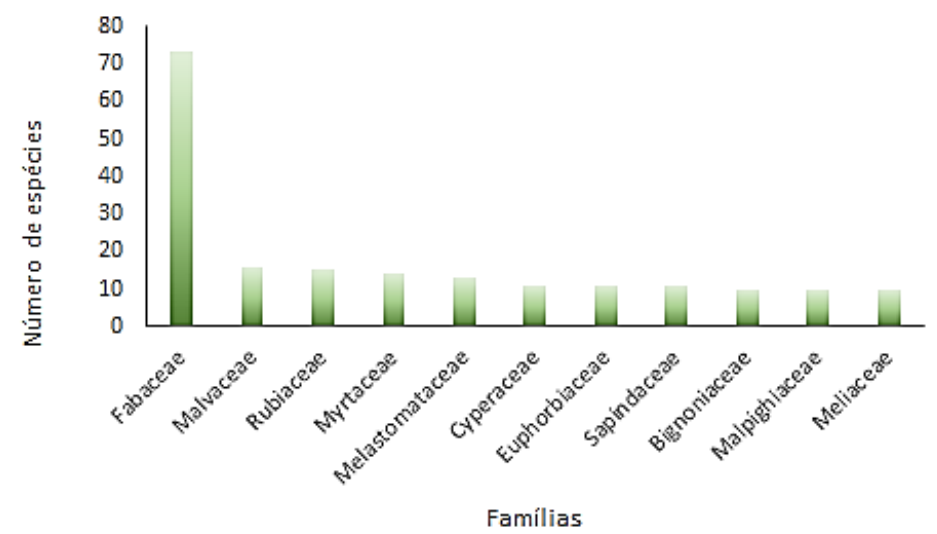

Fonte: Autoria própria.

Os gêneros com maior número de espécies foram: Cyperus com 10 espécies, Bauhinia com 7 espécies, Eugenia e Miconia com 6 espécies cada e Aspidosperma, Ficus, Piper e Trichilia com 5 espécies cada. Todos esses gêneros são bem representados na flora brasileira e comuns nas diferentes fitofisionomias de domínio do Cerrado, sendo citados também como mais ricos no trabalho de Ramos e Sartori (2013).

Analisando-se o hábito, houve predomínio do componente arbóreo em relação ao estrato herbáceo-subarbustivo (Figura 4). Porém, a maioria dos trabalhos revisados tiveram ênfase no componente arbustivo-arbóreo e assim, muito provavelmente, as espécies de herbáceas estão sub-inventariadas para a região. Isso ocorre também pela dificuldade taxonômica de algumas famílias, como em Poaceae, as quais necessitam de intensificação na amostragem e identificação na região.

Figura 4. Distribuição das espécies inventariadas por hábito, no ecótono Cerrado-Pantanal,

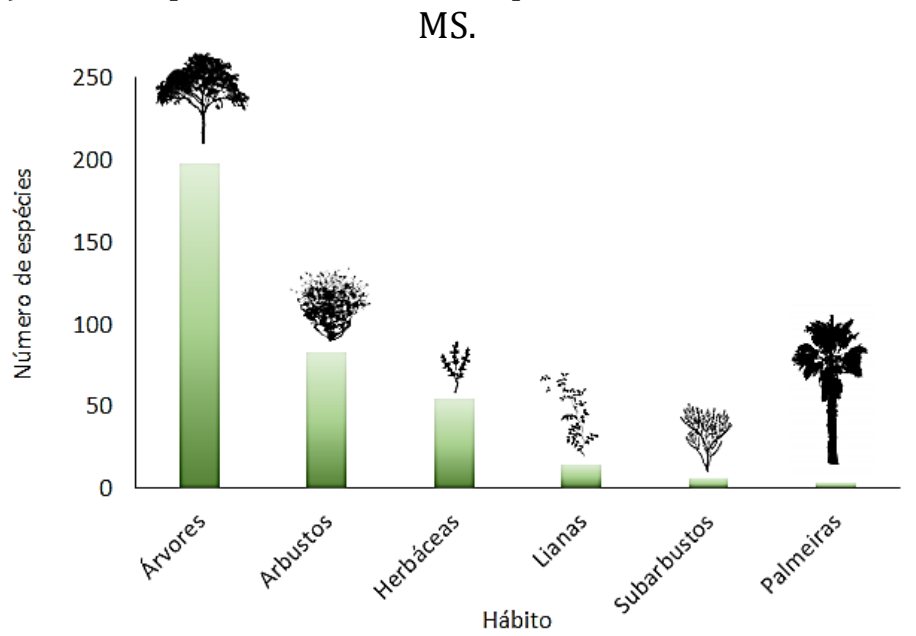

Fonte: Autoria própria. 
Embora a maioria das espécies registradas seja de ampla ocorrência (POTT; POTT, 2009), ressalta-se que algumas não são tão comuns haja vista a ocorrência de Mouriri elliptica Mart. (Figura 2B), Sloanea guianensis (Aubl.) Benth., Guibourtia hymenaeifolia (Moric.) J. Léonard, Tachigali aurea Tul, Cariniana legalis (Mart.) Kuntze entre outras.

A principal ameaça aos biomas Cerrado e Pantanal continua sendo o desmatamento e a expansão das atividades agropecuárias que promovem a substituição de muitas de suas áreas por lavouras e pastagens. Levando em consideração que a lista apresentada não contém nenhuma espécie ameaçada de extinção é necessária a proteção e uso racional de muitas dessas espécies citadas, dada sua intensa exploração econômica.

Ipês, aroeiras, jatobás, jequitibás, entre outras madeiras de lei, merecem especial atenção por serem protegidas por legislação estadual específica. 0 cumbaru (Dipteryx alata) está como vulnerável à extinção segundo a IUCN e cabe relatar que esta espécie está entre as madeiráveis mais usadas nas construções rurais.

Como espécies raras, com ocorrência pontual nas áreas amostradas, pode-se citar a peroba (Aspidosperma cylindrocarpon), peroba rosa (A. polyneuron), o bálsamo (Myroxylon peruiferum), jequitibá (Cariniana legalis) e o barreiro (Prosopis rubriflora). Aspidosperma cylindrocarpon e A. polyneuron (peroba-rosa) são consideradas raras no Mato Grosso do Sul devido à exploração madeireira (POTT; POTT, 2003), A. polyneuron, inclusive, é considerada em perigo de extinção (CARVALHO, 1994 apud POTT; POTT, 2003).

As diferentes fisionomias vegetacionais encontradas e seu contato direto nas áreas de ecótono (cerrado, cerradão, floresta estacional decídua, floresta estacional semidecídua, mata ciliar e mata de galeria) possibilita a sobreposição da flora, em proporções variadas, resultando na alta diversidade. Essa diversidade também pode ser influenciada pela heterogeneidade geomorfológica das áreas inventariadas, que acarreta na formação de diferentes tipos de solos. Segundo Durigan e Ratter (2006) as propriedades edáficas são o principal fator determinante da composição florística e estrutura das comunidades nas áreas transicionais.

Pott e Pott (2003) citaram um total de 355 espécies lenhosas pertencentes a 229 gêneros e 67 famílias amostradas em diferentes fragmentos de fisionomias florestais no Estado de Mato Grosso do Sul. Isso reitera a relevância do ecótono 
Cerrado-Pantanal aqui estudado, uma vez que apresentou diversidade florística superior aos biomas, quando em separado.

As fisionomias de cerrado e mata de galeria foram as que apresentaram maior quantidade de espécies (194 e 169 respectivamente), seguidas por mata semidecídua (93 espécies), cerradão com (71 espécies) e mata ciliar (37 espécies) (Figura 5). Para as matas semidecíduas existe estimativa de ocorrência de 497 espécies lenhosas para o Estado de Mato Grosso do Sul (DAMASCENO-JUNIOR et al., 2018) e de 78 espécies para Aquidauana (REGO, 2008). Para as matas de galeria, a estimativa era de 98 espécies na região de Aquidauana (FINA et al., 2012; RAMOS; SARTORI, 2013). No cerrado eram citadas 109 espécies (RAMOS; SARTORI, 2013), no cerradão 59 espécies (FINA, 2009) e para mata ciliar 53 espécies (OLIVEIRA et al., 2019) na região de Aquidauana.

Figura 5. Riqueza de espécies nas diferentes fisionomias da área de ecótono CerradoPantanal, MS.

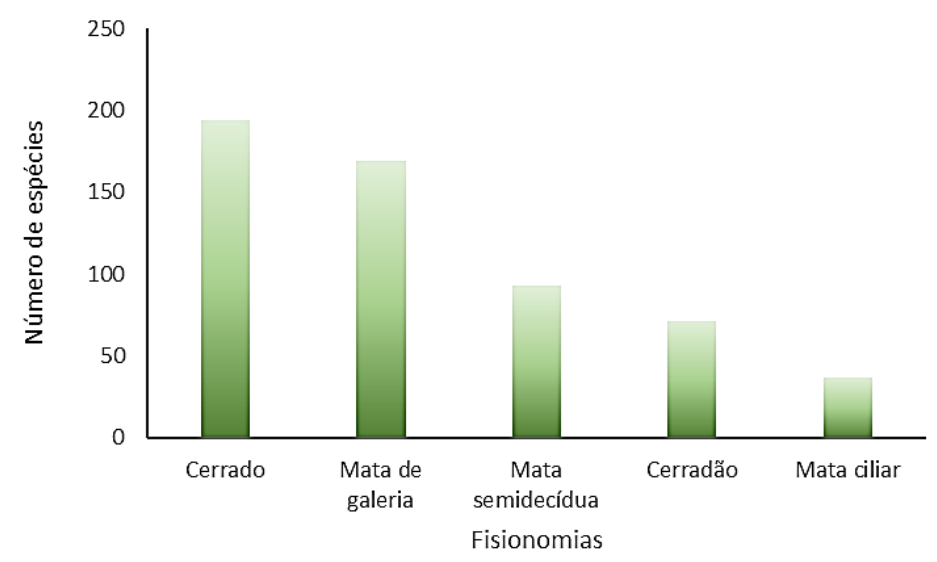

Fonte: Autoria própria.

As riquezas de todas as fisionomias estão dentro do padrão esperado e de acordo com outros estudos realizados em outras regiões (OLIVEIRA FILHO et al., 1989; FELFILI et al., 1993; SILVEIRA et al., 2000; FELFILI et al., 2002; SILVA et al., 2002; RATTER et al., 2003; BORGES; SHEPHERD, 2005; MARIMON JR; HARIDASAN, 2005; MEDEIROS et al., 2005; PEREIRA et al., 2007). A exceção é o cerradão que apresentou riqueza superior ao demais estudos no MS (SILVA et al., 2000; RATTER et al., 2003; SALIS et al., 2006) porém aproxima-se da média encontrada para os estados de Goiás, Tocantins e Mato Grosso (RATTER et al., 2003; MARIMON JR; HARIDASAN, 2005). Estas ocorrências podem ser justificadas por sua proximidade 
com as fisionomias de cerrado e mata estacional semidecídua, justamente por encontrar-se nesse ecótono Cerrado-Pantanal.

Sabe-se que o Estado de Mato Grosso do Sul apresenta o menor índice de coleta botânica por $\mathrm{km}^{2}$ do Brasil (DAMASCENO-JÚNIOR et al., 2018) e nesse sentido, além da escassez de coletas há também muitas áreas ainda não inventariadas na região, assim é provável que muitas novas espécies possam ser adicionadas à essa lista. Muitos ambientes ainda não contam com coletas na região, por exemplo, veredas e campos úmidos.

É possível observar que esforços vêm sendo feitos para ampliar as coletas nas diferentes fisionomias da região, que resultaram na melhoria do conhecimento sobre a flora do ecótono Cerrado-Pantanal, mas muito ainda precisa ser realizado. Também deve ser relevada a grande variação topográfica nesta região, considerando a Serra de Maracajú, que proporciona diversos ambientes que favorecem a colonização de maior número de espécies vegetais.

\section{AGRADECIMENTOS}

O presente trabalho foi realizado com apoio da Universidade Federal de Mato Grosso do Sul - UFMS/MEC - Brasil e da Coordenação de Aperfeiçoamento de Pessoal de Nível Superior (CAPES). Os autores agradecem à Fundação de Apoio ao Desenvolvimento do Ensino, Ciência e Tecnologia do Estado de Mato Grosso do Sul (FUNDECT) pelo apoio aos projetos desenvolvidos pelo grupo de pesquisa "Estudos Integrados em Biodiversidade do Cerrado e Pantanal". Os autores agradecem aos proprietários das áreas particulares que permitiram o acesso e a coleta de dados para a realização desse estudo.

\section{REFERÊNCIAS}

ABREU, G.M., BARBOSA, G.R.M., GUIRARDI, B.D., CHERRI, U., REGO, N. H. Estrutura de um fragmento florestal na microbacia do córrego Fundo, em região de ecótono Cerrado-Pantanal. Magistra, Cruz das Almas - BA, v. 27, n.3/4, p.333$343,2015$.

ALVES, F.M., LEHN, C.R., DAMASCENO-JÚNIOR, G.A., SARTORI, A.L.B.; POTT, A., POTT, V.J., BORTOLOTTO, I.M., ISHII, I.H., SALIS, S.M.; URBANETZ, C., BUENO, M.L. $e$ SCIAMARELLI, A. Coleções botânicas do estado de Mato Grosso do Sul: 
situação atual e perspectivas. Iheringia, Série Botânica 73(supl.):93-100. 2017.

ASSIS, E. L. M. e LABIAK, P. H. 2009a. Lycophyta da borda oeste do Pantanal, Mato Grosso do Sul, Brasil. Acta botanica brasilica 23(3): 703-712.

ASSIS, E. L. M. $e$ LABIAK, P. H. 2009b. Polypodiaceae da borda oeste do Pantanal sulmatogrossense, Brasil. Revista Brasileira de Botânica 32(2): 233-247.

BARBOSA-SILVA, S.M.; JESUS-SILVA, L.H.; CAIRES, C.S. Pteridófitas ocorrentes em dois vales no município de Aquidauana, Mato Grosso do Sul, Brasil. Brasília: Heringeriana, v. 4, n. 2, p. 20-37, 2010.

BORGES, H.B.N. $e$ SHEPHERD, G.J. 2005. Flora e estrutura do estrato lenhoso numa comunidade de cerrado em Santo Antonio do Leverger, MT, Brasil. Revista brasileira de botânica 28(1): 61-74.

BRASIL. Ministério do Meio Ambiente, dos Recursos Hídricos e da Amazônia Legal/ Plano de Conservação da Bacia do Alto Paraguai - PCBAP/Projeto Pantanal. Diagnóstico dos meios físicos e bióticos. Brasília: PNMA, 1997. v.2. Tomo II. $394 \mathrm{p}$

BRASIL. Ministério das Minas e Energia, Secretaria Geral. Projeto RADAMBRASIL: Levantamento de recursos naturais. Rio de Janeiro: 1990. v. 26.

DAMASCENO-JUNIOR,G.A., POTT,A., NEVES,D.R.M., SCIAMARELLI, A., FINA, B.G. Flora lenhosa de Florestas estacionais do Estado de Mato Grosso do Sul: estado da arte. Iheringia, Série Botânica, Porto Alegre, 73(supl.):65-79, 2018.

DURIGAN, G.; RATTER, J. A. Successional changes in cerradão and cerrado/ forest ecotonal vegetation in western São Paulo State, Brazil, 1962-2000. Edinburgh Journal of Botany, Cambridge, v. 63,p. 119-130, 2006.

FARINACCIO M.A., ROQUE F.O., GRACIOLLI G., SOUZA P.R., PINTO J.O.P. 2018. A flora no Biota-MS: montando o quebra-cabeça da biodiversidade de Mato Grosso do Sul. Iheringia, Série Botânica, Porto Alegre, 73(supl.):11-17., 2018.

FELFILI, J.M.; SILVA JÚNIOR, M.C.; REZENDE, A.V.; MACHADO, B.W.T.; SILVA, P.E.N. $e$ HAY, J.D. 1993. Análise comparativa da florística e fitossociologia da vegetação arbórea do cerrado sensu stricto na Chapada Pratinha, Brasil. Acta botanica Brasilica 6 (2) 2): 27-46.

FELFILI, J.M.; NOGUEIRA, P.E.; SILVA-JÚNIOR, M.C.; MARIMON, B.S. $e$ DELITTI, W.B.C. 2002. Composição florística e fitossociologia do cerrado sentido restrito no município de Água Boa-MT. Acta Botanica Brasilica 16(1): 103-112.

FINA, B.G. $e$ MONTEIRO, R. Análise da estrutura arbustivo-arbórea de uma área de cerrado sensu stricto, município de Aquidauana-Mato Grosso do Sul. Revista Árvore, Viçosa-MG, v.37, n.4, p.577-585, 2013. 
FINA, B.G., HAMERSKI, A., e MOREIRA, P. A. 2012. Estudo florístico em fragmentos de mata de galeria ao longo do Córrego João Dias. In: L. R. Ayach, N. Cappi $e$ R. H. Pereira (Org.), A bacia hidrográfica do Córrego João Dias. pp. 109-123. Campo Grande: UFMS.

FINA, B. G. Caracterização ambiental da Fazenda Experimental da Universidade Mato Grosso do Sul, município de Aquidauana-MS: distribuição de tipos edáficos e vegetacionais. Tese: Universidade Estadual Paulista "Júlio de Mesquita Filho", Instituto de Biociências de Rio Claro. 122 f., 2009.

Governo do Estado de Mato Grosso do Sul. 2009. Zoneamento ecológico-econômico - Mato Grosso do Sul: Contribuições técnicas, teóricas, jurídicas e metodológicas. Acessado em 01 de julho de 2021. http://www.semade.ms.gov.br/

GOMES, A. DE C. e AOKI, C. Efeito da sazonalidade hídrica sobre a fitossociologia de macrófitas aquáticas em uma lagoa no Pantanal, Brasil. Rev. Biol. Neotrop. 12(1): 1-7 . 2015.

MARIMON JUNIOR e HARIDASAN, 2005. Comparação da vegetação arbórea e características edáficas de um cerradão e um cerrado sensu stricto em áreas adjacentes sobre solo distrófico no leste de Mato Grosso, Brasil. Acta botânica brasílica 19(4): 913-926.

MEDEIROS, M.B.; GUARINO,E.S.G.; SILVA,G.P.S. 2005. Fitossociologia de um trecho de cerrado sensu stricto na bacia do Rio Corumbá - área de influência direta do aproveitamento hidroelétrico Corumbá IV (GO). Brasília: Embrapa recursos genéticos e biotecnologia.

MATO GROSSO DO SUL 1989. Secretaria de Planejamento e Coordenação Geral. Macrozoneamento Geoambiental. 242 p.

MINISTÉRIO DO MEIO AMBIENTE - MMA 2009. Relatório técnico de monitoramento do desmatamento no Bioma Cerrado, 2002 a 2008: Dados revisados. Brasília: Ministério do Meio Ambiente. 69 p.

OLIVEIRA, G.L.X., COUTINHO, B.A., CICALISE, B.G.F., AOKI, C. Florística da mata ciliar do rio Aquidauana (MS): subsídios à restauração de áreas degradadas. Oecologia Australis, 23(4):812-828, 2019.

OLIVEIRA FILHO, A.T.; SHEPHERD, G.D.; MARTINS, F.R. $e$ STUBBLEBINE, W.H. 1989. Environmental factors affecting physiognomic and floristic variation in na area of cerrado in central Brazil. Journal of Tropical Ecology 55: 413-431.

POTT, A. e POTT, V.J. Espécies de fragmentos florestais em Mato Grosso do Sul. In: Fragementação florestal e alternativas de desenvolvimento rural na região Centro-Oeste. Reginaldo Brito da Costa (org). Campo Grande: UCDB, p. 26-53, 2003. 
PEIXOTO, A.L. 2003. Coleções biológicas de apoio ao inventário, uso sustentável e conservação da biodiversidade. Rio de Janeiro: Instituto de Pesquisas Jardim Botânico do Rio de Janeiro.

PEREIRA, Z.V., SCIMARELLI, A., CEZESMUNDO, F.G., LOBTCHENKO, G e GOMES, M.E.S. 2007. Estrutura fitossociológica do estrato arbustivo-arbóreo de um fragmento de Floresta Estacional Semidecídua, no município de Dourados, MS. Nota científica. Porto Alegre: Revista brasileira de biociências 5 (2): 7274.

RAMOS, W.M.A; SARTORI, A.L.B. Floristic analysis and dispersal syndromes of woody species of the Serra de Maracaju, Mato Grosso do Sul, Brazil. Braz. J. Biol., 2013, vol. 73, no. 1, p. 67-78.

RATTER J.A., BRIDGEWATER,S. $e$ RIBEIRO,J.F. 2003. Analysis of the floristic composition of the Brazilian cerrado vegetation III: comparison of the woody vegetation of 376 areas. Edinburgh Journal of Botany 60: 57-109.

REGO, N.H. Variação da estrutura da vegetação arbórea em uma toposseqüência num vale da Serra de Maracaju, Aquidauana, MS. Tese: Universidade Estadual Paulista "Júlio de Mesquita Filho" - Faculdade de ciências agrárias e veterinárias, Campus de Jaboticabal. 105 f., 2008.

ROCHA, C.G., RESENDE, U.M., LUGNANI, J. de S. Diversidade de macrófitas em Ambientes aquáticos do IPPAN na Fazenda Santa Emília, Aquidauana, MS. Revista Brasileira de Biociências, Porto Alegre, v. 5, supl. 2, p. 456-458, 2007.

Shepherd, G.J. 2003. Plantas terrestres: Versão preliminar. Relatório de avaliação do estado do conhecimento da diversidade biológica do Brasil. 60 p.

SALIS, S.M.; ASSIS, M. A.; CRISPIM, S.M.A.; CASAGRANDE, J.C. 2006. Distribuição e abundancia de espécies arbóreas em cerradões no Pantanal, Estado do Mato Grosso do Sul, Brasil. Revista brasileira de botânica 29(3): 339-352.

SILVA, L.O., COSTA,D.A., SANTO FILHO,K., FERREIRA,H.D. $e$ BRANDÃO,D. 2002. Levantamento florístico e fitossociológico em duas áreas de cerrado sensu stricto no Parque Estadual da Serra de Caldas Novas, Goiás. Acta Botanica Brasilica 16(1): 43-53.

SILVA, M.P.; MAURO, R.; MOURÃO, G. e COUTINHO, M. 2000. Distribuição e quantificação de classes de vegetação do Pantanal através de levantamento aéreo. Revista brasileira de Botânica 23(2): 143 -152.

SILVEIRA, E.A.; BARROS, L.T.L.P.; ALMEIDA, N.N. 2000. Mapa de vegetação e uso do solo na região de Poconé - MT: caracterização florísitica e estrutural. In: III simpósio sobre recursos naturais e sócio-econômicos do Pantanal - os desafios do novo milênio. Corumbá-MS. P.1-28.

SOUZA, V.C.; FLORES, T. B.; COLLETA, G.D.; COELHO, R.L.G. Guia das plantas do cerrado. Piracicaba, SP: Taxon Brasil Editora e Livraria, 2019. 583 p. 
YANO, 0.; BASTOS, C. J.P. Adições à flora de briófitas de Mato Grosso do Sul, Brasil. Acta bot. bras. 18(3): 437-458. 2004.

ZAVALA, C.B.R; FERNANDES, S.S.L.; PEREIRA, Z.V.; SILVA, S.M. Análise fitogeográfica da flora arbustivo-arbórea em ecótono no Planalto da Bodoquena, MS, Brasil. Ciência Florestal, Santa Maria, v. 27, n. 3, p. 907-921, jul.-set., 2017. 


\title{
CAPÍTULO VI
}

\section{FENOLOGIA DE TRÊS ESPÉCIES DE PLANTAS DANINHAS DE PASTAGEM EM UMAÁREA DE ECÓTONO CERRADO- PANTANAL}

DDI: 10.51859/amplla.ecp672.1121-6

\author{
Erika Toshie Sato ${ }^{1}$ \\ Silvia Pereira Rahe ${ }^{2}$ \\ José Rimoli ${ }^{1}$ \\ Camila Aoki 1,3,4 \\ Bruna Gardenal Fina Cicalise ${ }^{1}$ \\ Valdemir Antonio Laura ${ }^{5,2}$ \\ Celice Alexandre Silva ${ }^{6}$ \\ Rogério Rodrigues Faria ${ }^{1,3}$
}

\begin{abstract}
${ }^{1}$ Universidade Federal de Mato Grosso do Sul, Campus de Aquidauana, Grupo de Estudos Integrados em Biodiversidade do Cerrado e Pantanal, Rua Oscar Trindade de Barros, 740, Bairro da Serraria, Aquidauana, MS, Brasil, CEP: 79200-000.

${ }^{2}$ Universidade Anhanguera-Uniderp, Programa de Pós-graduação em Produção e Gestão Agroindustrial, R. Alexandre Herculano, 1400, Taquaral Bosque, Campo Grande, MS, Brasil, 79035-470.

${ }^{3}$ Universidade Federal de Mato Grosso do Sul, Programa de Pós-Graduação em Recursos Naturais, Faculdade de Engenharias, Arquitetura e Urbanismo e Geografia (FAENG), Av. Costa e Silva, s/n - Cidade Universitária, Campo Grande, MS, Brasil, CEP 79070-900.

${ }^{4}$ Universidade Federal de Mato Grosso do Sul, Programa de Pós-Graduação em Biologia Vegetal, Instituto de Biociências (INBIO), Av. Costa e Silva, s/n - Bairro Universitário, Campo Grande, MS, Brasil, CEP 79070-900.

5Empresa Brasileira de Pesquisa Agropecuária, Embrapa Gado de Corte, Rodovia BR 262 km 4, Caixa Postal 154, Campo Grande, MS, Brasil, CEP 79002-970.

6Universidade Estadual de Mato Grosso, Campus Tangará da Serra, Programa de Pós-graudação em Genética e Melhoramento de Plantas (PGMP), Av Inacio Bittencourt S/N, Bairro Jd Aeroporto, Tangará da Serra, MT, Brasil, CEP 78300-000.
\end{abstract}

\section{INTRODUÇÃO}

A competição das plantas daninhas com as forrageiras em áreas de pastagens ocorre desde o momento da semeadura e perdura até mesmo após o estabelecimento do pasto (DIAS-FILHO, 1990; DIAS-FILHO, 2006), sendo que o manejo destas plantas envolve práticas associadas ao controle mecânico (remoção das plantas), controle químico (uso de herbicidas) e a queima (SANTOS et al., 2006). Na pecuária, algumas plantas daninhas são indesejáveis por prejudicar a produção animal, competir com as forrageiras, serem tóxicas e/ou causarem ferimentos ao 
homem ou aos animais (POTT; POTT; SOUZA, 2006). Por outro lado, outras espécies podem atuar na manutenção das pastagens, como as leguminosas que atuam na fixação de nitrogênio no solo (KEVAN, 1999; MAYER, 2004) e há, ainda, evidências empíricas que pastagens mais diversas podem ser mais produtivas, por enriquecer a dieta do gado (TOTTY et al., 2013).

Nos casos do Cerrado e do Pantanal, parte considerável das espécies daninhas de pastagens são plantas nativas, ou seja, já possuem associações com espécies locais e são oportunistas em relação à colonização de novos habitats (POTT; POTT; SOUZA, 2006; SANTOS et al., 2006). As pastagens (naturais e plantadas) ocupam mais de 172 milhões de hectares no Brasil (IBGE, 2007), sendo que 61,31 milhões estão na região Centro-Oeste. O Estado do Mato Grosso do Sul desponta como uma das principais áreas de criação de gado do Brasil. A flora do Estado, inclusas aí as espécies daninhas, contudo ainda é pouco conhecida e estudada (FARINACCIO et al., 2018). Ao mesmo tempo em que é considerado um pólo de produção animal, em especial, a região de ecótono do Cerrado-Pantanal, nas proximidades da Serra de Maracaju, é considerada área prioritária para conservação da biodiversidade (MMA, 2002). Nesse contexto, a pesquisa básica pode oportunizar práticas de manejo sustentáveis, seja para um melhor controle das plantas potencialmente nocivas, como o melhor aproveitamento das que são benéficas. Entre uma das formas de pesquisa básica está o estudo da fenologia das espécies vegetais.

A fenologia é definida como o estudo dos eventos do ciclo de vida dos organismos (FENNER, 1998; SAKAI, 2001). Para as plantas, a época de cada evento pode ser crítica para sua sobrevivência e reprodução (RATHCKE; LACEY, 1985). Deste modo, o comportamento fenológico das espécies é regulado por características endógenas associadas a fatores abióticos e bióticos, que são fatores de pressão seletiva para o desenvolvimento de padrões fenológicos (VAN SCHAIK; TERBORGH; WRIGHT, 1993; CHMURA et al., 2019). Além do interesse no conhecimento dos ciclos de vida das plantas, o estudo da fenologia também consta como uma ferramenta muito útil de monitoramento ambiental (MORELLATTO et al. 2016; SAKAI; KITAJIMA, 2019), pelo seu caráter preditivo das respostas ecológicas das plantas frente às variações do ambiente. 
Uma vez que o conhecimento da fenologia de plantas daninhas é crucial para práticas de controle mais adequadas das mesmas (SPADOTT et al., 1994; DIAS et al., 2013), o objetivo deste trabalho foi registrar e caracterizar os eventos fenológicos de três espécies de plantas daninhas de pastagens em uma área de ecótono CerradoPantanal: Croton campestris A. St.-Hil. (Euphorbiaceae), Sapium haematospermum Müll. Arg. (Euphorbiaceae) e Annona crassiflora Mart. (Annonaceae) e fornecer subsídios para o manejo e a conservação do ecótodo Cerrado-Pantanal.

\section{METODOLOGIA}

O estudo foi realizado no município de Aquidauana, Mato Grosso do Sul, em área considerada zona de transição entre o Cerrado e Pantanal (ANDRADES-FILHO; ZANI; GRADELHA, 2009; RODRIGUES; CARVALHO; SILVA, 2017). A região apresenta períodos climáticos sazonais definidos por inverno seco e verão chuvoso, com clima definido como tropical chuvoso de savana, subtipo Aw (C.f. PELL; FINLAYSON; MCMAHON, 2007). Há um ciclo sazonal de distribuição de temperaturas definidas em duas estações, uma de maio a setembro, com temperaturas médias entre $20,7^{\circ} \mathrm{C}$ a $24,5^{\circ} \mathrm{C}$ a estação seca; e outra de outubro a abril, quando as temperaturas médias oscilam entre $25,8^{\circ} \mathrm{C}$ a $29,9^{\circ} \mathrm{C}$ a estação chuvosa. A precipitação média anual é de $1.200 \mathrm{~mm}$, onde a maior concentração de precipitação ocorre de dezembro a março (SCHIAVO et al., 2010).

As áreas de pastagens cultivadas são comuns nesta região e para as observações foi selecionado um sistema pastoril com plantas daninhas de pastagens. O Sítio São José (20²8’23”S; 5544’07”0), situado à Rodovia MS-450 no município de Aquidauana, possui 35 hectares e está a aproximadamente 9,5 km do perímetro urbano. A vegetação caracterizada por estrato herbáceo abundante (especialmente pastagem de Urochloa spp.), poucos arbustos e árvores esparsas (JESUS, 2018). Foram avaliadas três espécies daninhas: Croton campestris, Sapium haematospermum e Annona crassiflora.

Croton campestris é um arbusto que pode chegar até $4 \mathrm{~m}$ de altura. No Brasil, ocorre nos domínios da Amazônia, Caatinga, Cerrado e Mata Atlântica, em ambientes de campo rupestres, afloramentos rochosos e cerrado (lato sensu) (REFLORA 2020, 
em construção). Na área de estudo foram amostrados indivíduos entre 0,30m a $0,80 \mathrm{~m}$.

Sapium haematospermum tem hábito de arbusto a arvoreta e pode atingir até 5,0m de altura. Ocorre nos domínios da Mata Atlântica e Cerrado, em matas ciliares, florestas pluviais ou em cerrado (lato sensu) (REFLORA 2020, em construção). Na área de estudo foram amostrados indivíduos entre 0,50m a 1,0m de altura.

Annona crassiflora é uma árvore que pode atingir até 8,0m de altura. Ocorre nos domínios da Amazônia, Cerrado e Pantanal, em ambientes de cerrado (lato sensu) (RFLORA 2020, em construção). Na área de estudo foram amostrados indivíduos de $1,0 \mathrm{~m}$ a $1,50 \mathrm{~m}$.

A escolha das espécies alvo levou em consideração a abundância das mesmas na área de estudo e o papel delas como plantas daninhas. Como procedimento padrão, todos os indivíduos adultos, foram marcados quando se encontravam com flores ou botões florais. Para cada espécie, 20 indivíduos foram marcados com lacres plásticos numerados, ao acaso, e mapeados com o auxílio de aparelho GPS portátil (Garmin eTrex $H ®$ ). Foram realizadas, quinzenalmente, as observações das seguintes fenofases: botões florais (flores em pré-antese), floração (flor aberta), frutos imaturos (frutos são verdes nas três espécies) e maduros (em C. Campestris e $S$. hametospermum os frutos maduros tornam-se escuros e secos; em A. crassipes além de escurecer, o fruto torna-se mais tenro); bem como, brotamento (ocorrência de folhas jovens) e senescência (queda foliar), entre setembro de 2015 e agosto de 2016. Cada fenofase foi analisada de acordo com a duração (quantos meses a planta desenvolveu tal fenofase), época (em que mês as plantas apresentaram a fenofase), intensidade (quantificação em número para flores, frutos e botões; ou presença/ausência para senescência e brotamento) e sincronia populacional (grau de concentração de indivíduos da mesma espécie em cada fenofase). Os dados climáticos foram obtidos por consulta ao site do Centro de Monitoramento de Tempo, do Clima e dos Recursos Hídricos de Mato Grosso do Sul (CEMTEC-MS).

A sazonalidade das fenofases, bem como a sincronia da atividade dos indivíduos de cada espécie, foi realizada através de estatística circular pelo teste de Rayleigh (Z) (KOVACH, 2004). No teste de Rayleigh, a hipótese nula (Ho) afirma que os ângulos ou datas são distribuídos uniformemente ao longo do ano, não há sazonalidade. Se Ho é rejeitada, o padrão das fenofases ao longo do ano é sazonal 
(MORELLATO et al., 2009). 0 comprimento do vetor no gráfico é relacionado com o valor de concentração, a sincronia populacional, (variando de 0 a 1), e a seta aponta para o ângulo médio (data média da fenofase) da distribuição de frequências (KOVACH, 2004). A análise dos fatores climáticos (temperatura e precipitação pluvial acumulada) foi feita a partir de um climatograma; e a intensidade das fenofases quantitativas (botão, flor e frutos) por meio de estatística descritiva (C.f. FARIA; ARAÚJO, 2016).

A identificação do material botânico foi feita a partir de herbários digitais: REFLORA 2020 (em construção), bem como consulta ao herbário INBIO/CPCG/UFMS e taxonomistas da instituição. Todo o material botânico coletado foi incorporado ao Herbário INBIO/CPCG/UFMS da Universidade Federal de Mato Grosso do Sul (C. campestris [60001]; S. haematospermum [60003]; A. crassiflora [60004]).

\section{RESULTADOS E DISCUSSÃO}

A temperatura média mensal se manteve acima de $25^{\circ}$ de setembro a abril, que também são os meses com maior registro de chuva. A queda de temperatura se deu entre abril e mês de agosto, sendo os meses de junho a agosto, o período de escassez de chuva (Figura 1).

Figura 1. Dados climáticos de setembro de 2015 a agosto de 2016 para o município de Aquidauana, Mato Grosso do Sul, Brasil. A temperatura média mensal está marcada pela linha tracejada; a precipitação pluvial acumulada mensal é representada pelas barras (Fonte: CEMTEC-MS).

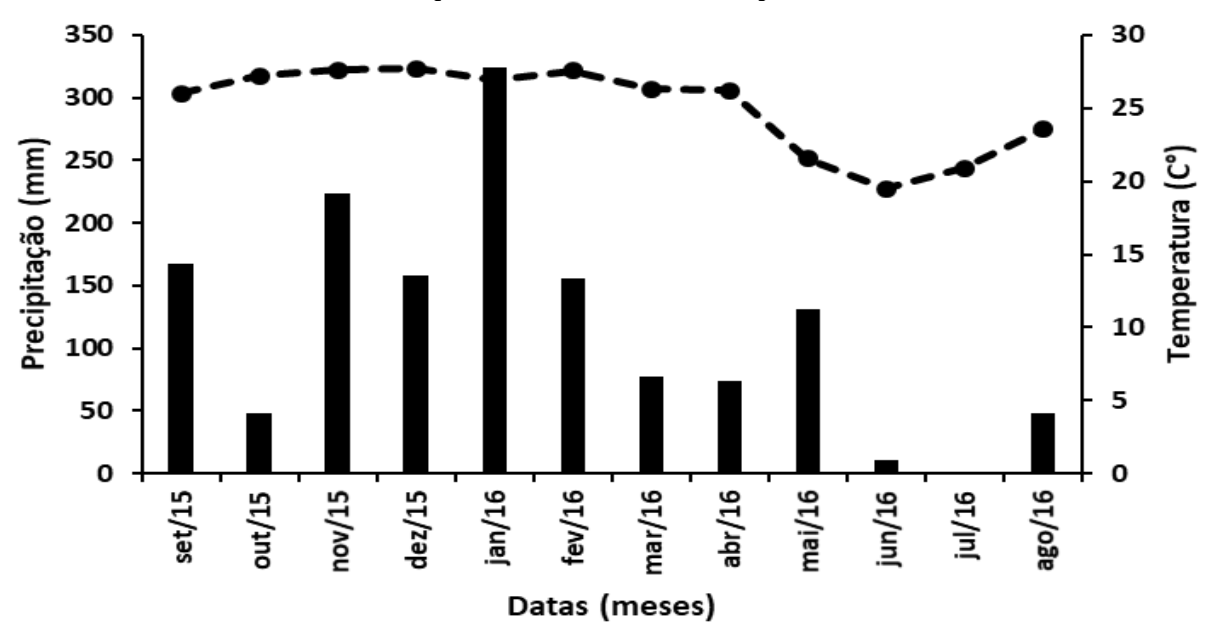

Fonte: Autoria própria. 
As análises circulares indicaram que todas as fenofases das espécies analisadas são sazonais (Tabela 1). As três espécies analisadas apresentaram padrão fenológico reprodutivo de caráter anual, ou seja, um evento ao ano; o que reforça a influência da sazonalidade sobre as fenofases. As estações são entendidas como a principal unidade para o entendimento dos eventos fenológicos, pois refletem um complexo conjunto de informações dos determinantes climáticos (JEANNERET; RUTISHAUSER, 2009). A Zona de Convergência Intertropical, responsável pela formação das chuvas e nuvens, produz estações secas e chuvosas na maior parte dos trópicos (WRIGHT, 1996). Desta forma, nos trópicos, como não há um inverno rígido, há uma longa estação de crescimento vegetal, assim as espécies vegetais apresentam ampla variedade de respostas fenológicas à sazonalidade (USINOWICZ et al., 2017). Os dados de data média indicam que as fenofases reprodutivas ocorreram ao longo de toda a estação chuvosa. No caso das três espécies estudadas, os dados de data média indicam que as fenofases reprodutivas ocorreram ao longo de toda a estação chuvosa. Em relação às fenofases vegetativas, de acordo com os dados de data média, o brotamento foi mais intenso na estação chuvosa e a senescência mais deslocada para o final da estação chuvosa e início da seca. (Tabela 1).

Tabela 1. Valores de data média (dia/mês/ano), sincronia (r), Rayleigh (Z) e valor de significância (P) de cada fenofase em C. campestris, S. haematospermum e A. crassiflora, entre 2015 e 2016, Aquidauana-MS.

\begin{tabular}{llcccc}
\hline \multicolumn{1}{c}{ Espécie } & Fenofase & Data média & $\begin{array}{c}\text { Sincronia } \\
\text { (r) }\end{array}$ & Rayleigh (Z) & $\boldsymbol{P}$ \\
& Botão & $07 / 11 / 2015$ & 0.345 & 91.869 & $<0.001$ \\
\hline Croton campestris & Flor & $10 / 11 / 2015$ & 0.354 & 94.156 & $<0.001$ \\
& $\begin{array}{l}\text { Fruto } \\
\text { imaturo }\end{array}$ & $06 / 01 / 2016$ & 0.285 & 63.365 & $<0.001$ \\
& & & & \\
& Fruto & $08 / 02 / 2016$ & 0.763 & 72.109 & $<0.001$ \\
& maduro & & & & \\
& Brotamento & $24 / 07 / 2016$ & 0.174 & 29.888 & $<0.001$ \\
& Senescência & $13 / 03 / 2016$ & 0.809 & 207.509 & $<0.001$ \\
\hline Sapium & Botão & $29 / 10 / 2015$ & 0.682 & 149.946 & $<0.001$ \\
haematospermum & & & & & \\
& Flor & $10 / 11 / 2015$ & 0.767 & 162.776 & $<0.001$ \\
& Fruto & $02 / 12 / 2015$ & 0.563 & 99.552 & $<0.001$ \\
& imaturo & & & & \\
& Fruto & $17 / 01 / 2016$ & 0.392 & 34.161 & $<0.001$ \\
& maduro & & & & \\
& Brotamento & $17 / 10 / 2015$ & 0.150 & 21.839 & $<0.001$ \\
& Senescência & $19 / 03 / 2016$ & 0.645 & 14.566 & $<0.001$ \\
\hline Annona crassiflora & Botão & $04 / 11 / 2015$ & 0.573 & 102.314 & $<0.001$ \\
& Flor & $06 / 01 / 2015$ & 0.600 & 56.123 & $<0.001$
\end{tabular}




\begin{tabular}{llcccc}
\hline Espécie & Fenofase & Data média & $\begin{array}{c}\text { Sincronia } \\
(\mathbf{r})\end{array}$ & Rayleigh (Z) & $\boldsymbol{P}$ \\
\hline & $\begin{array}{l}\text { Fruto } \\
\text { imaturo }\end{array}$ & $23 / 11 / 2015$ & 0.365 & 64.404 & $<0.001$ \\
& & & & \\
& $\begin{array}{l}\text { Fruto } \\
\text { maduro }\end{array}$ & $20 / 12 / 2015$ & 0.769 & 41.419 & $<0.001$ \\
& & & & \\
& $\begin{array}{l}\text { Brotamento } \\
\text { Senescência }\end{array}$ & 29/10/2015 & 0.083 & 6.314 & $<0.001$ \\
& & & & \\
\end{tabular}

Fonte: Autoria própria.

\subsection{CROTON CAMPESTRIS}

Em C. campestris ocorreram seis meses contínuos de botões florais (setembro ao início de fevereiro) com médias de 46,2 a 1219,12 botões na população. Posteriormente, há produção de botões novamente, porém em intensidades menores. As flores começam a surgir em setembro e zeram sua produção em fevereiro, indo de 64,82 a 168,53 flores em média (Figura 2). Na microrregião de Catolé do Rocha (PB) C. campestris também apresentou ocorrência de floração em épocas chuvosas.

A frutificação em C. campestris ocorreu o ano inteiro, com média de 1,1 a 60,6 frutos imaturos, com produção intensa nos meses de novembro a fevereiro. A maturação desses frutos ocorreu por quatro meses (de novembro de 2015 a fevereiro de 2016), com média de 0,25 a 6,02 frutos maduros. Veriifou-se brotamento foliar nas espécies durante o ano inteiro (15\% a 100\% dos indivíduos), com dois picos anuais, de setembro a dezembro de 2015 e de março a agosto em 2016. No final de dezembro essa espécie iniciou senescência foliar e cessou no mês de abril (20 a 75\% dos indivíduos amostrados), reaparecendo em menor porcentagem ( $5 \%$ dos indivíduos) no final de junho ao início de agosto (Figura 2).

Croton campestris apresentou maior sincronia populacional nas fases de senescência e de fruto maduro, o que significou que mudanças fenológicas mais bruscas ocorrem nesses estágios (Tabela 1). As proximidades das datas médias dos eventos de queda foliar e dispersão dos frutos indicaram que a senescência é o marco do estágio final da atividade reprodutiva destes indivíduos, já no final da estação chuvosa. No período de senescência é perceptível o esmaecimento das folhas. A sincronia mais baixa ocorreu nas fases de brotamento e de frutos imaturos. Ou seja, há um brotamento contínuo e um longo período de maturação dos frutos (Tabela 1). Cabe ressaltar aqui, que, apesar das grandes diferenças em intensidade e da sincronia moderada, as fases de botão e flor tem datas médias muito próximas, 
indicando que a produção de botão e flor está mais para concomitante que para sequencial.

Figura 2. Média e desvio padrão do número de botões, flores, frutos maduros e imaturos de $C$. campestris. Proporção de indivíduos em brotamento e senescência foliar em $C$. campestris. Período de setembro de 2015 a agosto de 2016, município de Aquidauana, Mato Grosso do Sul, Brasil.
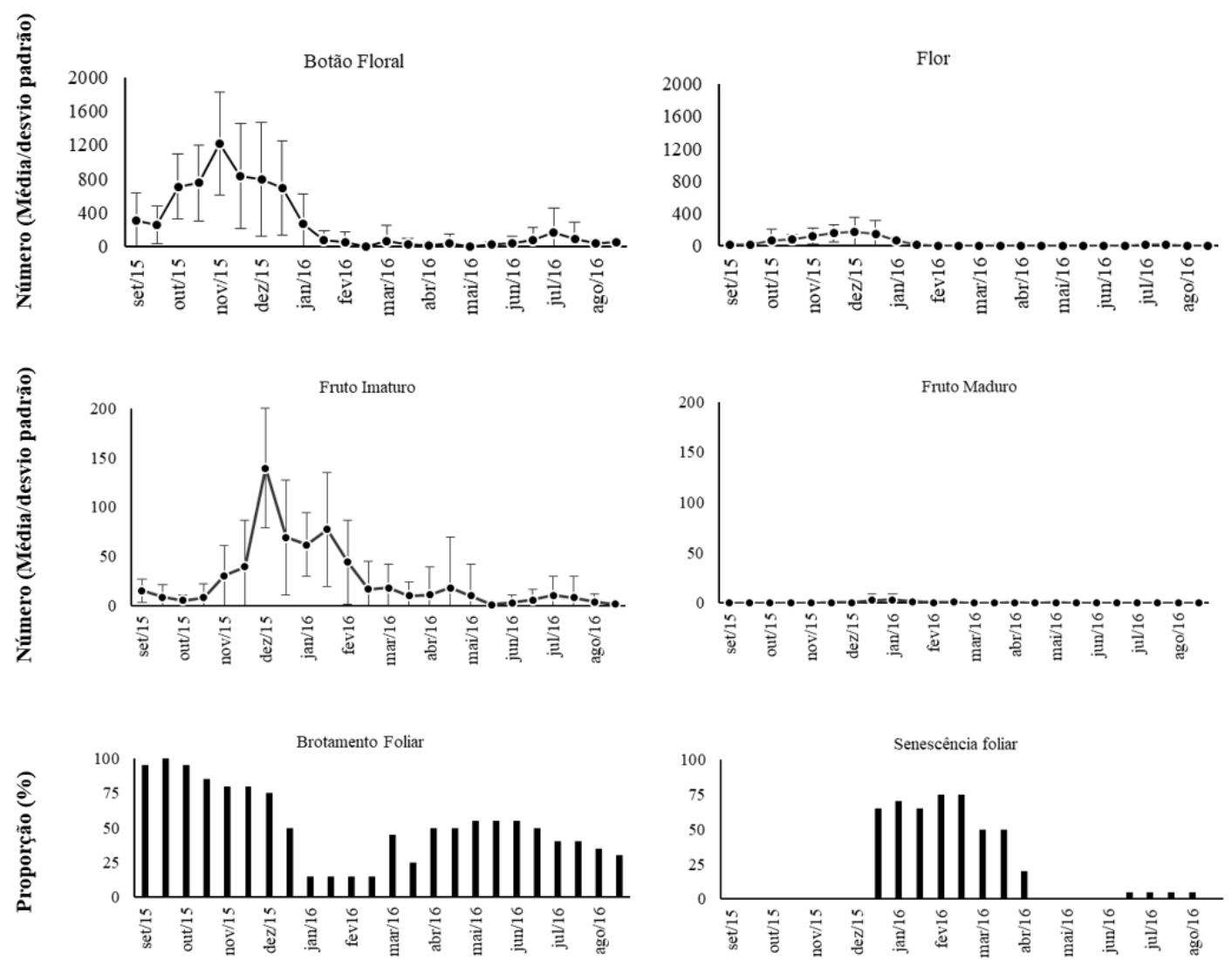

Data (meses)

Data (meses)

Fonte: Autoria própria.

\subsection{SAPIUM HAEMATOSPERMUM}

A produção de botões em $S$. haematospermum teve início em agosto e terminou no início de fevereiro, com médias de 1,6 a 110,63 botões florais. Há atividade descontínua em outros meses, porém com pouca quantidade. A floração começou no fim de agosto e pausou no início de fevereiro (com média de 0,2 a 142,64 flores) produzindo posteriormente em meses irregulares com baixa intensidade (Figura 3). Tal registro também foi relatado para a Bacia do Alto Paraguai, Corumbá-MS (SALIS; REIS; MARCONDES, 2009), com floração nos meses de março, abril, julho, agosto, setembro, outubro, novembro e dezembro. 
A produção de frutos imaturos em $S$. haematospermum se iniciou no fim de agosto até abril (em média de 0,07 a 13,35 frutos imaturos), esses se tornam maduros a partir de novembro e finalizaram sua maturação em junho (com média de 0,46 a 1,86 frutos maduros) (Figura 3). Sapium haematospermum teve brotamento foliar durante o ano inteiro sempre em grandes quantidades (de 15\% a $100 \%$ dos indivíduos amostrados) diminuindo sua produção apenas entre os meses de abril e julho. A senescência foliar ao longo do ano não passou de $10 \%$ dos indivíduos amostrados, indo de dezembro a julho (Figura 3).

Sapium heamatospermum apresentou maior sincronia nos eventos de flor, botão e senescência (Tabela 1). Ou seja, com eventos mais concentrados e com passagens mais rápidas de estágio. 0 evento menos sincronizado foi o brotamento (Tabela 1), que ocorreu com uma transição mais lenta, haja vista que possui folhas perenes, que permaneceram verdes o ano todo. 0 estágio de fruto imaturo e maduro teve sincronia moderada (Tabela 1). A transição menos acelerada entre essas fases, em comparação entre a fase de botão para flor, é corroborada pelas datas médias, que são mais próximas entre botão e flor do que entre fruto imaturo e maduro. Essa transição mais lenta pode ser o reflexo do longo período que a espécie permanece na formação do fruto, bem como um período mais lento de maturação. 
Figura 3. Média e desvio padrão do número de botões, flores, frutos maduros e imaturos de $S$. haematospermum. Proporção de indivíduos em brotamento e senescência foliar em $S$. haematospermum. Período de setembro de 2015 a agosto de 2016, município de Aquidauana, Mato Grosso do Sul, Brasil.
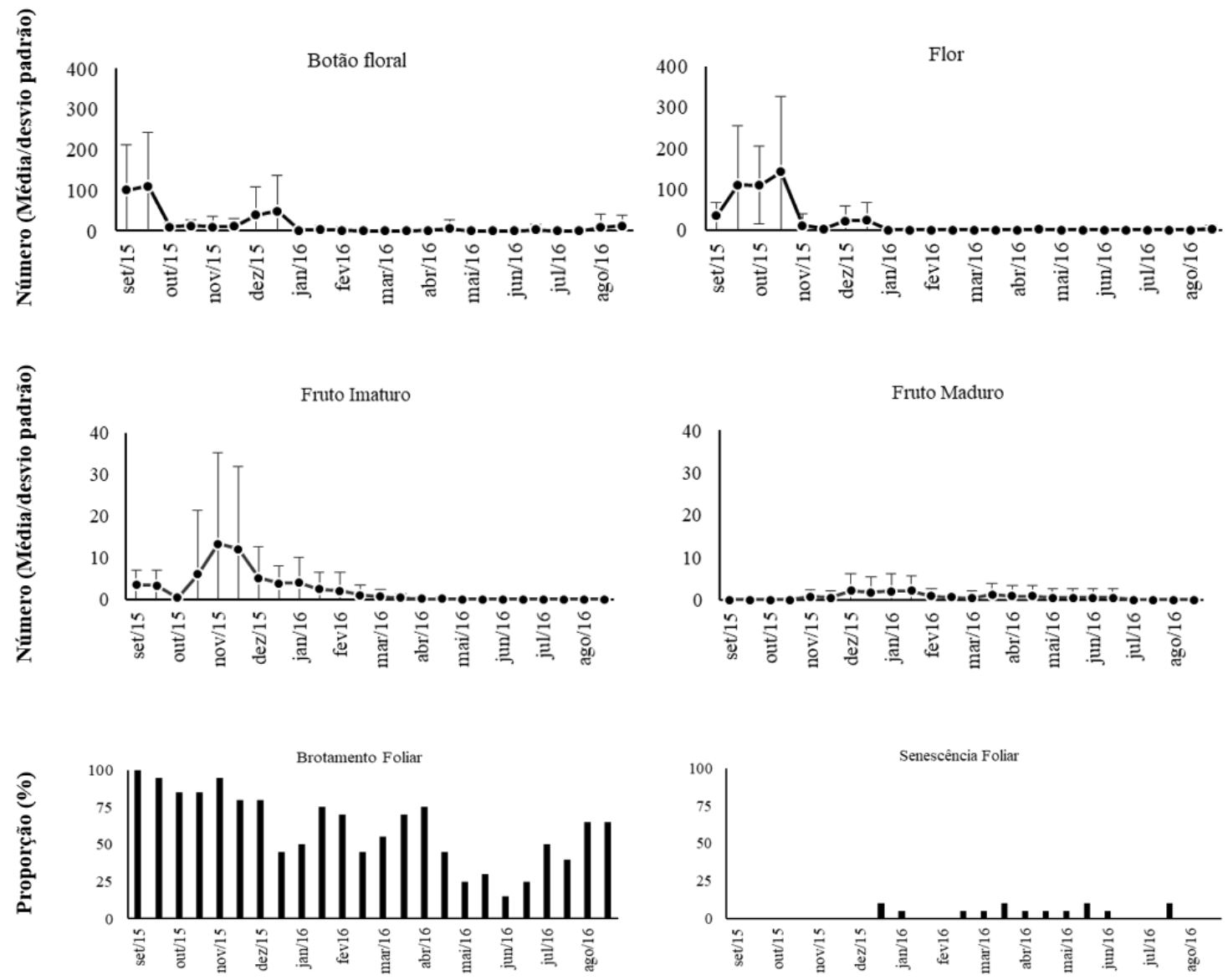

Data (meses)

Data (meses)

Fonte: Autoria própria.

\subsection{ANNONA CRASSIFLORA}

A produção de botões de $A$. crassiflora ocorreu em maiores quantidades de agosto a dezembro (0,5 a 8,2 em média). Após uma pausa, essa espécie produziu botões em intensidade menor. As flores se abriram de setembro a dezembro (0,05 a 0,95 em média) (Figura 4), um período muito similar ao registrado para a área de Cerrado no Sudeste do Brasil, Itirapina-SP (TANNUS; ASSIS; MORELLATO, 2006). Nesta localidade os autores registraram floração de $A$. crassiflora de outubro a dezembro, e, após uma pausa seguiram no final de fevereiro ao início de abril, em menores quantidades $(0,10$ a 0,21 em média).

Os frutos de A. crassiflora ocorreram praticamente em todos os meses, com pico entre setembro e fevereiro $(0,05$ a 6,05 em média), quando reduziram a 
quantidade, cessando a produção no fim de julho (Figura 4). Os frutos amadureceram entre os meses de novembro e março com médias de 0,1 a 0,65 frutos maduros. No Cerrado em Itirapina, somente em janeiro foram registrados frutos (TANNUS; ASSIS; MORELLATO, 2006). Houve 100\% de brotamento foliar em A. crassiflora nos meses de setembro a dezembro. Após esse período a produção diminuiu, apresentando apenas $10 \%$ de brotamento em janeiro e brotando novamente nos meses de fevereiro e março, respectivamente com $30 \%$ a $95 \%$ dos indivíduos. A senescência foliar se iniciou em dezembro cessando em agosto, com porcentagens de 5 a $80 \%$ dos indivíduos (Figura 4).

Annona crassiflora apresentou sincronia mais alta no estágio de fruto maduro, flor e botão. Primeiramente, há de se destacar o baixo número de flores em relação aos botões, bem como de frutos maduros em relação a frutos imaturos (Tabela 1). Há um indicativo de curta duração dos estágios de flor e frutos maduros, bem como a ocorrência de abortos ou predações. Ao analisarmos as datas médias, as fenofases de frutos imaturos e maduros apresentaram datas anteriores às de flores e muito próxima às de botões (Tabela 1). Possivelmente, houve uma maior eficiência de polinização nas flores que se abriram no início da floração. É um fator relacionado com disponibilidade e/ou qualidade dos polinizadores. A baixa quantidade de frutos corrobora, até certo ponto, essa evidência. Outro fator, é que como se trata de um fruto carnoso, por sua vez altamente energético, assim que madurou pode ter sido rapidamente removido pelos consumidores. As fases de frutos imaturos e de senescência apresentaram sincronia moderada. A fase de fruto imaturo mais longa que a de fruto maduro indicou o alto custo de produção dos mesmos; já a queda das folhas ficou mais alocada para o final da estação chuvosa, após a dispersão dos frutos. A fase de mais baixa sincronia foi encontrada para o brotamento (Tabela 1), o que pode indicar o alto custo de produção das folhas, que são relativamente espessas e rígidas. 
Figura 4. Média e desvio padrão do número de botões, flores, frutos maduros e imaturos de A. crassiflora. Proporção de indivíduos em brotamento e senescência foliar em $a$. crassiflora. Período de setembro e 2015 a agosto de 2016, município de Aquidauana, Mato Grosso do Sul, Brasil.
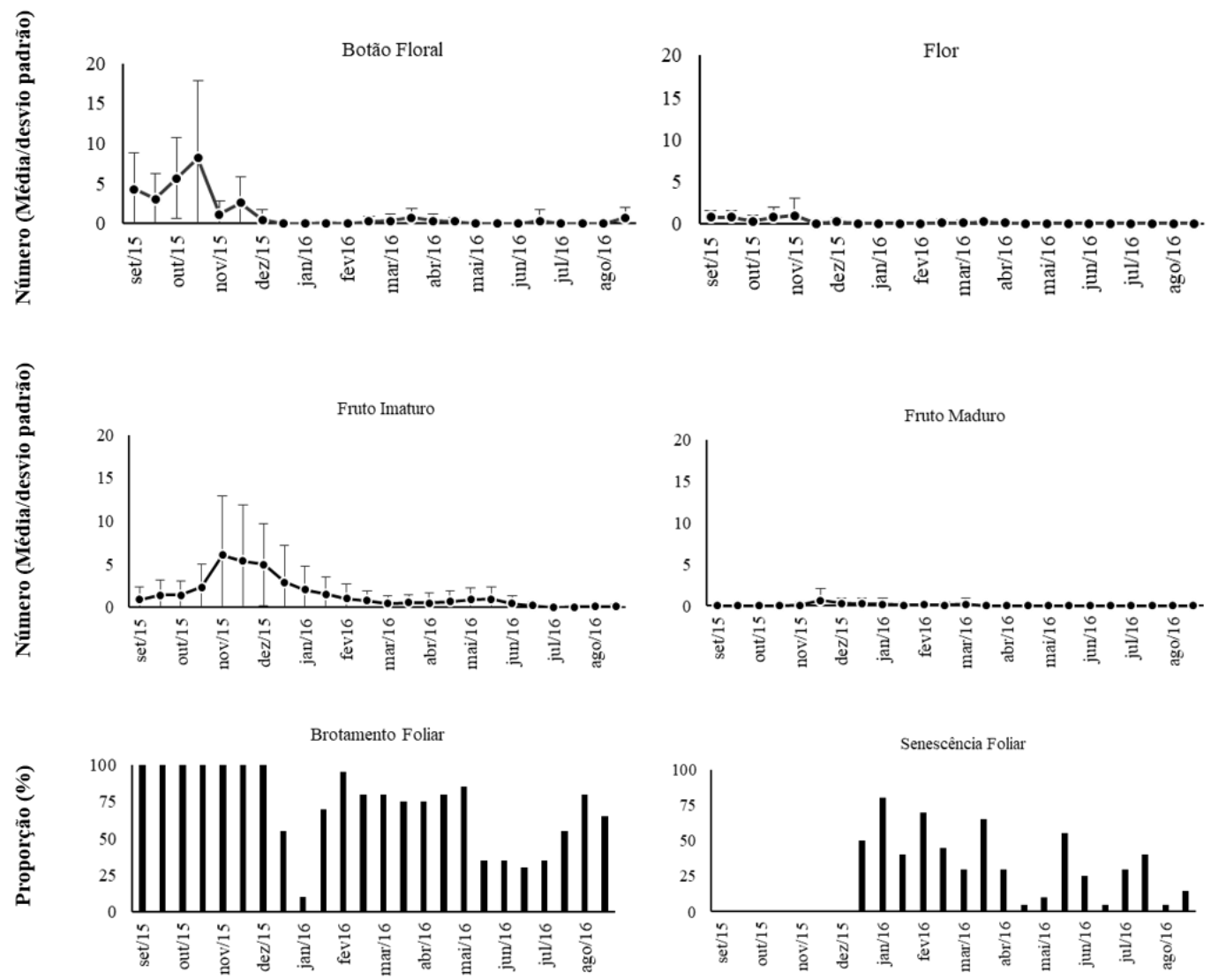

Data (meses)

Data (meses)

Fonte: Autoria própria.

\subsection{ASPECTOS GERAIS}

As plantas daninhas estudadas são plantas nativas que estão em ambiente que é produto da ação humana, no caso uma pastagem estabelecida com gramíneas exóticas. Portanto, a discussão sobre a biologia das mesmas deve levar em consideração o contexto no qual essas plantas estão inseridas. Tal contextualização levou em conta, os aspectos das estações climáticas e da vegetação locais.

Embora a área de estudo estivesse na faixa de ecótono Cerrado-Pantanal é intuitivo apontar que as respostas ecofisiológicas das plantas estudadas fossem mais ajustadas aos padrões encontrados para as plantas do Cerrado, visto que o clima e a vegetação circundante da área de estudo foram, claramente, típicos de Cerrado (JESUS, 2018). Além disso, as três espécies vegetais, por suas ocorrências são consideradas plantas típicas de Cerrado (REFLORA 2020, em construção). Ainda 
que o Cerrado tenha forte influência sobre o Pantanal, em termos de ocorrência de espécies (MMA, 2002), a dinâmica hidrológica, relevo, composição dos solos e demais características dos "diferentes tipos" de Pantanal (OLIVEIRA et al., 2006; GONÇALVES; MERCANTE; SANTOS, 2011; MERCANTE; RODRIGUES; ROSS, 2011) não se fizeram presentes na área de estudo. Portanto, os dados fenológicos apresentados neste trabalho refletiram uma influência típica de Cerrado.

Os resultados aqui apresentados corroboram as predições para o Cerrado, onde o período da estação seca pode atuar como uma referência para o desenvolvimento e para a sequência das fenofases (OLIVEIRA, 1998). Na área do estudo, as espécies amostradas foram plantas de pequeno porte e, portanto, potencialmente suscetíveis a serem afetadas pelo ressecamento do solo, que ocorre pela escassez de chuvas na estação seca. Por exemplo, é comum no Cerrado, assim como foi o encontrado para essas três espécies, que a alocação de recursos (como o brotamento) bem como o desenvolvimento das fases reprodutivas, ocorrerem, principalmente, no período com maiores precipitações pluviais, temperaturas e fotoperíodo, a estação chuvosa. Embora no Cerrado haja a produção de folhas, flores e frutos o ano todo, de maneira geral, a vegetação como um todo se desenvolve mais nesta estação. Tal estratégia é comum para as plantas em zonas tropicais, sendo reconhecida como uma estratégia para maximizar sua produção em um clima sazonal (SAKAI, 2001). Na estação chuvosa, além do aumento da temperatura e precipitação, que pode elevar a evapotranspiração; ainda ocorre o aumento da umidade do solo, que permite a disponibilização de nutrientes, tanto pela ação de microrganismos quanto pela dissolução de minerais (WRIGHT, 1996).

Dentro das fases reprodutivas das espécies estudadas, pôde-se observar que a produção de flores e botões florais foi mais coincidente dentro de cada espécie, do que entre as fases de frutos imaturos e maduros. Um padrão comum, uma vez que o processo de maturação dos frutos é determinado, principalmente, por fatores internos, que controlam sua taxa de desenvolvimento (PENHALBER; MANTOVANI, 1997). 


\section{CONSIDERAÇ̃̃ES FINAIS}

As três espécies vegetais estudadas tiveram um comportamento fenológico sazonal, com padrão de desenvolvimento reprodutivo observado principalmente na estação chuvosa e a fase vegetativa mais relacionada à estação seca.

\section{AGRADECIMENTOS}

V.J. Pott pela identificação das espécies vegetais; A. Viana pelo acesso ao Sítio São José. 0 presente trabalho foi realizado com apoio da Universidade Federal de Mato Grosso do Sul - UFMS/MEC - Brasil e da Coordenação de Aperfeiçoamento de Pessoal de Nível Superior (CAPES). Os autores agradecem à Fundação de Apoio ao Desenvolvimento do Ensino, Ciência e Tecnologia do Estado de Mato Grosso do Sul (FUNDECT) pelo apoio aos projetos desenvolvidos pelo grupo de pesquisa "Estudos Integrados em Biodiversidade do Cerrado e Pantanal”. À UFMS e FUNDECT pelas bolsas de iniciação científica à E.T.Sato.

\section{REFERÊNCIAS}

ANDRADES-FILHO, C. O.; ZANI, H.; GRADELHA, F. S. Compatibilidade da rede de drenagem obtida através de dados SRTM, ASTER e carta topográfica DSG:

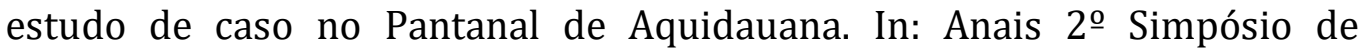
Geotecnologias no Pantanal. Embrapa Informática Agropecuária/INPE, 2009.

CEMTEC, Centro de Monitoramento de Tempo, do Clima e dos Recursos Hídricos de Mato Grosso do Sul. Banco de Dados. Disponível em: http://www.cemtec.ms.gov.br/?page_id=15. Acesso em: 20. mai. 2017.

CHMURA, H E. et al. The mechanisms of phenology: the patterns and processes of phenological shifts. Ecological Monographs, v. 89, n. 1, p. 1-20, 2019.

DIAS, A. C. R.; CARVALHO, S. J. P.; CHRISTOFFOLETI, P. J. Fenologia da Trapoeraba como indicador para tolerância ao herbicida Glyphosate. Planta Daninha, v. 31, n. 1, p. 185-191, 2013.

DIAS-FILHO, M. B. Plantas invasoras em pastagens cultivadas da Amazônia: Estratégia de manejo e controle. Empresa Brasileira de Pesquisa Agropecuária - EMBRAPA, 1990.

DIAS-FILHO, M.B. Sistemas silvipastoris na recuperação de pastagens degradadas. Belém: Embrapa Amazônia Oriental, 2006. 
FARIA, R. R.; ARAUJO, A. C. Flowering phenology and floral visitors in distylous populations of Psychotria carthagenensis (Rubiaceae) in Brazilian Cerrado. Annals of the Missouri Botanical Garden, v. 101, p. 636-647, 2016.

FARINACCIO, M. A. et al. A flora no Biota-MS: montando o quebra-cabeça da biodiversidade de Mato Grosso do Sul. Iheringia, Série Botânica v. 73, n (supl.), p. 11-17, 2018.

FENNER, M. The phenology of growth and reproduction in plants. Perspectives in Plant ecology, Evolution and Systematics, v. 1, p. 78-91, 1998.

FLORA DO BRASIL (REFLORA 2020 em construção). Jardim Botânico do Rio de Janeiro. Disponível em: http://floradobrasil.jbrj.gov.br. Acesso em: 11 jun. 2020.

GONÇALVES, H.C.; MERCANTE, MA.; SANTOS, E.T. Hydrological cycle. Brazilian. Journal of Biology, v. 71, n. 1, p. 241-253, 2011.

INSTITUTO BRASILEIRO DE GEOGRAFIA E ESTATÍSTICA (IBGE). 2007. Censo agropecuário 1920/2006. Disponível em: http://seriesestatisticas.ibge.gov.br. Acesso em: jul. 2021.

JEANNERET, F.; RUTISHAUSER, T. Seasonality as a core business of phenology. In: HUDSON, I. L; KEATLEY, M. C., editores. Phenological research: methods for environmental and climate change analysis. Dordrecht: Springer, 2009.

JESUS, C. C. C. Chuva e banco de sementes em pastagem cultivada no domínio do Cerrado. 2015. Tese (Mestrado em Biologia Vegetal) - Universidade Federal de Mato Grosso do Sul, Campo Grande, 2018.

KOVACH, W. L. Oriana for Windows, version 2.0. Software: Kovach Computer Services, Pentraeth, 2004.

KEVAN, P. G. Pollinators as bioindicators of the state of the environment: species, activity and diversity. Agriculture, ecosystems and environment, v. 74, p. 373-393, 1999.

MAYER, C. Pollination services under different grazing intensities. International Journal of Tropical Insect Science, v. 24, p. 95-103, 2004.

MINISTÉRIO DO MEIO AMBIENTE (MMA). 2002. Avaliação e identificação de áreas e ações prioritárias para a conservação, utilização sustentável e repartição dos benefícios da biodiversidade nos biomas brasileiros. Brasília: MMA/SBF, 2002. Disponível em: http://www.mma.gov.br. Acesso em: 10. mai. 2017.

MERCANTE, M. A.; RODRIGUES, S. C.; ROSS, J. L. S. Geomorphology and habitat diversity in the148Pantanal. Brazilian. Journal of Biology, v. 71, n. 1(sup), p. 233-240, 2011.

MORELATO, L. P. C.; ALBERTI, L. F.; HUDSON, I. L. Applications of Circular Statistics in Plant Phenology: a Case Studies Approach. In: HUDSON, I. L; KEATLEY, M. 
C., editores. Phenological research: methods for environmental and climate change analysis. Dordrecht: Springer, 2009.

MORELLATO, L.P.C. et al. Linking plant phenology to conservation biology. Biological Conservation, v. 195, p. 60-72, 2016.

OLIVEIRA, P.E. Fenologia e biologia reprodutiva das espécies de cerrado. In:. Sano, S.M.; Almeida, S.P. Cerrado: ambiente e flora. Planaltina: Embrapa-CPAC, 1998.

OLIVEIRA- JUNIOR, D. A. Caracterização fenológica das plantas apícolas herbáceas e arbustivas da microrregião da Catolé do Rocha-PB, Brasil. Revista Verde, v.3, n.4, p. 86-99, 2008.

OLIVEIRA, H. et al. Soils of the Pantanal. In: Encyclopedia of Soil Science. DOI: 10.1081/E-ESS-1200269011658. United Kingdom: Taylor e Francis, 2006. Disponível em: https://www.taylorfrancis.com/books. Acessado em: 10. mai. 2017.

PELL, M. C.; FINLAYSON, B. L.; MCMAHON, T. A. Updated world map of the KöppenGeiger climate classification. Australia, Hydrology and Earth System Sciences, v. 11, p. 1633-1644, 2007.

PENHALBER E. F.; MANTOVANI, W. Floração e chuva de sementes em mata secundária em São Paulo-SP. Revista Brasileira de Botânica, v. 20, p. 205-220, 1997.

POTT, A.; POTT, V. J.; SOUZA, T. W. Plantas daninhas de pastagem na região de Cerrados. Campo Grande Embrapa Gado de Corte, 2006.

RATHCKE, B.; LACEY, E. P. Phenological patterns of terrestrial plants. Annual Review of Ecology and Systematics, v. 16, p. 179-214, 1985.

Rodrigues, L. P.; Carvalho, E. M.; Silva, J. F. Unidades de Conservação no Ecótono entre Pantanal e Cerrado: o caso do Município de Aquidauana (MS). I Congresso Nacional de Geografia Física. Campinas, p. 1070-1081, 2017.

SAKAI, S. Phenological diversity in tropical forests. Population Ecology, v. 43, p. 7786, 2001.

SAKAI, S.; KITAJIMA, K. Tropical phenology: Recent advances and perspectives. Ecological Research, v. 34, p. 50- 54, 2019.

SALIS, S. M.; REIS, V. D. A.; MARCONDES, A. N. Floração de espécies apícolas no Pantanal baseada em informações de herbário e literatura. Corumbá: Embrapa Pantanal, 2009.

SANTOS, S. A. et al. Plantas invasoras no Pantanal: como entender o problema e soluções de manejo por meio de diagnóstico participativo. Corumbá: Embrapa Pantanal, Boletim de Pesquisa e Desenvolvimento, 2006. 
SCHIAVO, J. A. et al. Caracterização e classificação de solos desenvolvidos de arenitos da formação Aquidauana- MS. Rev. Bras. Ciência do Solo, v. 34, p. 881-889, 2010.

SPADOTT, C. A. et al. Determinação do período crítico para prevenção da interferência de plantas daninhas na cultura de soja: Uso do modelo "BrokenStick". Planta Daninha, v. 12, n. 2, 1994.

TANNUS, J. L. S.; ASSIS, M. A.; MORELLATO, L.P. C. Fenologia Reprodutiva em campo sujo e campo úmido numa área de Cerrado no Sudeste do Brasil, Itirapina SP. Biota Neotropica, v.6, n. 3, p.1-27, 2006.

TOTTY, V. K. et al. Nitrogen partitioning and milk production of dairy cows grazing simple and diverse pastures. Journal of Diary Science, v. 96, n. 1, p. 141-149. 2013.

USINOWICZ, J. et al. Temporal coexistence mechanisms contribute to the latitudinal gradient in forest diversity. Nature, v. 550, p. 105-108, 2017.

VAN SCHAIK, C. P.; TERBORGH, J. W.; WRIGHT, S. J. The phenology of tropical forests: adaptative significance and consequences for primary consumers. Annual Review of Ecology and Systematics, v. 24, p. 353-377, 1993.

WRIGHT, S. J. Phenological Responses to Seasonality in Tropical Forest Plants. In: Mulkey S.S.; Chazdon R.L.; Smith A.P, editores. Tropical Forest Plant Ecophysiology. Boston: Springer. 1996. 


\title{
CAPÍTULO VII
}

\section{TAMANHO DO FRUTO E DISTÂNCIA DA PLANTA-MÃE AFETAM A TAXA DE PREDAÇÃO DE ATTALEA PHALERATA (ARECACEAE)?}

DDI: 10.51859/amplla.ecp672.1121-7

Naíssa Elvis Martinez Benites ${ }^{1}$

Tatiane do Nascimento Lima ${ }^{1,2}$

Camila Aoki ${ }^{1,2,3}$

\begin{abstract}
${ }^{1}$ Universidade Federal de Mato Grosso do Sul, Campus de Aquidauana, Grupo de Estudos Integrados em Biodiversidade do Cerrado e Pantanal, Rua Oscar Trindade de Barros, 740, Bairro da Serraria, Aquidauana, MS, Brasil, CEP: 79200-000.

${ }^{2}$ Universidade Federal de Mato Grosso do Sul, Programa de Pós-Graduação em Recursos Naturais, Faculdade de Engenharias, Arquitetura e Urbanismo e Geografia (FAENG), Av. Costa e Silva, s/n - Cidade Universitária, Campo Grande, MS, Brasil, CEP 79070-900.

${ }^{3}$ Universidade Federal de Mato Grosso do Sul, Programa de Pós-Graduação em Biologia Vegetal, Instituto de Biociências (INBIO), Av. Costa e Silva, s/n - Bairro Universitário, Campo Grande, MS, Brasil, CEP 79070-900.
\end{abstract}

\section{INTRODUÇÃO}

A palmeira Attalea phalerata Mart. ex Spreng (Arecaceae), conhecida popularmente como acuri, ocorre em grande abundância no Pantanal de Mato Grosso do Sul, aparecendo muitas vezes em formação monodominantes, denominadas de acurizais (POTT; POTT, 1994). 0 acuri é considerado uma espécie ecologicamente importante em áreas tropicais, sendo utilizada como recurso alimentar por uma grande variedade de organismos, especialistas ou generalistas, tais como cotia, gado, porco, caititu, anta, queixada, veado, araras, periquitos e outras aves (LORENZI et al., 1996; DONATTI et al., 2011).

A predação dos pirênios (endocarpo mais semente) de palmeiras por besouros da família Bruquidae é bem documentada e ocorre também no acuri. A predação de sementes por invertebrados é geralmente dependente da densidade, de forma que o acúmulo de frutos próximos a planta mãe pode levar a um aumento na taxa de predação nesse local (WILSON; JANZEN, 1972). O modelo proposto por Janzen-Connell seria explicado pelo fato de que próximo a planta mãe haveria uma maior densidade de sementes, o que aumentaria as chances de predação por 
herbívoros. O tamanho das sementes também pode influenciar os níveis de predação (RODRIGUES, 2013). Estudos demonstraram que a fêmea do besouro bruquíneos (Ordem Coleoptera, Família Chrysomelidae, Subfamília Bruchinae) selecionam sementes maiores na oviposição, o que garantiria uma maior taxa de sobrevivência à prole (MOEGENBURG, 1996; COPE; FOX, 2003).

Os besouros bruquíneos colocam seus ovos na superfície externa do endocarpo de frutos que se encontram no solo e as primeiras larvas o adentram através da cicatriz placentária, alcançando o endosperma do qual se alimentam completamente (DELOBEL et al., 1995). As larvas e pupas destes besouros possuem, além de um alimento rico, proteção por se encontrarem no endosperma que está revestido por um endocarpo lenhoso (GRENHA, 2007). A produção de sementes é um estágio crítico na história de vida das plantas e os processos que ocorrem em sementes e plântulas são de grande importância para o entendimento da dinâmica de populações e comunidades de plantas (SCHUPP, 1992). Os frutos das maiorias das palmeiras representam uma rica fonte de energia para muitos grupos animais, especialmente para aqueles que se alimentam de endosperma e mesocarpo. Como resultado, a predação das sementes acaba sendo um destino mais provável do que a germinação (HENDERSON, 2002).

O objetivo deste trabalho foi avaliar se o modelo Janzen-Connell pode ser aplicado para a palmeira $A$. phalerata em uma área de ecótono entre os biomas Cerrado e Pantanal. Para tal foi observado se a taxa de predação dos pirênios de $A$. phalerata é maior próximo à planta mãe. Adicionalmente, foi avaliado se ocorre relação entre o tamanho do pirênio e a ocorrência de predação dos besouros bruquídeos.

\section{METODOLOGIA}

O estudo foi conduzido na fazenda experimental da Universidade Estadual de Mato Grosso do Sul (2028'16”, 5547'14”W) (FEUEMS), localizada no município de Aquidauana, Mato Grosso do Sul. A FEUEMS apresenta relevo esculpido em rochas areníticas e possui 806 ha, com aproximadamente 300ha ocupados por áreas de pastagens e 160 ha da área de preservação permanente, além das áreas com construções prediais e cultivos (FINA; MONTEIRO, 2013). Localiza-se na região da 
Serra de Maracaju, ecótono Cerrado-Pantanal e nela ocorre contato savana-floresta estacional, representando uma área de grande beleza cênica (FINA; MONTEIRO, 2013).

A coleta dos pirênios do acuri foi realizada em outubro de 2014, no entorno de dez palmeiras diferentes, sendo a distância da planta mãe medida com auxílio de trena. Em laboratório foi verificado o número de orifícios encontrados em cada semente e com o auxílio de um paquímetro digital de 0,01 $\mathrm{mm}$ de precisão, obtidas medidas de maior comprimento e diâmetro, sendo considerado como tamanho do pirênio a multiplicação dessas duas medidas. Para verificar se houve diferença no tamanho dos pirênios predados e não predados por bruquídeos e também em relação à distância da planta mãe foi realizado teste $t$, utilizando o programa BioEstat 5.0, consideramos o nível de significância de 5\%.

\section{RESULTADOS E DISCUSSÃO}

Foram coletadas 234 sementes, das quais 79,7\% apresentaram infestação por bruquídeos, tendo de um a seis orifícios por pirênio. Este percentual é elevado, se comparado com outros estudos em espécies de palmeiras. Para esta mesma espécie, Quiroga-Castro e Roldan (2001), registraram na Bolívia uma predação de até $61 \%$ dos pirênios de acuri. Ramos et al. (2001) encontrou cerca de $40 \%$ das sementes de Acrocomia aculeata (Jacq.) Lodd. ex Mart. predadas pelo bruquíneo Speciomerus revoili (Pic). Silva et al. (2007) também observou altas taxas de predação de frutos de Syagrus romanzoffiana (Cham.) Glassman, com 61,8\% das sementes predadas. A alta predação de sementes poderia influenciar negativamente o recrutamento de jovens para a população das espécies hospedeiras (HUFFAKER et al., 1984). Em áreas onde a taxa de predação de sementes de palmeiras por dispersores como aves e mamíferos é baixa ou ausente, geralmente ocorre um aumento da predação por besouros embaixo das plantas-mães devido ao acúmulo de sementes (WRIGHT; DUBER, 2001).

Não foi registrada diferença entre a distância de frutos predados e não predados em relação à planta mãe $(\mathrm{t}=0,87 ; \mathrm{p}=0,19)$ (Figura 1). Vários estudos tem testado o modelo de Janzen-Connell e os resultados tem variado (CINTRA, 1997; WRIGHT, 2002; ALLMEN et al., 2004; RIOS; PACHECO, 2006; NORGHAUER, 2006, 
mas vide revisão feita por CARSON et al., 2008). Hyatt et al. (2003) usaram metanálise para examinar evidências experimentais da predição de dependência à distância da hipótese de Janzen-Connell de 40 estudos publicados e não encontraram suporte geral para a dependência à distância. Em revisão mais recente, Comita et al. (2014) avaliaram mais de 40 anos de publicações sobre o assunto e a análise revelou ampla variação entre as espécies na força dos efeitos dependentes da distância e da densidade, e esses efeitos foram significativamente mais fortes no estágio de plântulas em comparação com a predação de sementes.

Entre os fatores que podem interferir na taxa de predação estão as escalas espaciais e temporais analisadas, a abundância e distribuição espacial das plantas hospedeiras, capacidade de dispersão e especificidade alimentar do predador, dispersão pré-predação, tamanho dos fragmentos analisados e sua taxa de defaunação (PIZO, 1997; FORGET; KITAJIMA; FOSTER, 1999; QUIROGA-CASTRO; ROLDAN 2001; WRIGHT, 2002; ALVES-COSTA, 2004; ALLMEN et al., 2004; RIOS; PACHECO, 2006; CARSON et al., 2008). Entre os principais dispersores dos frutos de A. phalerata estão a anta (Tapirus terrestris), a cutia (Dasiprocta aguti) e o falconídeo carcará (Caracara plancus) (GALETTI e GUIMARÃES, 2004; NASCIMENTO et al., 2004; QUIROGA-CASTRO e ROLDAN, 2001). Poucas espécies são capazes de predar as sementes, entre elas há registro da arara-azul (Anodorhynchus hyacinthinus), dois ratos-de-espinho (Trychomys apereoides e Clyomys laticeps) e dos besouros bruquíneos (DELOBEL et al., 1995; GUEDES; HARPER, 1995; NASCIMENTO et al., 2004).

Os dados mostram que não houve diferença significativa no tamanho das sementes predadas e não predadas $(\mathrm{t}=1,09 ; \mathrm{p}=0,13$ ) (Figura 2). A infestação de algumas espécies de bruquíneos em frutos de palmeiras pode ocorrer antes da formação completa do pirênio (OLMOS et al., 1999), isto pode fazer com que fêmeas não selecionem o tamanho dos frutos. Estudos demonstraram que as sementes de palmeiras sem exocarpo e sementes velhas são mais predadas por larvas de besouros, do que sementes com exocarpo e sementes novas (cf. JANZEN, 1971; WRIGHT, 1983; DELGADO COUTURIER; DELOBEL, 1997). Tal fato ocorre devido à necessidade de uma abertura que libere o poro germinativo para que as larvas possam entrar e atingir o endosperma, uma vez que o exocarpo pode agir como barreira. Sendo assim, o tempo de exposição da semente no ambiente poderia ser 
uma resposta mais importante para a sua infestação por bruquíneos do que o tamanho da semente.

Figura 1. Diagrama em caixa (boxplot) com mediana, quartis e valores máximo e mínimo de distância dos pirênios predados e não predados de Attalea phalerata até a planta-mãe, na fazenda experimental da Universidade Estadual de Mato Grosso do Sul, Aquidauana, MS.

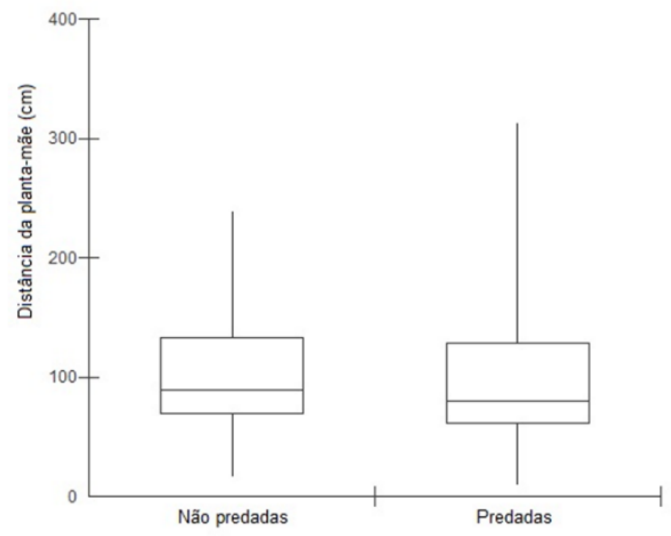

Fonte: Autoria própria.

Figura 2. Diagrama em caixa (boxplot) com mediana, quartis e valores máximo e mínimo de tamanho de pirênios de Attalea phalerata predados e não predados por bruquídeos na fazenda experimental da Universidade Estadual de Mato Grosso do Sul, Aquidauana, MS.

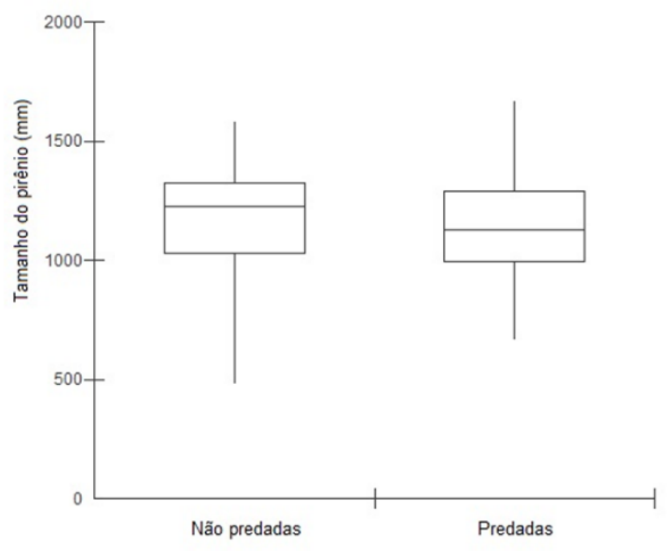

Fonte: Autoria própria.

\section{CONSIDERACÕES FINAIS}

Após a dispersão dos frutos de acuri (Attalea phalerata) pode ocorrer a predação do pirênio por besouros da família Bruchidae. Em área de ecótono Cerrado-Pantanal no Mato Grosso do Sul foi observada uma elevada taxa de predação $(79,7 \%)$ dos pirênios por besouros bruquídeos. A predação dos pirênios 
não esteve relacionada com a distância da planta-mãe, conforme proposto pelo modelo de Janzen-Connell. 0 tamanho dos pirênios não afetou a taxa de predação por besouros. 0 processo ecológico de predação de sementes é de extrema importância para avaliar o funcionamento de um ecossistema. Dessa maneira, estudos envolvendo aspectos da predação de sementes são particularmente importantes no entendimento da estrutura e a dinâmica de uma comunidade, o que se faz ainda mais importante em áreas pouco estudadas como a região de ecótono Cerrado-Pantanal.

\section{AGRADECIMENTOS}

O presente trabalho foi realizado com apoio da Universidade Federal de Mato Grosso do Sul - UFMS/MEC - Brasil e da Coordenação de Aperfeiçoamento de Pessoal de Nível Superior (CAPES). Os autores agradecem à Fundação de Apoio ao Desenvolvimento do Ensino, Ciência e Tecnologia do Estado de Mato Grosso do Sul (FUNDECT) pelo apoio aos projetos desenvolvidos pelo grupo de pesquisa "Estudos Integrados em Biodiversidade do Cerrado e Pantanal". Agradecemos à Universidade Estadual de Mato Grosso do Sul (UEMS), pela permissão de acesso à área de estudos.

\section{REFERÊNCIAS}

ALlMEN, C.V., MORELlATO, P.C.; PIZO, M.A. Seed predation under high seed condition: the palm Euterpe edulis in the Brazilian Atlantic Forest. Journal of Tropical Ecology, v. 20, p. 471-474, 2004.

ALVES-COSTA, C.P. Efeitos da defaunação de mamíferos herbívoros na comunidade vegetal. Tese de Doutorado, Universidade Estadual de Campinas, Campinas, $2004,107 \mathrm{p}$.

CARSON, W.P. et al. Challenges associated with testing and falsifying the JanzenConnell hypothesis: a review and critique. In Carson, W. P.; Schnitzer, S. A. (Eds). Tropical Forest Community Ecology. 2008. p. 219-241.

CINTRA, R. A test of the Janzen-Connell model with two common tree species in an Amazonian forest. Journal of Tropical Ecology, v. 13, p. 641-658, 1997.

COMITA, L. S.; QUEENBOROUGH, S. A.; MURPHY, S. J.; ECK, J. L.; XU, K.; KRISHNADAS, M.; BECKMAN, N.; ZHU, Y. Testing predictions of the Janzen-Connell hypothesis: a meta-analysis of experimental evidence for distance- and density-dependent seed and seedling survival. Journal of Ecology, v.102, n. 4, p. 845-856, 2014. 
COPE, J.M.; FOX, C.W. Oviposition decisions in the seed beetle, Callosobruchus maculatus (Coleoptera: Bruchidae): effects of seed size on superparasitism. Journal of Stored Products Research, v. 39, p. 355-365. 2003.

DELGADO, C.; COUTURIER, G.; DELOBEL, A. 1997. Oviposition of seed-beetle Caryoborus serripes (Sturm) (Coleoptera: Bruchidae) on palm (Astrocaryum chambira) fruits under natural conditions in Peru. Annals of the Society of Entomology, v. 33, p. 405-409, 1997.

DELOBEL, A. et al. 1995. Trophic relationships between palms and bruchids (Coleoptera Bruchidae: Pachymerini) in Peruvian Amazonia. Amazoniana, v. 13, p. 209-219, 1995.

DONATTI, C.I. et al. Analysis of a hyper-diverse seed dispersal network: modularity and underlying mechanisms. Ecology Letters, v. 14, p. 773-781, 2011.

FINA, B.; MONTEIRO, R. Análise da estrutura arbustivo-arbórea de uma área de cerrado sensu stricto, município de Aquidauana-Mato Grosso do sul. Revista Árvore, v. 37, n.4, p. 577-585, 2013.

FORGET, P.M.; KITAJIMA, K.; FOSTER, R. Pre-and post-dispersal in Tachigali versicolor (Caesalpinaceae): effects of timing of fruiting and variation among trees. Journal of Tropical Ecology, v. 15, p. 61-81, 1999.

GRENHA, V.; DE MACEDO, M.V.; MONTEIRO, R.F. Predação de sementes de Allagoptera arenaria (Gomes) O'Kuntze (Arecaceae) por Pachymerus nucleorum Fabricius (Coleoptera, Chrysomelidae, Bruchinae). Revista Brasileira de Entomologia, v. 52, p. 50-56, 2007.

GUEDES, N.M.R.; HARPER, L.H. Hyacionth macaws in the Pantanal, In: ABRAMSON, J.; SPEER, B. L.; THOMSEN, J. B. (Eds.). The large macaws: their care, breeding and conservation. Fort Bragg: Raintree Publications, 1995. p. 163-174.

HENDERSON, A. Evolution and ecology of palms. The New York Botanical Garden Press, Bronx, New York. 2002, 198 p.

HUFFAKER, C.B. et al. Insect influences in the regulation of plant populations and communities. In: HUFFAKER, C. B.,; RABB R. L. (eds.). Ecological Entomology. John Wiley; Sons, NY. 1984. pp. 659-691, 1984

HYATT, L.A. et al. The distance dependence prediction of the Janzen-Connell hypothesis: a meta-analysis. Oikos, v. 103, p. 590-602, 2003.

JANZEN, D.H. The fate of Scheelea rostrata fruits beneath the parent tree: predispersal attack by bruchids. Principes, v. 15, p. 89-101, 1971.

LORENZI, H. et al. Palmeiras no Brasil: nativas e exóticas. Nova Odessa: Plantarum. 1996, 303p. 
MOEGENBURG, S.M. Sabal palmetto seed size: causes of variation choices of predators, and consequences for seedlings. Oecologia, v. 106, n.4, p.539-543, 1996.

NASCIMENTO, V.L.A et al. Utilização de frutos de acuri (Attalea phalerata Mart. ex Spreng) por cutias (Dasyprocta azarae) no Pantanal da Nhecolândia. IV Simpósio sobre Recursos Naturais e Sócio-econômicos do Pantanal, 2004, Corumbá/ MS. Anais...p.1-7

NORGHAUER, J.M. et al. An experimental test of density and distant-dependent recruitment of mahogany (Swietenia macrophylla) in southeastern Amazonia. Oecologia, v.148, p. 437-446, 2006.

OLMOS, F. et al. Do tapirs steal food from palm seed predators or give them a lift? Biotropica, v. 31, p. 375-379, 1999.

PIZO, M. A. Seed dispersal and predation in two populations of Cabralea canjerana (Meliaceae) in the Atlantic Forest of south-eastern Brazil. Journal of Tropical Ecology, v. 13, p. 559-578, 1997

POTT, A.; POTT, V. J. 1994. Plantas do Pantanal. Brasília: Embrapa. 320 p.

QUIROGA-CASTRO, V. D.; ROLDÁN, A. I. The fate of Attalea phalerata (Palmae) seeds dispersed to a tapir latrine. Biotropica, v. 33, p. 472-477, 2001.

RAMOS, F.A. et al. Oviposição e predação por Speciomerus revoili (Coleoptera Bruchidae) em sementes de Acrocomia aculeata (Arecaceae) em Brasília, DF, Brasil. Brazilian Journal of Biology, v. 61, p. 449-454, 2001.

RIOS, R.S.; PACHECO, L.F. The effect of dung and dispersal on postdispersal seed predation of Attalea phalerata (Arecaceae) by bruchid beetles. Biotropica, v. 38, n. 6, p. 778-781, 2006.

RODRIGUES, L.M.S. Insetos predadores de sementes e suas relações com a qualidade e morfologia de frutos e sementes. Tese de doutorado, UNESP - Botucatu. 2013, 110 p.

SCHUPP, E. W. 1992. Annual variation in seedfall, postdispersal predation, and recruitment of a neotropical tree. Ecology 71: 504-515.

SILVA, F.R. et al. Predação de sementes de Syagrus romanzoffiana (Cham.) Glassman (Arecaceae) por Insetos na Ilha de Santa Catarina, SC. Revista Brasileira de Biociências, v. 5, p. 681-683, 2007.

WILSON, D.E.; JANZEN, D.H. Predation on Scheelea palm seeds by bruchid beetles: seed density and distance from the parent palm. Ecology, v. 53, p. 954-959, 1972.

WRIGHT, S.J. Plant diversity in tropical forests: a review of mechanisms of species coexistence. Oecologia, v. 130, p. 1-14, 2002. 
WRIGHT, S.J. The dispersion of eggs by a bruchid beetle among Scheelea palm seeds and the effect of distance to the parent palm. Ecology, v. 64, p. 1116-1021, 1983.

WRIGHT, S.J.; DUBER, H.C. Poachers and forest fragmentation alter seed dispersal, seed survival, and seedling recruitment in the palm Attalea butyracea, with implications for tropical tree diversity. Biotropica, v. 33, p. 583-595, 2001. 


\title{
CAPÍTULO VIII
}

\section{INTERAÇÃO ENTRE FORMIGAS (INSECTA, HYMENOPTERA) E ADENOCALYMMA PEREGRINUM (BIGNONIACEAE) EM PASTAGEM CULTIVADA, AQUIDAUANA-MS}

DDI: 10.51859/amplla.ecp672.1121-8

Jackeline Pereira da Silva ${ }^{1}$

Camila Aoki ${ }^{1,2,3}$

Tatiane do Nascimento Lima ${ }^{1,2}$

\begin{abstract}
${ }^{1}$ Universidade Federal de Mato Grosso do Sul, Campus de Aquidauana, Grupo de Estudos Integrados em Biodiversidade do Cerrado e Pantanal, Rua Oscar Trindade de Barros, 740, Bairro da Serraria, Aquidauana, MS, Brasil, CEP: 79200-000.

${ }^{2}$ Universidade Federal de Mato Grosso do Sul, Programa de Pós-Graduação em Recursos Naturais, Faculdade de Engenharias, Arquitetura e Urbanismo e Geografia (FAENG), Av. Costa e Silva, s/n - Cidade Universitária, Campo Grande, MS, Brasil, CEP 79070-900.

${ }^{3}$ Universidade Federal de Mato Grosso do Sul, Programa de Pós-Graduação em Biologia Vegetal, Instituto de Biociências (INBIO), Av. Costa e Silva, s/n - Bairro Universitário, Campo Grande, MS, Brasil, CEP 79070-900.
\end{abstract}

\section{INTRODUÇÃO}

Na associação entre plantas e formigas (Insecta, Hymenoptera), esses insetos têm sido observados patrulhando plantas que apresentam nectários extraflorais (NEFs). Essas estruturas são glândulas que secretam néctar que não estão diretamente relacionadas à polinização e podem estar localizados em folhas, pecíolos, ramos, estípulas ou próximas às partes reprodutivas (OLIVEIRA; OLIVEIRA-FILHO, 1991; DEL-CLARO; SANTOS, 2000). Os NEFs representam uma fonte de carboidratos, aminoácidos, vitaminas, água e outros compostos orgânicos. Sendo um valioso recurso alimentar para as formigas e outros artrópodes (BAKER et al., 1978; OLIVEIRA; BRANDÃO, 1991; RUHREN; HANDEL 1999).

Além do NEF, a presença de flor nos ramos das plantas, pode representar um aspecto que também interfere no patrulhamento das formigas. Dado o fato das flores receberem continuamente herbívoros, polinizadores e outros artrópodes como as aranhas, o patrulhamento de formigas, na tentativa de defender o recurso alimentar, nos ramos com flores pode ser maior do que o observado nos ramos sem flores 
(OLIVEIRA; OLIVEIRA-FILHO, 1991; NENTWIG, 1993; FARIA; LIMA, 2008). Além do recurso alimentar para os polinizadores, os ramos com flores acrescentam outra dimensão à arquitetura das plantas, devido à mudança nas condições microclimáticas e à disponibilidade de refúgio contra predadores para muitos artrópodes (SOUZA; MÓDENA, 2004).

$\mathrm{Na}$ relação conhecida como mutualismo, espécies diferentes podem se associar para aumentar suas chances de sobrevivência, ambas provendo e recebendo benefícios (HOWE; WESTLEY, 1988). Nestes tipos de relação, uma das espécies oferece um serviço ou produto que seu parceiro não pode conseguir sozinho e, em troca, recebe algum tipo de recompensa (HOEKSEMA; BRUNA, 2000; BRONSTEIN et al., 2006). Nesse contexto, diversas plantas atraem e recompensam as formigas, que por sua vez impedem ou matam os herbívoros que tentam atacar essas plantas (SCHUPP; FEENER, 1991; BRONSTEIN, 1994).

As relações entre formigas e plantas são complexas e fundamentais na distribuição e na abundância das espécies, através do tempo e do espaço. 0 entendimento dessas relações apresenta profundas implicações para a ecologia e os processos evolutivos dos organismos envolvidos (MELO; SILVA-FILHO, 2002). 0 papel protetor das formigas está bem estabelecido para algumas espécies, mas o seu papel não é universal, e os resultados podem variar (PEREIRA; TRIGO, 2013).

No momento de proteção da planta, as formigas podem atacar e remover artrópodes que visitam as flores (OLIVEIRA; OLIVEIRA-FILHO, 1991). Nesse processo as formigas também podem expulsar os polinizadores, o que pode levar a efeito negativo na reprodução da planta (HEIL; MCKEY, 2003; MALÉ et al., 2011; VEJA; HERRERA, 2013; CEMBROWSKI et al., 2014). Por outro lado, Stanley e colaboradores (2012) sugerem que a presença das formigas pode ter um efeito indireto, mas positivo. Quando as formigas expulsam os polinizadores, esses são induzidos a mudar de flor, resultando em um aumento no número de flores visitadas por unidade de tempo.

$\mathrm{O}$ arbusto Adenocalymma peregrinum (Miers) L. G. Lohmann pertencente à família Bignoniaceae, apresenta cerca de 1,5 m de altura e flor tubular de cor amarela. A espécie ocorre em áreas de Cerrado nos estados brasileiros de Mato Grosso, Goiás, Minas Gerais, Rio de Janeiro, Mato Grosso do Sul, São Paulo e Paraná (LOHMANN, 2010; MACHADO; ROMERO, 2014). A espécie A. peregrinum é 
considerada uma importante espécie invasora de pastagem. Por se tratar de uma espécie de pequeno porte e que necessita de luz direta e intensa, A. peregrinum faz parte das espécies vegetais que crescem primeiro durante o processo de regeneração (RICHARDS, 1996; NUNES, 1999, 2001, GRASSI et al., 2005).

Dentro da família Bignoniaceae muitas espécies são patrulhadas por formigas que se alimentam de nectários extraflorais (NOGUEIRA et al., 2012; BÄCHTOLD; ALVES-SILVA, 2013). No caso do arbusto A. peregrinum os NEF estão na região interpeciolar dos ramos. Enquanto que, no cálice e no fruto de A. peregrinum não há NEFs (SAMBAIO et al., 2016). 0 que poderia levar a um menor número de formigas nesses ramos. Por outro lado, a presença da flor, responsável por gerar recurso e atrair outros artrópodes, poderia levar a um aumento no número de formigas nesses ramos. 0 objetivo deste trabalho foi avaliar a ocorrência de formigas e outros artrópodes (outros insetos e aranhas) em ramos com e sem flor de A. peregrinum em uma área de pastagem cultivada no município de Aquidauana, MS.

\section{METODOLOGIA}

O estudo foi realizado no município de Aquidauana, situado na porção centro-oeste do estado de Mato Grosso do Sul, na depressão do Rio Paraguai. A região é localizada na área de transição entre a Planície Pantaneira e o Planalto de Maracaju-Campo Grande (RODRIGUES et al., 2017). O clima da região, segundo a classificação descrita por Köppen-Geiger é do tipo Aw (Tropical de Savana) com precipitação média anual de $1200 \mathrm{~mm}$ e temperaturas médias de $26,2{ }^{\circ} \mathrm{C}$, com inverno seco e verão chuvoso (ALVARES et al., 2013).

A coleta de dados foi realizada em área particular $\left(20^{\circ} 28^{\prime} 23^{\prime \prime} \mathrm{S} 55^{\circ} 44^{\prime} 07^{\prime \prime} \mathrm{W}\right)$ com um total de 35 ha e localizada a aproximadamente 9,5 km do perímetro urbano. A área está envolta por fisionomias de Cerrado e, anteriormente à introdução da pastagem cultivada, era um cerrado de típico a denso. 0 histórico de uso da área para pecuária é de pelo menos três décadas, onde se cultivou pastagem para o consumo do gado bovino, principalmente com a braquiária Urochloa spp. Atualmente, parte da área é utilizada para plantação de bananas e outra parte ainda é coberta por pastagem exótica. 
As coletas dos ramos de A. peregrinum foram realizadas no mês de fevereiro de 2019. Foram coletados 15 ramos com flor e 15 ramos sem flor de 15 indivíduos de A. peregrinum, medindo 30 centímetros cada ramo. Para a coleta utilizamos sacos plásticos para manuseio das plantas, até o local da triagem. Para não haver dispersão dos organismos coletados utilizamos a técnica de resfriar os sacos plásticos em congelador para melhor eficácia na hora da triagem.

Durante o processo de triagem os ramos foram alocados em uma bandeja para retirada de todos os artrópodes ali existentes, com auxílio de uma lupa e pinças. As formigas (Hymenoptera) foram enviados a especialista para identificação e os demais artrópodes foram separados por morfoespécies. A comparação do número de formigas entre os ramos com flor e sem flor de $A$. peregrinum foi feito através de Teste $\mathrm{t}$ pareado. A análise foi feita no software livre MyStat (https://systatsoftware.com/downloads/download-mystat/).

\section{RESULTADOS E DISCUSSÃO}

Foi observado um total de 145 artrópodes nos ramos de $A$. peregrinum com flor e sem flor, sendo110 formigas, 18 aranhas e 17 outros insetos (não-formigas) (Figura 1).

Figura 1. Total de artrópodes observados nos ramos com flor e sem flor de Adenocalymma peregrinum (Bignoniaceae) em pastagem cultivada, Aquidauana-MS.

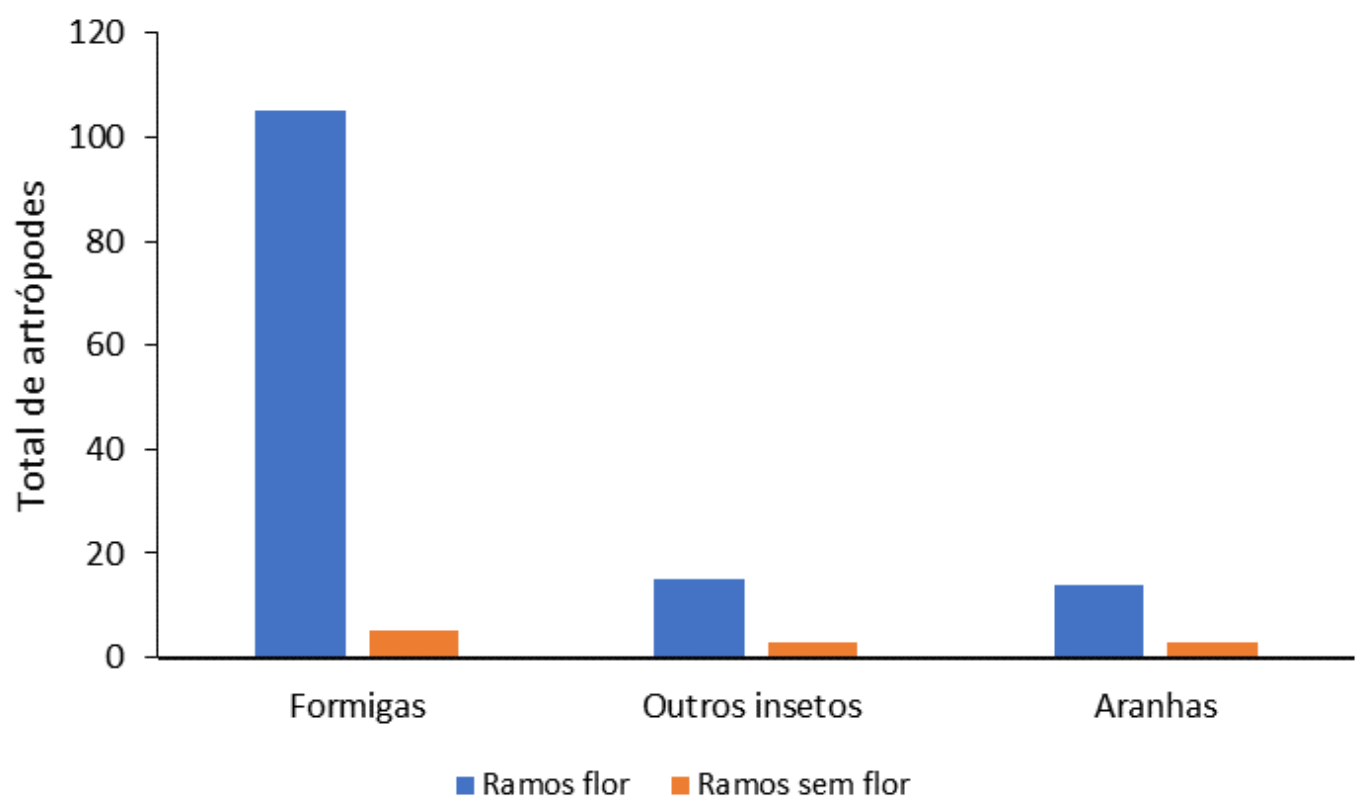

Fonte: Autoria própria. 
Do total de formigas, 105 estavam nos ramos com flor e apenas cinco nos ramos sem flor $(\mathrm{t}=2,34 ; \mathrm{gl}=14 ; \mathrm{p}=0,03)$. Foram coletadas sete espécies de formigas: Brachymyrmex patagonicus, Camponotus blandus, Camponotus crassus, Cephalotes pusillus, Crematogaster sp., Dorymyrmex brunneus e Pheidole gertrudae. Dessas, apenas as Ce. pusillus e Ca. crassus estavam nos ramos sem flor. A espécie $P$. gertrudae representou $78 \%$ da amostra de formigas. Formigas deste gênero são consideradas oportunistas do solo e de vegetação, as espécies constroem ninhos em locais diversificados e forrageiam em grandes áreas, tanto no solo como na vegetação, têm grandes colônias e recrutamento em massa (SILVESTRE; BRANDÃO; SILVA, 2003).

Quanto aos outros insetos (não formigas), do total observado, 14 estavam nos ramos com flor e três nos ramos sem flor de A. peregrinum. Entre esses, foram observados representantes das ordens Coleoptera, Blattaria, Hemiptera e Orthoptera. Quanto ao total de aranhas, 15 estavam nos ramos com flor e três nos ramos sem flor de A peregrinum. As aranhas foram classificadas em cinco morfoespécies.

A maior abundância de formigas e de outros artrópodes nos ramos com flores de $A$. peregrinum observada nesse trabalho, sugerem que a presença da estrutura floral na planta, representa para os organismos ali encontrados um microhabitat importante na oferta de recurso, de abrigo e/ou de reprodução. A flor está diretamente relacionada a evolução do processo reprodutivo das plantas. Mas, além da reprodução as flores desempenham diversas funções, tais como, recurso alimentar para herbívoros e abrigo de diversos artrópodes contra predadores (KARBAN; STRAUSS, 1993; CARIVEAU et al., 2004). 0 que ao mesmo tempo gera um local com alta densidade de presas para os predadores desses artrópodes (SOUZA; MÓDENA, 2004; SOUZA, 2007).

As flores são recursos extremamente ricos, podendo atrair tanto organismos mutualistas (e.g., polinizadores e as formigas) quanto os antagonistas, como herbívoros, pilhadores de recursos florais e predadores de sementes (KARBAN; STRAUSS, 1993; GALEN, 1999; CARIVEAU et al., 2004). A presença de todos esses organismos, convivendo em um mesmo microhabitat, é extremamente complexa do ponto de vista ecológico. Vários estudos têm sido desenvolvidos com o intuito de entender as variáveis de afetam essas relações e como essas relações podem ser 
positivas ou negativas para os organismos envolvidos (LOUDA, 1982; ASSUNÇÃO et al., 2014).

Dentro da perspectiva apresentada nesse trabalho, a relação entre as formigas e A. peregrinum, pode ter sido estabelecida pela presença dos NEFs, mas a presença da flor também deve ser considerada nos estudos envolvendo o patrulhamento das formigas. Bem como, a teia de interação desenvolvida com os diversos artrópodes que utilizam a estrutura floral.

\section{CONSIDERAÇÕES FINAIS}

0 arbusto $A$. peregrinum é um invasor de pastagem, sendo considerado um problema em áreas de pastagens cultivadas, principalmente aquelas em adiantado estado de degradação. 0 entendimento de aspectos da biologia e ecologia de $A$. peregrinum podem colaborar com estudos que envolvam seu manejo nessas áreas. Além disso, os dados desse trabalho demonstram que ramos com flores de $A$. peregrinum sustentam uma comunidade de artrópodes. Esses artrópodes, em destaque as formigas, desempenham uma complexa relação ecológica com $A$. peregrinum, a qual poderá ser investigada em trabalhos futuros. Através destes trabalhos poderão ser obtidas respostas mais finas dos fatores reguladores dessa coexistência. E ainda, a observação se essa associação entre essas diferentes espécies pode aumentar suas chances de sobrevivência, dentro do processo conhecido como mutualismo, com as espécies envolvidas promovendo e recebendo benefícios. $\mathrm{Ou}$, se a relação entre $A$. peregrinum e as formigas é facultativa e/ou oportunista.

\section{AGRADECIMENTOS}

Agradecemos à Mariah Tibcherani pela identificação das formigas e ao Rogério Rodrigues Faria pela ajuda na coleta dos dados.

\section{REFERÊNCIAS}

ALVARES, C. A. Köppen's climate classification map for Brazil. Meteorologische Zeitschrift, v. 22, n. 6, p. 711-728, 2013. 
ASSUNÇÃO, M.A.; TOREZAN-SILINGARDI, H.M.; DEL-CLARO, K. Do ant visitors to extrafloral nectaries of plants repel pollinators and cause an indirect cost of mutualisms. Flora, v. 209, p. 244-249, 2014.

BAKER, D. A.; HALL, J. L.; THORPE, J. L. A study of the extrafloral nectaries of Ricinus communis. New Phytologist, v. 81, p. 129-137, 1978.

BRONSTEIN, J. L. Our current understanding of mutualism. The Quarterly Review of Biology, v. 69, p. 31-51, 1994.

BRONSTEIN, J. L.; ALÁRCON, R.; GEBER, M. The evolution of plant-insects mutualisms. New Phytologist, v. 172, p. 412-428, 2006.

BÄCHTOLD, A.; ALVES-SILVA, E. Behavioral strategy of a lycaenid (Lepidoptera) caterpillar against aggressive ants in a Brazilian savanna. Acta Ethologica, v. 16 , p. 83-90, 2013.

CARIVEAU, D. et al. Direct and indirect effects of pollinators and seed predators to selection on plant and floral traits. Oikos, v. 104, p. 15-26, 2004.

CEMBROWSKI, A. R., et al. Ants and ant scent reduce bumblebee pollination of artificial flowers. The American Naturalist, v. 183, p. 133-139, 2014.

DEL-CLARO, K.; SANTOS, J. C. A função de nectários extraflorais em plantas do cerrado. In: Cavalcanti, T.B. (Ed). Tópicos atuais em botânica. Brasília, Embrapa, ed. 400p. 2000.

FARIA, R. R.; LIMA, T. N. Spiders associated with Psychotria carthagenensis Jacquin. (Rubiaceae): vegetative branches versus inflorescences, and the influence of Crematogaster sp. (Hymenoptera, Formicidae), in South-Pantanal. Brazilian Journal Biology, v. 68, n. 2, p. 229-232, 2008.

GALEN, C. Why do flowers vary? The functional ecology of variation in flower size and form within natural plant populations. Bioscience, v. 49, p. 631-640, 1999.

GRASSI, R. F. et al. Estudo fitoquímico e avaliação alelopática de Memora peregrina - ciganinha - Bignoniaceae, uma espécie invasora de pastagens em Mato Grosso do Sul. Química Nova, v. 28, p. 199-203, 2005.

HOWE, H. F.; WESTLEY, L. C. Ecological relationships of plants and animals. Oxford University Press, New York, 1988.

HOEKSEMA, J. D.; BRUNA, E. M. Pursuing the big questions about interspecific mutualism: a review of theoretical approaches. Oecologia, v. 125, p. 321-330, 2000.

HEIL, M.; MCKEY, L. C. Protective ant-plant interactions as model systems in ecological and evolutionary research. Annual Review of Ecology, Evolution, and Systematics, v. 34, p. 425-453, 2003. 
KARBAN, R.; STRAUSS, S. Y. Effects of herbivores on growth and reproduction of their perennial host, Erigeron glaucus. Ecology, v. 74. p. 39-46, 1993.

LOUDA, S. M. Inflorescence spiders: a cost/benefit analysis for the host plant, Haplopappus venetus Blake (Asteraceae). Oecologia, v. 55, p. 185-191, 1982.

LOHMANN L. G. Bignoniaceae. In: Lista De Espécies Da Flora Do Brasil. Jardim Botânico do Rio De Janeiro [online]. Jardim Botânico do Rio de Janeiro, Rio de Janeiro (2010). Available from: http://floradobrasil.jbrj.gov.br/reflora/floradobrasil/FB112409 (accessed 06/06/2020).

MELLO, M. O.; SILVA-FILHO, M. C. Plant-insect interactions: an evolutionary arms race between two distinct defense mechanisms. Brazilian Journal of Plant Physiological, v. 14, n. 2, p. 71-81, 2002.

MALÉ, P. J. G.; LEROY, C.; DEJEAN, A.; QUILICHINI, A.; ORIVEL. J. An ant symbiont directly and indirectly limits its host plant's reproductive success. Evolutionary Ecology, v. 26, p. 55-63, 2011.

MACHADO, A. I. M. R.; ROMERO, R. Bignoniaceae from mountains of Capitólio and Delfinópolis municipalities, Minas Gerais state. Rodriguésia, v. 65, n. 4, p. 1003-1021, 2014.

NENTWIG, W. Spiders of Panama. Biogeography, investigation, phenology, check list, key and bibliography of a tropical spider fauna. Fauna and Flora Handbook no. 12. Gainesville, USA: Sandhill Crane Press. 247p. 1993.

NUNES, S. G. Ciganinha Memora Peregrina (Miers) Sandw Nova Planta Invasora De Pastagem. Embrapa Gado De Corte Divulga/N³5, 1999.

NUNES, S. G. Controle De Plantas Invasoras Em Pastagens Cultivadas Nos Cerrados. Embrapa Gado de Corte, Campo Grande, 2001.

NOGUEIRA, A. et al. Do extrafloral nectaries present a defensive role against herbivores in two species of the family Bignoniaceae in a Neotropical savannas? Plant Ecology, v. 213, p. 289-301, 2012.

OLIVEIRA, P. S.; BRANDÃO, C. R. F. The ant community associated with extrafloral nectaries in Brazilian cerrados, p. 198-212. In D. F. Cutler; C. R. Huxley (eds.), Ant-Plant Interactions. Oxford, Oxford University Press, 601 p. 1991.

OLIVEIRA, P. S.; OLIVEIRA-FILHO, A. T. Distribution of extrafloral nectarines in the woody flora of tropical communities in westernBrazil. In: Price, P. W.; Lewinsohn, T. M.; Fernandes, G. W.; Benson, W. E. (eds.). Plant-animal interactions. John Wiley and Sons, New Yourk, NY. 163-175, 1991.

PEREIRA, M. F.; TRIGO, J. R. Ants have a negative rather than a positive effect on extrafloral nectaried Crotalaria pallida performance. Acta Oecologica, v. 51, p. 49-53, 2013. 
RICHARDS, P. W. The tropical rainforest: an ecological study. 2.ed. Cambridge University Press, Cambridge, 1996.

RUHREN, S.; HANDEL, S. N. 1999. Jumping spiders (Salticidae) enjance the seed production of a plant with extrafloral nectaries. Oecologia, v. 119, p. 227-230, 1999.

RODRIGUES, L. P.; CARVALHO, E. M.; SILVA, J. F. Unidades de Conservação no Ecótono entre Pantanal e Cerrado: o caso do Município de Aquidauana (MS). I Congresso Nacional de Geografia Física. Campinas, p. 1070-1081, 2017.

SCHUPP, E. W.; FEENER, D. H. Phylogeny, lifeform, and habitat dependence of antdefended plants in a Panamanian forest. In: Huxley CH, Cutler DF, eds. Antplant interactions. Oxford, UK: Oxford University Press, p. 175-197, 1991.

SILVESTRE, R.; BRANDÃO, C. R. F.; SILVA, R. R. Grupos funcionales de hormigas: El caso de los 693 gremios del Cerrado, Brasil. p. 113-143. In: Fernàndez F. (eds.), Introducción a las Hormigas de la Región Neotropical Bogotá, Instituto Humboldt, 398 p. 2003.

SOUZA, A. L. T.; MÓDENA, E. S. Distribution of spiders on different types of inflorescences in the Brazilian Pantanal. The Journal of Arachnology, v. 32, n. 2, p. 345-348, 2004.

SOUZA, A. L. T. Influência da estrutura do habitat na distribuição de aranhas. In GONZAGA, MO., JAPAYASSÚ, HF. and SANTOS, AJ. (eds). Ecologia e comportamento de aranhas, ed. Interciencia. Rio de Janeiro, 400 p, 2007.

STANLEY, M. C. et al. Invasive interactions: can Argentine ants indirectly increase the reproductive output of a weed? Arthropod-Plant Interactions, v. 7, p. 59$67,2012$.

SAMPAIO, D. S. et al. Pollination biology and breeding system of syntopic Adenocalymma nodosum and $A$. peregrinum (Bignonieae, Bignoniaceae) in the Brazilian savana. Flora, 223, 19-29, 2016.

VEGA, C. DE; HERRERA, C. M. Microorganisms transported by ants induce changes in floral nectar composition of an ant-pollinated plant. American Journal of Botany, v. 100, p. 792-800, 2013. 


\section{CAPÍTULO IX}

\section{A FAUNA DE MOLUSCOS E A OCORRÊNCIA DE BIOINVASORES EM DUAS LAGOAS DE MEANDRO ABANDONADO NO MUNICÍPIO DE AQUIDAUANA/MS, UM ESTUDO INICIALSOBRE A CLASSE BIVALVIA}

DDI: 10.51859/amplla.ecp672.1121-9

Eron Marques Barbosa ${ }^{1}$

Ricardo Henrique Gentil Pereira ${ }^{2}$

Adriana Barros ${ }^{3}$

${ }^{1}$ Acadêmico da Universidade Federal de Mato Grosso do Sul.

${ }^{2}$ Professor da Universidade Federal de Mato Grosso do Sul.

${ }^{3}$ Técnica do Laboratório de Limnologia - CPAQ/UFMS.

\section{INTRODUÇÃO}

O município de Aquidauana está localizado na região Centro-Oeste do país, encontra-se na porção oeste do Estado de Mato Grosso do Sul, sendo o início da planície pantaneira sul-mato-grossense. Sua altitude corresponde aproximadamente a 147,663 metros em relação ao nível do mar, distante da capital 139 km, a área urbana do município é banhada pelo rio Aquidauana, pelos córregos João Dias e Guanandy. A extensão territorial do município é de 16.957,783 Km² sua população é de 45.614, segundo dados do IBGE (2010).

O filo Mollusca é composto por sete classes, todas com representantes marinhos, das quais apenas Gastropoda e Bivalvia possuem representantes de água doce. Os bivalves são em geral, os animais bentônicos melhor representados em termos de biomassa, nos diversos locais que envolvem sistemas limnicos (MANSUR et al., 1987). Os moluscos bivalves de água doce até hoje registrados no Brasil pertencem a dois grandes grupos: os da ordem Unionoida e os da ordem Veneroida. Os membros da ordem Unionoida apresentam larvas do tipo véliger modificado, que podem ser parasitos temporários de peixes em algumas espécies e, de acordo com particularidades morfológicas, são denominadas glochidium ou lasidium (MANSUR et al., 1987). 
Esses organismos possuem grande importância para a cadeia alimentar, ocupando uma posição intermediária, se alimentando de algas e micro-organismos, tendo-os como sua fonte primária de recurso alimentar. Ao mesmo tempo, são predados por peixes e aves, sendo responsáveis, portanto pela manutenção dessas comunidades, além de seu alto potencial bioindicador (KARR, 1991). A camada nacarada das conchas pode ser utilizada como núcleo de pérolas cultivadas, pequenas lascas de nácar são incluídas nos pisos de granilite, são utilizados também na elaboração de peças de artesanatos, botões e de enfeites corporais; podendo ser utilizadas ainda como alimento para criações e para o ser humano, por possuir alto valor nutricional, com um conteúdo proteico próximo a do pescado. Segundo Avelar (1993), no Brasil existem cerca de 115 espécies distribuídas principalmente, em quatro famílias: Hyriidae, Mycetopodidae, Sphaeridae e Corbiculidae. Há expectativa de que a quantidade de espécies em nosso país alcance o número de 150.

Tendo como foco o estudo da fauna de moluscos bivalves para levantamento quali-quantitativo e registro de espécies existentes na região, foram escolhidas lagoas de meandro abandonado no município de Aquidauana localizadas próximas ao leito do rio e fazem parte da bacia do rio que nomeia a cidade, e que devido ao ciclo das cheias recebem água funcionando como área de refúgio e reprodução de várias espécies. Foram realizados estudos preliminares que indicaram a presença de moluscos bivalves, despertando o interesse na pesquisa, verificando também, a ocorrência de espécies exóticas invasoras, que representam uma ameaça para biodiversidade e o equilíbrio do ecossistema natural.

Uma espécie é exótica quando ela ocorre em um ecossistema onde não é nativa. Segundo Valéry et al. (2008) a "invasão biológica" consiste de espécies que adquirem uma vantagem competitiva, seguida do desaparecimento de obstáculos naturais à sua proliferação, o que permite que ela se disperse rapidamente e conquiste novas áreas, nas quais se tornem uma população dominante. A introdução de espécies é considerada pelo Ministério do Meio Ambiente a segunda maior causa de diminuição da biodiversidade, ficando atrás apenas da modificação de habitat, as espécies invasoras modificam o equilíbrio existente, levando a situações irreversíveis, como a extinção de espécies nativas.

Pouco ainda se conhece a respeito da fauna de moluscos bivalves da região de Aquidauana, neste trabalho propôs-se além de contribuir para o levantamento 
das espécies existentes, estimar a população e verificar a ocorrência e de moluscos exóticos invasores.

\section{MATERIAIS E MÉTODOS}

\section{1. ÁREA DE ESTUDO}

A área de estudo e coleta dos moluscos correspondeu em Lagoas de meandro abandonado, que são lagos marginais, e fizeram, no passado, parte do leito do rio Aquidauana. 0 período das coletas foi compreendido entre os meses de agosto a outubro de 2012, período de seca na região estudada. As lagoas estão localizadas à margem direita do rio, possuem características semelhantes, porém apresentaram diferenças na diversidade de espécies de moluscos encontrados e nos dados físicoquímico da água.

A primeira lagoa é denominada Lagoa do Ismael, localizada próxima ao centro urbano do município; localizada entre os paralelos 20²8'09.15" a

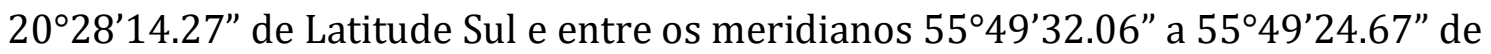
Longitude 0 (Figura 1).

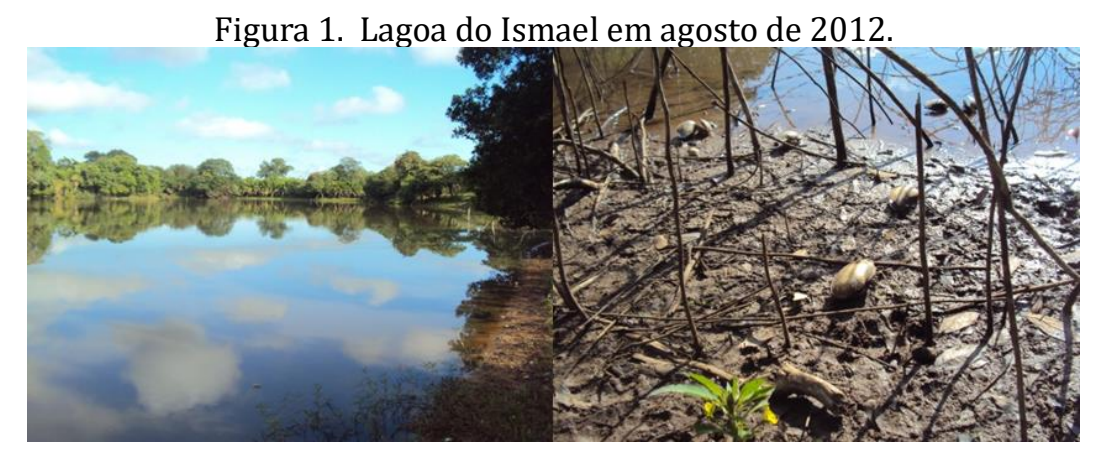

Fonte: Barbosa, E. M.

A segunda lagoa estudada é denominada Lagoa da Volta Grande por se encontrar dentro da Fazenda Volta Grande, foi formada recentemente, há cerca de 10 anos, está localizada à margem direita do Rio Aquidauana entre os paralelos $20^{\circ} 28^{\prime} 09.15^{\prime \prime}$ a $20^{\circ} 28^{\prime} 14.27^{\prime \prime}$ de Latitude Sul e entre os meridianos 55²9'24.67" a 5549’32.06" de Longitude 0 (Figura 2). 
Figura 2. Lagoa da Volta Grande em outubro de 2012.

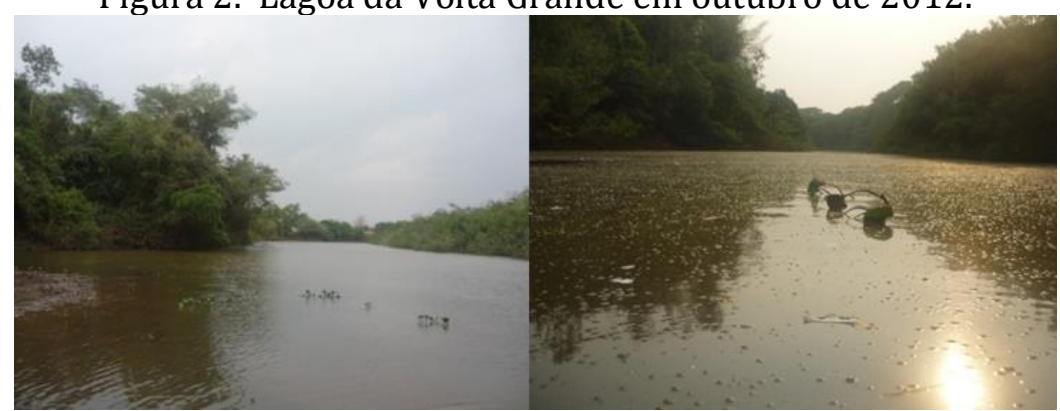

Fonte: Pereira, R. H. G.

\subsection{PROCEDIMENTOS AMOSTRAIS}

Foram selecionados em cada uma das lagoas, seis pontos amostrais distintos, escolhidos aleatoriamente. Também foram coletadas as conchas encontradas nas margens das lagoas. Os exemplares foram coletados manualmente com auxílio de um puçá de 0,30mm de malha, foram utilizados uma Draga (busca fundo) de Pitersen modificada (3 litros), uma Draga (busca fundo) de Van Veem, um quadrante de $1 \mathrm{~m}^{2}$, as buscas foram realizadas no interior do quadrante a aproximadamente 30 cm de profundidade. Dado o fato dos bivalves se localizarem normalmente com 2/3 da concha enterrada na areia, foram utilizadas também uma Sonda multiparâmetro para coleta dos dados físico-químico da água. Os moluscos coletados foram acondicionados em sacos plásticos, juntamente com uma pequena quantidade de água, o sedimento dragado foi fixado com formol $4 \%$ e acondicionados separadamente, o material coletado posteriormente foi recolhido ao laboratório.

Em laboratório as conchas coletadas foram medidas com o auxílio de um paquímetro e fotografadas, posteriormente as com parte mole foram relaxadas em água ambiente com gotas de álcool etílico e conservadas em álcool 70․․ Os exemplares coletados sem parte mole foram guardados a seco. A lavagem do sedimento foi em água corrente com o uso de peneira GRANUTEST com $0.5 \mathrm{~mm}$ de abertura de malha. Obedecendo a critério adotado pela International Organization for Standardization - ISO 7828 (apud ANDRADE, 1999). A cada ponto foi retirada quatro dragadas, que segundo Cummins (1962, apud ANDRADE, 1999), são necessárias, no mínimo, três dragadas para que a amostra seja representativa, sendo que uma foi utilizada para análise granulométrica. A triagem do material dragado foi feita manualmente, com o auxílio de esteriomicroscópio, pinças e agulhas histológicas, que os organismos triados foram conservados em álcool 70\%. 


\section{RESULTADOS E DISCUSSÃO}

Os moluscos foram coletados e identificados 475 exemplares, pertencentes a oito táxon diferentes, quatro espécies de moluscos bivalves nativos da América do Sul, pertencentes a Familia Mycetopodidea: Anodontites trapesialis (Lamark, 1819), Anodontites elongatus (Swainson, 1823), e Mycetopoda siliquosa (Spix, 1827); da família Sphaeridea os moluscos do gênero Eupera sp (Bourguinat, 1854). 0 estudo constatou a presença de moluscos gastrópodes nativos da família Ampullaridae o gênero Pomacea sp (Perry, 1810) e da família Planorbiidae o gênero Biomphalaria $s p$ (Preston, 1910). Foram registrados também moluscos exóticos invasores sendo eles: o primeiro pertence à classe Bivalvia, Ordem Veneroida, família Corbiculidae, a espécie Corbicula fluminea (Müller, 1774); a segunda espécie exótica encontrada, pertence a classe gastropoda, ordem Mesogastropoda, família Thiaridae, espécie Melanoides tuberculata (Müller, 1774).

\subsection{ANODONTITES TRAPESIALIS (LAMARK, 1819)}

Bivalve de água doce, conhecido com o nome de "saboneteira", exclusivo da América do Sul, que se diferencia dos demais Unionoidas por possuir uma larva do tipo lasidium, parasita temporária de peixes. Nesta família bem como nos Hyriidae, as demibrânquias têm também função de marsúpio, onde ocorre o desenvolvimento das larvas (CALLIL; MANSUR, 2007), ocorre em ambientes de água doce, lênticos ou lóticos, embora segundo Simone (1994), dificilmente seja encontrada em locais com águas rápidas. É o bivalve nativo mais abundante na região sendo encontrado nas duas lagoas. Nas espécies de A. trapesialis a forma da concha varia de oval a elíptica, os bivalves micetopodídeos ficam semi-enterrados em sedimentos de variáveis composições granulométricas, com populações mais densas em fundos argilosos ou argilo-arenosos, a parte interna de sua concha contém o nácar, uma camada brilhosa cinza azulado (Figura 3). 
Figura 3. A. trapesialis (Lamark, 1819), face externa (A) e face interna (B) coletada em outubro de 2012.

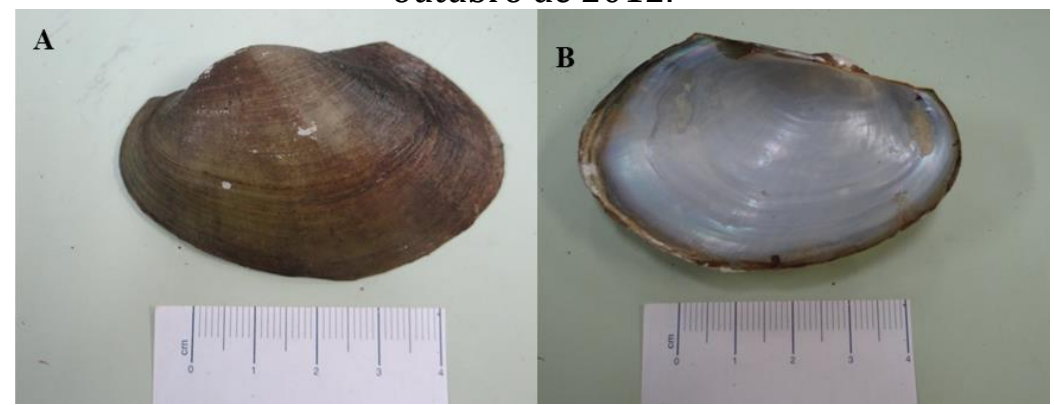

Fonte: Barbosa, E. M.

\subsection{ANODONTITES ELONGATUS (SWAINSON, 1823)}

Bivalve também nativo da América do Sul, encontrado somente em uma das lagoas, a Lagoa da Volta Grande, é bastante semelhante ao A. trapesialis no formato da concha, possuindo uma coloração mais escura e sua concha e mais espessa e consistente, são conhecidos como marisquinho pantaneiro, no substrato suas conchas ficam mais profundas, totalmente inseridas no substrato, também possui a camada nacarada e por possuir conchas mais grossas podem ser usadas para confecção de botões de artesanato (Figura 4).

Figura 4. A. elongatus (Swainson, 1823), face externa (A) e face interna (B) coletada em fevereiro de 2013.

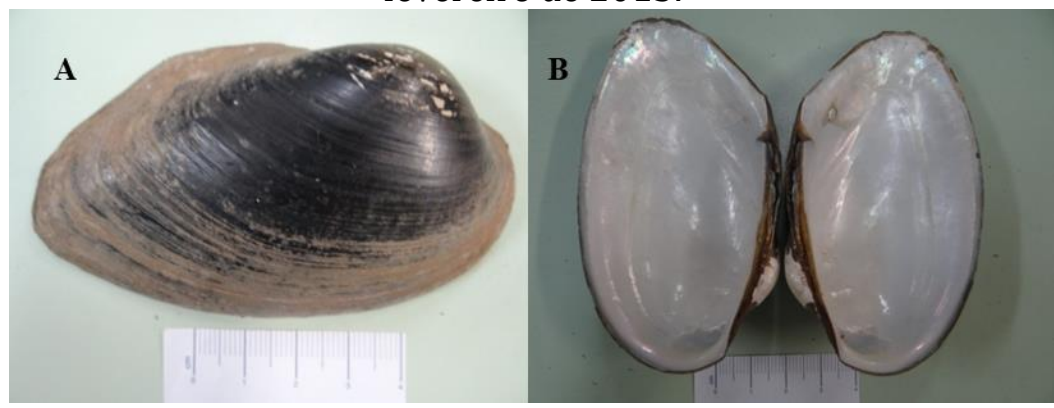

Fonte: Barbosa, E. M.

\subsection{MICETOPODA SILIQUOSA (SPIX, 1827)}

É uma das espécies mais amplamente distribuídas entre os bivalves de água doce da América do Sul, é conhecido também como "faquinha", foi encontrado somente na lagoa da Volta Grande. Distingue-se das demais espécies pelo pé: uma vez distendido, forma um ângulo de $30^{\circ}$ em relação ao eixo longitudinal da concha (Figura 5). 0 animal apresenta vida séssil, passando a vida enterrado dentro de um orifício vertical, cavado em substrato argilo-arenoso compactado. 
Fixa-se firmemente com o musculoso pé, cuja porção distal dilatada funciona como se fosse uma âncora, esse fato foi observado nas coletas dos exemplares com parte mole e dificulta a sua retirada do substrato, são mais frágeis em relação aos Anodontites sp; tem a concha mais alongada, fina, inflada, com as valvas entreabertas na região anteroventral, borda posterodorsal alongada, arredondada, terminando numa aresta pouco aguçada, junto à borda ventral; charneira reta, extremidade anterior curta e arredondada, a posterior oblíqua e truncada, perióstraco com linhas de crescimento irregulares, o pé é muito alongado e cilíndrico, também possui a face interna nacarada (MACHADO et al., 2008).

Figura 5. M. siliquosa (SPIX, 1827), sem parte mole (A) e com parte mole (B) coletada em outubro de 2012.

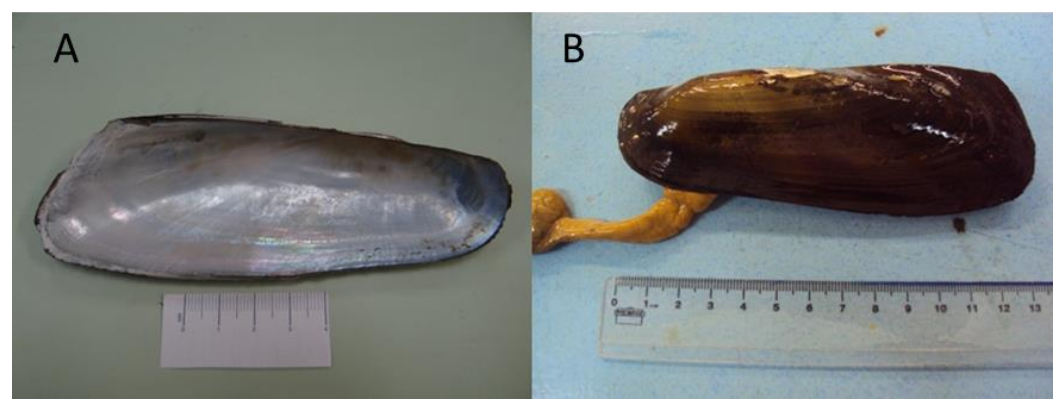

Fonte: Barbosa, E. M.

\subsection{SPHAERIDAE EUPERA SP(BOURGUINAT, 1854)}

Possui concha de tamanho inferior em relação a outras espécies coletadas atingindo cerca de 5 (cinco) $\mathrm{mm}$ de comprimento, sendo somente encontrados durante a triagem do sedimento em laboratório, são moluscos nativos da América do Sul e possui contorno oval arredondada e manchas escuras em sua face interna que podem ser vistas externamente (Figura 6).

Figura 6. Eupera sp (Bourguinat, 1854) face interna e externa (A), detalhe na face interna (B) coletada em outubro de 2012.

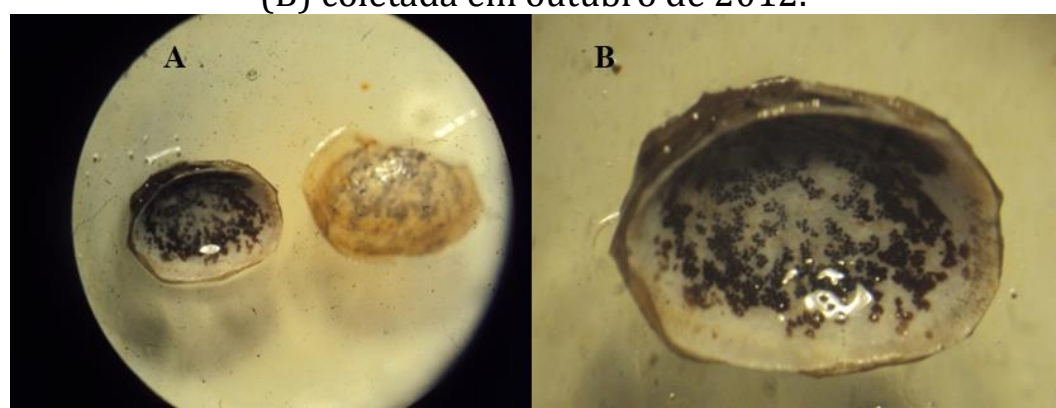

Fonte: Barbosa, E. M. 


\subsection{CORBICULA FLUMINEA (MÜLLER, 1774)}

C. flumínea, conhecido também como "O Berbigão Asiatico", é uma espécie de molusco bivalve de água doce originário da Ásia (Figura 7) (MCMAHON, 1982 apud MANSUR et al., 2012). Espalhou-se pelo mundo no início do século passado, encontrando-se hoje em vários locais da Europa e da América do Norte. Na América do Sul sua introdução deu-se no início da década de 1970, praticamente ao mesmo tempo em Buenos Aires e Porto Alegre (Ituarte, 1981; Veitenheimer-mendes, 1981). 0 primeiro trabalho que identificou e registrou a presença da espécie asiática no continente americano, especificamente nos EUA, foi o de Burch (1944, apud Mansur e Garces, 1988).

A introdução de C.fluminea na América do Sul ocorreu, provavelmente, entre 1965 e 1975, tendo o primeiro registro no estuário do rio da Prata, na Argentina (Ituarte, 1981). Veitenheimer-Mendes (1981) registrou pela primeira vez, a presença de representantes asiáticos do gênero Corbicula no sul do Brasil. A partir daí inúmeros trabalhos mostraram a ocorrência e dispersão da espécie na região sul do país e, pouco tempo depois, já em regiões mais distantes, habita preferencialmente ambiente lótico e substrato arenoso, onde pode dominar a comunidade de bivalves, numericamente e em termos de biomassa (HAKENKAMP; PALMER, 1999 apud MANSUR et al., 2012).

Figura 7. Corbicola fluminea (MÜLLER, 1774), face externa (A) e face interna (B) coletada em fevereiro de 2013.

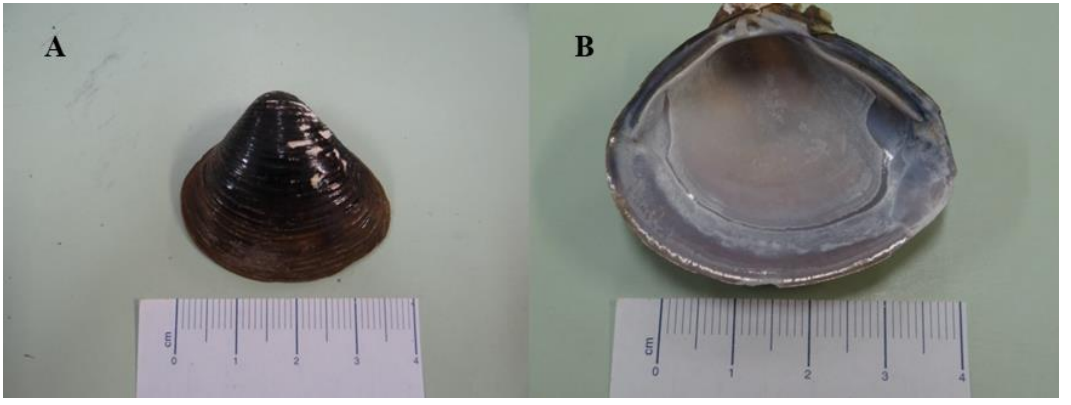

Fonte: Barbosa, E. M.

\subsection{AMPULLARIDAE E PLANORBIIDAE}

Foram coletados moluscos gastrópodes nativos bastantes comuns em nossa região, da família Ampullaridae, pertencentes ao gênero Pomacea sp (Perry, 1810). E, da família Planorbiide o gênero Biomphalaria sp (Preston, 1910) (Figura 8). 
Abrange cerca de vinte espécies, sendo amplamente distribuído na África, América do Sul, Caribe, sudoeste da Ásia (Arábia Saudita e Iêmen), na América Central e sul dos Estados Unidos (MALEK; CHENG, 1974).

Figura 8. Pomacea sp (Perry, 1810) (A) - Outubro 2012; Biomphalaria sp (Preston, 1910) (B) coletada em outubro 2012.

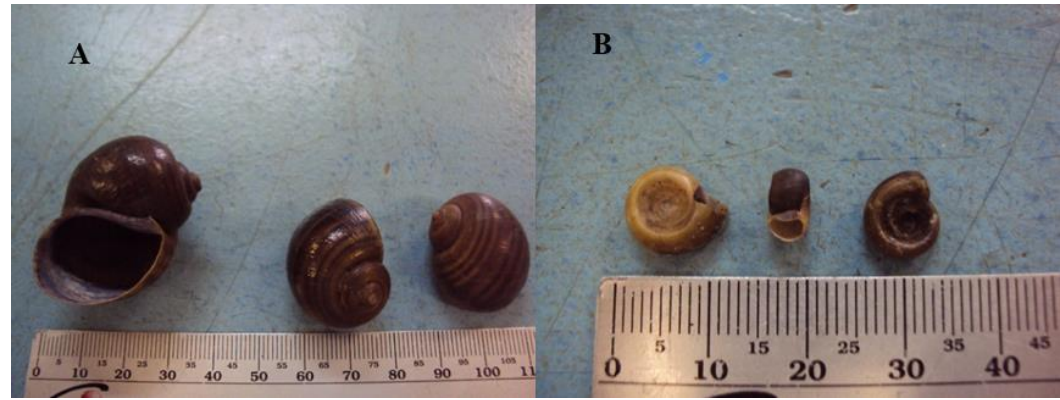

Fonte: Barbosa, E. M.

\subsection{MELANOIDES TUBERCULATA (MÜLLER, 1774)}

O gastrópode $M$. tuberculata (Müller, 1774), também encontrado na literatura com o nome de Melanoides tuberculatus, é conhecido ainda como “caramujo trombeta”. É nativo da Ásia e do leste africano, é um exemplo de espécie bioinvasora que coloca em risco a qualidade sanitária dos diversos corpos hídricos (Figura 9).

O primeiro registro de sua introdução no Brasil data de 1967 na cidade de Santos (SP), provavelmente introduzido nos corpos d'água através de soltura deliberada pela aquariofilia (VAZ et al., 1986). Foi o molusco mais abundante na região, sendo encontrado nas duas lagoas estudadas, é um Caenogastropoda da família dos Thiaridae, suas conchas em geral são espessas e fortemente esculturadas e moderadamente grossa, alongada e espiralada, turriforme (em forma de torre), com 12 a 16 voltas nos animais adultos.

Esse espécime de molusco é nativo da Ásia e do Leste da África, é uma espécie bioinvasora, porque coloca em risco a qualidade sanitária do manancial, por atuar como hospedeiro de trematódeos da família Heterophyidae, causadores de diversas enfermidades ao humano (BOGÉA et al., 2005). Além de problemas de ordem sanitária, o $M$. tuberculata pode causar diminuição da diversidade ecológica do ambiente, uma vez que a sua presença está relacionada com alta abundância e dominância sobre as espécies nativas (CALLISTO et al., 2005). Por ser uma espécie altamente invasiva, possui a capacidade de colonizar áreas impactadas por 
atividades antrópicas, principalmente locais de águas rasas, com substrato de granulometria fina e rico em detritos orgânicos (DE MARCO JUNIOR, 1999; MARTINS-SILVA; BARROS, 2001).

0 primeiro registro de sua introdução no Brasil ocorreu no ano de 1967 na cidade de Santos (SP), (VAZ et al., 1986). Posteriormente foi registrada em Brasília (DF), Rio de Janeiro (RJ), Minas Gerais (MG), Goiás (G0) e Espírito Santo (ES). A sua introdução no país está provavelmente relacionada ao comércio de plantas e peixes ornamentais (FERNANDEZ et al., 2003). No estado de Mato Grosso do Sul foi encontrado recentemente no Rio formoso no município de Bonito/MS, segundo pesquisa realizada por Xavier (2010).

Figura 9. M. tuberculata (Müller, 1774) coletada em outubro de 2012.

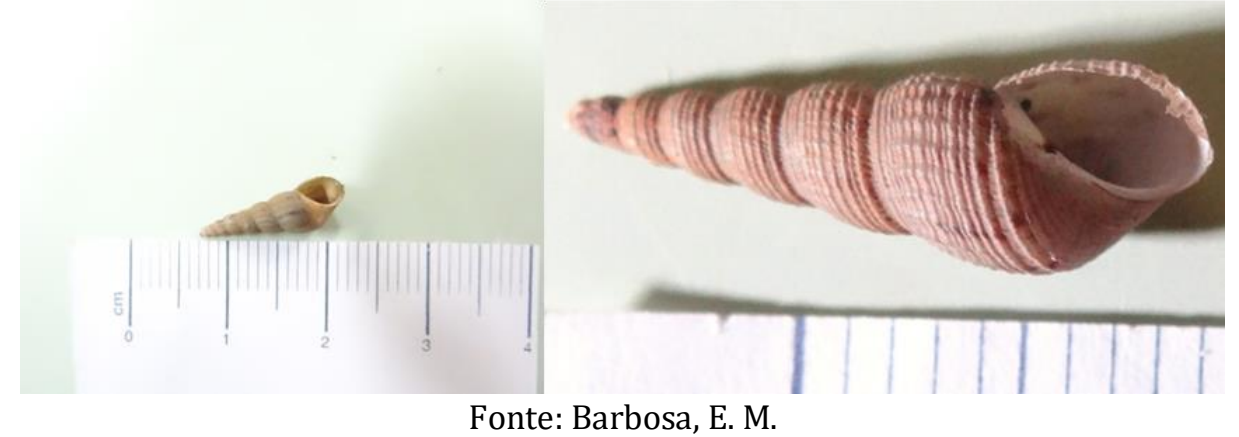

\subsection{LAGOA DO ISMAEL}

Os dados constantes na Tabela 1, refere-se a moluscos coletados no interior do quadrante e os que foram dragados, os moluscos referidos na Tabela 2, são os exemplares recolhidos na margem da Lagoa do Ismael. 0 ponto com maior número de moluscos nativos foi o ponto 2, e o com maior concentração de moluscos invasores $M$. tuberculata foi o ponto 4 com 104 indivíduos coletados. A draga utilizada na lagoa do Ismael foi a de Van Veem, que possui uma área de $540 \mathrm{~cm}^{2}$, que triplicada soma a área de $1620 \mathrm{~cm}^{2}$ em 6 pontos total de $9720 \mathrm{~cm}^{2}$.

O número total de exemplares coletados de M. tuberculata foi 181, dividido pela área da draga alcança a densidade de 0,018621 moluscos por $\mathrm{cm}^{2}$ ou $186,21 / \mathrm{m}^{2}$. O total de moluscos nativos coletados na Lagoa do Ismael foi de 19 exemplares sendo coletados dentro de um quadrante de $1 \mathrm{~m}^{2}$ triplicado nos 6 pontos amostrais soma uma área de $18 \mathrm{~m}^{2}$, a densidade dos moluscos nativos coletados no quadrante foi de $1,05 / \mathrm{m}^{2}$ 
Tabela 1. Resultado do levantamento dos moluscos da Lagoa do Ismael, Aquidauana/MS

\begin{tabular}{lccccccc}
\hline Táxon & Ponto 1 & Ponto 2 & Ponto 3 & Ponto 4 & Ponto 5 & $\begin{array}{c}\text { Ponto } \\
\text { 6 }\end{array}$ & TOTAL \\
\hline $\begin{array}{l}\text { A. trapezialis } \\
\begin{array}{l}\text { A. elongatus } \\
\text { M. siliquosa }\end{array}\end{array}$ & 3 & 5 & 3 & 4 & 2 & 2 & 19 \\
$\begin{array}{l}\text { C. flumínea } \\
\begin{array}{l}\text { Eupera sp* } \\
\text { M. tuberculata* }\end{array}\end{array}$ & & & & & & & 0 \\
$\begin{array}{l}\text { Biomphalaria } \\
\text { sp* }\end{array}$ & 1 & 26 & 40 & 104 & 9 & 0 & 0 \\
$\begin{array}{l}\text { Pomacea sp * } \\
\text { Total }\end{array}$ & & 0 & 0 & 0 & 0 & 0 & 181 \\
\hline
\end{tabular}

*Moluscos coletados na Draga

Fonte: Autoria própria.

Tabela 2. Lista de espécies de moluscos coletados na Margem da Lagoa do Ismael sem parte mole.

\begin{tabular}{|c|c|c|c|c|c|c|c|}
\hline Táxon & Ponto 1 & Ponto 2 & Ponto 3 & Ponto 4 & Ponto 5 & $\begin{array}{c}\text { Ponto } \\
6\end{array}$ & TOTAL \\
\hline A. trapezialis & 12 & 8 & 8 & 2 & 2 & 6 & 38 \\
\hline \multicolumn{8}{|l|}{ A. elongatus } \\
\hline \multicolumn{8}{|l|}{ M. siliquosa } \\
\hline C. fluminea & 1 & & & & & & 1 \\
\hline \multicolumn{8}{|l|}{ Eupera sp } \\
\hline \multicolumn{8}{|l|}{ M. tuberculata } \\
\hline $\begin{array}{l}\text { Biomphalaria } \\
\text { sp }\end{array}$ & 5 & 4 & 1 & & & 3 & 13 \\
\hline Pomacea sp & 4 & 5 & 1 & & & 2 & 12 \\
\hline Total & 22 & 17 & 10 & 2 & 2 & 11 & 64 \\
\hline
\end{tabular}

Fonte: Autoria própria.

\subsection{LAGOA DA VOLTA GRANDE}

Na lagoa da volta grande o ponto com maior número de moluscos nativos foi o ponto 2 com 24 exemplares, e o com maior concentração de moluscos invasores M. tuberculata foi o ponto 4 com 51 indivíduos coletados (Tabela 3). A draga utilizada na lagoa do Ismael foi a de Pitersen que possui uma área de $372 \mathrm{~cm}^{2}$, que triplicada soma a área de $1.116 \mathrm{~cm}^{2}$ em 6 pontos total de $6.696 \mathrm{~cm}^{2}$.

O número total de exemplares coletados de M. tuberculata foi 70, dividido pela área da draga alcança a densidade de 0,01045400 moluscos por $\mathrm{cm}^{2}$ ou $104,54 / \mathrm{m}^{2}$. O total de moluscos nativos coletados na Lagoa da Volta Grande foi de 48 exemplares, sendo coletados dentro de um quadrante de $1 \mathrm{~m}^{2}$ triplicado nos 6 pontos amostrais soma uma área de $18 \mathrm{~m}^{2}$. A densidade dos moluscos nativos coletados foi de aproximadamente $2,67 / \mathrm{m}^{2}$; outra espécie invasora $C$. flumínea não 
constou no sedimento dragado e nem nos quadrantes foi encontrada apenas na margem do ponto seis como mostra a Tabela 4.

Tabela 3. Levantamento de espécies de moluscos por ponto amostral coletados na Lagoa da Volta Grande, Aquidauana/MS.

\begin{tabular}{|c|c|c|c|c|c|c|c|}
\hline Táxon & Ponto 1 & Ponto 2 & Ponto 3 & Ponto 4 & Ponto 5 & $\begin{array}{c}\text { Ponto } \\
6\end{array}$ & TOTAL \\
\hline A. trapezialis & 1 & 21 & 8 & 6 & 3 & 2 & 41 \\
\hline A. elongatus & & 2 & & 1 & & & 3 \\
\hline M. siliquosa & & 1 & & 1 & & 2 & 4 \\
\hline C. fluminea & & & & & & & 0 \\
\hline Eupera sp* & 1 & & & & 15 & 3 & 19 \\
\hline M. tuberculata * & 2 & 6 & 51 & 1 & 6 & 4 & 70 \\
\hline $\begin{array}{l}\text { Biomphalaria } \\
\text { sp }^{*}\end{array}$ & & & & & & & 0 \\
\hline Pomacea sp * & & & & & & & 0 \\
\hline Total & 4 & 30 & 59 & 9 & 24 & 11 & 137 \\
\hline
\end{tabular}

*Moluscos coletados na Draga

Fonte: Autoria própria.

Tabela 4. Lista de espécies de moluscos coletados na Margem da Lagoa da volta grande.

\begin{tabular}{|c|c|c|c|c|c|c|c|}
\hline Táxon & Ponto 1 & Ponto 2 & Ponto 3 & Ponto 4 & Ponto 5 & $\begin{array}{c}\text { Ponto } \\
6\end{array}$ & TOTAL \\
\hline A. trapezialis & 0 & 9 & 15 & 0 & 1 & 16 & 41 \\
\hline A. elongatus & & 3 & 2 & & & 6 & 11 \\
\hline M. siliquosa & & & 3 & & & & 3 \\
\hline C. fluminea & & & & & & 18 & 18 \\
\hline Eupera SP & & & & & & & 0 \\
\hline M. tuberculata & & & & & & & 0 \\
\hline $\begin{array}{l}\text { Biomphalaria } \\
\text { sp }\end{array}$ & & & & & & & 0 \\
\hline Pomacea sp & & & & & & & 0 \\
\hline Total & 0 & 12 & 20 & 0 & 1 & 40 & 73 \\
\hline
\end{tabular}

Fonte: Autoria própria.

\subsection{DADOS FÍSICOS E QUIIMICOS}

As análises das características químicas e físicas dos sistemas de lagoas estudados indica uma forte influência de componentes orgânicos, evidenciados principalmente nos resultados de material em suspensão (Figura 10 e 11). 
Figura 10. Variação das concentrações de Clorofila $a$ nas lagoas do Ismael e Volta Grande, referente ao mês de outubro de 2012.

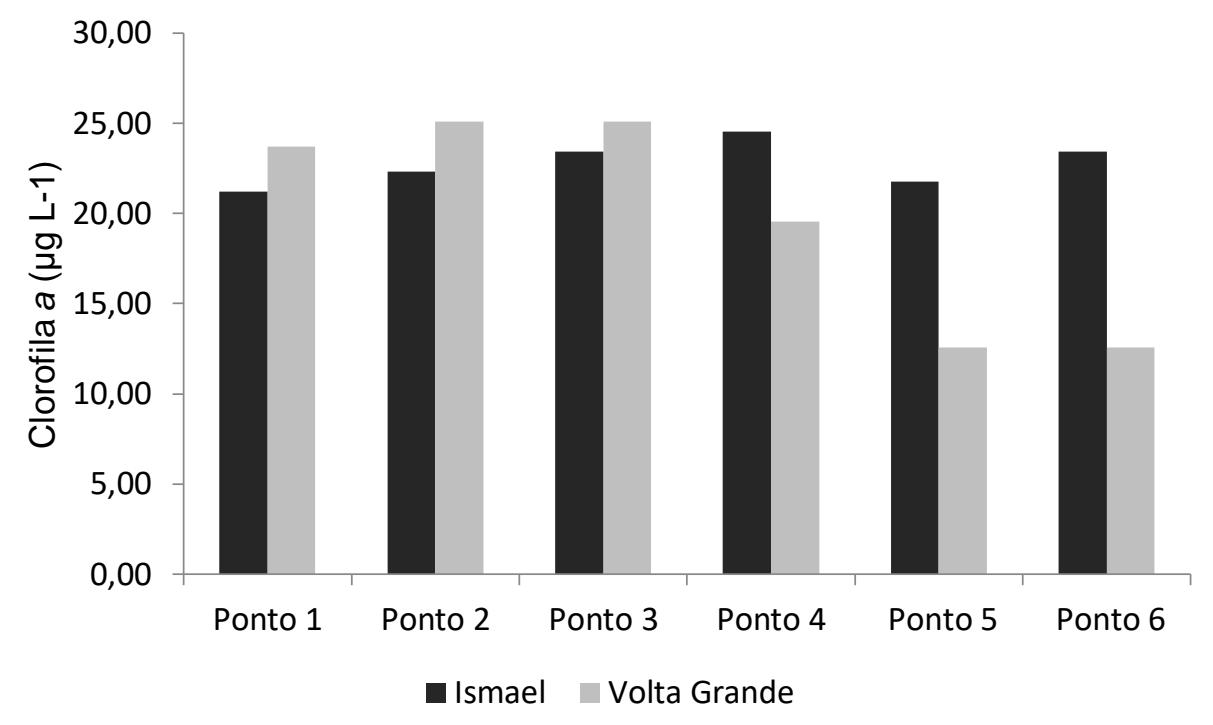

Fonte: Autoria própria.

Os resultados de $\mathrm{pH}$ demonstram que a lagoa do Ismael apresenta valores variando de 6,97 a 7,24 enquanto a lagoa Volta grande os valores de pH, com exceção do ponto 1, sempre estiveram abaixo de 7,0 com variação de 6,59 a 6,94 (Tabelas 5 e 6).

Uma outra variável limnológica que apresentou uma diferença sensível entre os dois sistemas estudados foi a concentração de Oxigênio Dissolvido onde se observa uma variação de 4,91 mg/L a 6,80 mg/L na lagoa do Ismael, e os resultados da lagoa Volta Grande estiveram em todos os pontos abaixo de 2,5 mg/L. 0 que aponta para uma maior produtividade na lagoa do Ismael.

Os valores das concentrações de fósforos de acordo com as Tabelas 5 e 6 sempre estiveram maiores na lagoa do Ismael o que corrobora com a tese da maior produtividade neste sistema. E, de acordo com a figura 11, demonstramos maiores valores do Índice de Estado Trófico para a Lagoa do Ismael. 
Figura 11. Variação do Índice do Estado Trófico nas lagoas do Ismael e na lagoa Volta Grande em 2012.

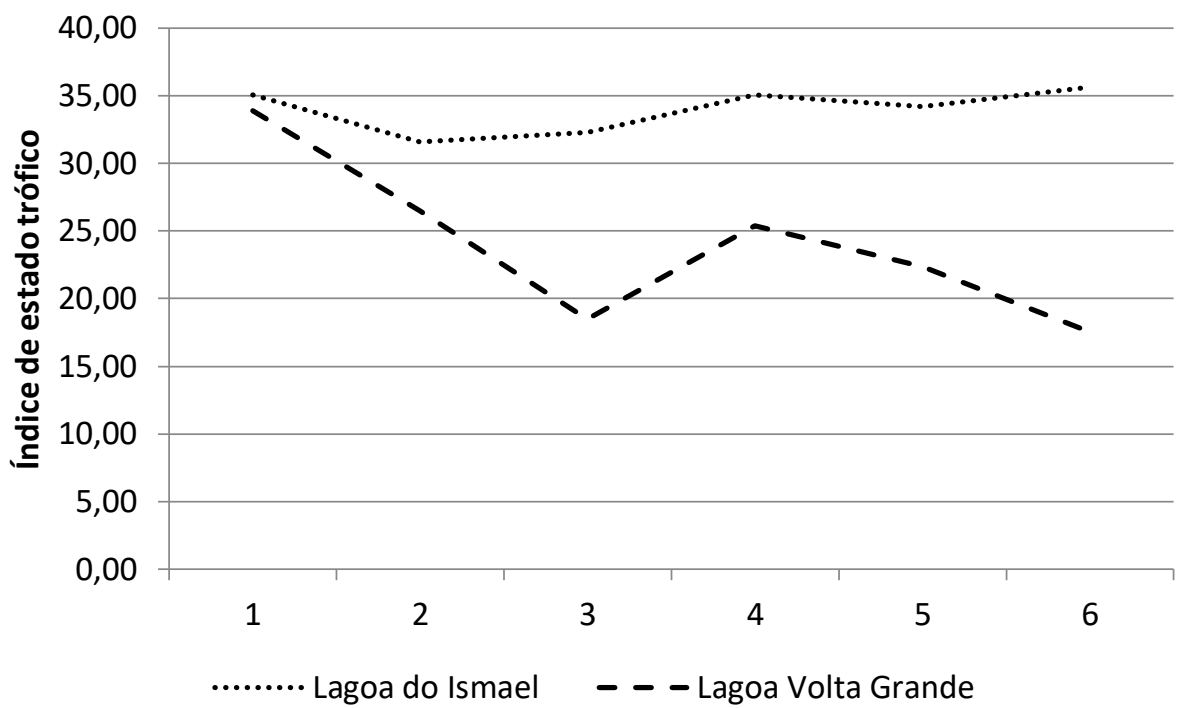

Fonte: Autoria própria.

Tabela 5. Resultados de análises das características químicas e físicas da água na Lagoa do Ismael.

\begin{tabular}{lrrrrrr}
\hline & Ponto 1 & Ponto 2 & Ponto 3 & Ponto 4 & Ponto 5 & Ponto 6 \\
\hline pH & 7,12 & 7,18 & 7,24 & 6,97 & 7,20 & 7,05 \\
$\begin{array}{l}\text { Condutividade } \\
(\boldsymbol{\mu S} / \mathbf{c m})\end{array}$ & 79,00 & 78,00 & 78,00 & 78,00 & 78,00 & 78,00 \\
$\begin{array}{l}\text { Turbidez } \\
(\text { UNT) }\end{array}$ & 24,30 & 22,60 & 20,80 & 24,20 & 18,00 & 25,10 \\
$\begin{array}{l}\text { Oxigênio } \\
\text { Dissolvido }\end{array}$ & 5,03 & 6,02 & 6,80 & 4,91 & 6,04 & 5,73 \\
(mg/L) & & & & & & \\
Temperatura & 25,33 & 25,93 & 26,03 & 25,64 & 25,86 & 26,10 \\
da água ( ${ }^{\circ}$ C) & & & & & & \\
$\begin{array}{l}\text { Temperatura } \\
\text { do Ar ( }{ }^{\circ} \text { C) }\end{array}$ & 27,90 & 29,9 & 30,50 & 32,40 & 34,60 & 34,90 \\
Nitrogênio & 0,16 & 0,19 & 0,21 & 0,13 & 0,17 & 0,18 \\
Total (mg L-1) & & & & & & \\
\hline $\begin{array}{l}\text { Nitrato (ug L- } \\
\text { 1) }\end{array}$ & 11,99 & 14,54 & 11,99 & 13,37 & 14,15 & 14,89 \\
\hline
\end{tabular}




\begin{tabular}{|c|c|c|c|c|c|c|}
\hline & Ponto 1 & Ponto 2 & Ponto 3 & Ponto 4 & Ponto 5 & Ponto 6 \\
\hline $\begin{array}{l}\text { Nitrito (ug L- } \\
\text { 1) }\end{array}$ & 0,00 & 0,00 & 0,00 & 4,78 & 2,08 & $\overline{5,16}$ \\
\hline $\begin{array}{l}\text { Amônio (ug L- } \\
\text { 1) }\end{array}$ & 119,72 & 61,54 & 43,36 & 64,27 & 56,09 & 71,54 \\
\hline $\begin{array}{l}\text { Fósforo Total } \\
\text { (ug L-1) }\end{array}$ & 8,53 & 6,70 & 7,03 & 8,53 & 8,03 & 8,87 \\
\hline $\begin{array}{l}\text { Fosfato } \\
\text { Inorgânico (ug } \\
\text { L-1) }\end{array}$ & 2,03 & 3,03 & 2,86 & 2,53 & 2,53 & 3,86 \\
\hline $\begin{array}{l}\text { Fosfato } \\
\text { Orgânico } \\
\text { (ug L-1) }\end{array}$ & 4,53 & 5,70 & 4,20 & 4,36 & 4,03 & 4,53 \\
\hline $\begin{array}{l}\text { Dureza Total } \\
\text { (mg L-1) }\end{array}$ & 33,63 & 30,62 & 31,62 & 32,12 & 32,63 & 31,12 \\
\hline $\begin{array}{l}\text { Cálcio (mg L- } \\
\text { 1) }\end{array}$ & 12,07 & 10,66 & 11,46 & 10,66 & 12,26 & 11,87 \\
\hline $\begin{array}{l}\text { Magnésio (mg } \\
\text { L-1) }\end{array}$ & 0,85 & 0,97 & 0,73 & 1,34 & 1,09 & 0,36 \\
\hline
\end{tabular}

Fonte: Autoria própria.

Tabela 6. Resultados de análises das características químicas e físicas da água na Lagoa Volta Grande.

\begin{tabular}{|c|c|c|c|c|c|c|}
\hline & $\begin{array}{l}\text { Ponto } \\
1\end{array}$ & $\begin{array}{l}\text { Ponto } \\
2\end{array}$ & $\begin{array}{l}\text { Ponto } \\
3\end{array}$ & $\begin{array}{l}\text { Ponto } \\
4\end{array}$ & $\begin{array}{l}\text { Ponto } \\
5\end{array}$ & $\begin{array}{l}\text { Ponto } \\
6\end{array}$ \\
\hline pH & 7,30 & 6,94 & 6,70 & 6,61 & 6,59 & 6,76 \\
\hline $\begin{array}{l}\text { Condutividade } \\
(\mu S / \mathrm{cm})\end{array}$ & 73,00 & 77,0 & 84,00 & 59,00 & 79,00 & 76,00 \\
\hline Turbidez (UNT) & 44,20 & 59,60 & 46,80 & 44,50 & 42,60 & 61,20 \\
\hline $\begin{array}{l}\text { Oxigênio Dissolvido } \\
\text { (mg/L) }\end{array}$ & 0,30 & 1,24 & 2,30 & - & - & 0,62 \\
\hline $\begin{array}{l}\text { Temperatura da água } \\
\left({ }^{\circ} \mathrm{C}\right)\end{array}$ & 28,24 & 27,83 & 29,30 & 27,00 & 27,20 & 27,17 \\
\hline
\end{tabular}




\begin{tabular}{|c|c|c|c|c|c|c|}
\hline & $\begin{array}{l}\text { Ponto } \\
1\end{array}$ & $\begin{array}{l}\text { Ponto } \\
2\end{array}$ & $\begin{array}{l}\text { Ponto } \\
3\end{array}$ & $\begin{array}{l}\text { Ponto } \\
4\end{array}$ & $\begin{array}{l}\text { Ponto } \\
5\end{array}$ & $\begin{array}{l}\text { Ponto } \\
6\end{array}$ \\
\hline $\begin{array}{l}\text { Temperatura do Ar } \\
\left({ }^{\circ} \mathrm{C}\right)\end{array}$ & 38,00 & 36,50 & 34,10 & 37,00 & 34,00 & 30,80 \\
\hline $\begin{array}{l}\text { Nitrogênio Total (mg L- } \\
\text { 1) }\end{array}$ & 0,40 & 0,46 & 0,38 & 0,42 & 0,46 & 0,35 \\
\hline Nitrato (ug L-1) & 17,17 & 28,52 & 26,84 & 12,46 & 33,61 & 25,43 \\
\hline Nitrito (ug L-1) & 6,70 & 5,55 & 7,86 & 6,32 & 5,55 & 8,63 \\
\hline Amônio (ug L-1) & 267,90 & 179,72 & 154,27 & 175,18 & 268,81 & 230,63 \\
\hline Fósforo Total (ug L-1) & 7,86 & 4,70 & 2,70 & 4,36 & 3,53 & 2,53 \\
\hline $\begin{array}{l}\text { Fosfato Inorgânico (ug } \\
\text { L-1) }\end{array}$ & 2,70 & 1,20 & 1,20 & 1,03 & 2,53 & 2,53 \\
\hline $\begin{array}{l}\text { Fosfato Orgânico (ug } \\
\text { L-1) }\end{array}$ & 2,70 & 1,20 & 1,36 & 2,36 & 1,20 & 1,03 \\
\hline Dureza Total (mg L-1) & 38,77 & 40,81 & 44,89 & 38,77 & 41,83 & 42,85 \\
\hline Cálcio (mg L-1) & 8,99 & 8,99 & 9,81 & 8,99 & 9,81 & 10,22 \\
\hline Magnésio (mg L-1) & 3,96 & 4,46 & 4,96 & 3,96 & 4,21 & 4,21 \\
\hline
\end{tabular}

Fonte: Autoria própria.

Os resultados das concentrações de Material em Suspensão, no entanto demonstram um maior aporte de matéria orgânica no sistema da lagoa Volta Grande indicando uma possível influência da dinâmica do rio Aquidauana que em épocas de cheia o volume de material que entra nesta lagoa é maior, principalmente devido ao recente episódio de isolamento do rio (Figuras 12 e 13). 
Figura 12. Variação das concentrações de material em suspensão na lagoa do Ismael.

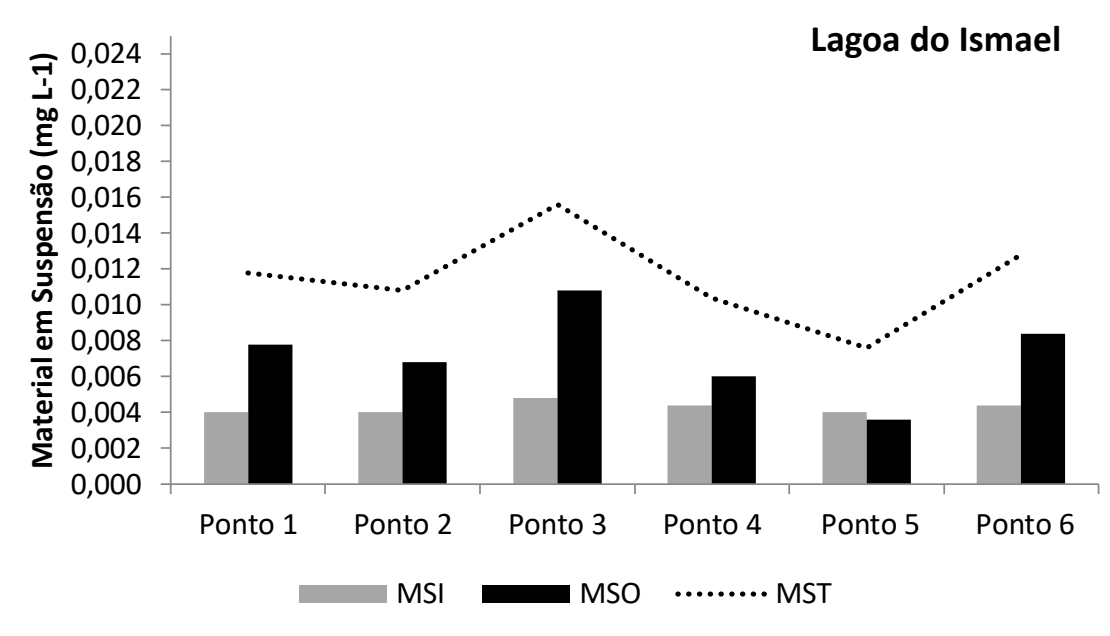

Fonte: Autoria própria.

Figura 13. Variação das concentrações de material em suspensão na lagoa do Ismael.

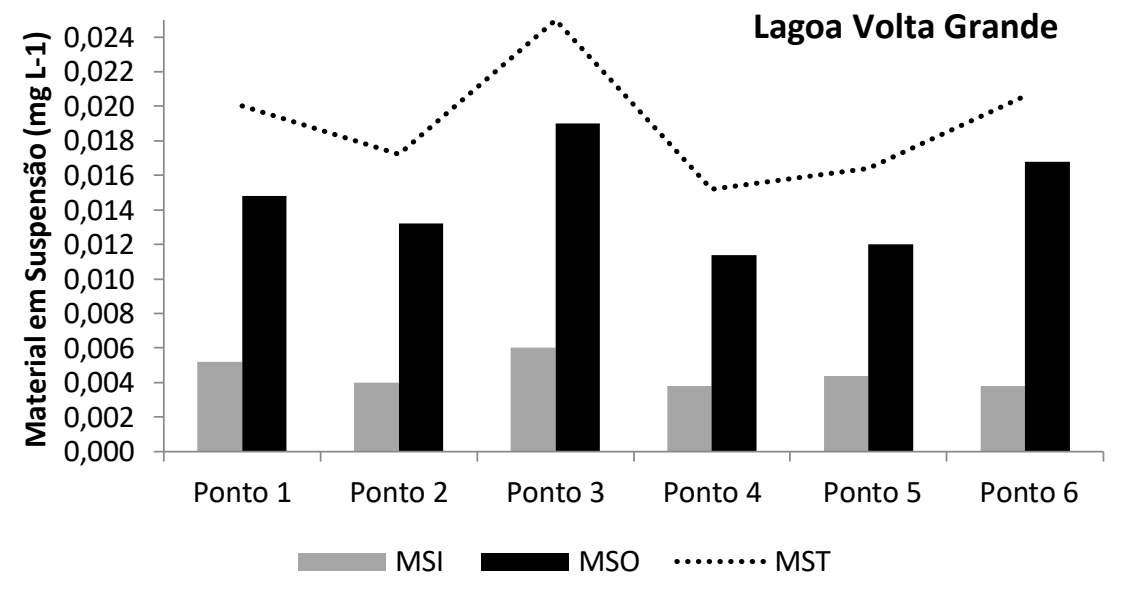

Fonte: Autoria própria.

A fauna de moluscos nativos encontrados na região foi bastante significativa, e constam na Lista Nacional das Espécies da Fauna Brasileira Ameaçadas de Extinção (MMA - Instrução Normativa №5 de 21 de maio de 2004). As espécies invasoras encontradas representam um risco às espécies nativas, podendo causar a diminuição e seu desaparecimento através da competição por recursos.

Além de danos ecológicos, $C$. fluminea podem causar prejuízos econômicos. Através de incrustações, entopem tubulações de usinas hidrelétricas e termoelétricas. E, também geram riscos de ordem sanitária, devido a bioacumulação de metais pesados. Segundo Cataldo et al. (2001 apud MANSUR et al., 2012) C. fluminea coletada em áreas mais poluídas do delta do Rio Paraná, ao ser utilizada 
como biomarcador de gradientes de poluição, mostrou um acúmulo significativo de cobre e cádmio em seu corpo.

As corbículas podem ser hospedeiros intermediários de trematódeos, Chung, et al. (2001 apud MANSUR et al., 2012) constataram em laboratório a possibilidade de $C$. fluminea ser um segundo hospedeiro de Echinostoma cinetorchis (Ando Ozaki 1923). 0 trematódeo adulto se instala no intestino delgado podendo causar fortes dores abdominais, náusea, vômitos, diarreia e febre. $C$. fluminea foi encontrada nas duas lagoas coletadas, 18 exemplares na Lagoa da Volta Grande e apenas um exemplar na Lagoa do Ismael.

O "caramujo trombeta" M. tuberculata, além de causar danos ecológicos podem causar problemas de ordem sanitária, podem servir de hospedeiros de trematoides que causam doenças no ser humano, como por exemplo, o que foi registrado por Pinto e Melo (2010 apud MANSUR et al., 2012). Infectando $M$. tuberculata o trematoide Centrocestus formosanus (Nishigori, 1924) responsável pela centrocestíase, tem como segundo hospedeiro intermediário diversas espécies de peixes dulceaquícolas e como hospedeiros definitivos, aves e mamíferos. 0 gastrópode invasor foi coletado nas duas lagoas, sendo mais abundante na lagoa do Ismael.

As lagoas apresentaram diferença na diversidade de espécies de moluscos coletados, A. elongatus, M. siliquosa e Eupera sp foram encontrados apenas na Lagoa da Volta Grande, a única espécie de molusco bivalve coletado no interior da Lagoa do Ismael foi o A. trapesialis, que é o molusco mais abundante da região, foram coletados no total 140 exemplares destes moluscos.

\section{CONSIDERACÕES FINAIS}

O presente estudo registrou a presença de moluscos bivalves e gastrópodes nativos da região. No entanto constatou-se também a presença de espécies exóticas invasoras, que foram encontradas nas duas lagoas estudadas. 0 Pantanal concentra a maior densidade faunística das Américas, densidade colocada em risco com a constatação de bioinvasão aquática. A espécie $C$. fluminea, foi mais abundante na Lagoa da Volta Grande e o M. tuberculata, apresentaram-se mais abundante na Lagoa do Ismael, porém com uma baixa densidade populacional registrada. 
Através desses dados conclui-se que os moluscos invasores encontrados representam um risco potencial para as espécies nativas encontradas. Propõem-se que novas coletas sejam realizadas para o monitoramento da bioinvasão e sua relação com outras espécies. Estima-se que mais lagoas localizadas no município de Aquidauana e Anastácio contenham os moluscos invasores, e desta forma a sugestão de que estudos devem ser realizados em um maior número de lagoas, justifica-se para um real diagnóstico da situação atual quanto a infestação na região.

\section{REFERÊNCIAS}

ANDRADE, M. H. S. 1999. Dissertação de Mestrado, Macroinvertebrados Bentônicos e Heterogeneidade de Habitats na Lagoa Albuquerque, Pantanal de Mato Grosso do Sul. UFMS 1999.

AVELAR, W. E. P. 1993. Functional anatomy of Fossula fossiculifera (D'Orbigny, 1843) (Bivalvia:Mycetopodidae). American Malacological Bulletin, Scranton, v. 10 , n. 2, p. $129-138,1993$.

BRASIL. MINISTÉRIO DO MEIO AMBIENTE. Lista Nacional das Espécies da Fauna Brasileira Ameaçadas de Extinção (Instrução Normativa №5 de 21 de Maio de 2004).

BOGÉA, T.; CORDEIRO, F. M. e GOUVEIA, J. S. Melanoides tuberculatus (Gastropoda: Thiaridae) as intermediate host of Heterophyidae (Trematoda: Digenea) in Rio de Janeiro metropolitan area, Brazil. Revista do Instituto Medicina Tropical, v. 47. n. 2, p. 87-90, 2005.

CALLIL, C. T.; Mansur, M. C. D. Gametogênese e dinâmica da reprodução de Anodontites trapesialis (Lamarck) (Unionoida, Mycetopodidae) no Lago Baía do Poço, planície de inundação do Rio Cuiabá, Mato Grosso, Brasil. Revista Brasileira de Zoologia, v. 24, n. 3, p. 825-840, 2007.

CALLISTO, M.; GOULART, M.; BARBOSA, F.A.R. $e$ ROCHA, O. Biodiversity assessment of benthic macroinvertebrates along a reservoir cascade in the lower São Francisco river (northeastern Brazil). Braz. J. Biol., 65(2): 229-240, 2005.

CMMAD - Comissão Mundial Sobre Meio Ambiente e Desenvolvimento, Nosso Futuro Comum. Rio de Janeiro: Editora da Fundação Getúlio Vargas, 430pp. 1988.

De MARCO JUNIOR, P. Invasion by the introduced aquatic snail Melanoides tuberculata (Müller, 1774) (Gastropoda: Prosobranchia: Thiaridae) of the Rio Doce State Park, Minas Gerais, Brazil. Studies on Neotropical Fauna and Environment, v. 34, p. 186-189, 1999. 
FERNANDEZ, M.A.; S.C. THIENGO $e$ L.R. SIMONE. 2003. Distribution of the introduced freshwater snail Melanoides tuberculatus (Gastropoda: Thiaridae) in Brazil. The Nautilus, v. 117, n. 3, p. 78-82.

GRANEY, R. L.; Cherry, D. S.; Rodgers Jr., J. H.; Cairns Jr., J. 1980. The influence of thermal discharges and substrate composition of the asiatic clam Corbicula fluminea, in the New River, Virginia. The Nautilus, v. 94, n. 4, p. 130-135.

IBGE. Instituto Brasileiro de Geografia e Estatística. Disponível em: https://censo2010.ibge.gov.br/.2010.

ITUARTE, C. F. Primera noticia acerca de la presencia de pelecípodos asiáticos en el área rioplatense. Neotropica, v. 27, p. 79-82, 1981.

KARR, J. R. Biological integrity: a long neglected aspect of water resource management. Ecological Applications, v. 1, n. 1.p. 26-35, 1991.

MALEK, E. A. e CHENG, T. C. Medical and Economic Malacology. London, Academic Press. 398 p. 1974.

MANSUR, M. C. D.; et al. 2012. Moluscos límnicos invasores no Brasil: biologia, prevenção e controle - Porto Alegre, Redes Editora. 412p. 2012.

MANSUR, M. C. D.; Garces, L. M. M. P. Ocorrência e densidade de Corbicula fluminea (Muller, 1774) e NeoCorbicula limosa (Maton, 1811) na Estação Ecologia do Taim e áreas adjacentes, Rio Grande do Sul, Brasil (Mollusca, Bivalvia, Corbiculidae). Iheringia, Série Zoológica, v. 68, p. 99-115, 1988.

MANSUR, M. C. D.; Schulz, C.; Garces, L. M. M. P. Moluscos bivalves de água doce: Identificação dos gêneros do sul e leste do Brasil. Acta Biológica Leopoldencia, v. 9, n. 2, p. 181-202, 1987.

MARTINS, D. S.; Veitenheimer-Mendes, I. L.; Faccione-Heuser, M. C. Corbicula (Bivalvia, Corbiculidae) em simpatria no lago Guaíba, Rio Grande do Sul, Brasil. Biociências, v. 12, n. 2, p. 129-138, 2004.

SIMONE, L. R. L. Anatomical characters and systematics of Anodontites tapesialis (Lamarck, 1819) from South America (Mollusca, Bivalvia, Uionoida, Muteloidea). Studies on Neotropical Fauna and Environment, Londres, v. 29, n. 3, p. 69-185, 1994.

VALÉRY, L.; Fritz, H.; Lefreuve, J.; Simberloff, D. In search of a real definition of the biological invasion phenomenon itself. Biological Invasions, v. 10, p. 13451351, 2008.

VEITENHEIMER-MENDES, I. Corbicula manilensis (Phillipi, 1844) molusco asiático, na bacia do Jacuí e do Guaíba, Rio Grande do Sul, Brasil (Bivalvia, Corbiculidae). Iheringia, v. 60, p.63-74, 1981.

VAZ, J. F.; TELES, H.M.S.; CORREA, M.A. $e$ LEITE, S.P.S. Ocorrência no Brasil de Thiara (Melanoides) tuberculata (O.F. Müller, 1774) (Gastropoda, Prosobranchia), 
primeiro hospedeiro intermediário de Clonorchis sinensis (Cobbold, 1875) (Trematoda, Plathyhelmintes). Revista Saúde Pública. São Paulo, v. 20, p. 318-322, 1986.

VIANNA, M. P. Avelar, W. E. P. 2010. Ocorrência da espécie invasora Corbicula fluminea (Bivalvia, Corbiculidae) no rio Sapucaí (São Paulo, Brasil). Biotemas, v. 23 , n. 3 , p. 59-66, 2010

XAVIER, Bruna Fernanda Sanches. Registro de Melanoides tuberculatus (Gastropoda: Thiaridae) presentes em sedimentos nas margens de um trecho do Rio Formoso em Bonito - MS, Brasil, 2010. 


\section{CAPÍtULOX X}

\section{DIVERSIDADE DE ESCORPIÕES CARACHNIDA: SCORPIONES) EM FRAGMENTOS DE CERRADO NO ECÓTONO CERRADO-PANTANAL SUL MATOGROSSENSE}

DDI: 10.51859/amplla.ecp672.1121-10

André Felipe de Araujo Lira ${ }^{1}$

Geraldo Jorge Barbosa de Moura ${ }^{1}$

Renato Portela Salomão ${ }^{2}$

César Murilo de Albuquerque Correa ${ }^{3}$

${ }_{1}^{1}$ Departamento de Biologia, Universidade Federal Rural de Pernambuco-UFRPE, Recife - 52171900, Pernambuco, Brasil. Programa de Pós-graduação em Biociência Animal-PPGBA/UFRPE.

2Instituto Nacional de Pesquisas da Amazônia, Av. André Araújo 2936, Manaus - 69060-001, Amazonas, Brasil. 32Departamento de Biologia e Zoologia, Instituto de Biociências, Universidade Federal de Mato Grosso, Cuiabá 78060-090, Mato Grosso, Brasil.

\section{INTRODUÇÃO}

Os escorpiões correspondem a um grupo mesodiverso de aracnídeos, com cerca de 2.600 espécies distribuídas em praticamente todos os ambientes terrestres (POLIS, 1990; REIN, 2021). Apesar da má fama destes invertebrados relacionados a questões de saúde pública, os escorpiões possuem um importante papel na dinâmica dos ecossistemas (POLIS, YAMASHITA, 1991; PONTES-DA-SILVA et al., 2016). Devido ao seu hábito alimentar predatório, os escorpiões apresentam uma forte influência sobre a população de suas presas dos locais onde vivem, como insetos e outros invertebrados (POLIS; YAMASHITA, 1991). Além do papel de predadores, os escorpiões correspondem a uma importante parte da dieta de diversos outros animais como corujas e pequenos mamíferos (POLIS et al., 1981; RODRÍGUEZCABRERA et al., 2020).

A maioria dos escorpiões apresentam hábitos sedentários e territorialistas, podendo ser agressivos com indivíduos da mesma espécie, exceto durante o período reprodutivo (BENTON et al., 1992; PERETTI et al., 1999). Deste modo, estes animais não são distribuídos de modo aleatório nos ambientes, apresentando preferências por condições microclimáticas, bem como microhabitats, específicos (PRENDINI, 
2001; OJANGUREN-AFFILASTRO et al., 2016; LIRA et al., 2018). Por exemplo, a assembleia de escorpiões da Mata Atlântica nordestina é majoritariamente composta por espécies nicho-especialistas como Tityus neglectus Mello-Leitão, 1932 e Tityus brazilae Lourenço $e$ Eickstedt, 1984, tipicamente encontrados em bromélias e debaixo de cascas de arvores, respectivamente (LIRA et al., 2018). Esta característica torna os escorpiões sensíveis a alterações no ambiente do qual vivem, revelando um potencial como bioindicadores de impactos ambientais (LIRA et al. 2021). Estudos recentes têm demonstrando que os escorpiões são responsivos a impactos produzidos pela ação humana em diferentes escalas espaciais (FOERSTER et al., 2020; LIRA et al., 2019, 2021). Contudo, apesar deste potencial como bioindicadores, os escorpiões ainda são pouco usados como modelos para estudos ecológicos na região Neotropical, em particular no Brasil (LIRA et al., 2021). Nesse contexto, as lacunas sobre a distribuição das espécies de escorpiões ao longo dos ecossistemas consistem numa limitante para a compreensão das dinâmicas ecológicas gerais do grupo (CARVALHO et al., 2017).

O Cerrado fica localizado na porção central do Brasil e representa cerca de 23\% do território nacional, composto por diferentes fitofisionomias, embora 80 90\% de sua área seja ocupada por vegetação de savana (RAMOS et al., 2018, BERNARDES jr et al., 2020). Este bioma se encontra há cerca de 30 anos sobre uma crescente conversão de sua vegetação natural para monoculturas e pastos (KLINK; MOREIRA, 2002; KLINK; MACHADO, 2005), restando apenas 24\% da sua cobertura de vegetação original distribuídos em fragmentos isolados entre si (BAGLIANO; LUIZ 2013; OVERBECK et al., 2015). Em adição, o Cerrado é considerado como a savana tropical com maior diversidade de espécies do mundo (MITTERMEYER et al., 2004). Contudo, a falta de conhecimento biológico básico como a ocorrência de espécies, atua como barreira na avaliação do nível de ameaça e aplicação de medidas conservacionistas para o bioma. Atualmente, os estudos com escorpiões do Cerrado estão majoritariamente relacionados a descrição de novas espécies restritas a localidade-tipo (LOURENÇO, 2019, 2021).

Mediante o exposto, neste estudo apresentamos uma lista das espécies de escorpiões registradas em fragmentos de Cerrado para uma região do ecótono Cerrado-Pantanal sul mato-grossense. Deste modo, visamos preencher uma lacuna geográfica e taxonômica de conhecimento sobre a distribuição das espécies de 
escorpião para o Cerrado brasileiro, objetivando fornecer subsídios para futuras medidas conservacionistas.

\section{METODOLOGIA}

\section{1. ÁREA DE ESTUDO}

A amostragem foi realizada na área de transição entre os ecossistemas Cerrado e Pantanal em Aquidauana, Mato Grosso do Sul, Brasil (20²8'15" S; $55^{\circ} 47^{\prime} 13^{\prime \prime}$ 0, 150 m a.s.l.). 0 clima da região, segundo a classificação de Köppen, é Aw - tropical quente-úmido, com uma estação de verão chuvosa (outubro a março) e inverno seco (abril a setembro) (ALVARES et al., 2014). A precipitação anual varia de 1.200 a $1.300 \mathrm{~mm}$ e a temperatura média anual é $26^{\circ} \mathrm{C}$ (CRISTALDO et al., 2017).

Os locais amostrados são remanescentes de Cerrado conservados com pouco sinal de atividade antropogênica, caracterizada por uma mistura de plantas de dois estratos distintos (fitofisionomia Cerrado sensu stricto) (FINA; MONTEIRO, 2013; RODRIGUES et al., 2017): uma camada lenhosa de árvores e arbustos grandes (frequentemente 3-8 m de altura; copa cobrindo 50-90\%) e uma camada de solo de gramíneas, ervas e pequenos arbustos (Figura 1).

Figura 1. Remanescente de Cerrado sensu stricto localizado numa região de ecótono Cerrado-Pantanal em Aquidauana, Mato Grosso do Sul, Brasil.

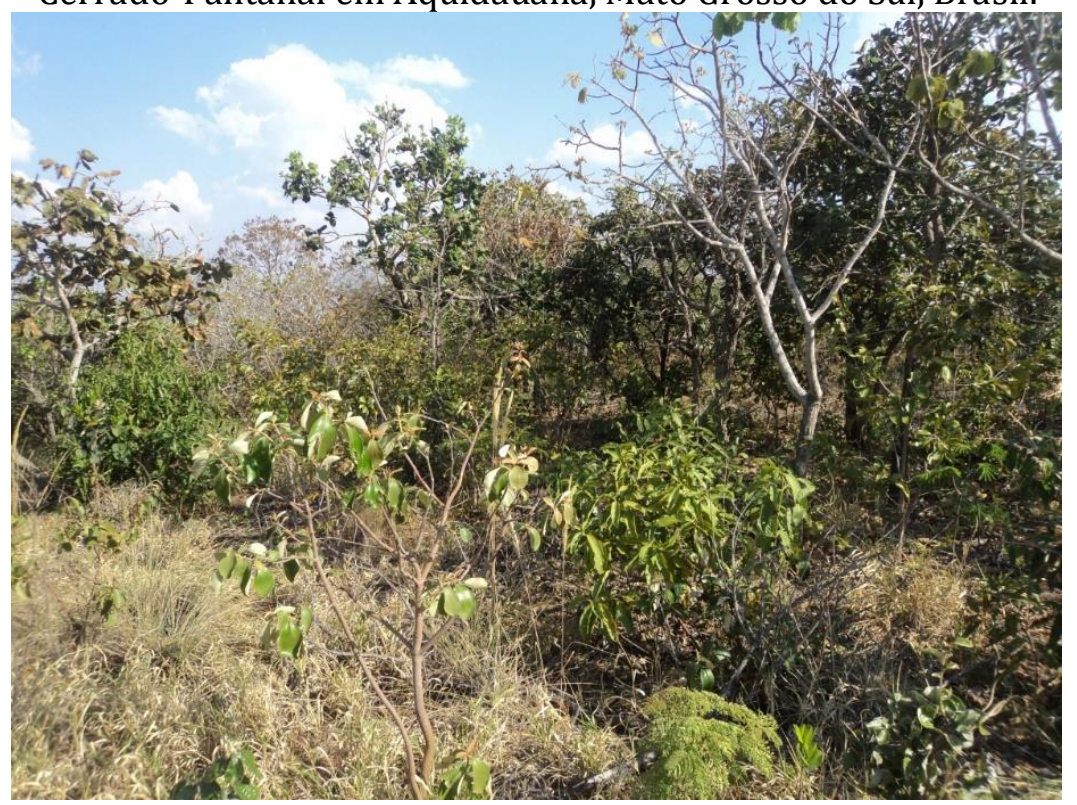

Fonte: Autoria própria. 


\subsection{AMOSTRAGEM E IDENTIFICAÇÃO DOS ESCORPIÕES}

Os escorpiões foram coletados em fevereiro de 2021 durante o período noturno em dez fragmentos distribuídos ao longo do município de Aquidauana-MS. Em cada localidade foram realizadas amostragens de busca ativa com uma hora de duração (19:00 às 22:00 h), sendo realizadas por três coletores equipados com lanternas de mão ultravioleta, pois devido a característica da cutícula dos escorpiões em fluorescer quando iluminados com essa irradiação, maximiza as chances de registro (Figura 2). Após as coletas, os escorpiões foram acomodados em recipientes plásticos contendo álcool etílico 70\% para conservação e em seguida foram enviados para o Dr. Leonardo Carvalho (UFPI - Campus Floriano) para identificação. Todos os escorpiões coletados foram depositados na Coleção de História Natural (Coleção Científica de Aracnídeos) da Universidade Federal do Piauí (CHNUFPI; curador J.F. Vilela), Floriano, Piauí.

Figura 2. Indivíduo macho de Tityus trivittatus Kraepelin, 1898 irradiado com luz ultravioleta. Registro realizado em fevereiro de 2021, no municipio de Aquidauana, MS,

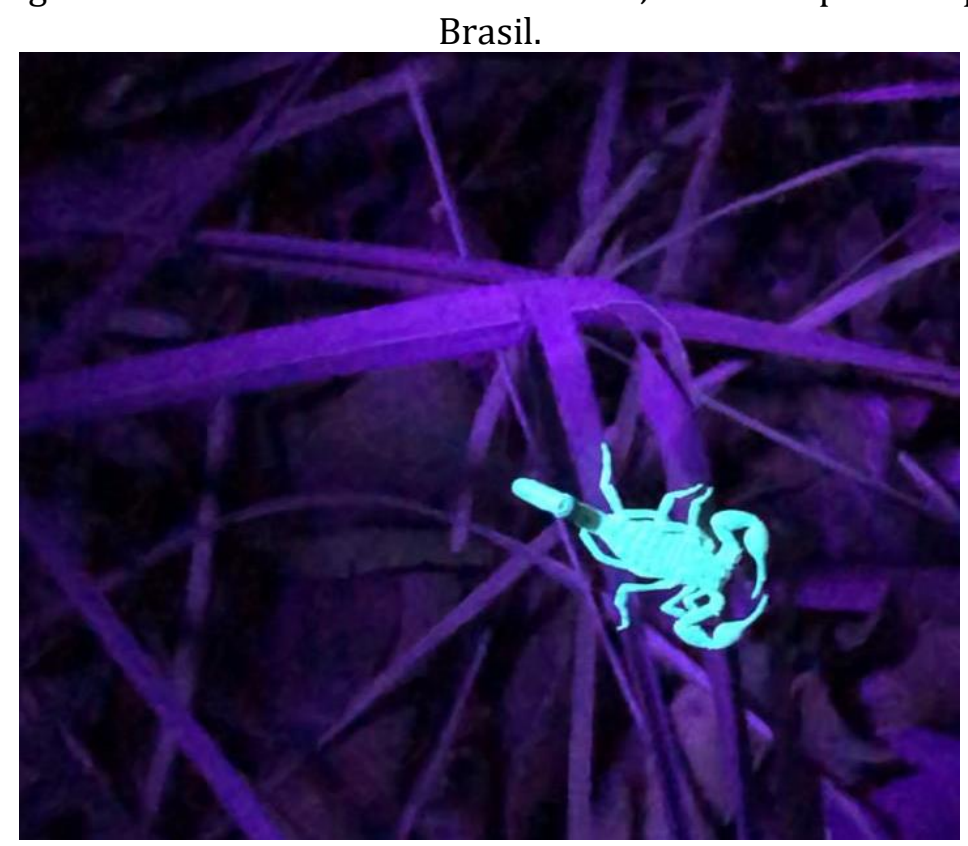

Fonte: Autoria própria.

\section{RESULTADOS E DISCUSSÃO}

No total foram registrados 129 indivíduos, pertencentes a duas famílias e distribuídos em cinco espécies e três gêneros de escorpiões: Bothriurus araguayae 
Vellard 1934 (Bothriuridae), Ananteris sp., Tityus confluens Borelli 1899, Tityus paraguayensis Kraepelin 1895 e Tityus trivittatus Kraepelin 1898 (Buthidae). Do total de espécies coletadas quatro (B. araguayae, T. confluens, T. paraguayensis, e T. trivittatus) representam novos registros de ocorrência para o município de Aquidauana (Figura 3).

O número de indivíduos por localidade variou entre 6-29 escorpiões sendo registrados de 2 a 4 espécies por local de amostragem. Ananteris sp. $(\mathrm{n}=55)$ e $T$. paraguayensis $(\mathrm{n}=36)$ foram as espécies mais abundantes representando $72 \%$ do total de escorpiões coletados. Além disso, estas duas espécies apresentaram ampla distribuição ocorrendo em 10 e 6 localidades, respectivamente. As demais espécies, B. araguayae $(\mathrm{n}=14), T$. confluens $(\mathrm{n}=9)$ e T. trivittatus $(\mathrm{n}=15)$ foram encontrados em 6, 4 e 3 localidades, respectivamente.

Figura 3. Espécies de escorpião com registro inédito para Aquidauana-MS. A) Bothriurus araguayae, B) Tityus paraguayensis, C) Tityus trivittatus e D) Tityus confluens.

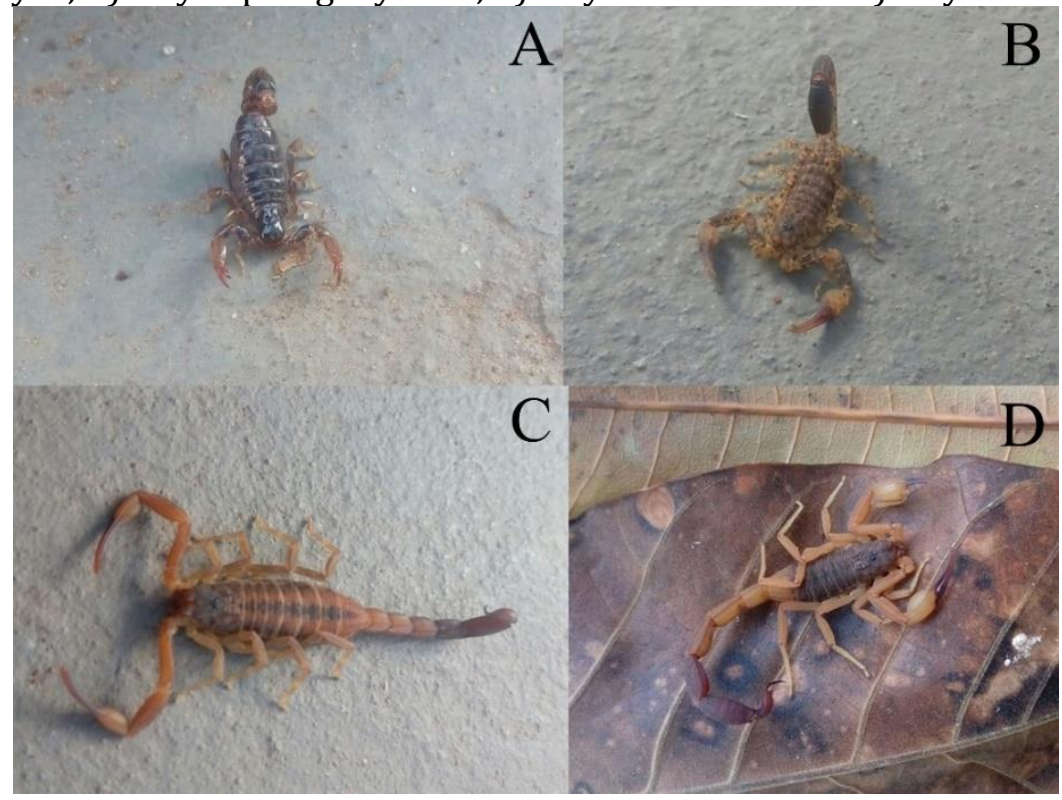

Fonte: Autoria própria.

No presente estudo, registramos a presença de cinco espécies de escorpião em fragmentos de Cerrado para uma região de ecótono Cerrado-Pantanal sul matogrossense, localizada no município de Aquidauana. No estado do Mato Grosso do Sul, 13 espécies de escorpião foram reportadas com base em registros de coleções científicas e publicações científicas (CARVALHO et al., 2017). Apesar da pequena área de Aquidauana relativa ao estado do Mato Grosso do Sul (correspondendo a ca. $5 \%$ da área do estado), nossos resultados mostraram que ca. 1/3 das espécies 
reportadas para o estado podem ser encontradas em Aquidauana. Este elevado número se deve ao fato da região ser um ecótono entre o Cerrado e o Pantanal (RODRIGUES et al., 2017). Assim, a transição entre dois ecossistemas pode gerar um aumento na biodiversidade, dado o fato dessas áreas apresentarem representantes de fauna e flora dos dois ecossistemas (VELOSO et al., 1991). Resultados similares foram descritos por Lira et al. (2019b) com a maior riqueza de espécies ocorrendo na região ecotonal entre a Mata Atlântica e a Caatinga. Uma hipótese alternativa é que as espécies de escorpiões do Cerrado possam ser de ampla distribuição e habitat-generalistas, o que poderia resultar na relativa alta riqueza de espécies em localidades pontuais, como no município de Aquidauana. Através dos nossos resultados, enaltecemos a importância da realização de futuros estudos para compreender os padrões de distribuição espacial das espécies de escorpiões na região do Cerrado brasileiro.

Os escorpiões registrados para o município de Aquidauana pertencem às famílias Buthidae (80\%) ou Bothriuridae (20\%), as mais diversas do Cerrado (LOURENÇO, 2002). Entre as espécies coletadas, o morfótipo Ananteris sp. foi o táxon mais amplamente coletado, sendo registrado em todas as localidades amostradas, representando ca. 40\% do total de indivíduos amostrados. Escorpiões pertencentes a esse gênero são de pequeno porte (14 - $40 \mathrm{~mm})$, tipicamente encontrados em serapilheira (LOURENÇO, 2002; LIRA et al. 2018). Para o estado do Mato Grosso do Sul, duas espécies são catalogadas $A$. balzanii Thorell, 1891 e $A$. mariaterezae Lourenço, 1987 (CARVALHO et al., 2017). Contudo, uma análise mais detalhada do material coletado se faz necessária para uma identificação mais precisa dos espécimes.

A segunda espécie mais abundante e uma das mais amplamente distribuídas foi T. paraguayensis. No Brasil, esta espécie apresenta uma distribuição restrita ao estado do Mato Grosso do Sul (CARVALHO et al., 2017), contudo pode ser encontrada na Argentina e Paraguai, ocorrendo em áreas de Cerrado e Chaco (LOURENÇO et al., 2006). Yamazaki et al. (2015) registraram a ocorrência desta espécie em copas de Callisthene fasciculata Mart. (Vochysiaceae) (Cinceiro ou Paujacaré) durante a inundação do Pantanal, sugerindo que a utilização dessa espécie como habitat seria uma possível estratégia de sobrevivência em épocas de inundações. A terceira espécie em ocorrência, B. araguayae apresenta uma ampla 
distribuição, podendo ser encontrado em áreas de Cerrado das regiões CentroOeste, Nordeste, Sul e Sudeste do Brasil (LOURENÇO, 2002; CARVALHO et al., 2017).

O butídeo T. trivittatus apresenta distribuição pela Argentina, Paraguai, Uruguai e Brasil (MAURY, 1970,1997), neste último ocorrendo em estados da região Centro-Oeste e Sul (CARVALHO et al. 2017). Tityus trivittatus, apesar de possuir populações sexuadas, apresenta a capacidade de reproduzir-se assexuadamente, através da partenogênese (TOSCANO-GADEA, 2004). Essa plasticidade reprodutiva permite que a espécie seja capaz de viver em áreas urbanas e seja considerada o principal escorpião causador de acidentes em países como a Argentina (DE ROODT, 2014). De modo similar, T. confluens apresenta a capacidade de reproduzir por partenogênese (SEITER, 2012) e causar acidentes severos através da sua ferroada (DE ROODT et al., 2009). Tityus confluens apresenta uma ampla distribuição ocorrendo em formações vegetais abertas como o Chaco, Cerrado e Caatinga (BERTANI et al., 2005; PORTO et al., 2014).

\section{CONSIDERAÇÕES FINAIS}

Nesse estudo, nós fornecemos a primeira lista das espécies de escorpiões para a região de ecótono Cerrado-Pantanal do município de Aquidauana, ampliando o registro com mais quatro espécies. Nossos dados demonstram uma assembléia de escorpiões rica em espécies na região de estudo, representando $1 / 3$ da diversidade descrita para o estado do Mato Grosso do Sul e assim evidenciando a importância da manutenção da vegetação natural para a conservação da fauna dos escorpiões e os ecossistemas que habitam.

\section{AGRADECIMENTOS}

Nós agradecemos a Fundação de Amparo à Ciência e Tecnologia do Estado de Pernambuco (FACEPE) pela bolsa de pós-doutoramento (BFP-0121-2.05/20) para André F.A. Lira, Coordenação de Aperfeiçoamento de Pessoal de Nível Superior (CNPq) pela bolsa de pós-doutoramento (PNPD PPG-Eco-INPA) para Renato P. Salomão e Coordenação de Aperfeiçoamento de Pessoal de Nível Superior (Capes) pela bolsa de pós-doutoramento (88882.316025/2019-01, Code 001) para César M.A. Correa. 


\section{REFERÊNCIAS}

ALVARES, C. A.; STAPE, J. L.; SENTELHAS, P. C.; GONÇALVES, J. L. M.; SPAROVEK, G. Köppen's climate classification map for Brazil. Meteorologische Zeitschrift, v. 22, 711-728, 2014.

BAGLIANO, R. V.; LUIZ, F. Fragmentação florestal retratado como perda da biodiversidade sobre os princípios científicos dos códigos florestais brasileiro. Revista Meio Ambiente e Sustentabilidade vol. 3, p. 67-79, 2013.

BENTON, T. G. The ecology of the scorpion Euscorpius flavicaudis in England. Journal of Zoology, vol. 226, p. 351-368, 1992.

BERNARDES JR., E. J.; ROCHA, E. C.; JESUS, F. G., OLIVEIRA M. A., ARAÚJO, M. S. Dry forest fragmentation in Brazilian Cerrado and its effects on communities of ground foraging ants. Florida Entomologist, vol. 103, p. 384-391, 2020.

BERTANI, R.; MARTINS, R.; CARVALHO, M. A. Notes on Tityus confluens Borelli, 1899 (Scorpiones: Buthidae) in Brazil. Zootaxa, vol. 869, p. 1-7, 2005.

CARVALHO, L. S.; BRESCOVIT, A. D.; SOUZA, C. A. R.; RAIZER, J. Checklist dos escorpiões (Arachnida, Scorpiones) do Mato Grosso do Sul, Brasil. Iheringia, vol. 107, p. 1-7, 2017.

CRISTALDO, M. F.; SOUZA, C. C.; de JESUS, L.; PADOVANI, C. R.; OLIVEIRA, P. T. S.; VIGANO, H. H. G. Analysis and distribution of rainfall monitoring network in a Brazilian Pantanal region. Revista Brasileira de Meteorologia, v. 32, p. 199205, 2017.

DE ROODT, A. R. Comments on environmental and sanitary aspects of the scorpionism by Tityus trivittatus in Buenos Aires City, Argentina. Toxins, vol. 6, p. 1434-1452, 2014.

DE ROODT, A. R.; LAGO, N. R.; SALOMÓN, O. D.; LASKOWICZ, R. D.; NEDER, L. E. R.; LÓPEZ, R. A.; MONTERO, T. E.; VEJA, V. V. A new venomous scorpion responsible for severe envenomation in Argentina: Tityus confluens. Toxicon, vol. 53, p. 1-8, 2009.

FINA, B. G.; MONTEIRO, R. Análise da estrutura arbustivo-arbórea de uma área de Cerrado sensu stricto, município de Aquidauana-Mato Grosso do Sul. Revista Árvore, v. 37, p. 577-585, 2013.

FOERSTER, S. I. A.; LIRA, A. F. A.; ALMEIDA, C. G. Vegetation structure as the main source of variability in scorpion assemblages at small spatial scales and further considerations for the conservation of Caatinga landscapes. Neotropical Biology and Conservation, vol. 15, p. 533-550.

KLINK, C. A.; MACHADO, R. B. Conservation of the Brazilian Cerrado. Conservation Biology, v. 19, n. 3, p. 707-713, 2005. 
KLINK, C. A.; MOREIRA, A. G. Past and current human occupation and land-use, In: Oliveira PS, Marquis RJ, editors. The Cerrado of Brazil. Ecology and natural history of a neotropical savanna. 2002.

LIRA, A. F. A., SALOMÃO, R. P., ALBUQUERQUE, C. M. R. Patterns of scorpion diversity across a bioclimatic dry-wet gradiente in Neotropical forests. Acta Oecologica, vol. 96, p. 10-17. 2019b.

LIRA, A. F. A.; DESOUZA, A. M.; ALBUQUERQUE, C. M. R. Environmental variation and seasonal changes as determinants of the spatial distribution of scorpions (Arachnida: Scorpiones) in Neotropical forests. Canadian Journal of Zoology, vol. 96, p. 963-972, 2018.

LIRA, A. F. A.; PORDEUS, L. M.; SALOMÃO, R. P.; BADILLO-MONTAÑO, R.; ALBUQUERQUE, C. M. R. Effects of anthropogenic land-use on scorpions (Arachnida: Scorpiones) in Neotropical forests. International Journal of Tropical Insect Science, vol. 39, p. 211-218, 2019.

LOURENÇO, W. R. New insights on the scorpion species of the "Tityus trivittatus group" of subgenus Tityus C.L. Koch, 1836 (Scorpiones: Buthidae). Revista Ibérica de Aracnología, vol. 34, p. 119-125, 2019.

LOURENÇO, W. R. Some additional comments on the Ananteridae or 'Ananteris group' and description of a new species of Ananteris Thorell from Central Brazil (Scorpiones: Buthidae). Zootaxa, doi: 10.11646/zootaxa.4984.1.25, 2021.

LOURENÇO, W. R.; JESUS-JUNIOR, M. M. B. G.; LIMEIRA-DE-OLIVEIRA, F. A new species of Tityus C. L. Koch, 1836 (Scorpiones, Buthidae) from the State of Maranhão in Brazil. Boletín Sociedad Entomológica Aragonesa, vol. 38, p. 117-120, 2006.

LOURENÇO, W.R. Scorpions of Brazil. Paris: Les Édition de I'lf. Pp. 308. 2002.

MAURY, E. A. Tityus trivittatus en la Argentina. Nuevos datos sobre distribución, partenogénesis, sinantropía y peligrosidad (Scorpiones, Buthidae). Revista del Museo Argentino de Ciencias Naturales, vol. 24, p. 1-24, 1997.

MAURY, E.A. Redescripción y distribución en la Argentina de Tityus trivittatus trivittatus Kraepelin 1898 (Scorpiones, Buthidae). Comentarios sobre sus hábitos domiciliarios y su peligrosidad. Physis, vol. 29, p. 405-421, 1970.

MITTERMEIER, R. A.; GIL, P. R.; HOFFMANN, M.; PILGRIM, J.; BROOKS, T.; MITTERMEIER, C. G.; LAMOREAUX, J.; FONSECA, G. A. B. Hotspots revisited: earth's biologically richest and most endangered terrestrial ecoregions. Cemex and University of Chicago Press, Chicago, Illinois, 2004.

OJANGUREN-AFFILASTRO, A. A.; MATTONI, C. I.; OCHOA, J. A.; RAMÍREZ, M. J.; CECCARELLI, F. S.; PRENDINI, L. Phylogeny, species delimitation and convergence in the South American bothriurid scorpion genus Brachistosternus Pocock 1893: integrating morphology, nuclear and 
mitochondrial DNA. Molecular Phylogenetics and Evolution, vol. 94, p. 159$170,2016$.

OVERBECK, G. E.; VÉLEZ-MARTIN, E.; SCARANO, F. R.; LEWINSOHN, T. M.; FONSECA, C. R.; MEYER, S. T.; MULLER, S. C.; CEOTTO, P.; DADALT, L.; DURIGAN, G.; GANADE, G.; GOSSNER, M. M., GUADGNIN, D. L.; LORENZEN, K.; JACOBI, C. M.; WEISSER, W. W.; PILLAR, V. D. Conservation in Brazil needs to include nonforest ecosystems. Diversity and Distributions, vol. 21, p. 1455-1460, 2015.

PERETTI, A. V.; ACOSTA, L. E.; BENTON, T. G. 1999. Sexual cannibalism in scorpions: fact or fiction? Biological Journal of the Linnean Society, vol. 68, p. 485-496, 1999.

POLIS, G. A. The Biology of Scorpions. Stanford Universtiy Press, Stanford. 614 pp, 1990.

POLIS, G. A.; SISSOM, W. D.; MCCORMICK, S. J. Predators of scorpions: field data and review. Journal of Arid Environments, v. 4, p. 309-326, 1981.

POLIS, G. A.; YAMASHITA, T. The ecology and importance of predaceous arthropods in desert communities. In: Polis GA (ed) The Ecology of Desert Communities. The University of Arizona Press, Tucson, pp. 180-222, 1991.

PONTES-DA-SILVA, E.; PACHECO, M. L. T.; PEQUENO, P. A. C. L; FRANKLIN, E.; KAEFER, I. L. Attitudes towards scorpions and frogs: a survey among teachers and students from schools in the vicinity of na amazonian protected area. Journal of Ethnobiology, v. 36, p. 395-411, 2016.

PORTO, T. J.; CARVALHO, L. S.; SOUZA, C. A. R.; OLIVEIRA, U.; BRESCOVIT, A. D. Escorpiões da Caatinga: conhecimento atual e desafios. In Bravo, F.; Calor, A. (Eds.) Artrópodes do semiárido: biodiversidade e conservação. Printmídia, Feira de Santana, pp. 33-46. 2014.

RAMOS, T. V.; SANTOS, L. A. C.; SOUZA, W. G.; SOUZA, K. R.; LIMA, N. L.; GUIMARÃES, L. E.; BRANDÃO, D. C.; SILVA, J. P.; GONÇALVES, R. A.; GONÇALVES, B. B.; ARRUDA, E. M.; CALIL, F. N.; SILVA NETO, C. M. Chemical attributes of Brazilian Cerrado soil under different management systems. Australian Journal of Crop Science vol. 12, p. 505-510, 2018.

REIN, J. O. The Scorpion Files. https://www.ntnu.no/ub/scorpion-files/ Acessado em 30 de junho de 2021.

RODRIGUES, L. P.; de CARVALHO, E. M.; da SILVA, J. F. Unidades de conservação no ecótono entre Pantanal e Cerrado: o caso do município de Aquidauana (MS). In: Perez Filho A, Amorim RR (eds) Os desafios da geografia física na fronteira do conhecimento. Instituto de Geociências-UNICAMP, Campinas, pp 10701081, 2017.

RODRÍGUEZ-CABRERA, T. M.; TERUEL, R.; SAVALL, E. M. Scorpion predation in Cuba: new cases and a review. Euscorpius, v. 2020, p. 1-7, 2020. 
SEITER, M. Developmental stages and reproductive biology in Tityus confluens Borelli, 1899 and Tityus ocelote (Francke $e$ Stockwell, 1987) (Scorpiones, Buthidae). Revista Ibérica de Aracnología, vol. 21, p. 113-118, 2012.

TOSCANO-GADEA, C. A. Confirmation of parthenogenesis in Tityus trivittatus Kraepelin 1898 (Scorpiones, Buthidae). The Journal of Arachnology, vol. 32, p. 866-869, 2004.

VELOSO, H. P.; RANGEL FILHO, A. L. R.; LIMA, J. C. A. Classificação da Vegetação Brasileira, adaptada a um sistema universal. IBGE, Rio de Janeiro. 112 pp, 1991.

YAMAZAKI, L.; MARQUES, M. I.; BRESCOVIT, A. D.; BATTIROLA, L. D. Tityus paraguayensis (Scorpiones: Buthidae) in the canopies of Callisthene fasciculata (Vochysiaceae) in the Pantanal of Mato Grosso (Brazil). Acta Biológica Paranaense, vol. 44, p. 153-158, 2015. 


\section{CAPÍTULO XI}

\section{DIVERSIDADE DE BESOUROS SCARABAEINAE (COLEOPTERA: SCARABAEIDAE) DO ECÓTONO CERRADO-PANTANAL}

DDI: 10.51859/amplla.ecp672.1121-11

César Murilo de Albuquerque Correa ${ }^{1}$

Anderson Puker ${ }^{2}$

Fernando Zagury Vaz-de-Mello ${ }^{1}$

1 Departamento de Biologia e Zoologia, Instituto de Biociências, Universidade Federal de Mato Grosso, Cuiabá 78060-090, Mato Grosso, Brasil

2 Instituto Federal de Educação, Ciência e Tecnologia de Rondônia, Colorado do Oeste - 76993-000, Rondônia, Brasil

\section{INTRODUÇÃO}

Os besouros da subfamília Scarabaeinae (Coleoptera: Scarabaeidae) são conhecidos popularmente como "besouros rola-bostas" devido ao hábito de inúmeras espécies construírem esferas com matéria orgânica em decomposição para depositar seus ovos e transportá-las até locais protegidos, onde constroem seus ninhos (HALFFTER; MATTEWS, 1966). Assim, estes insetos podem ser divididos em três grupos funcionais, baseado no transporte de alimento até o ninho: (1) os roladores ou telecoprídeos, que rolam a "bola" de alimento na superfície do solo até certa distância da fonte do recurso; (2) os escavadores ou paracoprídeos, que transportam o recurso alimentar para o interior do solo fazendo túneis ao lado ou imediatamente sob o recurso; e (3) os residentes ou endocoprídeos, que não alocam o recurso, utilizando-o somente no local (HALFFTER; MATTEWS, 1966; HALFFTER; EDMONDS, 1982; HANSKI; CAMBEFORT, 1991).

A maioria dos besouros Scarabaeinae é coprófaga, alimentando-se principalmente de fezes de grandes herbívoros, mas há exceções na dieta desses insetos. Além de fezes, os Scarabaeinae podem se alimentar de carcaças (necrófagos), de fungos (micetófagos), de frutos em decomposição (carpófagos) e de material vegetal em decomposição (saprófagos), e podem ainda ser predadores ou 
generalistas (HALFFTER; MATTEWS, 1966; HANSKI; CAMBEFORT, 1991; SCHOLTZ et al., 2009). Portanto, ao incorporar as massas fecais no solo, os Scarabaeinae desempenham importantes funções ecológicas nos habitats em que vivem, tais como ciclagem de nutrientes, melhoria na fertilidade do solo, aumento na infiltração de água no solo, dispersão secundária de sementes, controle de parasitas de gado (NICHOLS et al., 2008), além da redução de emissão de gases do efeito estufa (PENTTILÄ et al., 2013).

Os besouros Scarabainae também são considerados indicadores eficientes de mudanças ambientais porque sofrem alterações nas métricas da comunidade (por exemplo, abundância, riqueza de espécies, composição e/ou diversidade funcional) quando submetido a mudanças ambientais de origem antrópica ou natural (NICHOLS et al., 2007; BARRÁGAN et al., 2011; BICKNELL et al., 2014; FRANÇA et al., 2016; BEIROZ et al., 2018). Além disso, como os Scarabaeinae possuem um alto grau de especificidade de habitat, eles podem ser úteis como organismos focais para avaliar impactos antrópicos em diversos ecossistemas ao redor do mundo (NICHOLS et al., 2007; BRAGA et al., 2013; KORASAKI et al., 2013; AUDINO et al., 2014).

A distribuição geográfica dos Scarabaeinae é ampla com maior diversidade nas regiões tropicais, onde representam importante porção da biodiversidade, tanto em paisagens de formação aberta quanto em florestas (HANSKI; CAMBEFORT, 1991). Atualmente, a subfamília Scarabaeinae abriga 257 gêneros e mais de 6.500 espécies em todo o mundo (SCHOOLMEESTERS, 2020). Na América do Sul, existem registros de mais de 1.250 espécies destes insetos, das quais 726 espécies em 63 gêneros são reportadas no Brasil (VAZ-DE-MELLO et al., 2011; VAZ-DE-MELLO, 2020), e 117 espécies em 29 gêneros são reportadas para o estado de Mato Grosso do Sul (VAZ-DE-MELLO et al., 2017).

O número de estudos sobre os Scarabaeinae no ecótono Cerrado-Pantanal vem aumentando consideravelmente nos últimos 10 anos (PUKER et al., 2013, 2014; CORREA et al., 2016, 2019b, 2020, 2021a), acrescentando novos registros de espécies para esse tipo de ecossistema. Entretanto, até o presente momento, ainda não existe uma lista das espécies desses insetos para o ecótono Cerrado-Pantanal. Portanto, neste estudo, foram revisados os registros de literatura e a identificação das espécies de Scarabaeinae reportadas para uma região do ecótono Cerrado- 
Pantanal. Desse modo, fornecemos a primeira lista completa de espécies e discutimos as lacunas existentes de amostragem para a região, visando contribuir para o conhecimento e conservação da diversidade de Scarabaeinae do ecótono Cerrado-Pantanal.

\section{METODOLOGIA}

O estudo foi realizado mediante pesquisa bibliográfica em virtualmente toda a literatura publicada até meados de 2021 cujo escopo das publicações tenham sido besouros Scarabaeinae amostrados no ecótono Cerrado-Pantanal. Para tanto, foram considerados apenas artigos científicos publicados em revistas científicas indexadas nas bases: Scopus, Web of Science, Google Scholar, Portal Periódicos Capes e Scielo. Essa compilação incluiu estudos faunísticos, taxonômicos, ecológicos e de interesse econômico que citassem ocorrência de espécies identificadas de Scarabaeinae de uma região do ecótono Cerrado-Pantanal, dentro dos territórios dos municípios de

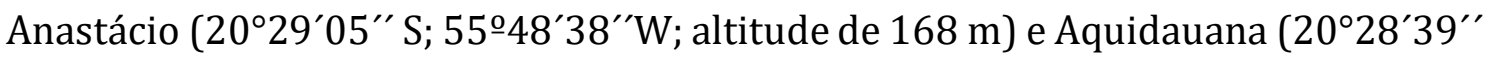
S; 554ㄱ'24" W; altitude de 150 m), Mato Grosso do Sul, Brasil (AIDAR et al., 2000; RODRIGUES et al., 2001a,b; PUKER et al., 2013, 2014; CORREA et al., 2013, 2016, 2019b, 2020a,b, 2021a,b,c). Todos os registros previamente existentes foram revisados quanto a suas identificações (quando possível inclusive com base em exemplares-testemunho) para uma correta identificação das espécies. Foram também listados os registros da coleção que possui o maior acervo de espécies de Scarabaeinae do ecótono Cerrado-Pantanal, o Setor de Entomologia da Coleção Zoológica da Universidade Federal de Mato Grosso (CEMT, curador F. Z. Vaz-deMello). Registros da coleção do Laboratório de Entomologia da Universidade Estadual de Mato Grosso do Sul (responsável Alfredo R. Abot) foram também incorporados.

Finalmente, as espécies de Scarabaeinae citadas no presente estudo puderam ser também associadas aos habitats naturais presentes na região de ecótono Cerrado-Pantanal estudada (Campos nativos, Cerrado, Cerrado urbano ou Mata ciliar) ou a um tipo de ecossistema antrópico (pastagem exótica; Urochloa spp.) (Figura 1), com base em dados de coleções ou distribuição geográfica conhecida. 
Figura 1. Habitats de amostragem de besouros Scarabaeinae (Coleoptera: Scarabaeidae) no ecótono Cerrado-Pantanal (Anastácio e Aquidauana, Mato Grosso do Sul, Brasil): A) Campo nativo, B) Cerrado, C) Cerrado urbano, D) Mata ciliar, E) Pastagem exótica e F) armadilha do tipo pitfall.

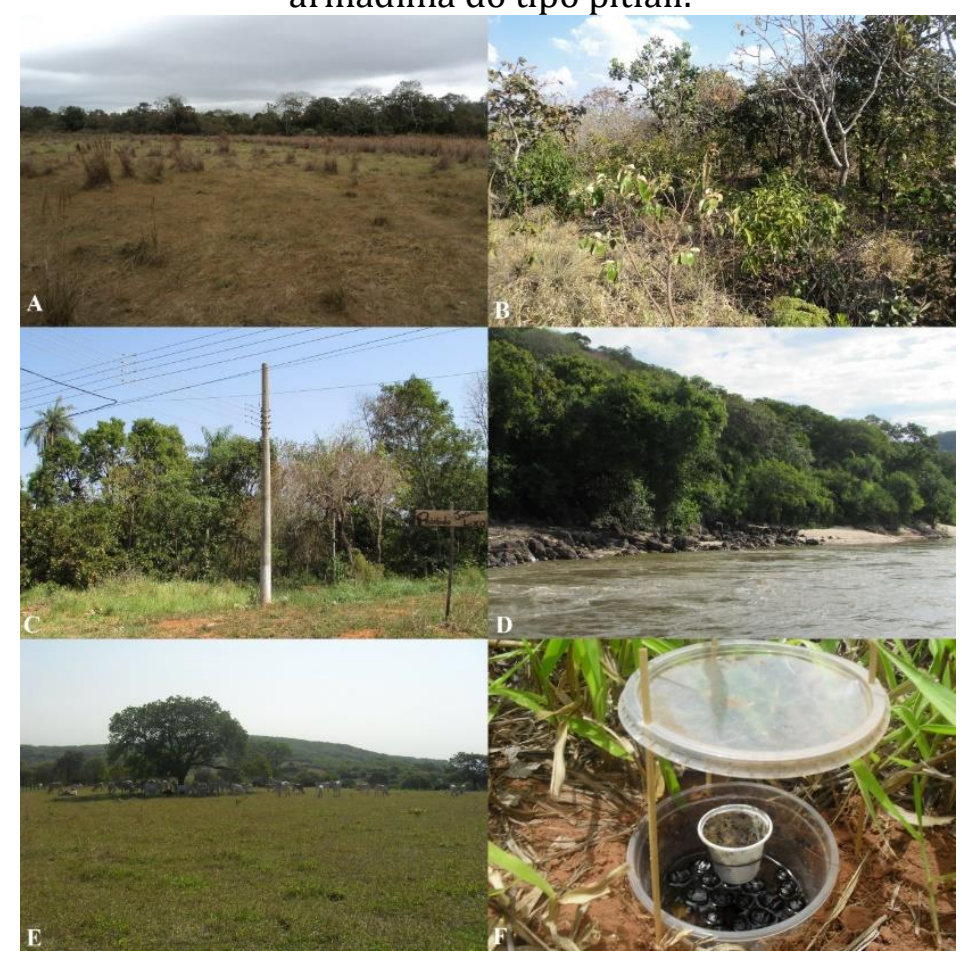

Fonte: Autoria própria.

\section{RESULTADOS E DISCUSSÃO}

Foram registradas 59 espécies distribuídas em 19 gêneros de Scarabaeinae (Tabela 1). Como a sistemática supragenérica do grupo está em constante mudança (VAZ-DE-MELLO et al., 2008), as tribos não foram citadas. Foi registrado um maior número de espécies nas pastagens exóticas $(S=46)$, seguida do Cerrado (36), Mata ciliar (23), Cerrado em área urbana (15) e campos nativos (13) (Tabela 1). Em relação às espécies exclusivas de cada habitat, pastagens exóticas tiveram 14 espécies, quatro espécies foram exclusivas dos campos nativos, três do Cerrado, duas do Cerrado em área urbana e nenhuma da Mata ciliar (Figura 2). 
Figura 2. Número de artigos publicados sobre besouros Scarabaeinae (Coleoptera: Scarabaeidae) em diferentes habitats no ecótono Cerrado-Pantanal, Brasil. Números dentro das barras indicam o número de espécies exclusivas para cada tipo de habitat.

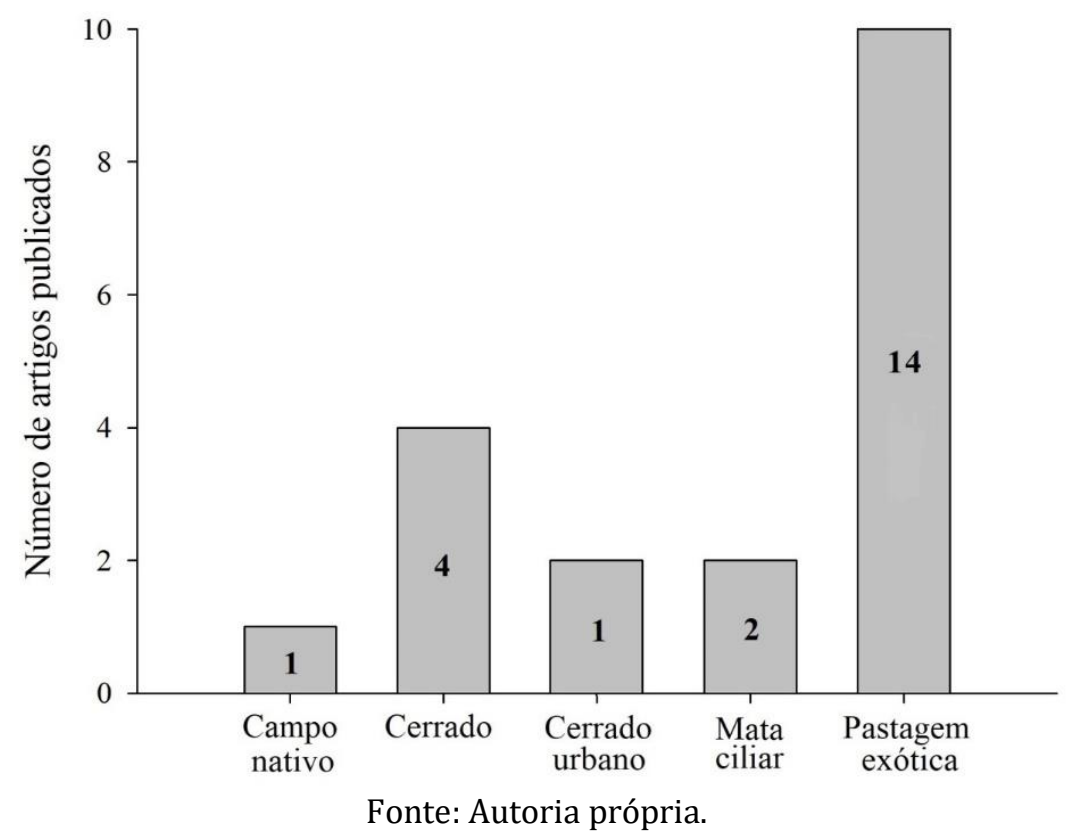

Pastagens exóticas foram mais representadas em número de publicações científicas ( $n=10$ artigos) quando comparada aos demais habitats; Cerrado (4 artigos), Mata ciliar (2 artigos), Cerrado urbano e Campo nativo (1 artigo) (Figura 2). A amostragem com o uso de armadilhas pitfall iscadas (por exemplo; fezes bovinas, suínas, ovinas, humanas e carcaça) foi o único método utilizado em todos os artigos avaliados.

Nesse estudo registramos 59 espécies de besouros Scarabaeinae para uma região do ecótono Cerrado-Pantanal, dentro do território dos municípios de Anastácio e Aquidauana, correspondendo a cerca de 50\% de toda diversidade de Scarabaeinae reportada para o estado de Mato Grosso do Sul (VAZ-DE-MELLO et al., 2017). Por se tratar de uma região de transição de biomas, muitas das espécies registradas são importantes componentes do bioma Pantanal (CORREA et al., 2016a, 2019a) e Cerrado (ALMEIDA; LOUZADA 2009; ALMEIDA et al., 2011). Assim, a alta riqueza de espécies de Scarabeinae registrada nesse estudo, demonstra a importância da região estudada para a conservação de besouros Scarabaeinae no ecótono Cerrado-Pantanal.

Todas as espécies listadas em nosso estudo apresentam uma ampla distribuição geográfica, sendo assim nenhuma endêmica da região de estudo ou 
prioritária para conservação. Dentre as espécies registradas, destacam-se aquelas consideradas importantes para as pastagens brasileiras devido à sua frequência, abundância e ampla distribuição: Dichotomius bos (Blanchard, 1843), Dichotomius nisus (Olivier, 1789), Digitonthophagus gazella (Fabricius, 1787), Ontherus appendiculatus (Mannerheim, 1829) e Trichillum externepunctatum Preudhomme de Borre, 1886 (TISSIANI et al., 2017). Essas espécies são adaptadas às condições encontradas nas pastagens como, altas temperaturas, intensa exposição solar (HALFFTER; NAVARRETE, 2008) e solos compactados devido ao pastoreio do gado (CORREA et al., 2019a).

Digitonthophagus gazela é a única espécie não nativa registrada em nosso estudo. Esta espécie africana foi introduzida no Brasil durante os anos 1980 para ajudar a controlar vermes gastrointestinais e moscas parasitas de gado (MIRANDA et al., 2000; GÉNIER; DAVIS, 2017). Ela é estritamente coprófaga (CORREA et al., 2020d) e se beneficia da presença do gado (CORREA et al. 2019a). Entretanto, D. gazella é uma ameaça à fauna de Scarabaeinae nativa, e pode impactar negativamente os ecossistemas locais (MESQUITA FILHO et al., 2018).

O maior número de espécies foi registrado nas pastagens exóticas, o que está diretamente relacionado ao amplo esforço amostral nesse tipo de habitat (Figura 1). De fato, esse resultado $(S=45)$ reflete uma comunidade rica em espécies de Scarabaeinae na região de estudo no ecótono Cerrado-Pantanal quando comparada a outras pastagens exóticas em diferentes regiões do Brasil (LOUZADA; CARVALHO e SILVA, 2009; SILVA et al., 2017). Isso se deve aos componentes bióticos de biomas abertos como Pantanal e Cerrado que conseguem se adaptar as pastagens da região de estudo, incrementando o número de espécies nesse tipo de habitat. Assim, a conservação dos habitats nativos é uma fonte primária de espécies de Scarabaeinae para as pastagens exóticas (CORREA et al., 2019b)

Habitats compostos por vegetação nativa (campo nativo, cerrado e mata ciliar) tem recebido menos atenção nos estudos desenvolvidos sobre as comunidades de Scarabaeinae na região de estudo, quando comparado com pastagens exóticas. Nesse sentido, desde que a composição de espécies de Scarabaeinae em habitats nativos é diferente da composição encontrada em pastagens exóticas (CORREA et al., 2019b), novas coletas sistematizadas em habitats nativos podem revelar espécies previamente não reportadas para essa região do 
ecótono Cerrado-Pantanal. Além disso, o número de espécies exclusivas nos diferentes habitats nativos reforça a necessidade de novas coletas para um melhor conhecimento das comunidades de Scarabaeinae nesses habitats. Finalmente, métodos de coleta ainda não utilizados na região de estudo, como armadilhas de interceptação de voo, armadilhas luminosas e coleta manual, poderão auxiliar na captura de espécies de Scarabaeinae que não são geralmente capturadas em armadilhas pitfall com iscas (PUKER et al., 2020).

Atualmente, pesquisadores da Universidade Estadual de Mato Grosso do Sul (UEMS) tem publicado ou têm em andamento projetos com Scarabaeinae no ecótono Cerrado-Pantanal, em parceria com pesquisadores da Universidade Federal de Mato Grosso (UFMT), Instituto Federal de Educação, Ciência e Tecnologia de Rondônia (IFRO), Instituto Federal de Educação, Ciência e Tecnologia de Mato Grosso (IFMT) e Universidade Federal de Lavras (UFLA). Os estudos têm investigado geralmente aspectos econômicos ou ecológicos de espécies associadas às pastagens, levantamentos faunísticos e impactos de atividades antrópicas sobre ecossistemas nativos usando Scarabaeinae como bioindicadores da qualidade ambiental.

Tabela 1. Espécies de besouros Scarabaeinae (Coleoptera: Scarabaeidae) registradas no ecótono Cerrado-Pantanal (Anastácio e Aquidauana, Mato Grosso do Sul, Brasil), e seus habitats de ocorrência: CN - Campo nativo; CER - Cerrado; CEU - Cerrado urbano; MC - Mata ciliar e PE - Pastagem exótica.

\begin{tabular}{|c|c|c|c|c|c|}
\hline \multirow{3}{*}{ Espécies } & \multicolumn{5}{|c|}{ Ocorrência } \\
\hline & $\mathrm{C}$ & $\mathrm{CE}$ & $\mathrm{CE}$ & M & $P$ \\
\hline & $\mathrm{N}$ & $\mathrm{R}$ & $\mathrm{U}$ & C & E \\
\hline 1. Anomiopus pereirai (Martínez, 1955) & & $\mathrm{X}$ & & & \\
\hline 2. Ateuchus aff. Puncticollis & & $\mathrm{X}$ & & & $\mathrm{X}$ \\
\hline 3. Ateuchus ovalis Boucomont, 1928 & & & & & $\mathrm{X}$ \\
\hline 4. Ateuchus pauperatus (Germar, 1824) & & & & & $\mathrm{X}$ \\
\hline 5. Ateuchus pruneus (Boucomont, 1828) & & $\mathrm{X}$ & & & $\mathrm{X}$ \\
\hline 6. Ateuchus viduus (Blanchard, 1845) & & $\mathrm{X}$ & & & \\
\hline 7. Ateuchus vividus Germar, 1824 & & & & & $\mathrm{X}$ \\
\hline 8. Canthidium aff. Angulicolle & & & $\mathrm{X}$ & & \\
\hline 9. Canthidium aff. Barbacenicum & & $\mathrm{X}$ & $\mathrm{X}$ & $\mathrm{X}$ & $\mathrm{X}$ \\
\hline 10. Canthidium aff. Breve & & $\mathrm{X}$ & & $\mathrm{X}$ & $\mathrm{X}$ \\
\hline 11. Canthidium aff. Pinotoides & & $\mathrm{X}$ & & & $\mathrm{X}$ \\
\hline 12. Canthidium aff. Refulgens & $\mathrm{X}$ & & & & \\
\hline 13. Canthidium aff. Viride & $\mathrm{X}$ & $\mathrm{X}$ & & $\mathrm{X}$ & $\mathrm{X}$ \\
\hline 14. Canthidium prasinum (Blanchard, 1846) & & & & & $\mathrm{X}$ \\
\hline 15. Canthon aff. Tristis & & $\mathrm{X}$ & & $\mathrm{X}$ & \\
\hline 16. Canthon chalybaeus Blanchard, 1843 & & $\mathrm{X}$ & & $\mathrm{X}$ & $\mathrm{X}$ \\
\hline
\end{tabular}




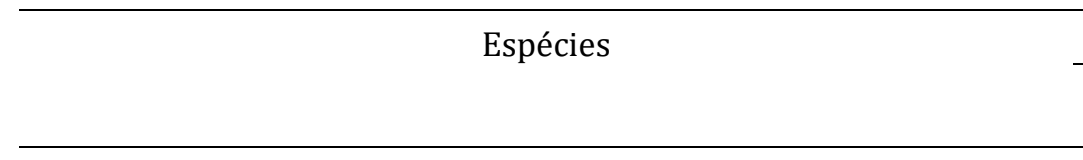

17. Canthon conformis Harold, 1868

18. Canthon curvodilatatus Schmidt, 1920

19. Canthon histrio (Lepelletier de Saint-Fargeau $e$ Audinet-Serville, 1828)

20. Canthon lituratus (Germar,1813)

21. Canthon maldonadoi Martínez, 1951

22. Canthon mutabilis Lucas, 1857

23. Canthon unicolor Blanchard, 1843

24. Canthon virens (Mannerheim, 1829)

25. Coprophanaeus cyanescens (d'Olsoufieff, 1924)

26. Coprophanaeus ensifer (Germar, 1824)

27. Croprophanaeus spitzi (Pessôa, 1935)

28. Deltochilum aff. komareki

29. Deltochilum pseudoicarus Balthasar, 1939

30. Dendropaemon nitidicollis Olsoufieff, 1924

31. Diabroctis mimas (Linnaeus, 1758)

32. Diabroctis mirabilis (Harold, 1877)

33. Dichotomius aff. carbonarius

34. Dichotomius cuprinus (Felsche, 1901)

35. Dichotomius bos (Blanchard, 1843)

36. Dichotomius glaucus Harold, 1869

37. Dichotomius nisus (Olivier, 1789)

38. Dichotomius opacipennis Luederwaldt, 1931

39. Dichotomius semianeus (Germar, 1824)

40. Dichotomius sexdentatus (Luederwaldt, 1925)

41. Dichotomius zikani (Luederwaldt, 1922)

42. Digitonthophagus gazella (Fabricius, 1787)

43. Eurysternus caribaeus (Herbst, 1789)

44. Eurysternus nigrovirens Génier, 2009

45. Genieridium bidens (Balthasar, 1942)

46. Malagoniella punctatostriata (Blanchard, 1845)

47. Malagoniella puncticollis (Blanchard, 1846)

48. Ontherus appendiculatus (Mannerheim, 1829)

49. Ontherus dentatus Luederwaldt, 1930

50. Ontherus digitatus Harold, 1868

51. Ontherus sulcator (Fabricius, 1775)

52. Onthophagus aeneus Blanchard, 1845

53. Onthophagus hircus Billberg, 1815

54. Onthophagus buculus Mannerheim, 1829

55. Onthophagus ptox Erichson, 1842

56. Oxysternon palemo (Castelnau, 1840)

57. Phanaeus kirbyi Vigors, 1825

58. Phanaeus palaeno Blanchard, 1846

59. Trichillum externepunctatum Preudhomme de Borre, 1886

\begin{tabular}{ccccc}
\multicolumn{5}{c}{ Ocorrência } \\
\hline $\mathrm{C}$ & $\mathrm{CE}$ & $\mathrm{CE}$ & $\mathrm{M}$ & $\mathrm{P}$ \\
$\mathrm{N}$ & $\mathrm{R}$ & $\mathrm{U}$ & $\mathrm{C}$ & $\mathrm{E}$ \\
$\mathrm{X}$ & & & &
\end{tabular}

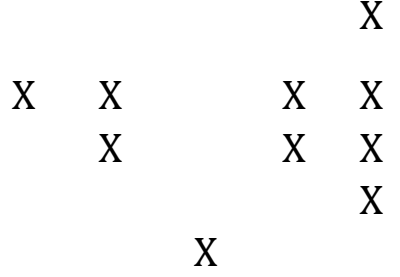

$\mathrm{X}$

$\begin{array}{ccccc} & \text { X } & & & \text { X } \\ \text { X } & & \text { X } & & \\ & & \text { X } & & \text { X } \\ & \text { X } & & \text { X } & \text { X } \\ \text { X } & \text { X } & \text { X } & \text { X } & \text { X } \\ & \text { X } & & & \end{array}$

$\mathrm{X}$

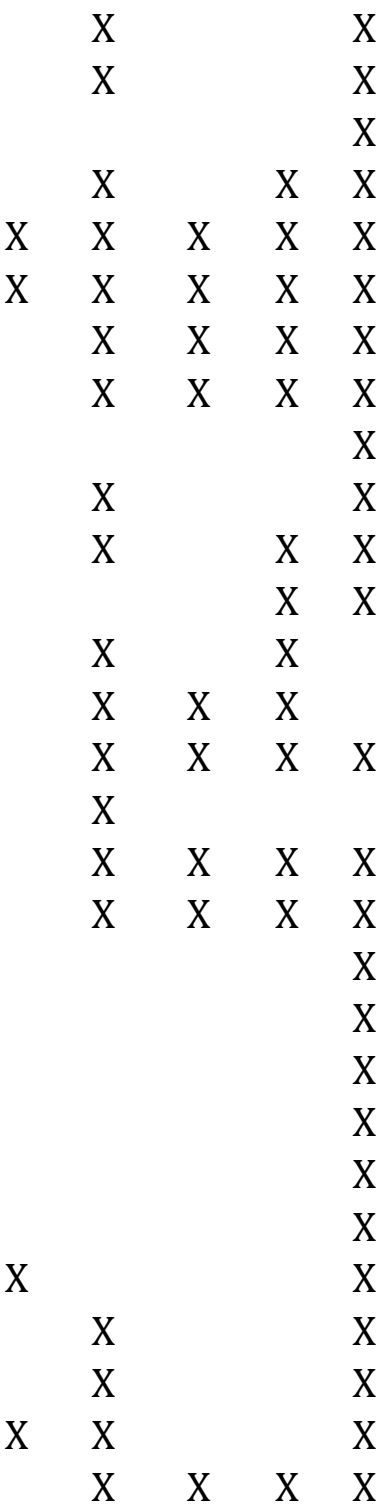




\begin{tabular}{lllllll}
\hline & \multirow{2}{*}{ Espécies } & \multicolumn{5}{c}{ Ocorrência } \\
\cline { 3 - 7 } & & $\mathrm{C}$ & $\mathrm{CE}$ & $\mathrm{CE}$ & $\mathrm{M}$ & $\mathrm{P}$ \\
& & $\mathrm{N}$ & $\mathrm{R}$ & $\mathrm{U}$ & $\mathrm{C}$ & $\mathrm{E}$ \\
\hline 60. Uroxys aff. corporaali & & $\mathrm{X}$ & $\mathrm{X}$ & & $\mathrm{X}$ & $\mathrm{X}$ \\
\hline
\end{tabular}

Fonte: Autoria própria.

\section{CONSIDERAÇÃOES FINAIS}

Nesse estudo, nós fornecemos a primeira lista das espécies de besouros Scarabaeinae do ecótono Cerrado-Pantanal. Nossos dados demonstram uma comunidade de Scarabaeinae rica em espécies na região de estudo, evidenciando a importância da manutenção dos diversos habitats para a conservação da fauna de Scarabaeinae local. De modo geral, as pastagens exóticas estão relativamente bem amostradas na região de estudo, por isso novas coletas devem priorizar os habitats nativos (Cerrado, campo nativo e mata ciliar). Finalmente, métodos de coleta ainda não utilizados na região de estudo, como armadilhas de interceptação de voo, armadilhas luminosas e coleta manual, podem auxiliar na captura de espécies de Scarabaeinae que não são geralmente capturadas em armadilhas pitfall com iscas. Assim, um esforço amostral maior em habitats nativos e utilização de diferentes métodos de coletas poderão trazer novos registros de espécies de Scarabaeinae para o ecótono Cerrado-Pantanal.

\section{AGRADECIMENTOS}

Nós agradecemos a Coordenação de Aperfeiçoamento de Pessoal de Nível Superior (Capes) pela bolsa de pós-doutoramento (88882.316025/2019-01, Code 001) para César M.A. Correa.

\section{REFERÊNCIAS}

AIDAR, T.; KOLLER, W. W.; RODRIGUES, S. R.; CORREA, A. M.; SILVA, J. C. C.; BALTA, O. S.; OLIVEIRA, J. M.; OLIVEIRA, V, L. Besouros coprófagos (Coleoptera: Scarabaeidae) coletados em Aquidauana, MS, Brasil. Anais da Sociedade Entomológica do Brasil, Londrina, v. 29, n. 4, p. 817-820, 2000.

ALMEIDA, S. S. P.; LOUZADA, J. N. C. Estrutura da comunidade de Scarabaeinae (Scarabaeidae: Coleoptera) em fitofisionomias do Cerrado e sua importância 
para a conservação. Neotropical Entomology, Londrina, v. 38, n. 1, p. 32-43, 2009.

ALMEIDA, S.; LOUZADA, J.; SPERBER, C.; BARLOW, J. Subtle-use change and tropical biodiversity: dung beetle communities in Cerrado grasslands and exotic pastures. Biotropica, Hoboken, v. 43, n. 6, p. 704-710, 2011.

AUDINO, L. D.; LOUZADA, J.; COMITA, L. Dung beetle as indicators of tropical forest restauration success: is it possible to recover species and functional diversity? Biological Conservation, Amsterdam, v. 169, p. 248-257, 2014.

BARRAGÁN, F.; MORENO, C. E.; ESCOBAR, F.; HALFFTER, G.; NAVARRETE, D. Negative impacts of human land use on dung beetle functional diversity. PLoS ONE, São Francisco, v. 6, e17976, 2011.

BEIROZ, W.; SAYER, E.; SLADE, E. M.; AUDINO, L.; LOUZADA, J.; BARLOW, J. Spatial and temporal shifts in functional and taxonomic diversity of dung beetle in a human-modified tropical forest landscape. Ecological Indicators, Amsterdam, v. 95, p. 518-526, 2018.

BICKNELL, J. E.; PHELPS, S. P.; DAVIES, R. G.; MANN, D. J.; STRUEBIG, M. J.; DAVIES, G. D. Dung beetle as indicators for rapid impact assessments: evaluating best practice forestry in neotropics. Ecological Indicators, Amsterdam, v. 43, p. 154-161, 2014.

BRAGA, R. F.; KORASAKI, V.; ANDRESEN, E.; LOUZADA, J. Dung beetle community and functions along a habitat-disturbance gradient in the Amazon: a rapid assessment of ecological functions associated to biodiversity. PLoS ONE, São Francisco, v. 8, e5778, 2013.

CORREA, C. M. A.; PUKER, A.; KORASAKI, V.; OLIVEIRA, N. G. Dung beetles (Coleoptera, Scarabaeinae) attracted to sheep dung in exotic pastures. Revista Brasileira de Entomologia, Curitiba, v. 57, n. 1, p. 113-116, 2013.

CORREA, C. M. A.; PUKER, A.; FERREIRA, K. R.; CRISTALDO, C. M.; FERREIRA, F. N. F.; ABOT, A. R.; KORASAKI, V. Using dung beetles to evaluate the conversion effects from native to introduced pasture in the Brazilian Pantanal. Journal Insect Conservation, Berlin, v. 20, p. 447-456, 2016 a.

CORREA, C. M. A.; PUKER, A.; KORASAKI, V.; FERREIRA, K. R.; ABOT, A. R. Attractiveness of baits to dung beetles in Brazilian savanna and exotic pasturelands. Entomological Science, Tóquio, v. 19, n. 3, 112-123, 2016b.

CORREA, C. M. A.; BRAGA, R. F.; PUKER, A.; ABOT, A. R.; KORASAKI, V. Optimising methods for dung beetle (Coleoptera: Scarabaeidae) sampling in Brazilian pastures. Environmental Entomology, Annapolis, v. 47, n. 1, p. 48-54, 2018.

CORREA, C. M. A.; BRAGA, R. F.; LOUZADA, J.; MENÉNDEZ, R. Dung beetle diversity and functions suggest no major impacts of cattle grazing in the Brazilian Pantanal wetlands. Ecological Entomology, St Albans, v. 44, n. 4, p. 524-533, 2019a. 
CORREA, C. M. A.; BRAGA, R. F.; PUKER, A.; KORASAKI, V. Patterns of taxonomic and functional diversity of dung beetles in a human-modified landscape in Brazilian Cerrado. Journal of Insect Conservation, Berlin, v. 23, p. 89-99, 2019b.

CORREA, C. M. A.; AUDINO, L. D.; HOLDBROOK, R.; BRAGA, R. F.; MENÉNDEZ, R.; LOUZADA, J. Successional trajectory of dung beetle communities in a tropical grassy ecosystem after livestock removal. Biodiversity and Conservation, Berlin, v. 29, 2311-2328, 2020a.

CORREA, C. M. A.; PERES, N. D.; HOLDBROOK, R. Patterns of alimentary resource use by dung beetles in introduced Brazilian pastures: cattle versus sheep dung. Entomological Science, Tóquio, v. 23, n. 3, 1-10, 2020b.

CORREA, C. M. A.; FERREIRA, K. R.; PUKER, A.; AUDINO, L. D.; KORASAKI, V. Greenspace sites conserve taxonomic and functional diversity of dung beetles in an urbanized landscape in the Brazilian Cerrado. Urban Ecosystems, Berlin, v. 24, doi.org/10.1007/s11252-021-01093-8, 2021a.

CORREA, C. M. A.; DA SILVA, P. G.; FERREIRA, K. R.; PUKER, A. Residential sites increase species loss and cause high temporal changes in functional diversity of dung beetles in an urbanized Brazilian Cerrado landscape. Journal of Insect Conservation, Berlin, v. 25, p. 417-418, 2021 b.

CORREA, C. M. A.; LARA, M. A.; PUKER, A.; NORIEGA, J. A.; KORASAKI, V. Quantifying responses of dung beetle assemblages to cattle grazing removal over a shortterm in introduced Brazilian pastures. Acta Oecologica, Amsterdam, v. 110, 103661, 2021c.

FRANÇA, F.; LOUZADA, J.; KORASAKI, V.; GRIFFITHS, H.; SILVEIRA, J. M.; BARLOW, J. Do space-for-time assessments underestimate the impacts of logging on tropical biodiversity? An Amazonian case study using dung beetles. Journal of Applied Ecology, Londres, v. 53, p. 1098-1105, 2016.

GÉNIER, F.; DAVIS, A. L. V. Digitonthophagus gazella auctorum: an unfortunate case of mistaken identity for a widely introduced species (Coleoptera: Scarabaeidae: Scarabaeinae: Onthophagini). Zootaxa, Auckland, v. 4221, p. 497-500, 2017.

HALFFTER, G.; MATHEWS, E. G. The natural history of dung beetles of the subfamily Scarabaeinae (Coleoptera, Scarabaeidae). Folia Entomológica Mexicana, Texcoco, v. 12/14, p. 1-312, 1966.

HALFFTER, G.; EDMONDS, W. D. The nesting of dung beetles (Scarabaeinae): an ecological and evolutive approach. Xalapa: Instituto de Ecología, 1982.176 p.

HANSKI, I.; CAMBEFORT, Y. Dung beetle ecology. Princeton: Princeton University Press, 1991. $481 \mathrm{p}$.

KORASAKI, V.; BRAGA, R. F.; ZANETTI, R.; MOREIRA, F. M. S.; VAZ-DE-MELLO, F. Z.; LOUZADA, J. Conservation value of alternative land-use systems for dung 
beetles in Amazon: valuing traditional farming practices. Biodiversity and Conservation, Berlin, v. 22, p. 1485-1499, 2013.

LOUZADA, J. N. C.; CARVALHO E SILVA, P. R. Utilisation of introduced Brazilian pastures ecosystems by native dung beetles: diversity patterns and resource use. Insect Conservation and Diversity, St Albans, v. 2, n. 1, p. 45-52, 2009.

MESQUITA FILHO, W.; FLECHTMANN, C. A. H.; GODOY, W. A. C.; BJORNSTAD, O. N. The impact of introduced Digitonthophagus gazella on a native dung beetle community in Brazil during 26 years. Biological Invasions, Berlin, v. 20, p. 963-979, 2018.

MIRANDA, C. H. B.; SANTOS, J. C.; BIANCHIN, I. The role of Digitonthophagus gazella in pasture cleaning and production as result of burial of cattle dung. Pasturas Tropicales, Cali, v. 22, n. 1, p. 14-18, 2000.

NAVARRETE, D.; HALFFTER, G. Dung beetle (Coleoptera: Scarabaeidae: Scarabaeinae) diversity in continous forest, forest fragments and cattle pastures in a landscape of Chiapas, México: the effects of anthropogenic changes. Biodiversity and Conservation, Berlin, v. 17, p. 2869-2898, 2008.

NICHOLS, E.; LARSEN, T.; SPECTOR, S.; DAVIS, A. L.; ESCOBAR, F.; FAVILA, M.; VULINEC, K. Global dung beetle response to tropical forest modification and fragmentation: a quantitative literature review and meta-analysis. Biological Conservation, Amsterdam, v. 137, p. 1-19, 2007.

NICHOLS, E.; SPECTOR, S.; LARSEN, J.; AMEZQUITA, S.; FAVILA, M. E. Ecological functions and ecosystem services provided by Scarabaeinae dung beetles. Biological Conservation, Amsterdam, v. 141, n. 6, p. 1461-1474, 2008.

PENTTILÄ, A.; SLADE, E. M.; SIMOJOKI, A.; RIUTTA, T.; MINKKINEN, K.; ROSLIN, T. Quantifying beetle-mediated effects on gas fluxes from dung pats. PLoS ONE, São Francisco, v. 8, e71454, 2013.

RODRIGUES, S. R.; MARCHINI, L. C.; CARBONARI, J. J. Ácaros da família Scutacaridae e Pygmephoridae (Acari: Heterostigmata) associados aos besouros coprófagos (Coleoptera: Scarabaeidae) no Brasil. Neotropical Entomology, Londrina, v. 30, n. 3, p. 387-390, 2001a.

RODRIGUES, S. R.; MARCHINI, L. C.; MENDES, M. C. Ácaros da família Macrochelidae (Gamasida) associados a besouros coprófagos (Scarabaeidae). Revista Brasileira de Entomologia, Curitiba, v. 45, n. 3, p. 207-214, 2001b.

PUKER, A.; CORREA, C. M. A.; KORASAKI, V.; FERREIRA, K. R.; OLIVEIRA, N. G. Dung beetles (Coleoptera: Scarabaeidae) attracted to dung of the largest herbivorous rodent on Earth: a comparison with human feces. Environmental Entomology, Annapolis, v. 42, n. 6, p. 1218-1225, 2013.

PUKER, A.; CORREA, C. M. A.; KORASAKI, V. Deltochilini and Phanaeini dung beetles (Coleoptera: Scarabaeidae: Scarabaeinae) in introduced and native 
ecosystems of Brazil. Journal of Natural History, Londres, v. 48, n. 35-36, p. 2105-2116, 2014.

PUKER, A.; SILVA, K. K. G.; SANTOS, D. C.; CORREA, C. M. A.; VAZ-DE-MELLO, F. Z. Dung beetles collected using flight intercept traps in an Amazon rainforest fragment and adjacent agroecosystems. International Journal of Tropical Insect Science, Berlin, v. 40, n. 3, p. 1-8, 2020.

SCHOOLMEESTERS, P. Scarabs: Scarabs: World Scarabaeidae Database (version 2019-11-02). In: ROSKOV, Y.; OWER, G.; ORRELL, T.; NICOLSON, D.; BAILLY, N.; KIRK, P. M.; BOURGOIN, T.; DEWALT, R. E.; DECOCK, W.; NIEUKERKEN, E. VAN; PENEV, L. (Eds.) Species $2000 e$ ITIS Catalogue of Life, 2020-04-16 Beta. Species 2000: Naturalis, Leiden, The Netherlands. Disponível em: $<$ www.catalogueoflife.org/col>. Acesso em: 23 junho, 2021.

SCHOLTZ, C. H.; DAVIS, A. L. V.; KRYGER, U. Evolutionary biology and conservation of dung beetles. Sofia: Pensoft, 2009. 567 p.

SILVA, R. J.; PELISSARI, T. D.; KRINSKI, D.; CANALE, G.; VAZ-DE-MELLO, F. Z. Abrupt species loss of the Amazonian dung beetle in pastures adjacent to speciesrich forests. Journal Insect Conservation, Berlin, v. 21, p. 487-494, 2017.

TISSIANI, A. S. O.; VAZ-DE-MELLO, F. Z.; CAMPELO-JÚNIOR, J. H. Dung beetle of Brazilian pastures and key to genera identification (Coleoptera: Scarabaeidae). Pesquisa Agropecuária Brasileira, Brasília, v. 52, n. 6, p. 401418, 2017.

VAZ-DE-MELLO, F. Z. Synopsis of the new subtribe Scatimina (Coleoptera: Scarabaeidae: Scarabaeinae: Ateuchini), with descriptions of twelve new genera and review of Genieridium, new genus. Zootaxa, Auckland, v. 1955, p. 1-75, 2008.

VAZ-DE-MELLO, F. Z. Scarabaeinae in Catálogo Taxonômico da Fauna do Brasil. PNUD.

Disponível

em: <http://fauna.jbrj.gov.br/fauna/faunadobrasil/127498>. Acesso em: $23 \mathrm{de}$ Junho, 2021.

VAZ-DE-MELLO, F. Z.; EDMONDS, W. D.; OCAMPO, F. C.; SCHOOLMEESTERS, P. A multilingual key to the genera and subgenera of the subfamily Scarabaeinae of the New World (Coleoptera: Scarabaeidae). Zootaxa, Auckland, v. 2854, p. 1-73, 2011.

VAZ-DE-MELLO, F. Z.; BAVUTTI, L. O. L.; FLECHTMANN, C. A. H.; PUKER, A.; CORREA, C. M. A. Lista de espécies dos Scarabaeinae (Coleoptera, Scarabaeidae) do Estado de Mato Grosso do Sul. Ilheringia, Série Zoologia, Porto Alegre, v. 107, e2017120, 2017. 


\section{CAPÍTULO XII}

\section{FLUTUAÇÃO POPULACIONALE ASPECTOS MORFOLÓGICOS DAS LARVAS MYRMELEON BRASILIENSIS (NEUROPTERA, MYRMELEONTIDAE) NO ECÓTONO CERRADO-PANTANAL}

DDI: 10.51859/amplla.ecp672.1121-12

Vitor Gabriel de Oliveira Leite ${ }^{1}$ Raquel Braga Aquino Florenciano ${ }^{1}$

Andreça de Andrade da Silva ${ }^{1}$

Alfredo Raúl Abot ${ }^{2}$

Edihanne Gamarra Arguelho ${ }^{3}$

Tatiane do Nascimento Lima ${ }^{3}$

\footnotetext{
${ }^{1}$ Universidade Federal de Mato Grosso do Sul, Campus de Aquidauana, Curso de Ciências Biológicas.

${ }^{2}$ Universidade Estadual de Mato Grosso do Sul, Unidade de Aquidauana.

${ }^{3}$ Universidade Federal de Mato Grosso do Sul, Campus de Aquidauana, Laboratório de Estudos da Biodiversidade.
}

\section{INTRODUÇÃO}

As formigas-leão são insetos pertencentes a família Myrmeleontidae, considerada a maior dentro da ordem Neuroptera com, aproximadamente, 1500 espécies descritas (STANGE, 2004). Suas larvas são populares por construírem armadilhas em forma de funil no solo seco e arenoso (GOTELLI, 1993; ARNETT; GOTELLI, 2001). A construção das armadilhas ocorre dentro da tribo Myrmeleontini (Nova 1991) e é uma característica do gênero Myrmeleon (LUCAS; STANGE, 1981). A formiga-leão adulta é semelhante os insetos da ordem Odonata, mas apresentam antenas visíveis a olho nu (NEW, 1991).

Em função da granulação da areia e da inclinação das paredes do funil, os artrópodes, que se movem na superfície do solo, ao caírem na armadilha tem dificuldade de escapar e são facilmente subjugados pelas larvas (NONATO; LIMA, 2011, ALCALAYA et al., 2014). As principais presas são as formigas, não por excelência, mas devido a sua grande abundância da maioria dos ecossistemas. 
Quando uma eventual presa, cai na armadilha, a larva de formiga-leão tenta capturála, inserindo suas mandíbulas e injetando enzimas dentro de seu corpo, as quais dissolvem seus tecidos moles internos (BOTZ et al., 2003; DEVETAK et al., 2005). 0 fluído é então extraído pelas mandíbulas, que vão sendo inseridas ao longo do corpo da presa, e conduzido para dentro do canal alimentar. Após a presa ser consumida sua carcaça é atirada para fora do funil (GRIFFTHS, 1980a).

O desenvolvimento larval da formiga-leão é dividido em três instares antes da formação da pupa (MISSIRIAN et al., 2006; LIMA; SILVA, 2017). Experimentos de laboratório demonstraram que cada instar dura, por volta de, 26 dias. No entanto, no ambiente natural, esses valores podem ser variáveis, sendo afetados pela disponibilidade de alimento e pela perturbação ambiental (FURUNICHI; MASAKI, 1981, 1982). Para as larvas de formiga-leão o aumento no tamanho corpóreo (mudança de instar) é proporcional ao tamanho da armadilha e está positivamente relacionado ao sucesso de captura das presas. Quanto maior o diâmetro do funil, maior é a abundância e a amplitude de tamanhos das presas capturadas, sendo este o principal benefício com o incremento em superfície de captura da armadilha (DAY; ZALUCKI, 2000; HUMEAU et al., 2015; LIMA; LOPES, 2016).

As formigas-leão estão presentes na maioria das regiões zoogeográficas, sendo mais abundantes nos trópicos (FARJI-BRENER, 2003). No Brasil, estudos envolvendo as formigas-leão ainda são escassos. Em áreas de Cerrado foram coletadas larvas de formiga-leão da espécie Myrmeleon brasiliensis (Návas, 1914) (MISSIRIAN et al., 2006; UCHÔA; MISSIRIAN, 2014) e Myrmeleon uniformis DeGeer (FARIA et al., 1994). Esses estudos avaliaram aspectos do desenvolvimento (qualidade da dieta, distribuição espacial, canibalismo e parasitoidismo). No entanto, dados referentes a ocorrência desses insetos em outras áreas do país e aspectos da sua biologia e ecologia ainda são insuficientes ou inexistentes.

O objetivo deste estudo foi avaliar em uma área de ecótono Cerrado-Pantanal no município de Aquidauana (MS) a flutuação populacional e as características morfológicas dos instares larvais de formiga-leão Myrmeleon brasiliensis. 


\section{METODOLOGIA}

O estudo foi realizado em uma Área de Proteção Permanente da Universidade Estadual de Mato Grosso do Sul, situada no município de Aquidauana, MS (2026'25" S, 5539'21" W). A área está entre os biomas Cerrado e Pantanal e na transição entre o Planalto de Maracaju-Campo Grande e a Planície Pantaneira (FILHO et al., 2009). Na região a vegetação predominante é do tipo savana arbórea aberta (cerrado), com algumas inclusões do tipo savana arbórea densa (cerradão). 0 clima da região, segundo a classificação descrita por Köppen-Geiger é do tipo Aw (Tropical de Savana) com precipitação média anual de 1200 mm e temperaturas médias de 26,2 ${ }^{\circ} \mathrm{C}$, com inverno seco e verão chuvoso.

As observações e coletas foram feitas, mensalmente, entre março de 2019 e fevereiro de 2020. Na área estudada, foi estabelecido um ponto fixo e, a partir dele, foi sorteada a coordenada de coleta (norte, sul, leste e oeste). Na área sorteada, foi feita busca visual das armadilhas, sendo registradas e coletadas as 50 primeiras. Assim que eram visualizadas, as larvas tiveram o diâmetro de sua armadilha registrado. Após a medição do diâmetro da armadilha (Figura 1A) as larvas $M$. brasiliensis foram coletadas e levadas ao Laboratório de Estudos de Biodiversidade da Universidade Federal de Mato Grosso do Sul no campus de Aquidauana.

No laboratório foram aferidas as medidas do tamanho corpóreo, da cabeça ao abdômen, e da largura da cápsula cefálica, as medidas foram feitas com paquímetro (Figura 1B). As medidas corpóreas, juntamente com o tamanho das armadilhas, foram utilizadas para a caracterização do instar larval (c.f. MISSIRIAN et al., 2006; NONATO; LIMA, 2011). No microscópio e esteromicroscópio foram observadas características do arranjo das setas de escavação "digging setae" localizadas no último esternito abdominal (c.f. ALDINI, 2007; DEVETAK et al., 2010). 
Figura 1. Registro do diâmetro das armadilhas (A) e do tamanho das larvas M. brasiliensis (B) em região de ecótono Cerrado-Pantanal, Aquidauana/MS.

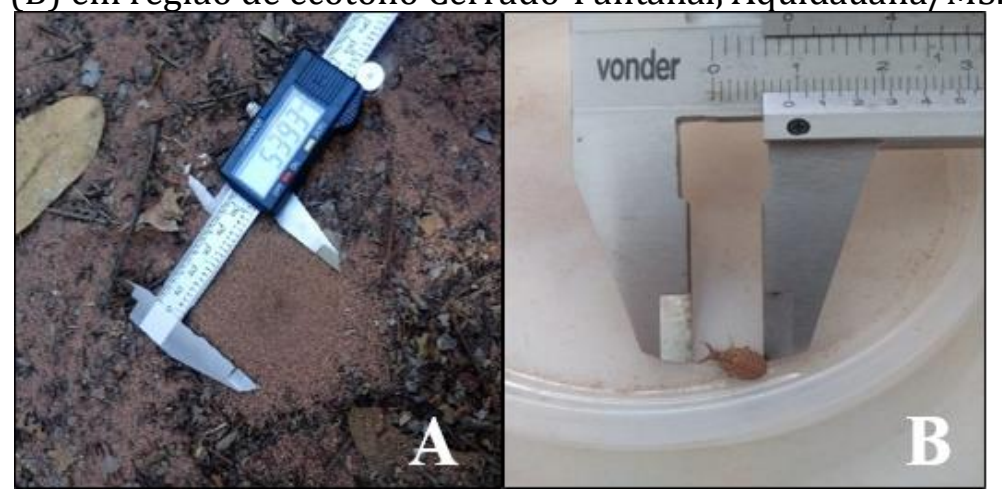

Fonte: Foto A - Tatiane do Nascimento Lima; Foto B - Bruna Barba Algarve.

As medidas morfológicas (tamanho corpóreo da cabeça ao abdômen, largura da cápsula cefálica) e o tamanho da armadilha, dos três instares larvais, foram comparadas por Análise Variância. A relação entre o tamanho da armadilha e o tamanho corpóreo (de todas as larvas coletadas e classificados por instar) foi feita por Regressão Linear. Os dados foram analisados no software livre BioStat 5.0 (AYRES et al., 2007). Os dados de clima foram obtidos no CEMTEC (Centro de Monitoramento do Tempo e do Clima de MS).

\section{RESULTADO E DISCUSSÃO}

No período de amostragem (março de 2019 e fevereiro de 2020) as temperaturas médias mensais variaram entre $19,84^{\circ} \mathrm{C}$ (julho/2019) e 28,30 (janeiro/2020). Quanto a pluviosidade, na estação seca (maio-outubro) e chuvosa (novembro-abril) a incidência média foi de 15,03 $\mathrm{mm}$ e $84,53 \mathrm{~mm}$, respectivamente. 0 mês de dezembro foi atípico para a região com uma pluviosidade acumulada de 236,2 mm (Figura 2). 
Figura 2. Precipitação pluviométrica e temperatura média, entre março de 2019 e fevereiro de 2020, em região de ecótono Cerrado-Pantanal, Aquidauana/MS.

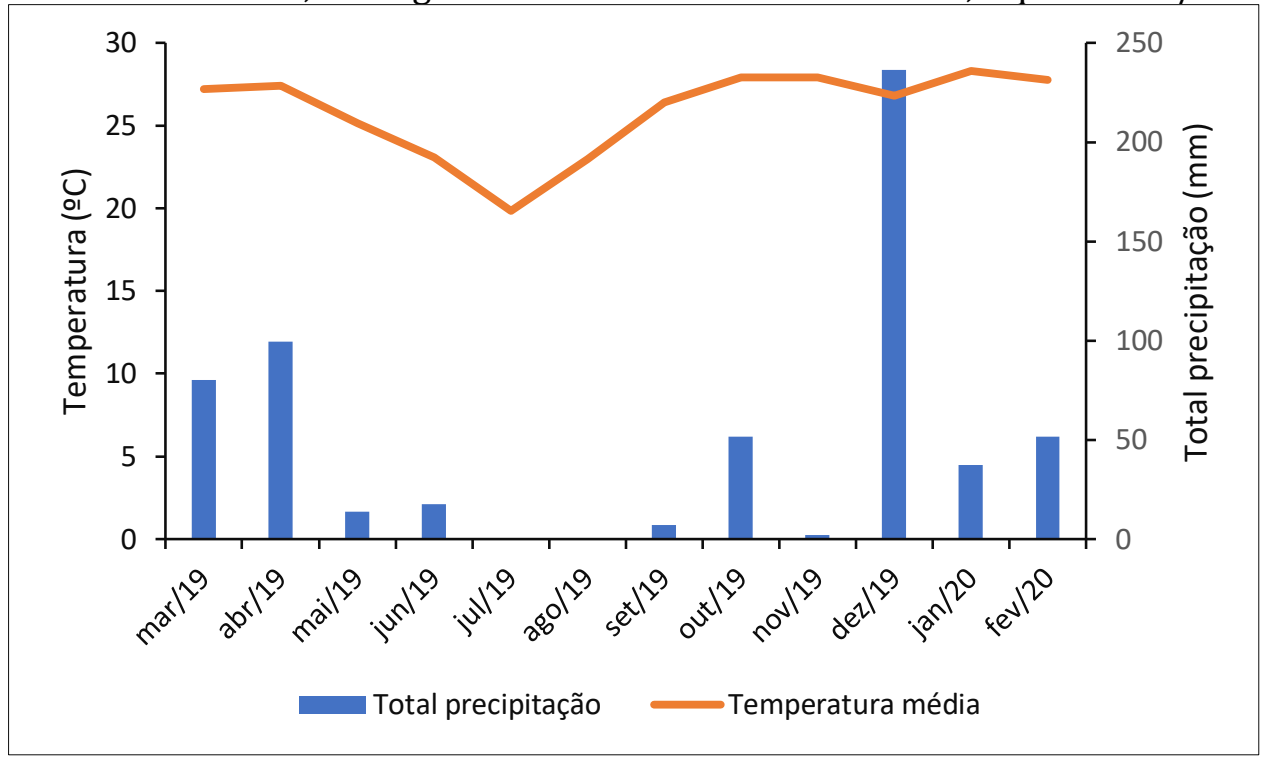

Fonte: Autoria própria.

Segundo Scharf e Ovadia (2006) as características do clima como a temperatura e a pluviosidade são fatores que afetam a ocorrência, as atividades de forrageamento e a construção de armadilhas das larvas de formiga-leão. Os autores observaram que na estação chuvosa a abundância de larvas construindo armadilhas fica reduzida, já o tamanho das armadilhas pode ter um pequeno aumento, em temperaturas mais elevadas. No entanto, larvas Myrmeleon immaculatus construíram armadilhas com tamanho normais em temperaturas entre 20 e $28^{\circ} \mathrm{C}$, abaixo ou acima dessas temperaturas houve uma diminuição no tamanho da armadilha e até mesmo a não construção destas (ARNETT; GOTELLI, 2001).

Gotelli (1993) observou que a seleção de habitat por Myrmeleon crudellis e Myrmeleon immaculatus, ocorre principalmente em função da proteção contra chuva, porque além da destruição dos funis, a chuva causa o encharcamento do solo o que impossibilita que o funil possa ser reconstruído. Lima e Faria (2007) observaram que as larvas Myrmeleon brasiliensis constroem suas armadilhas, preferencialmente, embaixo da vegetação, mantendo-as protegidas da ação direta da chuva, do sol e do pisoteio de outros animais. Dessa maneira, ao construir a armadilha em um micro-habitat protegido, a larva evita gasto energético com a manutenção e relocação da armadilha. Neste estudo também foi observado que as larvas constroem suas armadinhas em áreas protegidas, como embaixo de plântulas e de troncos caídos (Figura 3). 
Figura 3. Armadilhas de M. brasiliensis construídas embaixo de troncos caídos (A) e embaixo de plântulas (B) em região de ecótono Cerrado-Pantanal, Aquidauana/MS.

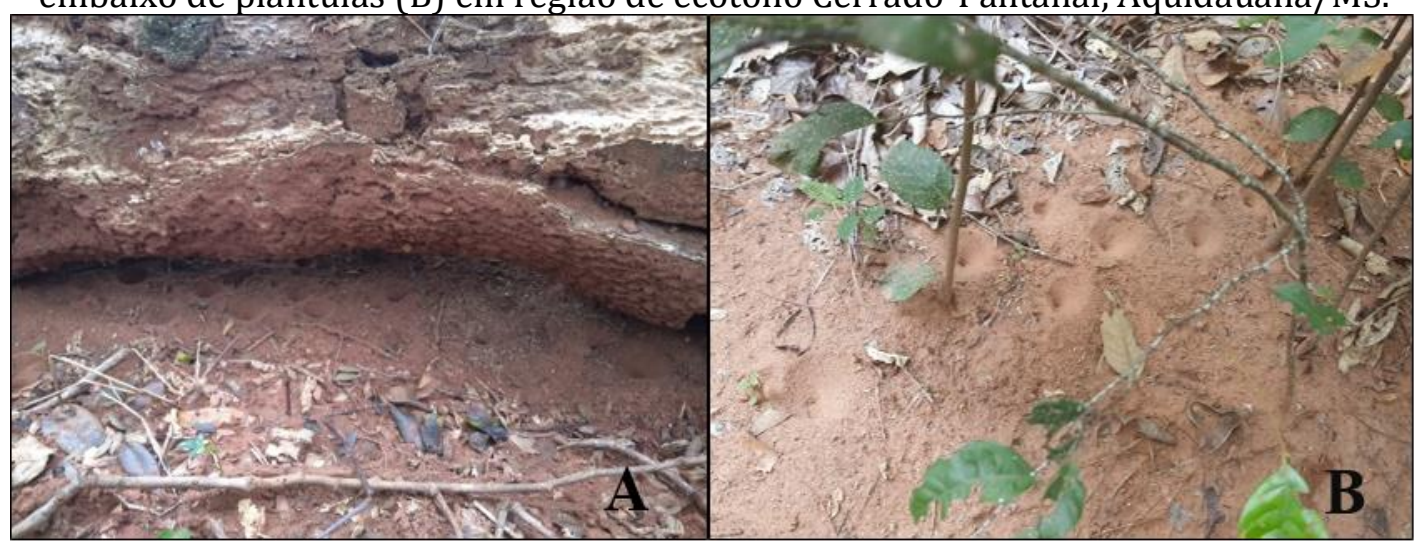

Fonte: Tatiane do Nascimento Lima

Além disso, na área de estudo, foi observado clima com duas estações bem definidas (seca e chuvosa) (Figura 2), o que pode ter contribuído para a evolução de uma estratégia de forrageamento com períodos sem construir armadilhas, devido ao encharcamento do solo. Estudos conduzidos com M. brasiliensis em áreas com clima seco e chuvoso, apontam para uma maior abundância de larvas no terceiro instar ao final da estação seca, dessa maneira no período chuvoso as formigas-leão estariam em sua maioria na fase adulta. E ainda, após uma chuva, as larvas $M$. brasiliensis demoram em torno de cinco dias para reconstruir suas armadilhas (FREIRE; LIMA, 2019).

Foram observados picos de eclosão de larvas M. brasiliensis (maior frequência de larvas do primeiro instar) em junho de 2019 (começo da estação seca) e novembro de 2019 (começo da estação chuvosa). 0 final do desenvolvimento larval (terceiro instar) foi observado com maior frequência nos meses de agosto de 2019 (meio da estação seca) e fevereiro de 2020 (meio da estação chuvosa) (Figura 4). 0 que representa um período de desenvolvimento larval para a área em torno de torno de 90 dias. 
Figura 4. Flutuação populacional de larvas de formiga-leão M. brasiliensis, entre março de 2019 e fevereiro de 2020, em região de ecótono Cerrado-Pantanal, Aquidauana/MS.

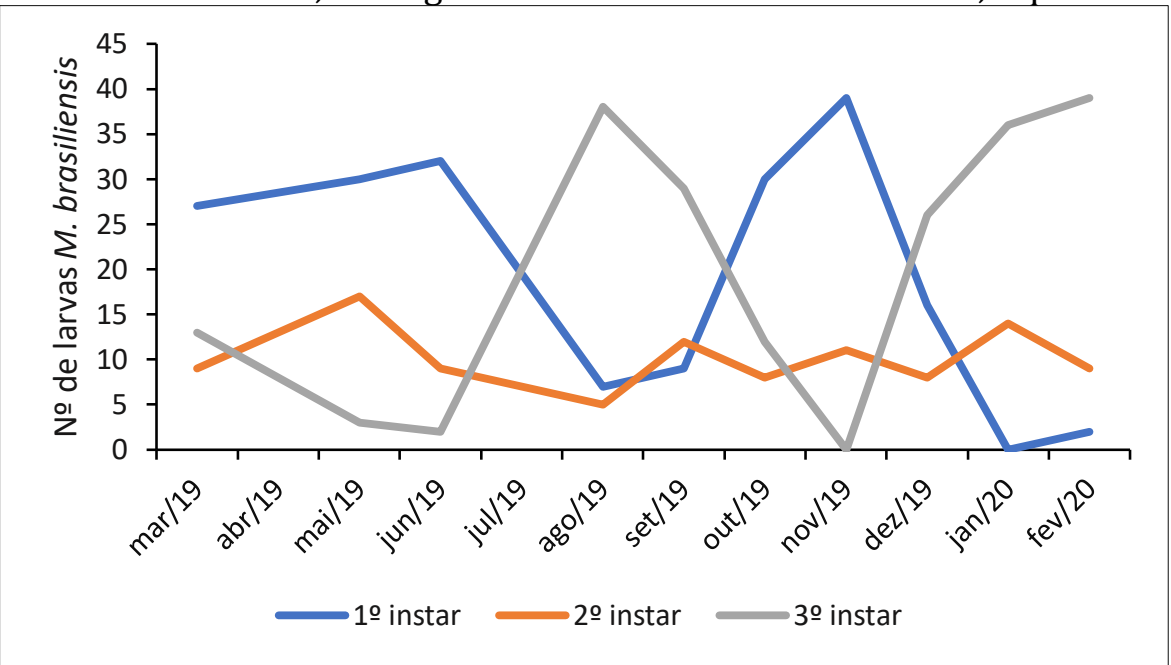

Fonte: Autoria própria.

Fatores como a qualidade da dieta, a temperatura e a perturbação ambiental afetam o tempo desenvolvimento das larvas de formiga-leão (LIMA; SILVA, 2017; LIANG et al., 2010), Missirian et al., (2006) observaram que larvas de M. brasiliensis mantidas em laboratório levaram em torno de 50 dias no segundo e terceiro instar. Como no laboratório é possível acompanhar desde o primeiro dia do segundo instar até o final do terceiro instar, é esperado que o tempo de desenvolvimento mensurado pareça ser maior, pois no campo não é possível observar o momento exato da entrada e saída de cada instar. 0 que faz com que esses os valores no campo fiquem subestimados.

A existência de dois picos de eclosão de larvas, um na estação seca e um na estação chuvosa (Figura 4), merece especial atenção. 0 fato dessas larvas eclodirem e começarem seus forrageamentos no período de maior incidência chuvosa, pode representar um fator prejudicial para a obtenção de alimento. Dessa forma, possivelmente, essa dinâmica populacional esteja relacionada ao fato da fêmea selecionar locais protegidos para a oviposição (como, por exemplo, embaixo de plântulas e de troncos caídos) (ver Figura 3). Isto significa que mesmo no período chuvoso as larvas estariam protegidas da ação direta da chuva que destrói suas armadilhas.

Quando comparados os tamanhos das armadilhas e das larvas de formigaleão $M$. brasiliensis, observou-se que o tamanho médio ( \pm desvio padrão) das armadilhas aumentou em função do tamanho das larvas. A menor armadilha observada na área de estudo apresentou 7,14 mm de diâmetro, com larva de 1,99 
$\mathrm{mm}$, enquanto a maior armadilha apresentou 53,77 $\mathrm{mm}$, com larva de 6,87 $\mathrm{mm}$ (Tabela 1).

Tabela 1. Medidas morfológicas (média \pm desvio padrão) dos instares larvais de formigaleão M. brasiliensis coletadas entre março de 2019 e fevereiro de 2020 em região de ecótono Cerrado-Pantanal, Aquidauana/MS.

\begin{tabular}{lccc}
\hline & $\begin{array}{c}\text { Diâmetro da } \\
\text { armadilha }\end{array}$ & $\begin{array}{c}\text { Comprimento da } \\
\text { cabeça ao abdômen }\end{array}$ & $\begin{array}{c}\text { Largura da cápsula } \\
\text { cefálica }\end{array}$ \\
\hline 1은 Instar $^{\text {o }}$ & $16,70 \pm 5,92$ & $2,80 \pm 0,64$ & $0,71 \pm 0,15$ \\
\hline $3^{\text {o }}$ Instar & $22,06 \pm 3,47$ & $4,73 \pm 1,01$ & $1,04 \pm 0,21$ \\
\hline
\end{tabular}

Fonte: Autoria própria.

A Análise de Variância mostrou um aumento significativo no tamanho das armadilhas $\left(\mathrm{F}_{4,7}=94,4 ; \mathrm{p}<0,01\right)$, tamanho corpóreo $\left(\mathrm{F}_{129,69}=304,65 ; \mathrm{p}<0,01\right) \mathrm{e}$ largura da cápsula cefálica $\left(\mathrm{F}_{3,63}=223,17 ; \mathrm{p}<0,01\right)$ em função do instar (primeiro, segundo e terceiro) (Figura 5). Dessa forma, evidenciou-se que as medidas de tamanho (da larva e da armadilha) são uteis para separar os instares larvais de $M$. brasiliensis.

Figura 5. Tamanho médio ( \pm desvio padrão) do tamanho da armadilha, tamanho corpóreo e largura da cápsula cefálica nos instares 1, 2 e 3 de $M$. brasiliensis coletadas entre março de 2019 a fevereiro de 2020 em região de ecótono Cerrado-Pantanal, Aquidauana/MS.
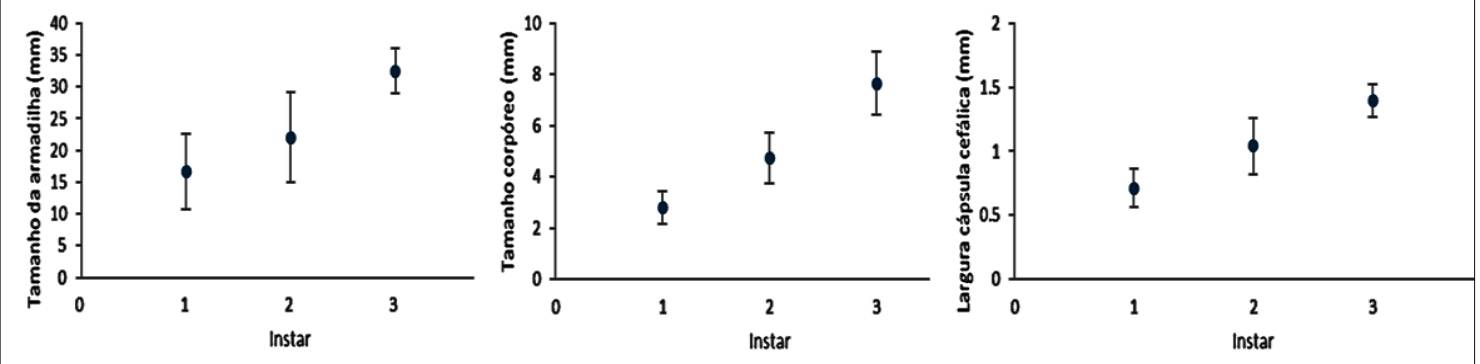

Fonte: Autoria própria.

Quando foi feita a relação, entre o tamanho corpóreo de todas as larvas $M$. brasiliensis coletadas (sem separação por instar) com o tamanho da armadilha, o resultado foi significativamente positivo $\left(r^{2}=0,47 ; p<0,001\right)$ (Figura 6). Esse dado corrobora com o observado em outros estudos (e.g. DIAS et al., 2006; GRIFFITHS, 1980a, 1986, HEINRICH; HEINRICH, 1984; LIMA; FARIA, 2007). Entretanto, ao fazer a relação do tamanho corpóreo de cada instar em separado com o tamanho de suas armadilhas, apenas larvas no segundo instar apresentaram essa relação significativa 
$\left(r^{2}=0,32 ; p<0,05\right)$. Ou seja, as larvas no primeiro $\left(r^{2}=0,12 ; p>0,05\right)$ e terceiro instar $\left(r^{2}=0,18 ; p>0,05\right)$ não apresentam essa relação (Figura 7).

Figura 6. Relação entre o tamanho corpóreo (cabeça-abdômen) das larvas M. brasiliensis como tamanho de suas armadilhas $(\mathrm{mm})$ considerando todos os três instares das larvas.

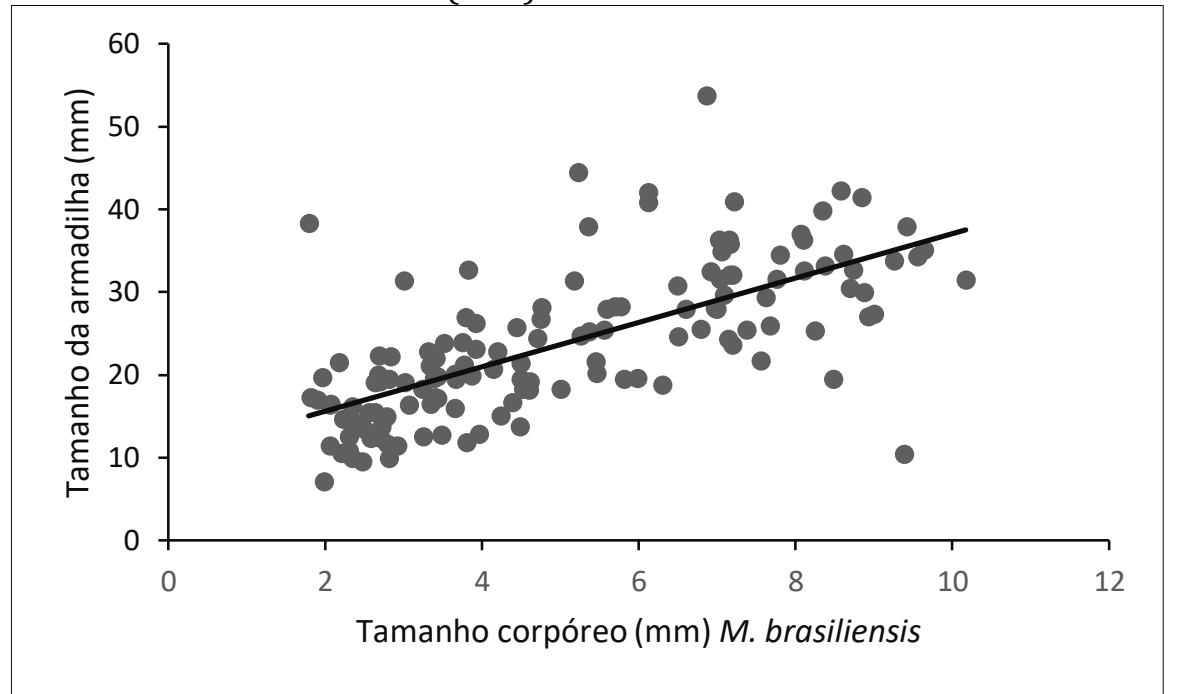

Fonte: Autoria própria.

Figura 7. Relação entre o tamanho corpóreo (cabeça-abdômen) das larvas M. brasiliensis com o tamanho de suas armadilhas ( $\mathrm{mm}$ ) considerando os instares larvais em separado (primeiro, segundo e terceiro).
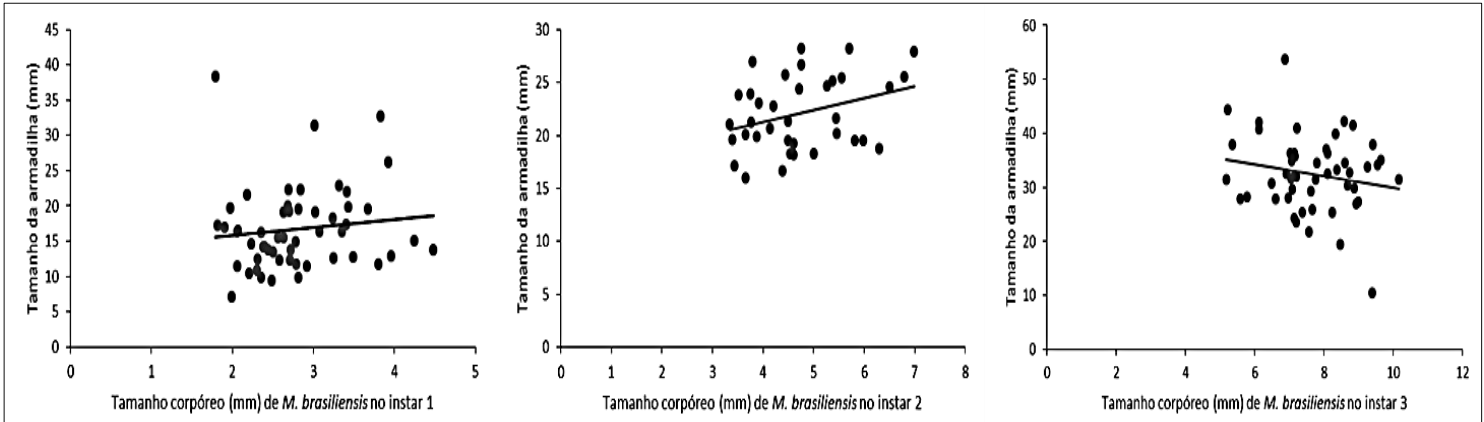

Fonte: Autoria própria.

Possivelmente, as larvas no começo do desenvolvimento (primeiro instar) armazenam pouca energia para investir em tamanho de armadilha e, quando conseguem obtê-la, investem na muda para o segundo instar. Desta forma, não é observado variação no tamanho de suas armadilhas em função do tamanho corpóreo. Essa pressão sobre as larvas menores, na obtenção de alimento e na manutenção da armadilha, também foi observada por Faria et al. (1994) em Myrmeleon uniformis. Os pesquisadores observaram que os indivíduos menores 
tendem a desaparecer com maior frequência do que os indivíduos maiores, pois os maiores além de obterem maior sucesso durante o seu forrageamento, também suportam maiores períodos sem alimento. As larvas maiores, no segundo e terceiro instares, em função de seu tamanho corpóreo e das características de sua armadilha, apresentam um ataque a presa mais eficiente, o que reduz o seu custo energético com a captura e a manipulação da presa. Além disso, essa eficiência também pode estar associada a adaptação das larvas maiores à vibração que as presas exercem na areia, ou seja, a associação entre a vibração e a disponibilidade de presa (GUILLETTE et al., 2009). Estas características possibilitam às larvas maiores não variarem o tamanho de suas armadilhas, o que se reflete no baixo desvio padrão dessa variável (desvio padrão = 3,47) (Figura 5).

As larvas que conseguem se alimentar e passar pelo período de transição do $1^{\mathrm{o}}$ para o $2^{\mathrm{o}}$ instar, que é considerado um período crítico, em razão das larvas terem maior dificuldade para capturar suas presas (NONATO; LIMA, 2011), podem vir a garantir um aumento em seu tamanho corpóreo e no de sua armadilha, passando a garantir um maior sucesso na captura de suas presas. Dessa forma, o crescimento das larvas de formiga-leão pode assegurar um maior sucesso de forrageamento.

De maneira geral, os insetos necessitam atingir um determinado tamanho ou uma determinada reserva energética para que ocorram as mudanças de instar, a formação da pupa e a emergência dos adultos (GULLAN; CRANSTON, 2007). Tratando-se das larvas de formiga-leão, a duração das fases e do processo de desenvolvimento (larva, pupa e adulto) pode ser acelerado ou retardado em função de vários fatores, tais como o fotoperíodo, a temperatura, a disponibilidade de presa e o tamanho corpóreo (GRIFFITHS, 1980b; MISSIRIAN et al., 2006; SCHARF et al., 2009a, 2009c).

Dados de Eltz (1997) sugerem que o processo de muda em Myrmeleon mobilis pode ser acelerado em indivíduos que são bem alimentados e sofrem uma menor perturbação em suas armadilhas. Missirian et al. (2006) observaram que $M$. brasiliensis alimentadas com uma dieta rica energeticamente, também tiveram seu desenvolvimento acelerado. Por outro lado, é possível que organismos que vivam em ambientes mais instáveis, mostrem menores taxas de crescimento, mesmo quando presas são fornecidas. Isso ocorre porque os indivíduos que crescem em 
condições adversas não são adaptados a um aumento significativo na sua taxa de crescimento, mesmo quando expostos a melhores condições (SCHARF et al., 2009b).

A análise do arranjo das setas de escavação (digging setae) demonstrou que M. brasiliensis apresenta, nos instares um, dois e três um padrão de uma fileira com quatro setas, seguida por uma segunda fileira com oito setas (Figura 8). 0 aspecto das setas dessas duas fileiras foi curto e grosso (c.f. NGAMO; MAOGE, 2014), diferentemente das outras cerdas do abdômen que são mais finas.

Figura 8. Detalhe do último seguimento abdominal com as setas de escavação das larvas de formiga-leão (A) e vista dorsal da larva de formiga-leão (B).

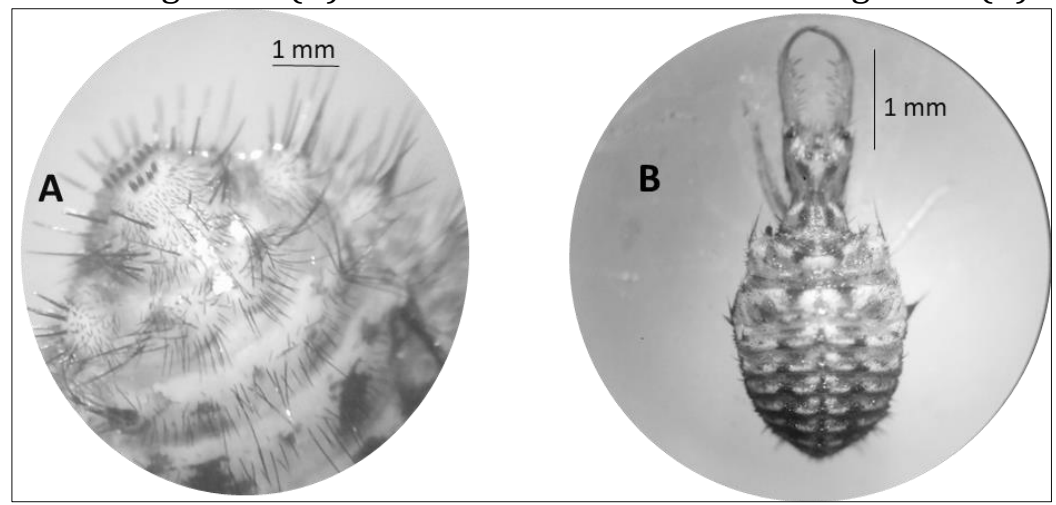

Fonte: Tatiane do Nascimento Lima

As larvas de formiga-leão utilizam o corpo para cavar suas armadilhas, de maneira que o abdômen é usado como uma espécie de "enxada” para escavar o solo arenoso, enquanto a sua cabeça é utilizada para lançar a areia removida para fora do funil (FERTIN; CASAS, 2006). As setas de escavação, localizadas no último esternito abdominal, são cerdas que servem de auxílio para as larvas escavarem em movimento espiral para trás durante a construção de suas armadilhas (NGAMO et al., 2010). 0 padrão de organização dessas cerdas varia entre espécies e podendo também variar dentro de uma mesma espécie entre os diferentes instares larvais (ALDINI, 2007; DEVETAK et al., 2010).

\section{CONSIDERAÇÕES FINAIS}

As larvas de formiga-leão da espécie $M$. brasiliensis observadas na área de ecótono Cerrado-Pantanal foram encontradas ao longo de todo o ano. Foram observados dois picos de eclosão das larvas (1ํinstar) e dois picos de final de desenvolvimento ( $3^{\circ}$ instar). Possivelmente a ocorrência das larvas durante todo $o$ 
ano, mesmo no período chuvoso, está relacionado com o fato das larvas construírem suas armadilhas em locais protegidos da ação direta da chuva. Foi observado relação entre o tamanho das larvas M. brasiliensis e o tamanho de suas armadilhas. Entretanto, ao realizar essa avaliação em separado para cada instar, apenas as larvas no $2^{\circ}$ instar apresentaram essa relação significativa.

As medidas morfológicas das larvas $M$. brasiliensis mostraram-se úteis para caracterizar o instar larval. Porém, a organização das setas de escavação teve o mesmo padrão para os três instares, não podendo ser utilizada para caracterização de instares larvais específicos.

No Brasil, as formigas-leão são pouco estudadas, neste trabalho foram reunidas informações referentes a biologia e a ecologia desses insetos, bem como, dados de ocorrência para uma região de ecótono Cerrado-Pantanal. Entretanto, ainda não há informações quanto à sua ocorrência e comportamento no bioma Pantanal e muito ainda precisa ser compreendido sobre o Cerrado. Neste contexto, espera-se que novos estudos possam ser desenvolvidos, ampliando a compreensão da biologia e dos aspectos ecológicos que guiam a distribuição desses insetos em áreas com diferentes dinâmicas climáticas.

\section{AGRADECIMENTOS}

O presente trabalho foi realizado com apoio da Universidade Federal de Mato Grosso do Sul - UFMS/MEC - Brasil e da Universidade Estadual de Mato Grosso do Sul (Aquidauana).

\section{REFERÊNCIAS}

ALCALAYA, Y.; BARKAEA, E. D.; OVADIA, O.; SCHARF, I. Consequences of the instar stage for behavior in a pit-building antlion. Behavioural processes, v. 103, p. 105-111, 2014.

ALDINI, R. N. Observation on the larval morphology on the Antlion Myrmeleon bore (Tjelder, 1941) (Neuroptera Myrmeleontidae) and its life cycle in the Po Valley (northern Italy). Ann. Mus. civ. St. nat. Ferrara, v. 8, p. 59-66, 2007.

ARNETT, A. E.; GOTELLI, N. J. Pit-building decisions of larval ant lions: effects of larval age, temperature, food, and population source. Journal of Insect Behavior, v. 14, n. 1, p. 89-97, 2001. 
AYRES, M.; AYRES JÚNIOR, M.; AYRES, D. L.; SANTOS, A. D. A. Aplicações estatísticas nas áreas das ciências bio-médicas. Instituto Mamirauá, Belém, v. 364, 2007.

BOTZ, J. T.; LOUDON, C.; BARGER, J. B.; OLAFSEN, J. S.; STEEPLES, D. W. Effects of slope and particle size on ant locomotion: implications for choice of substrate by antlions. Journal of the Kansas Entomological Society, p. 426-435, 2003.

CEMTEC, Centro de Monitoramento de Tempo, do Clima e dos Recursos Hídricos de Mato Grosso do Sul. Banco de Dados. Disponível em: http://www.cemtec.ms.gov.br/?page_id=15. Acesso em: 20 mai. 2020.

DAY, M. D.; ZALUCKI, M. P. Effect of density on spatial distribution, pit formation and pit diameter of Myrmeleon acer Walker, (Neuroptera: Myrmeleontidae): patterns and processes. Austral Ecology, v. 25, n. 1, p. 58-64, 2000.

DEVETAK, D.; LIPOVŠEK, S.; PABST, M. A. Morphology and biology of the antlion Myrmeleon yemenicus Hölzel, 2002 (Neuroptera, Myrmeleontidae). Zootaxa, v. 2531, n. 1, p. 48-56, 2010.

DEVETAK, D.; ŠPERNJAK, A.; JANŽEKOVIČ, F. Substrate particle size affects pit building decision and pit size in the antlion larvae Euroleon nostras (Neuroptera: Myrmeleontidae). Physiological Entomology, v. 30, n. 2, p. 158$163,2005$.

DIAS, S. C.; SANTOS, B. A.; WERNECK, F. P.; LIRA, P. K.; CARRASCO-CARBALIDO, V.; FERNANDES, G. W. Efficiency of prey subjugation by one species of Myrmeleon larvae (Neuropetra: Myrmeleontidae) in the central Amazonia. Brazilian Journal of Biology, v. 66, n. 2A, p. 441-442, 2006.

ELTZ, T. Foraging in the ant-lion Myrmeleon mobilis hagen 1888 (neuroptera: Myrmeleontidae): Behavioral flexibility of a sit-and-wait predator. Journal of Insect Behavior, v. 10, n. 1, p. 1-11, 1997.

FARIA, M. L.; PRADO, P. I.; BEDÊ, L. C.; FERNANDES, G. W. Structure and dynamics of a larval population of Myrmeleon uniformis (Neuroptera: Myrmeleontidae). Revista Brasileira de Biologia, v. 54, n. 2, p. 335-344, 1994.

FARJI-BRENER, A. G. Microhabitat selection by antlion larvae, Myrmeleon crudelis: effect of soil particle size on pit-trap design and prey capture. Journal of Insect Behavior, v. 16, n. 6, p. 783-796, 2003.

FERTIN, A.; CASAS, J. Efficiency of antlion trap construction. Journal of Experimental Biology, v. 209, n. 18, p. 3510-3515, 2006.

FILHO, C. O. A.; ZANI, H.; GRADELLA, F. S. Compatibilidade da rede de drenagem obtida através de dados SRTM, ASTER e carta topográfica DSG: estudo de caso no Pantanal de Aquidauana. Anais 2ำ Simpósio de Geotecnologias no Pantanal, Corumbá, 7-11 novembro 2009, Embrapa Informática Agropecuária/INPE, p.51-61, 2009. 
FREIRE, L. G.; LIMA, T. N. Effect of rain on trap building by Myrmeleon brasiliensis in a riparian woodland from the Cerrado biome in Brazil. Entomologia Experimentalis et Applicata, v. 167, n. 6, p. 561-565, 2019.

FURUNISHI, S.; MASAKI, S. Photoperiodic response of the univoltine ant-lion Myrmeleon formicarius (Neuroptera, Myrmeleontidae). Kontyu, v. 49, n. 4, p. 653-667, 1981.

FURUNISHI, S.; MASAKI, S. Seasonal life cycle in two species of ant-lion (Neuroptera: Myrmeleontidae). Japanese Journal of Ecology, v. 32, n. 1, p. 7-13, 1982.

GOTELLI, N. J. Ant lion zones: causes of high-density predator aggregations. Ecology, v. 74, n. 1, p. 226-237, 1993.

GRIFFITHS, D. Pit construction by ant-lion larvae: a cost-benefit analysis. The Journal of Animal Ecology, p. 39-57, 1986.

GRIFFITHS, D. The feeding biology of ant-lion larvae: growth and survival in Morter obscurus. Oikos, p. 364-370, 1980b.

GRIFFITHS, D. The feeding biology of ant-lion larvae: prey capture, handling and utilization. The Journal of Animal Ecology, p. 99-125, 1980a.

GUILLETTE, L. M; HOLLIS, K. L.; MARKARIAN, A. Learning in a sedentary insect predator: antlions (Neuroptera: Myrmeleontidae) anticipate a long wait. Behavioural Processes, v. 80, n. 3, p. 224-232, 2009.

GULLAN, P. J.; CRANSTON, O. S. Os Insetos: Um Resumo de Entomologia. São Paulo: Roca, 2007.

HEINRICH, B.; HEINRICH, M. J. E. The pit-trapping foraging strategy of the ant lion, Myrmeleon immaculatus DeGeer (Neuroptera: Myrmeleontidae). Behavioral Ecology and Sociobiology, v. 14, n. 2, p. 151-160, 1984.

HUMEAU, A.; ROUGÉ, J.; CASAS, J. Optimal range of prey size for antlions. Ecological entomology, v. 40, n. 6, p. 776-781, 2015.

LIANG, S. H.; LIN, W. Y.; LIN, Y. C.; CHEN, Y. C.; SHIEH, B. S. Variations in the pit size of Cueta sauteri (Neuroptera: Myrmeleontidae) larvae in response to past pitbuilding experience and food limitation. Zoological studies, v. 49, n. 1, p. 102107, 2010.

LIMA, T. N.; FARIA, R. R. Seleção de microhabitat por larvas de formiga-leão Myrmeleon brasiliensis (Návas)(Neuroptera: Myrmeleontidae), em uma Reserva Florestal, Aquidauana, MS. Neotropical Entomology, v. 36, n. 5, p. 812-814, 2007.

LIMA, T. N.; LOPES, F. S. Efeito da densidade, perturbado e alimento no deslocamento de Myrmeleon brasiliensis (Navás 1914) (Neuroptera, Myrmeleontidae). Ecología austral, v. 26, n. 2, p. 166-170, 2016. 
LIMA, T. N.; SILVA, D. C. R. Effect of energetic cost to maintain the trap for Myrmeleon brasiliensis (Neuroptera, Myrmeleontidae) in its development and adult size. Brazilian Journal of Biology, v. 77, n. 1, p. 38-42, 2017.

LUCAS, J. R.; STANGE, L. A. LUCAS, Jeffrey R.; STANGE, Lionel A. Key and descriptions to the Myrmeleon larvae of Florida (Neuroptera: Myrmeleontidae). Florida Entomologist, p. 207-216, 1981.

MISSIRIAN, G. L. B; UCHÔA-FERNANDES, M. A.; FISCHER, E. Desenvolvimento de Myrmeleon brasiliensis (Navás) (Neuroptera, Myrmeleontidae), em laboratório, com diferentes dietas naturais. Revista Brasileira de Zoologia, v. 23, n. 4, p. 1044-1050, 2006.

NEW, T. R. Neuroptera, In: COMMONWEALTH SCIENTIFIC; INDUSTRIAL RESEARCH ORGANIZATION. (Org.). The Insects of Australia: a textbook for students and research workers. Melbourne: Melbourne University Press, 1991. v. 1.

NGAMO, L. S. T.; MAOGE, J. Chetae of larva of antlions (Neuroptera: Myrmeleontidae) Hagenomyia tristis (Walker, 1853) and Myrmeleon obscurus (Rambur, 1842) involve in the construction of pitfall traps. Journal of Biodiversity and Environmental Sciences (JBES), v. 5, p. 511-519, 2014.

NGAMO, L.; MAOGE, J.; BELLO, A. Predation of Myrmeleon obscurus (Navas, 1912) (neuroptera: Myrmeleontidae) on the ground ant Myrmicaria opaciventris emery (Formicidae: yrmicinae). International Journal of Biological and Chemical Sciences, v. 4, n. 2, 2010.

NONATO, L. M.; LIMA, T. N. Predation behavior of the Myrmeleon brasiliensis (Neuroptera: Myrmeleontidae) larval instars. Revista Colombiana de Entomologia, v. 37, n. 2, p. 354-356, 2011.

SCHARF, I.; FILIN, I.; BEN-YEHOSHUA, D.; OVADIA, O. Phenotypic plasticity and variation in morphological and life-history traits of antlion adults across a climatic gradient. Zoology, v. 112, n. 2, p. 139-150, 2009a.

SCHARF, I.; FILIN, I.; OVADIA, 0. A trade-off between growth and starvation endurance in a pit-building antlion. Oecologia, v. 160, n. 3, p. 453-460, 2009 b.

SCHARF, I.; GOLAN, B.; OVADIA, O. The effect of sand depth, feeding regime, density, and body mass on the foraging behaviour of a pit-building antlion. Ecological Entomology, v. 34, n. 1, p. 26-33, 2009c.

SCHARF, I.; OVADIA, O. Factors influencing site abandonment and site selection in a sit-and-wait predator: a review of pit-building antlion larvae. Journal of Insect Behavior, v. 19, n. 2, p. 197-218, 2006.

STANGE, L. A. A systematic catalog, bibliography and classification of the world antlions (Insecta: Neuroptera: Myrmeleontidae). Gainesville, American Entomologist Institute, 2004. 
UCHÔA, M. A.; MISSIRIAN, G. L. B. Myrmeleon brasiliensis's parasitoids (Neuroptera: Myrmeleontidae) in the south Pantanal, Brazil. Florida Entomologist, v. 97, n. 1, p. 313-316, 2014. 


\section{CAPÍTULO XIII}

\section{MAMÍFEROS NÃO VOADORES DO ECÓTONO CERRADO- PANTANAL, SUDOESTE DO BRASIL}

DDI: $10.51859 / a m p l l a . e c p 672.1121-13$

Wellington Hannibal ${ }^{1}$

Alessandra Venturini²

${ }^{1}$ Laboratório de Ecologia e Biogeografia de Mamíferos, Universidade Estadual de Goiás, Quirinópolis, Goiás, Brasil.

2Laboratório de Estudos Integrados em Biodiversidade do Cerrado e Pantanal, Universidade Federal de Mato Grosso do Sul, Aquidauana, MS, Brasil.

\section{INTRODUÇ̃̃O}

O Brasil é um país de grandes proporções territoriais, abriga várias zonas climáticas e consequentemente grandes variações ecológicas, formando domínios fitogeográficos distintos (BRANDON et al., 2005; MMA, 2020). Essa variedade reflete a enorme riqueza de fauna e flora, tornando o Brasil um dos países com a maior biodiversidade do planeta (MMA, 2020; MYERS et al., 2000), embora esta diversidade ainda seja pouco conhecida.

Atualmente, o Brasil abriga 722 espécies de mamíferos (154 espécies endêmicas), distribuídas em 246 Gêneros (PERCEQUILLO; GREGORIN, 2020). Estas espécies estão amplamente distribuídas entre os domínios fitogeográficos brasileiros, com destaque para a Amazônia, Mata Atlântica e Cerrado (PAGLIA et al., 2012). O Pantanal, não está entre os domínios brasileiros de maior riqueza de mamíferos e também não apresenta um número expressivo de espécies endêmicas (PAGLIA et al., 2012). No entanto, abriga as maiores populações conhecidas de grandes mamíferos ameaçados, como o "veado-campeiro" Ozotoceros bezoarticus, o "cervo-do-pantanal" Blastocerus dichotomus, a "ariranha" Pteronura brasiliensis e a “onça-pintada" Panthera onca (HARRIS et al., 2005).

Apesar dos avanços no conhecimento sobre a diversidade de mamíferos brasileiros (PERCEQUILLO et al., 2017), poucos estudos tem investigado a diversidade da mastofauna em áreas de transição entre os domínios fitogeográficos, 
com alguns deles realizados nos ecótonos Amazônia-Cerrado (BEZERRA; CARMIGNOTTO; RODRIGUES, 2009; LACHER JR; ALHO, 2001), Cerrado-Mata Atlântica (HANNIBAL et al., 2018; MAGIOLI et al., 2016), Cerrado-Pantanal (CÁCERES et al., 2012) e Amazônia-Cerrado-Pantanal (CASAGRANDE; SANTOSFILHO, 2019). Considerando que o conhecimento sobre a riqueza de mamíferos brasileiros está longe de uma estabilização, e que o número de espécies ainda deve aumentar, conforme os inventários sejam intensificados (PAGLIA et al., 2012; REIS et al., 2011). Neste estudo, nós descrevemos a riqueza de mamíferos não voadores para uma área de transição entre o Cerrado e o Pantanal no estado de Mato Grosso do Sul, centro-oeste do Brasil. Além disso, nós investigamos a associação entre o número de espécies inventariadas e o esforço amostral empregado para pequenos mamíferos e mamíferos de médio e grande porte.

\section{METODOLOGIA}

O estudo foi conduzido em uma região de transição entre o Cerrado e o Pantanal, no estado de Mato Grosso do Sul, centro-oeste do Brasil. Para caracterizar a fauna de mamíferos nessa região, nós consideramos apenas locais que tivessem sido amostrados até uma distância de $50 \mathrm{~km}$ do limite entre estes dois domínios fitogeográficos. Com a área de estudo definida, nós utilizamos dois conjuntos de dados: i) dados não publicados, tratados aqui como "novas áreas", referentes a levantamentos conduzidos em 11 fazendas no Pantanal sul mato-grossense e ii) dados publicados, referentes a quatro estudos (CÁCERES et al., 2010a, 2012; HANNIBAL; NEVES-GODOI, 2015; TROLLE, 2003) conduzidos na região (Figura 1, Anexo 1). Com isso, listamos 24 áreas de amostragem de mamíferos não voadores: 13 no Pantanal e 11 no Cerrado (Figura 1). 
Figura 1. Mapa das 24 áreas amostradas na transição Cerrado-Pantanal no estado de Mato Grosso do Sul, centro-oeste do Brasil. Os números se referem as áreas apresentadas no Anexo 1.

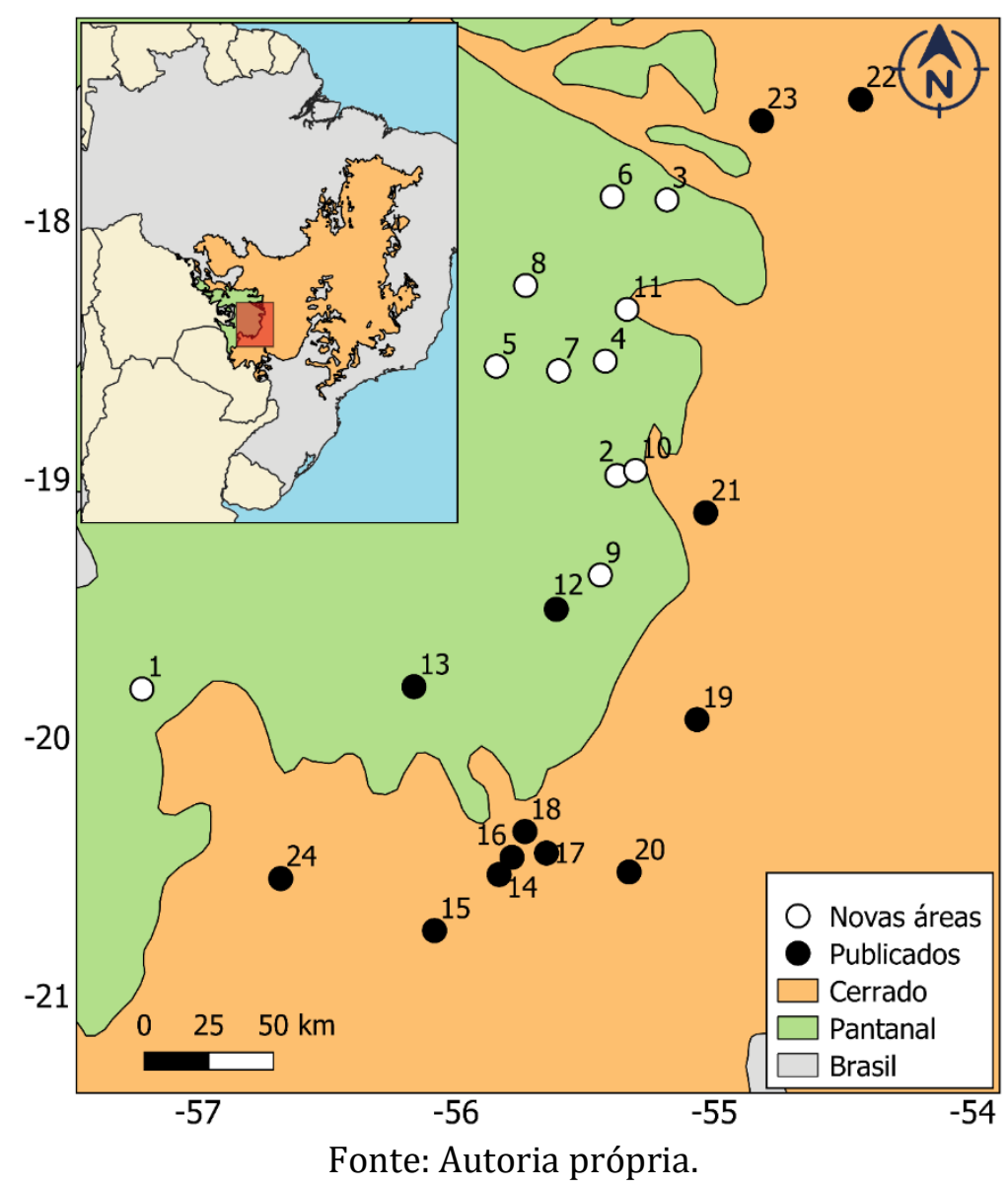

A coleta de dados primários ocorreu entre os anos de 2011 a 2018. Cada área foi amostrada ao menos duas vezes, uma no período seco (abril a setembro) e outro no chuvoso (outubro a março). Os pequenos mamíferos (marsupiais e pequenos roedores) foram capturados por meio de armadilhas de metal live traps, dos tipos: gaiola de arame e Sherman®. Nós utilizamos 40 armadilhas (20-gaiolas e 20Sherman ${ }^{\circledR}$ ) em cada área, distribuídas em duas transecções, contendo dez estações de captura por transecção. Cada estação de captura esteve distante 10 metros uma da outra, e contou com duas armadilhas: 1-gaiola de arame no solo e 1-Sherman ${ }^{\circledR}$ no sub-bosque (1,5 a 2 metros de altura). As armadilhas ficaram ativas por três noites em cada campanha, totalizando um esforço de 120 armadilhas-noite. A identificação das espécies seguiu o Guia dos Roedores do Brasil (BONVICINO; OLIVEIRA; D’ANDREA, 2008) e o livro Mamíferos não voadores do Pantanal e entorno (HANNIBAL; DUARTE; SANTOS, 2015). 
Os mamíferos de médio e grande porte foram inventariados por meio de busca ativa nas áreas. As espécies presentes foram anotadas conforme evidências observadas por meio de $i$ ) visualizações, ii) pegadas, iii) tocas no caso dos tatus, iv) fezes e $v$ ) sons. Os esforços em campo foram feitos no sentido de considerar apenas registros fidedignos, ou seja, que não pudessem colocar em risco a identificação da espécie e compreenderam em média 3 horas de amostragem em cada área e campanha. A identificação dos rastros seguiu o Guia de rastros e outros vestígios de mamíferos do Pantanal (BORGES; TOMAS, 2004). A classificação taxonômica, segui a adotada por Paglia et al. (2012), com atualizações para a espécie Thrichomys fosteri (D’ELÍA; MYERS, 2014), para o gênero Marmosa (VOSS et al., 2014), e para a família Chlamyphoridae, ordem Cingulata (FEIJÓ; CORDEIRO-ESTRELA, 2016).

Investigamos a eficiência de nosso esforço amostral (número de áreas) para pequenos mamíferos e mamíferos de médio e grande porte por meio da rarefação das curvas de acumulo (número de espécies observadas) e do estimador Jackknife 1 (número de espécies estimadas), usando o programa EstimateS 9.1 (COLWELL, 2013). Nós também avaliamos a frequência das espécies de mamíferos não voadores por meio de uma matriz de presença-ausência nas áreas de Cerrado e Pantanal.

\section{RESULTADOS E DISCUSSÃO}

Nós listamos 61 espécies, pertencentes a 21 famílias e nove ordens de mamíferos não voadores, para a área de transição Cerrado-Pantanal no sudoeste do Brasil (Tabela 1). As famílias mais representativas foram Cricetidae (12 espécies) e Didelphidae (11 spp.). Nossa lista incluiu 15 espécies ameaçadas de extinção, representando $16 \%$ das espécies de mamíferos não voadores para o estado de Mato Grosso do Sul (TOMAS et al., 2017) e 13,5\% das espécies brasileiras ameaçadas de extinção (ICMBIO/MMA, 2018). Nossa lista representou 66\% das espécies de mamíferos não voadores para o estado de Mato Grosso do Sul, no sudoeste do Brasil, o qual também abrigou uma maior riqueza para as famílias Cricetidae e Didelphidae (TOMAS et al., 2017). 
Tabela 1. Lista de mamíferos não voadores em áreas de transição Cerrado-Pantanal no sudoeste do Brasil. Status de conservação: DD = deficiente de dados, NT = quase ameaçada, $\mathrm{VU}=$ vulnerável, $\mathrm{EN}=$ em perigo.

\begin{tabular}{|c|c|c|c|}
\hline \multirow[t]{2}{*}{ Táxon } & \multirow[t]{2}{*}{ Nome comum } & \multicolumn{2}{|c|}{$\begin{array}{c}\text { Status de } \\
\text { Conservação }\end{array}$} \\
\hline & & Brasil & IUCN \\
\hline \multicolumn{4}{|l|}{ DIDELPHIMORPHIA [11 spp.] } \\
\hline \multicolumn{4}{|l|}{ DIDELPHIDAE } \\
\hline Caluromys philander (Linnaeus, 1758) & Cuíca-lanosa & & \\
\hline Chironectes minimus (Zimmermann, 1780) & Cuíca-d’água & & \\
\hline Cryptonanus agricolai (Moojen, 1943) & Cuíca & & DD \\
\hline Didelphis albiventris Lund, 1840 & Gambá & & \\
\hline Gracilinanus agilis (Burmeister, 1854) & Cuíca & & \\
\hline Marmosa constantiae (Thomas, 1904) & Mucura & & \\
\hline Marmosa murina (Linnaeus, 1758) & Cuíca & & \\
\hline Monodelphis domestica (Wagner, 1842) & Catita & & \\
\hline Monodelphis kunsi Pine, 1975 & Catita & & \\
\hline Philander opossum (Linnaeus, 1758) & $\begin{array}{l}\text { Cuíca-quatro- } \\
\text { olhos }\end{array}$ & & \\
\hline Thylamys macrurus (Olfers, 1818) & Cuíca & VU & NT \\
\hline \multicolumn{4}{|l|}{ CINGULATA [4 spp.] } \\
\hline \multicolumn{4}{|l|}{ CHLAMYPHORIDAE } \\
\hline Cabassous unicinctus (Linnaeus, 1758) & $\begin{array}{l}\text { Tatu-de-rabo- } \\
\text { mole }\end{array}$ & & \\
\hline Euphractus sexcinctus (Linnaeus, 1758) & Tatu-peba & & \\
\hline Priodontes maximus (kerr, 1792) & Tatu-canastra & VU & VU \\
\hline \multicolumn{4}{|l|}{ DASYPODIDAE } \\
\hline Dasypus novemcinctus Linnaeus, 1758 & Tatu-galinha & & \\
\hline \multicolumn{4}{|l|}{ PILOSA [2 spp.] } \\
\hline \multicolumn{4}{|l|}{ MYRMECOPHAGIDAE } \\
\hline Myrmecophaga tridactyla Linnaeus, 1758 & $\begin{array}{l}\text { Tamanduá- } \\
\text { bandeira }\end{array}$ & VU & VU \\
\hline Tamandua tetradactyla (Linnaeus, 1758) & Tamanduá-mirim & & \\
\hline \multicolumn{4}{|l|}{ PRIMATES [2 spp.] } \\
\hline \multicolumn{4}{|l|}{ ATELIDAE } \\
\hline Alouatta caraya (Humboldt, 1812) & Bugio-preto & & \\
\hline \multicolumn{4}{|l|}{ CEBIDAE } \\
\hline Sapajus cay (Illiger, 1815) & Macaco-prego & VU & \\
\hline \multicolumn{4}{|l|}{ LAGOMORPHA [1 sp.] } \\
\hline \multicolumn{4}{|l|}{ LEPORIDAE } \\
\hline Sylvilagus brasiliensis Thomas, 1901 & Tapeti & & EM \\
\hline \multicolumn{4}{|l|}{ RODENTIA [20 spp.] } \\
\hline \multicolumn{4}{|l|}{ CAVIIDAE } \\
\hline Cavia aperea Erxleben, 1777 & Preá & & \\
\hline Hydrochoerus hydrochaeris (Linnaeus, 1766) & Capivara & & \\
\hline \multicolumn{4}{|l|}{ CRICETIDAe } \\
\hline Calomys callidus (Thomas, 1916) & Rato-do-chão & & \\
\hline Calomys callosus (Rengger, 1830) & Rato-do-chão & & \\
\hline Cerradomys scotti (Langguth $e$ Bonvicino, 2002) & Rato-do-chão & & \\
\hline Hylaeamys megacephalus (G. Fischer, 1814) & Rato-do-mato & & \\
\hline Necromys lasiurus (Lund, 1841) & Rato-do-mato & & \\
\hline Nectomys rattus (Pelzeln, 1883) & Rato-d'água & & \\
\hline Oecomys bicolor (Tomes, 1860) & Rato-da-árvore & & \\
\hline Oecomys mamorae (Thomas, 1906) & Rato-da-árvore & & \\
\hline Oligoryzomys chacoensis (Myers and Carleton, 1981) & Rato-do-mato & & \\
\hline Oligoryzomys mattogrossae (J. A. Allne, 1916) & Rato-do-mato & & \\
\hline Oligoryzomys nigripes (Olfers, 1818) & Rato-do-mato & & \\
\hline Rhipidomys macrurus (Gervais, 1855) & Rato-da-árvore & & \\
\hline
\end{tabular}




\begin{tabular}{|c|c|c|c|}
\hline \multirow[t]{2}{*}{ Táxon } & \multirow[t]{2}{*}{ Nome comum } & \multicolumn{2}{|c|}{$\begin{array}{c}\text { Status de } \\
\text { Conservação }\end{array}$} \\
\hline & & Brasil & IUCN \\
\hline Cuniculus paca (Linnaeus, 1766) & Paca & & \\
\hline \multicolumn{4}{|l|}{ DASYPROCTIDAE } \\
\hline Dasyprocta azarae Lichtenstein, 1823 & Cotia & & DD \\
\hline \multicolumn{4}{|l|}{ ECHIMYIDAE } \\
\hline Clyomys laticeps (Thomas, 1909) & Rato-de-espinho & & \\
\hline Proechimys longicaudatus (Rengger, 1830) & Rato-de-espinho & & \\
\hline Thrichomys fosteri (Wagner, 1845) & Punaré & & \\
\hline \multicolumn{4}{|l|}{ ERETHIZONTIDAE } \\
\hline Coendou prehensilis (Linnaeus, 1758) & Ouriço-cacheiro & & \\
\hline \multicolumn{4}{|l|}{ CARNIVORA [14 spp.] } \\
\hline \multicolumn{4}{|l|}{ CANIDAE } \\
\hline Cerdocyon thous (Linnaeus, 1766) & $\begin{array}{l}\text { Cachorro-do- } \\
\text { mato }\end{array}$ & & \\
\hline Chrysocyon brachyurus (Illiger, 1815) & Lobo-guará & $\mathrm{VU}$ & NT \\
\hline \multicolumn{4}{|l|}{ FELIDAE } \\
\hline Herpailurus yagouaroundi (É. Geoffroy, 1803) & Jaguarundi & $\mathrm{VU}$ & \\
\hline Leopardus guttulus (Hensel, 1872) & $\begin{array}{l}\text { Gato-do-mato- } \\
\text { pequeno }\end{array}$ & $\mathrm{VU}$ & VU \\
\hline \multicolumn{4}{|l|}{ Leopardus pardalis (Linnaeus, 1758) } \\
\hline Panthera onca (Linnaeus, 1758) & Onça-pintada & VU & NT \\
\hline Puma concolor (Linnaeus, 1771) & Onça-parda & VU & \\
\hline \multicolumn{4}{|l|}{ MEPHITIDAE } \\
\hline Conepatus amazonicus (Lichtenstein, 1838) & Jaritataca & & \\
\hline \multicolumn{4}{|l|}{ MustelidAE } \\
\hline Eira barbara (Linnaeus, 1758) & Irara & & \\
\hline Galictis cuja (Molina, 1782) & Furão & & \\
\hline Lontra longicaudis (Olfers, 1818) & Lontra & & NT \\
\hline Pteronura brasiliensis (Gmelin, 1788) & Ariranha & VU & EM \\
\hline \multicolumn{4}{|l|}{ PROCYONIDAE } \\
\hline Nasua nasua (Linnaeus, 1766) & Quati & & \\
\hline Procyon cancrivorus (Cuvier, 1798) & Mão-pelada & & \\
\hline \multicolumn{4}{|l|}{ PERISSODACTYLA [1 sp.] } \\
\hline \multicolumn{4}{|l|}{ TAPIRIDAE } \\
\hline Tapirus terrestris (Linnaeus, 1758) & Anta & VU & VU \\
\hline \multicolumn{4}{|l|}{ ARTIODACTYLA [6 spp.] } \\
\hline \multicolumn{4}{|l|}{ CERVIDAE } \\
\hline Blastocerus dichotomus (Illiger, 1815) & $\begin{array}{l}\text { Cervo-do- } \\
\text { Pantanal }\end{array}$ & VU & VU \\
\hline Mazama americana (Erxleben, 1777) & Veado-mateiro & & DD \\
\hline Mazama gouazoubira (Fischer, 1814) & $\begin{array}{l}\text { Veado- } \\
\text { catingueiro }\end{array}$ & & \\
\hline Ozotoceros bezoarticus (Linnaeus, 1758) & Veado-campeiro & $\mathrm{VU}$ & NT \\
\hline \multicolumn{4}{|l|}{ TAYASSUIDAE } \\
\hline Pecari tajacu (Linnaeus, 1758) & Cateto & & \\
\hline Tayassu pecari (Link, 1795) & Queixada & $\mathrm{VU}$ & $\mathrm{VU}$ \\
\hline
\end{tabular}

Fonte: Autoria própria.

As curvas de acúmulo de espécies tenderam a estabilização. Especificamente, após a $10^{\text {a }}$ área amostrada não houve um aumento no número de mamíferos de médio e grande porte, enquanto que para os pequenos mamíferos houve o acréscimo de $\sim$-espécie a cada dois esforços amostrais (Figura 2). Nossa fauna 
representou 78\% das espécies de pequeno porte e 95\% das de médio e grande porte estimadas pelo Jackknife 1 (Figura 2).

Figura 2. Curva de acúmulo de espécies por rarefação da riqueza estimada (Jackknife 1) e observada de A) pequenos mamíferos e B) mamíferos de médio e grande porte em área de transição Cerrado-Pantanal no sudoeste do Brasil.
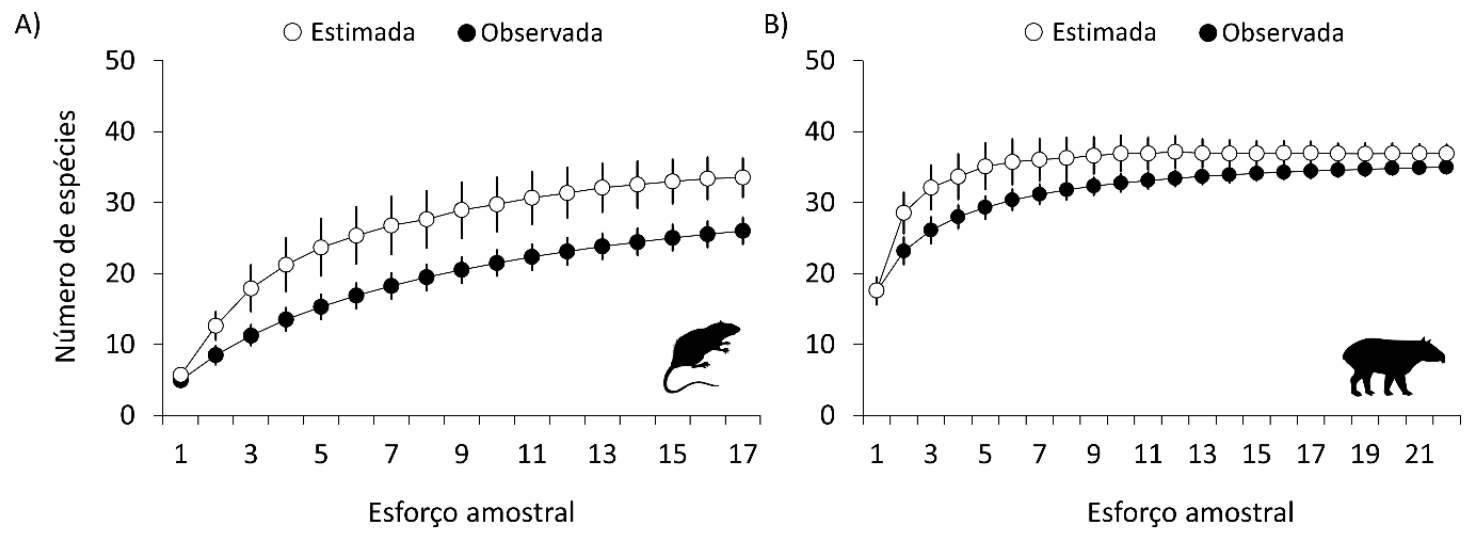

Fonte: Autoria própria.

Fatores biogeográficos podem estar relacionados ao fato de algumas espécies de pequenos mamíferos, com ocorrência para estado de Mato Grosso do Sul, não terem sido listadas para as áreas de transição Cerrado-Pantanal. Os marsupiais, Marmosops ocellatus e Cryptonanus chacoensis, e os roedores Akodon toba, Euryoryzomys nitidus, Holochilus chacarius e Oecomys paricola ocorrem em áreas da Floresta Chiquitana, no extremo oeste do Estado (CACERES et al., 2011; HANNIBAL et al., 2017). Outras espécies como Didelphis aurita, Akodon montensis, Cerradomys maracajuensis, Nectomys squamipes, Oecomys catherinae e Oxymycterus delator ocorrem em áreas de transição Cerrado-Mata Atlântica, a leste e cone-sul de Mato Grosso do Sul (CÁCERES et al., 2012; GONÇALVES et al., 2018). O hábito de vida e comportamento das espécies também devem ser considerados quanto a ausência no registros, por exemplo, os marsupiais Caluromys lanatus e Lutreolina crassicaudata estão amplamente distribuídos na área de transição Cerado-Pantanal (GARDNER, 2008). No entanto, C. lanatus habita o dossel - estrato mais alto das árvores e $L$. crassicaudata é restrita a campo úmidos e matas de galeria (GARDNER, 2008). Portanto, o uso de metodologia adequada deve ser empregado em estudos sobre a mastofauna.

Padrões biogeográficos e comportamentais também estão associados a presença-ausência de mamíferos de médio e grande porte nas áreas de transição Cerrado-Pantanal. Três espécies de primatas com ocorrência para Mato Grosso do 
Sul, são restritas a porção oeste do Estado (HANNIBAL et al., 2017). A ausência de registros de algumas espécies de canídeos e felídeos podem estar associados ao hábito de vida dessas espécies. Todas são espécies ameaçadas, raras na maior parte de sua distribuição (Leopardus colocolo, Speothos venaticus), ou com baixas densidade em áreas de Cerrado-Pantanal (Leopardus wiedii). Portanto, são espécies extremamente crípticas e difíceis de observar, sendo necessário um grande esforço, com armadilhas fotográficas (ICMBIO/MMA, 2018).

A frequência na presença de pequenos e grandes mamíferos foi heterogênea entre as espécies e ao longo do gradiente Cerrado-Pantanal. 0 punaré Thrichomys fosteri e os marsupiais D. albiventris, Gracilinanus agilis e Thylamys macrurus foram as espécies mais frequentes, ocorrendo ao longo do gradiente Cerrado-Pantanal, no entanto, $58 \%$ dos pequenos mamíferos ocorreram em um ou dois locais apenas, ocupando áreas do Pantanal ou Cerrado (Figura 3). Por outro lado, 57\% dos mamíferos de médio e grande porte foram frequentes, ocorrendo em mais da metade das áreas amostradas, e ao longo de todo o gradiente Cerrado-Pantanal (Figura 3).

Figura 3. Matriz de presença de A) pequenos mamíferos e B) mamíferos de médio e grande porte em áreas de transição Pantanal (verde) e Cerrado (laranja) no sudoeste do Brasil. As linhas representam as espécies de mamíferos ordenadas de forma decrescente (de cima para baixo) conforme a frequência, e as colunas representam as áreas amostradas.

A)

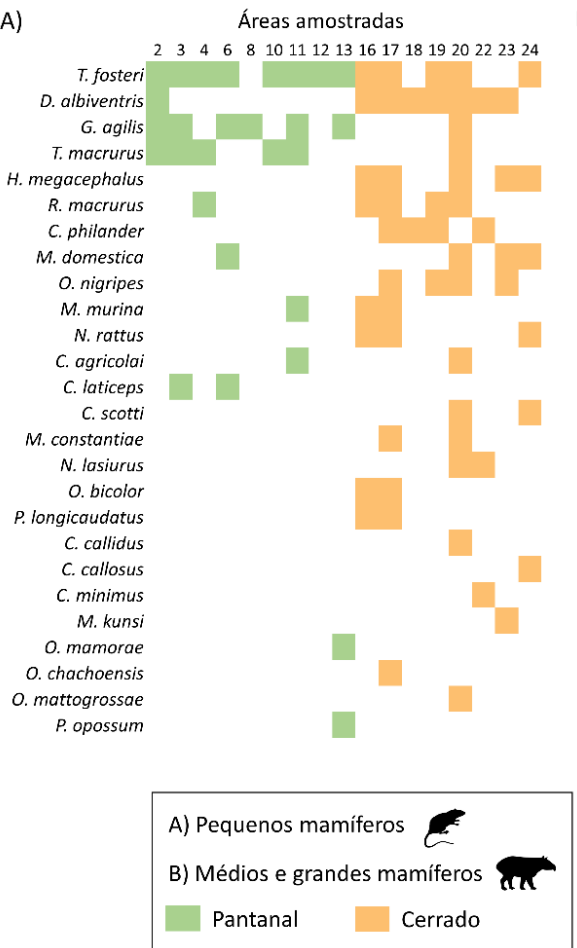

B)

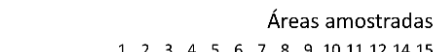

Fonte: Autoria própria.

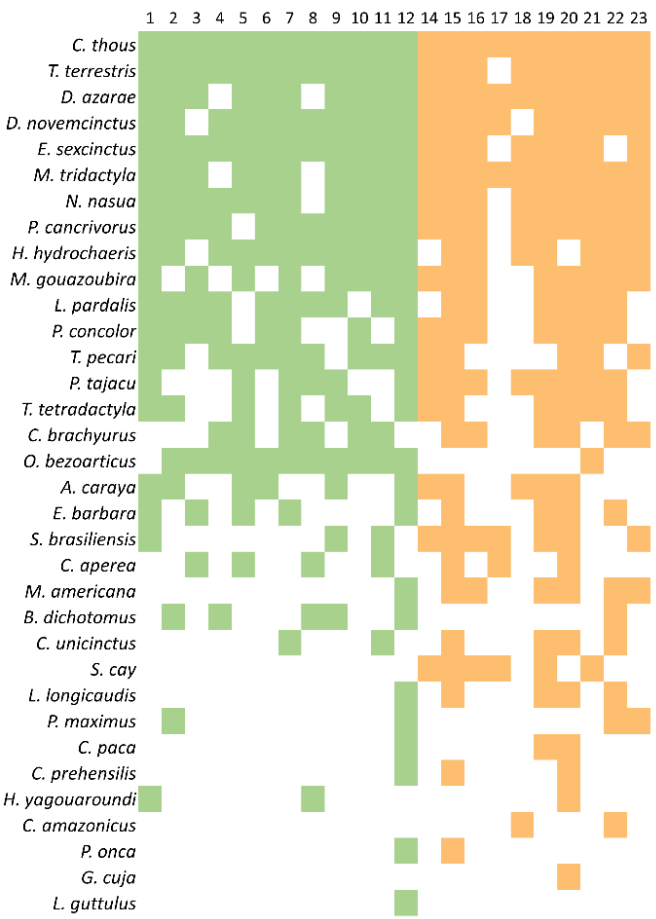


As espécies de pequenos mamíferos frequentes em áreas de Pantanal e Cerrado no sudoeste do Brasil compartilham algumas características biogeográficas e ecológicas. Por exemplo, ocorrem nos principais domínios fitogeográficos da diagonal de áreas abertas da América do Sul, sendo comuns e abundantes em sua área de distribuição. 0 punaré $T$. fosteri é um dos roedores mais abundantes nos ambientes de floresta estacional e cerradão do Pantanal brasileiro (MENEZES; MOURÃO; KOTLER, 2018). Didelphis albiventris, G. agilis e T. macrurus também tem sido os marsupiais mais capturados em fragmentos de floresta estacional e cerradão do centro ao sudoeste do Brasil (CÁCERES et al., 2010b; HANNIBAL et al., 2018).

Os mamíferos de médio e grande porte frequentes em nossa área de estudo são espécies frequentes e muito frequentes no sul do Cerrado, em áreas que fazem transição com Mata Atlântica e Pantanal (CÁCERES; BORNSCHEIN; LOPES, 2008). Com relação ao uso do habitat, as espécies frequentes nas áreas de transição Cerrado-Pantanal, podem ainda ser classificadas em: $i$ ) generalistas - "anta" $T$. terrestris, "cotia” D. azarae, "tatu-galinha" D. novemcinctus, "jaguatirica” L. pardalis, "onça-parda" P. concolor; ii) savânicas - "cachorro-do-mato" C. thous, "tatu-peba” E. sexcinctus, "tamanduá-bandeira" M. tridactyla, "veados" Mazama sp. e O. bezoarticus, "cateto" P. tajacu; e iii) florestais - "guaxinim" P. cancrivorus, "macaco-prego" S. cay, "bugio" A. caraya (CÁCERES; BORNSCHEIN; LOPES, 2008).

\section{CONSIDERAÇÕES FINAIS}

As áreas de transição entre Cerrado e Pantanal, no estado de Mato Grosso do Sul, sudoeste do Brasil abrigam 66\% das espécies de mamíferos não voadores listada para o Estado. Consideramos nossa amostragem satisfatória, pois representou 78\% das espécies de pequenos mamíferos e 95\% das espécies de mamíferos de médio e grande porte estimadas (Jackknife 1), para a região. 0 punaré T. fosteri e os marsupiais D. albiventris, G. agilis e T. macrurus são as espécies de pequenos mamíferos mais comuns na região, enquanto que 57\% das espécies de mamíferos de médio e grande porte tem se mostrado comum para esta área de transição. Nós destacamos que os padrões biogeográficos, ecológicos e comportamentais podem estar associados as presenças/ausências das espécies de mamíferos não voadores para o ecótono Cerrado-Pantanal no sudoeste do Brasil. 


\section{REFERÊNCIAS}

BEZERRA, A. M. R.; CARMIGNOTTO, A. P.; RODRIGUES, F. H. G. Small non-vollant mammals of an ecotone region between the Cerrado hotspot and the Amazonian reinforest, with commnets ont their taxonomy and distribution. Zoological Studies, v. 48, n. 6, p. 861-874, 2009.

BONVICINO, C. R.; OLIVEIRA, J. A. DE; D'ANDREA, P. S. Guia dos roedores do Brasil com chave para gêneros baseadas em caracteres externos. 1. ed. Rio de Janeiro: Centro Pan-Americano de Febre Aftosa - OPAS/OMS, 2008.

BORGES, P. A. L.; TOMAS, W. M. Guia de rastros e outros vestígios de mamíferos do Pantanal. Corumbá: Embrapa Pantanal, 2004.

BRANDON, K. et al. Conservação brasileira: desafios e oportunidades. Megadiversidade, v. 1, n. 1, p. 7-13, 2005.

CACERES, N. C. et al. Effects of altitude and vegetation on small-mammal distribution in the Urucum Mountains, western Brazil. Journal of Tropical Ecology, v. 27, n. 3,2011 .

CÁCERES, N. C. et al. Mammals in a fragmented savannah landscape in southwestern Brazil. Journal of Natural History, v. 44, n. 7-8, 2010a.

CÁCERES, N. C. et al. Mammals in a fragmented savannah landscape in southwestern Brazil. Journal of Natural History, v. 44, n. 7-8, p. 491-512, 2010b.

CÁCERES, N. C. et al. Efeitos da conservação e da distância geográfica sobre comunidades de pequenos mamíferos do Cerrado e Pantanal no oeste do Brasil. In: FREITAS, T. R. O. DE; VIEIRA, E. M. (Eds.). . Mamíferos do Brasil: genética, sistemática, ecologia e conservação. Rio de Janeiro: Sociedade Brasileira de Mastozoologia, 2012. p. 9-18.

CÁCERES, N. C.; BORNSCHEIN, M. R.; LOPES, W. H. CÁCERES_et al. 2008_Uso do hábitat e a conservação de mamíferos no sul do bioma Cerrado.pdf. In: REIS, N. R.; PERACCHI, A. L.; SANTOS, G. A. S. D. (Eds.). . 1. ed. Londrina: Technical Books, 2008. p. 123-132.

CASAGRANDE, A. F.; SANTOS-FILHO, M. DOS. Use of forest remnants and teak (Tectona grandis) plantations by small mammals in Mato Grosso, Brazil. Studies on Neotropical Fauna and Environment, v. 54, n. 3, p. 181-190, 2019.

COLWELL, R. K. EstimateS: Statistical estimation of species richness and shared species from samples. Disponível em: <http://purl.oclc.org/estimates>. Acesso em: 15 jun. 2020.

D'ELÍA, G.; MYERS, P. On Paraguayan Thrichomys (Hystricognathi: Echimyidae): the distinctiveness of Thrichomys fosteri Thomas, 1903. Therya, v. 5, n. 1, p. 153166, 2014. 
FEIJÓ, A.; CORDEIRO-ESTRELA, P. Taxonomic revision of the Dasypus kappleri complex, with revalidations of Dasypus pastasae (Thomas, 1901) and Dasypus beniensis Lönnberg, 1942 (Cingulata, Dasypodidae). Zootaxa, v. 4170, p. 271-297, 2016.

GARDNER, A. L. Mammals of South America, vol 1. Marsupials, Xenarthrans, Shrews, and Bats. 1. ed. Chicago: The University of Chicago Press, 2008.

GONÇALVES, F. et al. Non-volant mammals from the Upper Paraná River Basin: a data set from a critical region for conservation in Brazil. Ecology, v. 99, n. 2, 2018.

HANNIBAL, W. et al. Biogeography and conservation of non-volant mammals from the Urucum Mountains: A Chiquitano dry forest ecoregion in western Brazil. Mammalia, v. 81, n. 2, 2017.

HANNIBAL, W. et al. Multi-scale approach to disentangle the small mammal composition in a fragmented landscape in central Brazil. Journal of Mammalogy, v. 99, n. 6, p. 1455-1464, 2018.

HANNIBAL, W.; DUARTE, L. A.; SANTOS, C. C. Mamíferos não voadores do Pantanal e entorno. Campo Grande: Natureza em Foco, 2015.

HANNIBAL, W.; NEVES-GODOI, M. Non-volant mammals of the Maracaju Mountains, southwestern Brazil: Composition, richness and conservation. Revista Mexicana de Biodiversidad, v. 86, n. 1, 2015.

HARRIS, M. B. et al. Desafios para proteger o Pantanal brasileiro: ameaças e iniciativas em conservação. Megadiversidade, v. 1, n. 1, p. 156-164, 2005.

ICMBIO/MMA. Livro Vermelho da Fauna Brasileira Amaeaçada de Extinção, Volume II - Mamíferos. 1. ed. ed. Brasília: Instituto Chico Mendes de Conservação da Biodiversidade, 2018.

LACHER JR, T. E.; ALHO, C. J. R. Terrestrial small mammal richness and habitat associations in an Amazon Forest-Cerrado contact zone. Biotropica, v. 33, n. 1, p. 171-181, 2001.

MAGIOLI, M. et al. Connectivity maintain mammal assemblages functional diversity within agricultural and fragmented landscapes. European Journal of Wildlife Research, v. 62, n. 4, p. 431-446, 2016.

MENEZES, J. F. S.; MOURÃO, G. M.; KOTLER, B. P. Understory cover increases patch use in rodent Thrichomys fosteri. Ethology Ecology and Evolution, v. 30, n. 3, p. 267-276, 2018.

MMA. Biodiversidade Brasileira. Disponível em: <https://www.mma.gov.br/biodiversidade/biodiversidade-brasileira>.

MYERS, N. et al. Biodiversity hotspots for conservation priorities. Nature, v. 403, p. 853-858, 2000. 
PAGLIA, A. P. et al. Lista anotada dos mamíferos do Brasil. [s.l: s.n.]. v. 4

PERCEQUILLO, A. R. et al. How many species of mammals are there in Brazil? New records of rare rodents (Rodentia: Cricetidae: Sigmodontinae) from Amazonia raise the current known diversity. PeerJ, v. 2017, n. 12, p. 1-34, 2017.

PERCEQUILlo, A. R.; GREGORIN, R. Catálogo Taxonômico da Fauna do Brasil: Mammalia. Disponível

em:

<http://fauna.jbrj.gov.br/fauna/faunadobrasil/64>.

REIS, N. R. DOS et al. Sobre os mamíferos do Brasil. In: REIS, N. R. DOS et al. (Eds.). . Mamíferos do Brasil. 2a ed. Londrina: Nelio R. dos Reis, 2011. p. 23-30.

TOMAS, W. M. et al. Lista de mamíferos do Mato Grosso do Sul, Brasil. Iheringia Serie Zoologia, v. 107, p. 1-17, 2017.

TROLLE, M. Mammal survey in the southeastern Pantanal, Brazil. Biodiversity and Conservation, v. 12, p. 823-836, 2003.

VOSS, R. S. et al. Phylogenetic relationship of mouse opossums (Didelphidae, Marmosa) with a revised subgeneric classification and notes on sympatric diversity. American Museum Novitates, p. 27, 2014. 


\section{ANEXO 1. LISTA DAS 24 ÁREAS AMOSTRADAS NAS PROXIMIDADES DO LIMITE CERRADO-}

\section{PANTANAL, SUDOESTE DO BRASIL. LEGENDA: NÚMERO NA FIGURA 1. - MUNICÍPIO,}

\section{LOCALIDADE (FONTE).}

1. Corumbá, Fazenda Alvorada (Neste estudo). 2. Rio Verde de Mato Grosso, Fazenda Campo Cyra (Neste estudo). 3. Coxim, Fazenda Dois Buritis (Neste estudo). 4. Corumbá, Fazenda Donato (Neste estudo). 5. Corumbá, Fazenda Estrela (Neste estudo). 6. Corumbá, Fazenda Girassol (Neste estudo). 7. Corumbá, Fazenda Goiaba (Neste estudo). 8. Corumbá, Fazenda Guanabara (Neste estudo). 9. Aquidauana, Fazenda Querência (Neste estudo). 10. Rio Verde de Mato Grosso, Fazenda Santa Clara (Neste estudo). 11. Rio Verde de Mato Grosso, Fazenda Tupã (Neste estudo). 12. Aquidauana, Fazenda Santa Emília (TROLLE, 2003). 13. Miranda, Refúgio Ecológico Caiman (CÁCERES et al., 2012).14. Anastácio, Fazenda Jatiúca (HANNIBAL; GOIDOI, 2015). 15. Anastácio, Fazenda Boa Esperança (HANNIBAL; GOIDOI, 2015). 16. Aquidauana, UEMS (HANNIBAL; GODOI, 2015). 17. Aquidauana, Piraputanga (HANNIBAL; GODOI, 2015). 18. Aquidauana, Córrego João Dias e Faz Rolândia (HANNIBAL; GODOI, 2015). 19. Corguinho, RPPNs Gavião de Penacho e Vale do Bugio (HANNIBAL; GODOI, 2015). 20. Dois Irmãos do Buriti, Fazendas Correntes e São Cristóvão [CÁCERES et al., 2010; HANNIBAL; GODOI, 2015]. 21. Rio Verde de Mato Grosso, Fazenda Cruzeiro (HANNIBAL, GODOI, 2015). 22. Sonora, PCH Santa Gabriela (HANNIBAL; GODOI, 2015). 23. Sonora, Usina Sonora (HANNIBAL; GODOI, 2015). 24. Bodoquena, Fazenda Califórnia (CÁCERES et al., 2012). 


\title{
CAPÍTULO XIV
}

\section{ALOUATTA CARAYA (HUMBOLDT, 1812): 0 QUE 0 TAMANHO E A DINÂMICA DE UM GRUPO PODEM NOS DIZER?}

DDI: 10.51859/amplla.ecp672.1121-14

\author{
Nara Inácio Luccas Lazaro ${ }^{1}$ \\ Antonio Edson Lazaro Junior ${ }^{2}$ \\ Gilson Rocha ${ }^{2}$ \\ Vanessa Katherinne Stavis ${ }^{2}$
}

${ }^{1}$ Universidade Federal de Mato Grosso do Sul. Campus de Aquidauana. Laboratório de Zoologia.

${ }^{2}$ Universidade Federal de Mato Grosso do Sul. Campus de Aquidauana.

\section{INTRODUÇÃO}

O Gênero Alouatta Lacépède, 1799 são primatas sociais, ou seja, vivem em grupos que, frequentemente, são familiares. Estes grupos podem variar seu tamanho e composição sexo-etária tanto entre as espécies como intraespecificamente (MIRANDA; PASSOS, 2005). Em relação ao tamanho, foram relatados grupos da espécie Alouatta caraya variando entre 2 a 21 indivíduos (TREVES, 2001; BRAVO; SALLENAVE, 2003).

Quanto à composição sexo-etária, os grupos de Alouatta caraya são formados por normalmente um macho adulto, uma ou mais fêmeas, além de indivíduos jovens e filhotes (RIMOLI et al., 2012; LUCCAS-LAZARO, 2013). Mas, também são encontrados grupos temporários constituídos por mais de um macho adulto, por somente fêmeas e seus filhotes, além de animais solitários (MIRANDA et al., 2004; SILVA; CODENOTTI, 2005; AGUIAR et al., 2014; STAVIS et al., 2019). 0 tamanho de grupo e a sua composição podem estar relacionados com variáveis como o tamanho da sua área de vida, a disponibilidade de recursos alimentares e também do comportamento social.

Em relação ao comportamento social, questões como as fissões de grupos, as migrações e nascimentos de indivíduos refletem grandemente no tamanho do 
grupo. Para o gênero, já é conhecido que as migrações podem ser realizadas tanto por machos quanto por fêmeas, induzidas pelo comportamento reprodutivo (BROCKETT et al., 2000; MIRANDA; PASSOS, 2005). O que pode propiciar a formação de novos grupos ou mesmo, a introdução de um indivíduo num grupo já existente em outras áreas, e também para a proteção de filhotes contra infanticídios (MIRANDA et al., 2006).

Em relação aos recursos alimentares e ao tamanho da área de vida, baseado na teoria de metapopulações pode-se supor que áreas maiores suportam grupos maiores (HANSKI, 1999). Porém, estudos relatam incertezas para esta afirmação, pois alguns indicam que a densidade populacional de Alouatta são superiores em fragmentos menores (JARDIM, 2005; ARROYO-RODRÍGUEZ; DIAS 2009; DE ALMEIDA E SILVA et al., 2017).

O mais interessante é que Aloutta caraya observada em alguns estudos (BICCA-MARQUES, 2003; SILVA; CODENOTTI, 2005) parecem possuir características de adaptabilidade para a sobrevivência em pequenos fragmentos, fato que é um posicionamento da pesquisa mal-interpretado. É verdade que há um grande número de populações de Alouatta caraya espalhados no Brasil, porém este grande número está ilhado em pequenos fragmentos sem corredores, com baixa troca genética e com pouca perspectiva. Vale ressaltar, que os bugios (Alouatta) possuem um comportamento territorialista, o que de fato exige a necessidade de êxodo em busca de formação de novos grupos e de novos habitats, aumentando ainda mais a necessidade de expansão territorial.

A considerada alta adaptabilidade dos bugios em pequenos fragmentos é observada por primatólogos ao analisar o comportamento alimentar e verificar que a dieta do gênero, de um modo geral, é majoritariamente folívora e/ou frugívora quando há frutos disponíveis (ESTRADA et al., 2002; BICCA-MARQUES, 2003; LAZARO- JUNIOR, 2009; RIMOLI et al., 2012; LUCCAS-LAZARO, 2013; CHAVES; BICCA-MARQUES, 2016; STAVIS et al., 2018) e que conseguem extrair nutrientes da riqueza da vegetação local, incluindo também plantas exóticas (BICCA-MARQUES, 1994; BICCA-MARQUES; CALEGARO-MARQUES, 1994; MUHLE, 2008; PRATTES; BICCA-MARQUES, 2012). Alguns grupos de bugios conseguem sobreviver com uma dieta não muita diversa o que atualmente pode ser mais sensato considerar uma necessidade do que uma adaptabilidade. Assim, salientar que eles sobrevivem muito 
bem em áreas fragmentadas pode realmente ser preocupante, pois, em que ponto de vista?

Assim, busca-se discutir as afirmações acima citadas com os estudos realizados em um grupo de bugios moradores de um fragmento de mata ciliar, situada na margem esquerda do Rio Aquidauana, traçando possíveis paralelos com as situações demonstradas por outros grupos de bugios que se encontram nas mesmas circunstâncias em relação a sua dinâmica populacional, buscando evidenciar uma realidade preocupante.

Desta forma, o objetivo deste trabalho é demonstrar a dinâmica da composição de um grupo de bugio isolado em uma zona urbana do município de Anastácio- MS. E, também, alertar sobre a necessidade constante da conservação da vegetação fragmentada. Pois, este grupo de bugios não representa um caso isolado da situação desta espécie, e sim representa uma situação que deixou de ser latente sobre a manutenção da espécie Alouatta caraya.

\section{MATERIAL E MÉTODOS}

A pesquisa foi realizada no município de Anastácio Mato Grosso do Sul, Brasil (20²9'01'S, 5547'88'W) em um fragmento considerado como Mata Ciliar localizado na margem esquerda do Rio Aquidauana (Figura 1). Esta área sofre inundações na época da cheia, sendo que os meses de inundações variaram nos anos de estudo. Assim, as inundações ocorreram no mês de janeiro em 2008 e 2010, no final de dezembro em 2009, fevereiro em 2011 (considerada uma das maiores cheias da região), ocorreu de maneira atípica no mês de julho em 2012, e em abril de 2013. 
Figura 1. Área de estudo que se encontra na margem esquerda do Rio Aquidauana. Município de Anastácio- MS. (Imagem retirada de RÍMOLI, J.; NANTES, R. DOS S. $e$ LÁZAROJÚNIOR 2012).

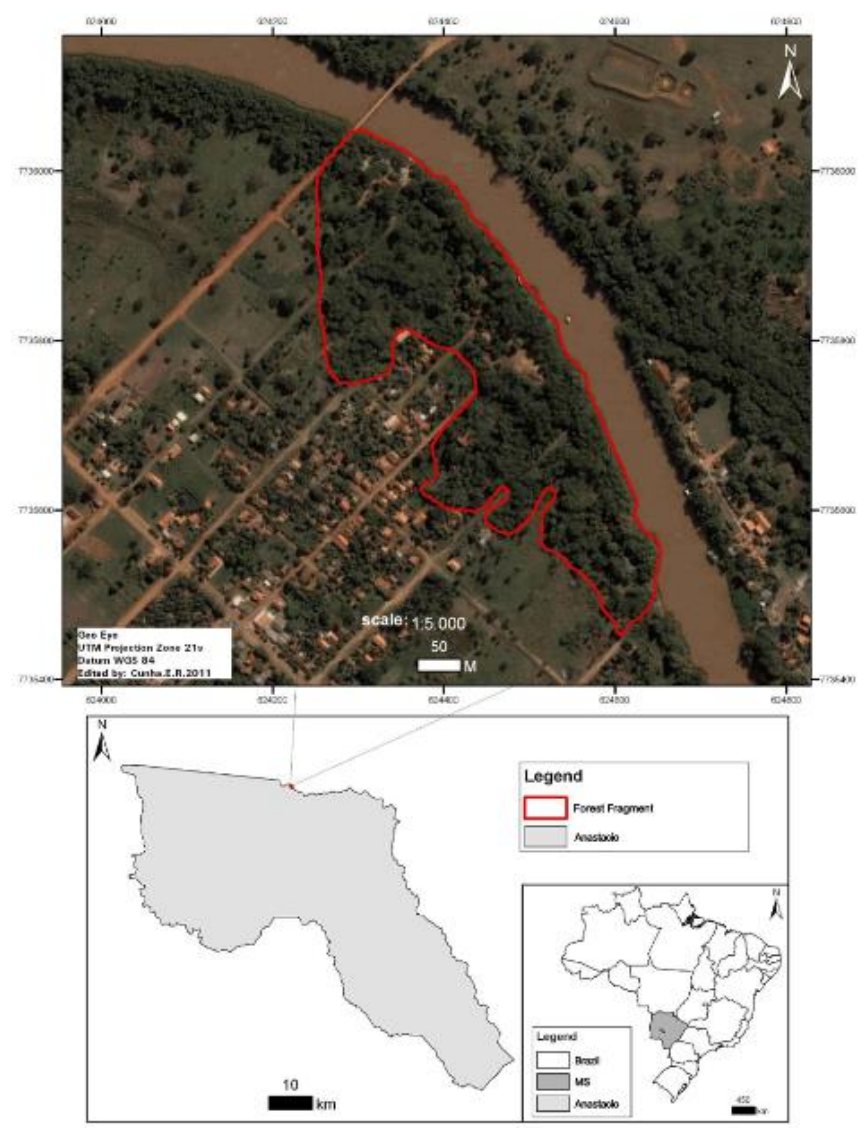

Fonte: Rímoli et al, 2012.

As espécies vegetais presentes na área e frequentemente na observadas na dieta do grupo consistem em Ingá, Jatobá, Tarumã, Genipapo, Mangueira, Embaúba e Figueira.

A composição sexo-etária e o tamanho do grupo foram acompanhados de 2008 até 2013 por meio de estudos sobre a ecologia, dieta e comportamento de Alouatta caraya (LAZARO-JUNIOR 2010; ROCHA-SANTOS 2011; LAZARO-LUCCAS, 2013). Sendo que em 2010, por não haver estudos diretos na área, o censo do grupo corresponde as possíveis mudanças ocorridas no intervalo de 2009 -2011.

Os dados sobre a composição sexo-etária foram descritos, bem como a dinâmica das mudanças de faixas etárias, nascimentos e desaparecimentos. Vale ressaltar que para a identificação dos indivíduos foram utilizadas características biológicas fenotípicas como a coloração distinta entre machos (coloração preta) e fêmeas (coloração dourada), além do tamanho corporal e características individuais (coloração, marcas). As categorias de idade utilizadas foram adaptadas e baseadas 
na proposta de Mendes (1989), a fim de facilitar a organização dos dados. Assim as idades foram organizadas de modo a compor as seguintes categorias: infantes (foram incluídos recém-nascido até 12 meses), jovens (maior que 12 meses até 30 meses) e subadultos (acima de 30 meses até 48 meses) e adultos (acima de 48 meses).

\section{RESULTADOS E DISCUSSÃO}

Ao longo do período de observação do grupo de Alouatta caraya foi realizado o censo populacional e assim pode-se observar que o tamanho do grupo variou de oito a dez indivíduos e a composição sexo-etária do grupo está descrita na Tabela 1.

Tabela 1. Composição do grupo de bugios-pretos (Alouatta caraya) observada nos respectivos estudos: 2008 e 2009 Lazaro-Junior (2010) e Rímoli e colaboradores (2012);

2010 (período sem observação do grupo); 2011 Rocha-Santos (2011) e 2012 e 2013 Lazaro-Luccas (2013).

\begin{tabular}{lccccccc}
\hline & & 2008 & 2009 & 2010 & 2011 & 2012 & 2013 \\
\hline Adulto & Macho & 2 & 1 & 1 & 1 & 2 & 1 \\
Adulto & Fêmea & 3 & 3 & 3 & 3 & 3 & 3 \\
Subadulto & Macho & 0 & 0 & 0 & 1 & 2 & 2 \\
Subadulto & Fêmea & 1 & 1 & 1 & 0 & 0 & 0 \\
Jovem & Macho & 0 & 0 & 0 & 2 & 1 & 1 \\
Jovem & Fêmea & 0 & 1 & 1 & 1 & 0 & 1 \\
Infante & Macho & 1 & 2 & 2 & 1 & 1 & 0 \\
Infante & Fêmea & 1 & 0 & 0 & 0 & 1 & 0 \\
Total & & $\mathbf{8}$ & $\mathbf{8}$ & $\mathbf{8}$ & $\mathbf{9}$ & $\mathbf{1 0}$ & $\mathbf{8}$ \\
\hline
\end{tabular}

Fonte: Autoria própria.

O grupo foi estudado de 2008- 2013 e o acompanhamento do desenvolvimento dos indivíduos foram monitorados sendo possível verificar mudanças na categoria etária, nascimentos e emigrações (Tabela 2). Os nascimentos de filhotes ocorreram no mês de abril (LAZARO-JUNIOR, 2010; ROCHA-SANTOS, 2011; LAZARO-LUCCAS, 2013). Em 2009, 2010 e 2012 duas fêmeas tiveram filhotes, nos outros anos apenas uma fêmea do grupo ficou gestante. No período de estudo foram acompanhados sete nascimentos, sendo cinco machos e duas fêmeas.

Os machos subadultos abandonaram o grupo em 2008 no mês de abril e em 2012 no mês de outubro. Foi observado a emigração de macho juntamente com fêmea do mesmo grupo em 2008 e 2012. Os locais de migração destes indivíduos 
não foram encontrados. Durante os períodos de convivência de dois adultos machos (pai e filho) não foram observados eventos de violência em relação a disputas de fêmeas (LAZARO-JUNIOR, 2010; LAZARO-LUCCAS, 2013).

Também foi observada uma migração de uma fêmea jovem, que abandonou o grupo em 2011, em 2010 ano que não houve estudo outra fêmea pode ter emigrado, já que não foi localizada e nem avistada no censo de 2011.

Tabela 2. Representação da variação demográfica do grupo de Alouatta caraya durante 2008-2013. Os períodos de estudos foram: 2008 e 2009 Lazaro-Junior (2010) e Rímoli e colaboradores (2012); 2010 (período sem observação do grupo); 2011 Rocha-Santos (2011) ;2012 e 2013 Lazaro-Luccas (2013)

Legenda: $(\rightarrow)$ permanece na categoria; (O)migração ; $(+)$ nascimento; $(\cdots \cdots \cdots)$ mudança de

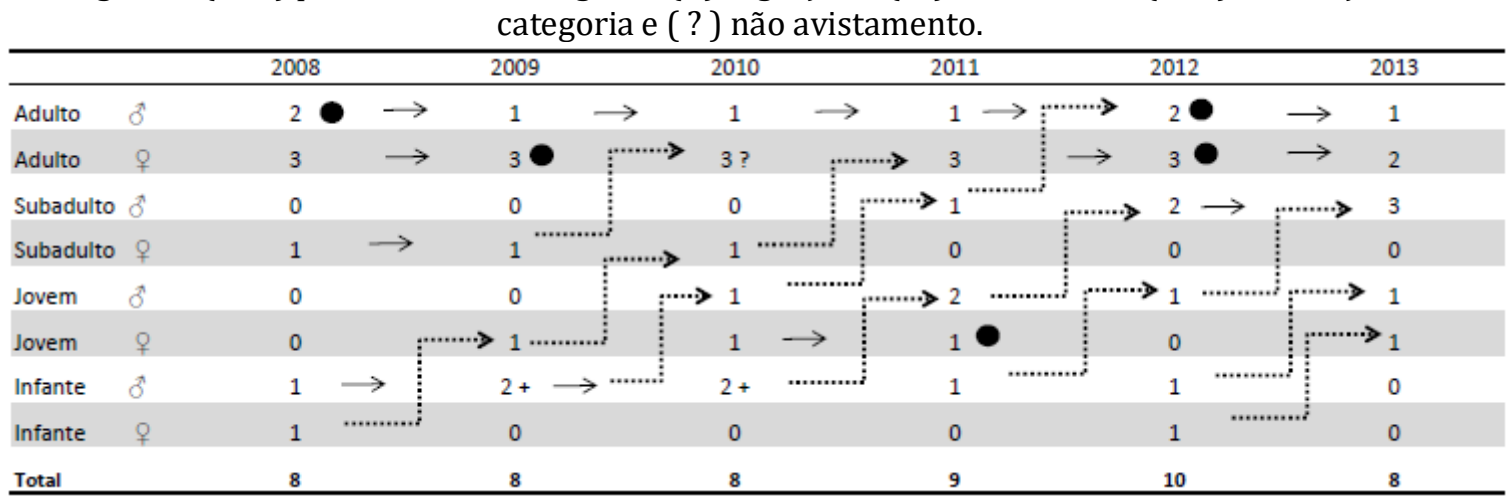

Fonte: Autoria própria.

O tamanho de grupo de primatas sofre influências de condições ambientais, na busca em equilibrar as vantagens e as desvantagens da vida em grupo (CHAPMAN; CHAPMAN, 2000). Como condições ambientais pode-se entender: disponibilidade de recursos alimentares e tamanho da área de vida. Outro fator que influencia o tamanho de grupo e a composição sexo-etária são os fatores comportamentais.

Em relação às influências geradas por fatores comportamentais, estudos apontam que o limite de indivíduos no grupo é estabelecido por comportamentos sociais como agressões de machos e risco de infanticídios em primatas com dieta folívora, já que para estes a disponibilidade de recursos alimentares não é um agravante (CHAPMAN; PAVELKA, 2005; KNOPFF; PAVELKA, 2006). Porém esta afirmação não corrobora com outros estudos, pois são poucos os registros de comportamentos agonísticos para o gênero Alouatta (MORO-RIOS et al., 2009; FERMOSELI, 2010). Comportamentos agonístico executados por membros do grupo estudado são foram expressivos. 
O tamanho do grupo de estudo mostrou uma tendência para a manutenção de oito indivíduos. Pode-se notar que entre 2008-2013, ocorreu um maior número de nascimentos de indivíduos machos, o que de fato pode ajudar para a manutenção do tamanho do grupo, pois quando completam a idade adulta seu comportamento social força uma migração. 0 êxodo de primatas machos em idade adulta é um comportamento frequente que visa garantir o sucesso reprodutivo e a formação de novos grupos (NUNN, 1999; JARDIM, 2005). As duas migrações que ocorreram durante o período de estudo, foram provavelmente pacíficas, até porque não foram observados comportamentos agonísticos ente pai e filho. Onde o comportamento pacífico de migração pode ser resultado da tentativa de evitar conflitos entre machos parentes (MORO-RIOS et al., 2009).

Em um estudo com Alouatta guariba clamitans ao longo de três anos, foi observado uma fissão no grupo (10 indivíduos) de modo gradual, a partir da morte do macho alfa, mantendo assim grupos menores (grupo I - 6 indivíduos e grupo II 3 indivíduos) que provavelmente habitam áreas de vidas distintas, mas não desconexas (MIRANDA et al., 2006).

No presente estudo também foi observado o êxodo de fêmeas na maioria das vezes, para acompanhar o macho que alcançara a maturidade sexual. Este fato pode corroborar com a ideia de que a migração ocorre quando seus custos forem menores do que os de permanecer no grupo com limitadas oportunidades reprodutivas (MORO-RIOS et al., 2009). O sucesso das migrações que ocorreram é incerto, pois os migrantes não foram localizados e assim, ainda há dúvidas sobre o novo habitat/ grupo já que o fragmento estudado não se conecta com outras manchas de mata ciliar por meio do dossel. Porém já se sabe que os bugios conseguem migrar para áreas desconectas utilizando o solo (DE ALMEIDA E SILVA et al., 2017).

A manutenção do tamanho de grupo permite deduzir que os grupos de Alouatta também tem sua densidade populacional relacionada com o tamanho da área habitada e também com a disponibilidade de recursos (COSTA et al., 2012) onde mudanças sexo-etárias ocorrem sem alterar o número de indivíduos do grupo ao longo do tempo. Assim, sugere-se que os tamanhos de grupos de Alouatta tem um limite baseado na capacidade de suporte da área (MORO-RIOS et al., 2009). Uma revisão do gênero demonstra que eles habitam áreas que variam de 0,3 a 1700 hectares (DIAS; RANGEL-NEGRIN, 2015). 
Por mais que o tamanho da área seja um fator relevante, estudos observaram que há maior densidade populacional em fragmentos menores, fato que pode ser explicado pela impossibilidade de êxodo dos indivíduos quando atingem a idade adulta, principalmente quando este fragmento é completamente isolado de outras manchas de vegetação (JARDIM, 2005; SILVA; CODENOTTI, 2005; DE ALMEIDA E SILVA, et al., 2017). De fato, o que pode comprometer a manutenção - não só do tamanho do grupo, mas também da espécie - é o isolamento dos fragmentos, o que dificulta o sucesso do êxodo de alguns membros do grupo em busca de novas áreas de vida, como também do sucesso reprodutivo.

Contudo, o tamanho do fragmento não é uma característica que sozinha pode ser capaz de influenciar na abundância dos primatas. A qualidade do habitat também é relevante (VIEIRA et al., 2003). Por exemplo, a riqueza de recursos alimentares como folhas e frutos tende a diminuir em fragmentos menores (BICCAMARQUES, 2003). Estudos demostraram que quando se trata da dieta de um grupo específico, os bugios podem consumir uma variedade de 12 a 200 espécies vegetais diferentes e esta relação se torna ainda mais relevante quando comparada a dieta para o gênero Alouatta que consumem mais de 1000 espécies vegetais diferentes (DIAS; RANGEL-NEGRIN, 2015). Assim, quanto mais informações sobre a espécie que envolva levantamentos de populações, dieta, área de uso, e dinâmica da composição sexo-etária, maiores serão os refinamentos para o entendimento da ecologia populacional a fim de avaliar seu status de conservação (FORTES, 2008).

Outra questão que também pode trazer uma perspectiva inexata, diz respeito a ampla distribuição geográfica da espécie Alouatta caraya o que pode camuflar sua real situação. A fragmentação dos habitats e o desmatamento da mata ciliar e, principalmente a falta de fiscalização compromete a sobrevivência desta espécie. Sabendo que sua distribuição geográfica concentra-se na região de Cerrado - que a cada dia encontra-se mais degradado pela expansão da fronteira agrícola brasileira - mensurar a sobrevivência da espécie a longo prazo requer estudos com análises de vários fatores: como mudanças climáticas, crescimento da matriz agrícola, variabilidade genética e possíveis epidemias. Sendo que talvez a falta de conexão entre as áreas de vida dos bugios seja uns dos fatores mais preocupantes para a manutenção da sua sobrevivência (BICCA-MARQUES et al., 2019). 
Pois, para a conservação do Alouatta caraya é sem dúvida essencial buscar expandir suas áreas de vida para que a dispersão da espécie ocorra, não somente para permitir seu crescimento populacional, mas que está questão reflita a viabilidade da espécie, onde adjetivá-lo como fortes sobreviventes de áreas com baixa riqueza e marginalizadas, não necessariamente conduz a conservação da espécie. Pesquisas apontam que muitos grupos de Alouatta caraya estão habitando ambientes fragmentados (ALBUQUERQUE e CODENOTTI, 2006, PRATES, 2007; LUDWIG, 2008, ODALIA-RÍMOLI et al, 2008; RÍMOLI et al, 2012), porém com uma qualidade de vida subjetiva e um sucesso evolutivo reduzido devido a baixa variabilidade genética imposta pela fragmentação de seu habitat.

Portanto, o risco de extinção que essa espécie enfrenta deve ser analisado com cautela e medidas paliativas devem ser administradas e fiscalizadas de modo atento e urgente, pois desde a década de 90 estudiosos como Brown $e$ Zunino (1994), Deluycker (1995) relataram que a principal ameaça para Alouatta caraya é a fragmentação do seu habitat. Em 2015, foi realizada uma avaliação da situação da espécie e esta foi categorizada como Quase Ameaçada (NT), justificada por sua ampla distribuição geográfica e ponderada por fatores como declínio populacional relacionados a fragmentação do hábitat (por motivos como expansão rodoviária e da matriz energética, agricultura, pecuária), além da caça e das atuais epidemias de febre amarela (LUDWIG et al., 2015).

Corroborando, estudos com outras espécies do gênero Alouatta evidenciam que as áreas de vida fragmentadas resultam em risco para a manutenção das espécies, o que pode ser observado no Livro Vermelho da Fauna Brasileira Ameaçada de Extinção de 2018, onde se encontram na lista: Alouatta belzebul, Alouatta discolor e A. guariba clamitans como vulneráveis; A. guariba guariba como criticamente em perigo e A. ululata como em perigo. Portanto, é evidente que a fragmentação de habitats é uma ameaça para o gênero, e para Alouatta caraya, pois a sua permanência, considerada ainda como adaptabilidade a estes fragmentos pode não salientar a pungente necessidade de estudos sobre a sua dinâmica social e, principalmente, de ações para conservação da sua área de vida. 


\section{CONSIDERACÕES FINAIS}

Por fim, por mais que grupos de bugios possam ser encontrados em fragmentos bastante diminutos, a definição de adaptabilidade pode não demonstrar a real relação de sobrevivência (o que não necessariamente significa viver). Pois a existência de uma espécie está intimamente ligada a qualidade e tamanho de habitat e se nada for feito para a manutenção destes espaços a sérios riscos a sobrevivência do gênero Alouatta - seja qual for a fitofisionomia em que viva já que todos estão sofrendo grande pressão antrópica. Contudo, espera-se que esta discussão proporcione reflexões e ações de conservação, para que o status de conservação das espécies de Alouatta seja melhor em um futuro breve.

\section{REFERÊNCIAS}

AGUIAR, L. M., TONETTO, J., e BICCA-MARQUES, J. C. Novas zonas de contato entre Alouatta caraya (Humboldt, 1812) e A. guariba clamitans Cabrera, 1940 no sul do Brasil. In F. C. Passos e J. M. Miranda (Eds.), A primatologia no Brasil (Vol. 15, pp. 338-344). Sociedade Brasileira de Primatologia: Curitiba. 2014

ALBUQUERQUE, V. J de; CODENOTTI, T. L. Etograma de um grupo de bugios-pretos, Alouatta caraya (Humboldt, 1812) (Primates, Atelidae) em um habitat fragmentado. Rev. etol., São Paulo, v. 8, n. 2, p. 97-107, dez. 2006.

ARROYO-RODRÍGUEZ, V., $e$ DIAS, P. A. D. Effects of habitat fragmentationand disturbance on howler monkeys: A review. American Journal of Primatology, 72,1-16. 2010

BICCA-MARQUES, J.C. $e$ CALEGARO-MARQUES, C. Feeding behavior of the black howler monkey (Alouatta caraya) in a seminatural Forest. Acta Biologica Leopoldensia, 16: 69-84. 1994

BICCA-MARQUES, J.C. Padrão de utilização de uma ilha de mata por Alouatta caraya (Primates: Cebidae). Revista Brasileira de Biologia 54:161-171.1994

BICCA-MARQUES, J.C. How do howler monkeys cope with habitat fragmentation? In: Primates in Fragments: Ecology and Conservation (L.K. Marsh, ed.). Kluwer Academic/Plenum, New York, pp. 283-303. 2003

BICCA-MARQUES, J.C.; CHAVES, O.M; HASS, G.P. Howler monkey tolerance to habitat shrinking: Lifetime warranty or death sentence? Commentary Am J Primatol. 2019. DOI: $10.1002 /$ ajp. 23089 
BRAVO, S.P. e SALLENAVE, A. Foraging behavior and activity patterns of Alouatta caraya in the northeastern argentinean flooded forest. International Journal of Primatology, 24: 825-846. 2003

BROCKETT, R.C.; R.H. HORWICH $e$ C.B. JONES. Female dispersal in the Belizean black howling monkey (Alouatta pigra). Neotropical Primates, Washington, 8 (1): 32-34.2000

BROWN, A.D. e ZUNINO, G.E. Hábitat, densidad y problemas de conservación de los primates de Argentina. Vida Silvestre Neotropical 3:30-40. 1994

CHAVES, Ó. M., e BICCA-MARQUES, J. C. Feeding strategies of brownhowler monkeys in response to variations in food availability. PLOSOne, 11, 2016. https://doi.org/10.1371/journal.pone.0145819

CHAPMAN, C. A. $e$ CHAPMAN, L. J. Determinants of group size in primates: the importance of travel costs. In: Boinski, S., and Garber, P. (Eds.) On the Move: How and Why Animals Travel in Groups (pp. 24-42). Chicago, The University of Chicago Press.2000.

CHAPMAN, C. A. $e$ PAVELKA, M. S. M. Group size in folivorous primates:ecological constraints and the possible influence of social factors. Primates, 46, 1-9. 2005

COSTA, M. D.; FERNANDES, F. A. B.; HILÁRIO, R. R.; GONÇALVES, A.V.; SOUZA, J. M. Densidade, tamanho populacional e conservação de primatas em fragmento de Mata Atlântica no sul do Estado de Minas Gerais, Brasil. Série Zoologia, v. 102, n. 1, p. 311-316, 2012.

DE ALMEIDA E SILVA, A. S; BARBISAN FORTES, V; VOLTOLINI, J. C. Influência da paisagem na presença e abundância do bugio-ruivo Alouatta guariba clamitans em fragmentos Florestais no sudeste do Brasil. Mastozool. neotrop., v. 24, n. 2, p. 323-331. 2017

DELUYCKER, A. Deforestation, selective cutting, and habitat fragmentation: the impact on a black howler monkey (Alouatta caraya) population in northern Argentina. Boletim Primatologico Latinoamericano 5:17-24. 1995

DIAS, P. A. D., e RANGEL-NEGRÍN, A. Diets of howler monkeys. InM. K. Kowalewski, P. A. Garber, L. Cortés-Ortiz, B. Urbani $e$ D.Youlatos (Eds.), Howler monkeys: Behavior, ecology, and conservation (pp.21-56). New York, NY: Springer.2015.

ESTRADA, A.; MENDOZA, A.; CASTELLANOS, L.; PACHECO, R.; VAN BELLE, S.; GARCÍA, Y e MUÑOZ, D. Population of the black howler monkey (Alouatta pigra) in a fragmented landscape in Palenque, Chiapas, México. American Journal of Primatology, 58, 45-55. 2002

FERMOSELI, A. F. de O.; SANTOS, W. F. dos. Comportamento social e resposta hormonal: hierarquia e estresse em um grupo de bugio-pretos (Alouatta 
caraya) de uma ilha de mata urbana em Ribeirão Preto/SP. Universidade de São Paulo, Ribeirão Preto. 2010

FORTES,V.B. Ecologia e comportamento do Bugio-ruivo (Alouatta guariba clamitans Cabrera, 1940) em fragmentos florestais na depressão central do Rio Grande do Sul, Brasil.Tese de Doutorado. Rio Grande do Sul,2008. 145pg.

HANSKI, I. Habitat connectivity, habitat continuity, and metapopulation in dynamic landscapes. Oikos 87(2):209-219. 1999

ICMBio-Instituto Chico Mendes de Conservação da Biodiversidade. Livro Vermelho da Fauna Brasileira Ameaçada de Extinção. Brasília: ICMBio. 4162 p. 2018

JARDIM, M. M. A. Ecologia populacional de bugios-ruivos (Alouatta guariba) nos municípios de Porto Alegre e Viamão, RS, Brasil. Tese de Doutorado, Universidade Estadual de Campinas, Campinas, SP.2005

KNOPFF, K. H. e PAVELKA, M. S. M. Feeding competition and group size in Alouatta pigra. International Journal of Primatology, 27, 1059-1078. 2006

LAZARO-JUNIOR, A.E. Dispersão e Predação de sementes por bugios pretos (Alouatta caraya, Atelinae) em fragmento florestal na margem esquerda do Rio Aquidauana, município de Anastácio, Mato Grosso do Sul. Trabalho de Conclusão de Curso. Graduação em Ciências Biológicas. Universidade Federal de Mato Grosso do Sul. 2010

LUCCAS- LAZARO, N.I. Cuidado parental e relações sociais entre fêmeas adultas e seus filhotes de bugios-pretos-e-dourados (Alouatta caraya; Primates, Atelidae) em fragmentos urbanos de Cerrado-Pantanal em Aquidauana, Mato Grosso do Sul. Dissertação (Mestrado em Biologia Animal). Fundação Universidade Federal de Mato Grosso do Sul, Mato Grosso do Sul. 2012 63p

LUDWIG, G. et al . Comparison of the diet of Alouatta caraya (Primates: Atelidae) between a riparian island and mainland on the Upper Parana River, southern Brazil. Rev. Bras. Zool., Curitiba , v. 25, n. 3, p. 419-426, 2008

LUDWIG, G., BICC A- MARQUES, J. C., RÍMOLI, J., CUNHA, R. G. T., ALVES, S. L.,MARTINS, V., ... MESSIAS, M. R. Avaliação do risco de extinçãode Alouatta caraya (H umboldt, 1812) no Brasil. Processo deavaliação do risco de extinção da fauna brasileira. ICMBio.2015

MENDES, S. L. Estudo ecológico de Alouatta fusca (Primates-Cebidae) na Estação Biológica de Caratinga, MG. Revista Nordestina de Biologia, 6, 71-104 . 1989

MIRANDA, J. M. D., BERNARDI, I. P., MORO-RIOS, R. F., AGUIAR, L. M., LUDWIG, G. E PASSOS, F. C. Social structure of Alouatta guariba clamitans: a group with a dominant female. Neotrop. Primates 12(3): 135-138.2004

MIRANDA, J. M. D.; PASSOS, F. C.. Composição e dinâmica de grupos de Alouatta guariba clamitans Cabrera (Primates, Atelidae) em Floresta Ombrófila Mista 
no Estado do Paraná, Brasil. Rev. Bras. Zool., Curitiba , v. 22, n. 1, p. 99106, Mar. 2005.

MIRANDA, J.M.D.; BERNARDI, I.P., MORO-RIOS, R.F., PASSOS, R.C . Three years on demography of a group of Alouatta guariba clamitans Cabrera (Primates, Atelidae): growth and fragmentation. Revista Brasileira de Zoologia 23: 703706.2006

MUHLE, C. B. Estratégias adaptativas de um grupo de bugios-pretos, Alouatta caraya (Humboldt, 1812), em um bosque dominado por eucaliptos. 2008. $52 \mathrm{f}$. Dissertação (Mestrado em Zoologia) - Pontifícia Universidade Católica do Rio Grande do Sul, Porto Alegre, 2008.

NUNN, C. L. The number of males in primate social groups: a comparative test of the socioecological model. Behavioural Ecology and Sociobiology, 46, 1-13. 1999

ODALIA- RÍMOLI A., VALDIVINO E.M., RÍMOLI, J., FERRARI, S. F. BEHAVIOR patterns of a group of black howler monkeys Alouatta caraya (Humboldt, 1812) in a forest fragment in Terenos, Mato Grosso do Sul: a seasonal analysis. In: Rímoli J, Ferrari SF (eds) A primatologia no Brasil 9. Sociedade Brasileira de Primatologia, Biología Geral e Experimental-UFS, Aracaju, Brasil. 2008

PRATES, H. M . Ecologia e comportamento de um grupo de bugios-pretos (Alouatta caraya) habitante de um pomar em Alegrete, RS, Brasil, Dissertação de Mestrado. Pontifícia Universidade Católica do Rio Grande do Sul, 2007,

PRATES, H.M.; BICCA- MARQUES, J.C. Vivendo no limite? Dieta de um grupo de bugios-pretos (Alouatta caraya) habitante de um pomar. In: Melo FR, Mourthé I. A primatologia no Brasil 11. Belo Horizonte: Sociedade Brasileira de Primatologia. p 77-91.2012

RÍMOLI, J.; NANTES, R. DOS S. $e$ LÁZARO-JÚNIOR, A. Diet and activity patterns of black howler monkeys Alouatta caraya (Humboldt, 1812, Primates, Atelidae) in ecotone Cerrado-Pantanal in left bank of Aquidauana river, Mato Grosso do Sul, Brazil. OecologiaAustralis, 16 (4): 836-851.2012

ROCHA-SANTOS, G. Comportamento Social de um grupo de bugios pretos e dourados (Alouata caraya) na margem esquerda do Rio Aquidauana, Anastácio, Mato Grosso do SUl. Trabalho de Conclusão de Curso. Graduação em Ciências Biológicas. Universidade Federal de Mato Grosso do Sul. 2011

S TAVIS, V.; MARQUES, M.; BORDIGNON, M.; PEREIRA, W., LUCCAS-LAZARO, N.I.; RODRIGUES, E.; GARDENAL, B.F. Black howler monkeys (Alouatta caraya): behaviour and diet in brazilian savannah (cerrado). Research Journal of Pharmaceutical, Biological and Chemical Sciences. 4. 33-53. 2018

STAVIS, V.; MARQUES, M.; BORDIGNON, M.; PEREIRA, W., RODRIGUES, E.; GARDENAL, B.F. area of use and space used by Alouatta caraya in the centerwest of Brazil. Research Journal of Pharmaceutical, Biological and Chemical Sciences. 5(1). 787-805. 2019 
TREVES, A. Reproductive consequences of variation in the composition of howler monkey (Alouatta spp.) groups. Behavioral Ecology and Sociobiology, Heidelberg, 50 (1): 61-71. 2001

SILVA, V. M.; CODENOTTI, T. Mapeamento das áreas de ocorrência de Alouatta caraya em fragmentos florestais de Tupanciretã, Rio Grande do Sul. A Primatologia no Brasil 10.10.181-191.2007

VIEIRA, M. V.; FARIA, D. M.; FERNANDEZ, F. A. S.; FERRARI, S. F.; FREITAS, S. R.; GASPAR, D. A.; MOURA, R. T.; OLIFIERS, N.; OLIVEIRA, P. P.; PARDINI, R.; PIRES, A. S.; RAVETTA, A; MELLO, M. A. R.; RUIZ, C. R. e SETZ, E. Z. F. Mamíferos. In MMA. Fragmentação de ecossistemas: causas, efeitos sobre a biodiversidade e recomendações de políticas públicas (pp.125-151). Brasília, Ministério do Meio Ambiente. 


\section{rcótONO cirrirno pANTAMAL

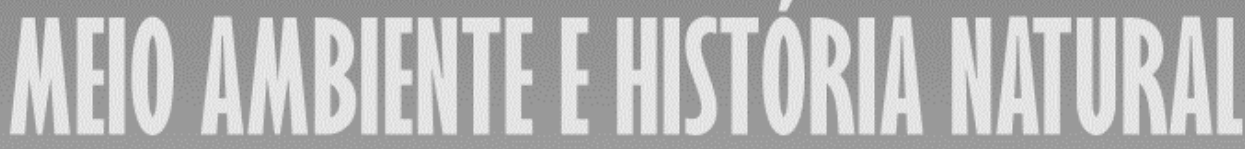




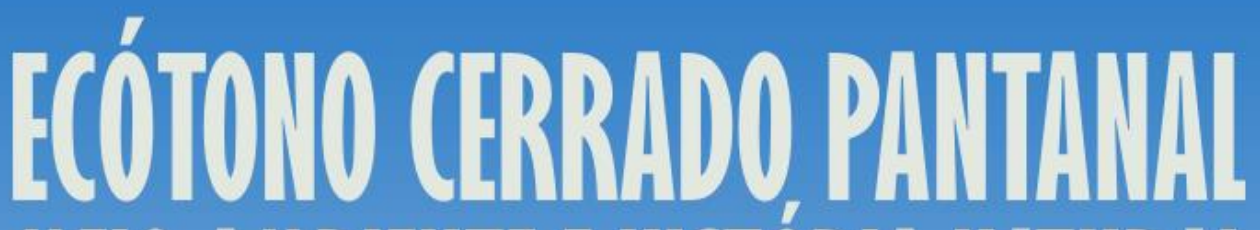

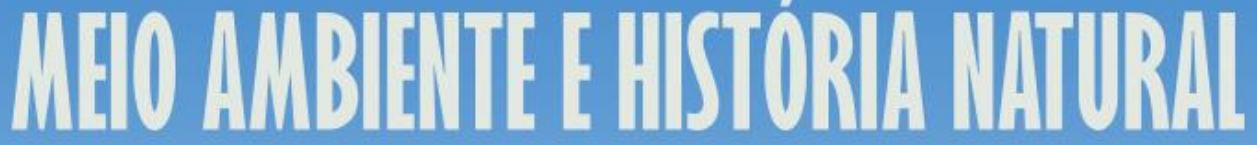

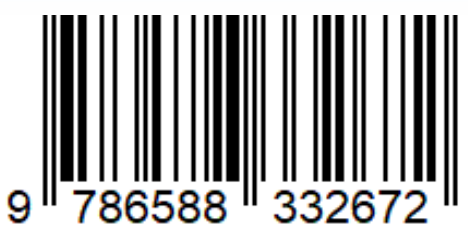

